\title{
Temas introductorios al estudio De RELACIONES INTERNACIONALES
}

\author{
Ileana Cid Capetillo
}

CoOrdinadora
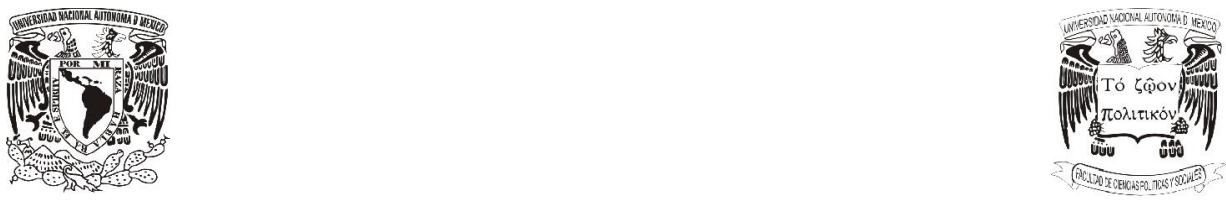
2 BLANCA 


\title{
UNIVERSIDAD NACIONAL AUTÓNOMA DE MÉXICO
}

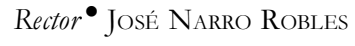 \\ Secretario General $\bullet^{\bullet}$ Eduardo BÁrZana García \\ Secretario Administrativo • LeOpoldo SiLva GutiérReZ \\ Abogado General $\bullet$ Luis Raúl González Pérez \\ Director General de Publicaciones y Fomento Editorial • Javier Martínez Ramírez
}

\section{FACULTAD DE CIENCIAS POLÍTICAS Y SOCIALES}

\author{
Director $\bullet$ Fernando Castañeda Sabido \\ Secretaria General $\bullet$ Claudia Bodek Stavenhagen \\ Secretario Administrativo • José Luis Castañón Zurita \\ Jefa del Departamento de Publicaciones $\bullet^{-}$Ma. Eugenia Campos Cázares

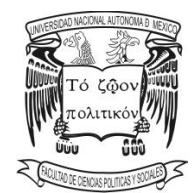 \\ Facultad de Ciencias \\ Políticas y Sociales

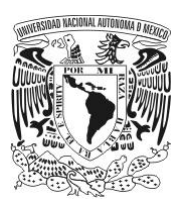 \\ Universidad NACIONAL \\ Autónoma de México
}


Esta investigación arbitrada por especialistas en la materia se privilegia con el aval de la Facultad de Ciencias Políticas y Sociales, UNAM.

Este libro fue financiado con recursos de la Dirección General de Asuntos del Personal Académico (DGAPA) de la Universidad Nacional Autónoma de México, mediante el proyecto "La enseñanza de la Teoría de Relaciones Internacionales para un mundo en transición", como parte del Programa de Apoyo a Proyectos para la Innovación y Mejoramiento de la Enseñanza (PAPIME) PE303909 y cuya responsable es la doctora Ileana Cid Capetillo.

\section{Temas introductorios al estudio de Relaciones Internacionales}

Primera edición, 19 de noviembre de 2013

D.R. (C) Facultad de Ciencias Políticas y Sociales, UNAM.

Circuito Cultural Mario de la Cueva, Ciudad Universitaria C.P. 04510, Deleg. Coyoacán, México, D. F.

ISBN: 978-607-02-4922-8

Cuidado de la edición: Domingo Cabrera Velázquez

Queda prohibida la reproducción parcial o total, directa o indirecta, del contenido de la presente obra, sin contar previamente con la autorización expresa y por escrito de los editores, en términos de lo así previsto por la Ley Federal de Derechos de Autor y, en su caso, por los tratados internacionales aplicables. 


\section{Índice}

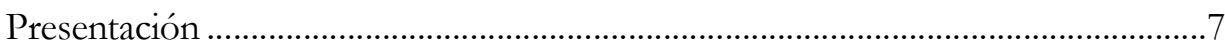

El debate del método en la disciplina de

Relaciones Internacionales: ordenando el caos

\section{Roberto Peña Guerrero}

Desarrollo de la sociedad internacional. Objeto material .....................................37 David J. Sarquís

Una mirada a la disciplina de Relaciones Internacionales 77 Mayra López Díaz

Los protagonistas de las relaciones internacionales .111

Ileana Cid Capetillo

Factores, procesos y temas de la agenda internacional ........................................153 Teresa del Socorro Pérez Rodríguez

En torno al entorno: los factores internacionales 177

María Fuencisla Marín Castán 
6 BLANCA 


\section{Presentación}

La enseñanza de Relaciones Internacionales en México tiene una larga tradición que, en un sentido amplio, se remonta a la fundación de la Escuela de Ciencias Políticas y Sociales (hoy Facultad) en 1951 en la Universidad Nacional Autónoma de México y, en un sentido más limitado, al momento en que se sustituye la vieja denominación de Estudios Diplomáticos a la actual, que es la generalmente aceptada en las instituciones más prestigiadas de nuestro país y de otros lugares del mundo.

Sin temor a equivocarnos consideramos que la estructura del Plan de Estudios, a pesar de los cambios que ha tenido en diferentes ocasiones, se ha constituido en un modelo de referencia obligada para otros programas de la licenciatura, sobre todo en México pero, probablemente, también de América Latina.

En dicho modelo, el estudio de la Teoría de Relaciones Internacionales ha ocupado un lugar destacado al partirse del supuesto de que es esta área la que le da coherencia y permite integrar los estudios del Derecho Internacional, la Economía, la Política Internacional, México y su política exterior e incluso los estudios regionales que son partes componentes de la compleja totalidad que abarca nuestra disciplina y que individualmente o de manera desarticulada carecen del sentido que les otorga la matriz disciplinaria.

La materia de Introducción al Estudio de Relaciones Internacionales, como preámbulo al área teórica, se constituye, entonces, en una base fundamental para que el estudiante y todos aquellos interesados en el conocimiento de una problemática cuya importancia es creciente en el mundo de hoy, se adentren en la comprensión de la disciplina como una más de las Ciencias Sociales y el manejo del lenguaje especializado que comparten los profesionales y estudiosos de la misma.

En esta asignatura, los futuros internacionalistas también apreciarán la identidad que hace de la disciplina única y distinta de las otras Ciencias Sociales a pesar de compartir con ellas muchos elementos que a lo largo de su desarrollo nos han enriquecido mutuamente. No es casualidad que la academia de Relaciones Internacionales se encuentre ubicada en una Facultad de Ciencias Políticas y Sociales, por el contrario, al ser fundada por académicos y estudiantes provenientes de la Facultad de Derecho, de la misma UNAM, se reconocía-como estaba pasando 


\section{Presentación}

en otras partes del mundo- que una parte de la realidad política y social estaba siendo insuficientemente estudiada (pero sobre todo explicada) por las Humanidades y las Ciencias Sociales.

Ni el Derecho, ni la Economía, ni la Ciencia Política o la Sociología, por no hablar de la Administración Pública o las Ciencias de la Información tenían o tienen la capacidad de analizar la especificidad de la sociedad internacional integrada por los Estados y otros actores internacionales, que bajo circunstancias específicas determinadas por factores naturales, políticos, económicos, sociales y, ahora se reconoce, hasta medioambientales, demográficos, científicotecnológicos, de género, entre los principales, se constituye en el ámbito en que se producen las relaciones de conflicto (guerra) y cooperación (paz) que predominan en un momento histórico determinado.

Al igual que ha sucedido en todos los lugares en que se estudia y se enseña la carrera de Relaciones Internacionales, también aquí hemos participado en el debate acerca de su autonomía, la cual no es de ninguna manera independencia, como no lo es en el caso de ninguna otra de las Ciencias Sociales puesto que todas ellas son interdependientes y complementarias. Podríamos decir que las fronteras que las dividen son muy porosas y solamente son defendidas por las ciencias positivas que pretenden conservar bastiones aislados que poco contribuyen al avance de la ciencia.

La supuesta ascendencia de la Ciencia Política, de la Sociología, del Derecho, de la Historia o de cualquier otra disciplina o incluso la pretensión de convertir a Relaciones Internacionales en un área de estudio de alguna de ellas, ha sido superada por la fuerza del conocimiento que en ésta se produce y la formación de profesionales que participan en un campo de trabajo ya muy definido.

Pero pretender aportar análisis apropiados al conocimiento de las relaciones internacionales exige el manejo fluido del lenguaje especializado, la comprensión de los conceptos que nos sirven para identificar los componentes de la sociedad internacional, el discernimiento de los discursos políticos y académicos que en su interior se presentan, el ejercicio metodológico que imprima lógica a las explicaciones y, finalmente, la exposición teórica que permita superar el nivel de las apariencias para adentrarnos en el de la esencia de las relaciones internacionales.

El libro que aquí presentamos tiene el propósito de preparar al estudiante a fin de que se introduzca en el estudio de las relaciones internacionales, como el objeto material de la disciplina de Relaciones Internacionales.

Los capítulos que lo integran han sido elaborados por académicos que nos hemos dedicado durante un largo tiempo a la academia y que presentamos aquí nuestra concepción sobre los principales aspectos de la materia. 
Roberto Peña Guerrero, en el capítulo "El debate del método en la disciplina de Relaciones Internacionales: ordenando el caos", busca ubicarnos dentro de la discusión sobre los problemas teórico metodológicos que preocupan a los estudiosos de las Ciencias Sociales en general, ofrece una propuesta para elegir, dentro de la parsimonia de los niveles cognoscitivos, el método que brinda más posibilidades de alcanzar un conocimiento objetivo, para, finalmente, adentrarse en el planteamiento de los paradigmas vigentes en el corpus de Relaciones Internacionales.

Por su parte, David J. Sarquís, nos presenta su aportación con el tema "Desarrollo de la sociedad internacional. Objeto material" en donde explica la correspondencia entre Relaciones Internacionales (objeto formal - nivel gnoseológico) y relaciones internacionales (objeto material - nivel ontológico) que tiene implicaciones de carácter histórico pero también de orden teórico conceptual que todo internacionalista debe manejar con fluidez. El objetivo del autor es desentrañar la manera como se va complejizando la realidad hasta presentar la totalidad de manifestaciones que hacen posible hablar de una sociedad internacional que se constituye en el objeto de estudio de nuestra disciplina. La articulación de los elementos que se van integrando permitirá al lector entender con más acuciosidad los aspectos que se desarrollan en otros capítulos de este libro, como son los protagonistas y el tipo de las relaciones que establecen en el nivel internacional, afectados o influidos por un conjunto de factores objetivos.

Mayra López Díaz, ofrece sus propias reflexiones en el capítulo "Una mirada a la disciplina de Relaciones Internacionales", en donde profundiza en el surgimiento y constitución de nuestro objeto formal, motivados por las condiciones históricas de la sociedad internacional de la primera parte del siglo $\mathrm{xx}$. Asimismo, considera la necesaria vinculación que tiene con la ciencia en general y con las ciencias sociales en particular, superando la vieja noción de "ciencias auxiliares" que se manejó durante mucho tiempo en la literatura de nuestra disciplina, para visualizarla como una cuestión de inter, multi y transdisciplinariedad, con efectos directos en la manera como el cuerpo teórico se ve enriquecido con las aportaciones de dos paradigmas centrales: el idealista y el realista que se traducen en un cúmulo de teorías con sus propios cuerpos conceptuales. Por otra parte, la autora nos introduce en el conocimiento de las condiciones en que se funda en México nuestra disciplina, recuperando los aspectos más relevantes de su desarrollo.

En el siguiente capítulo, Ileana Cid Capetillo aborda "Los protagonistas de las relaciones internacionales", para lo cual establece una distinción entre los 
conceptos de actor, sujeto y agente que se emplean en distintas corrientes de estudio de la disciplina, sustentadas respectivamente en una visión funcionalista, materialista dialéctica o constructivista. Asimismo, explica por qué se ha impuesto una visión estatocéntrica considerando los elementos constitutivos y las atribuciones del actor más relevante de la escena internacional, al lado de la organización internacional que también desempeña un papel relevante. Aunque también señala la presencia de otros actores calificados por muchos autores como "nuevos", como es el caso de las organizaciones no gubernamentales (ONG) y de la empresa transnacional.

En el capítulo "Factores, procesos y temas de la agenda internacional", Teresa Pérez Rodríguez explica cómo se ven éstos como condicionantes de la acción de los protagonistas y, por lo tanto, como relevantes para el curso de las relaciones internacionales, especialmente en las vigentes condiciones de globalización que estamos viviendo.

Finalmente, María Fuencisla Marín Castán, en el capítulo "Entorno al entorno: los factores internacionales", profundiza sobre la relevancia de considerarlos para la comprensión del sistema internacional. La autora define a los factores como los condicionantes de las interacciones entre los actores en el ámbito internacional, lo que los convierte en una parte fundamental en el estudio de las relaciones internacionales. Asimismo, destaca la incidencia de estos condicionantes en la definición de los diferentes tipos o modelos de sociedad internacional y su dinámica, presentando así una perspectiva novedosa respecto a la evolución y transformación de la sociedad internacional.

Sólo nos queda señalar que ofrecemos este libro a la comunidad de estudiantes y público interesado en el conocimiento y la comprensión de los asuntos que afectan al mundo y que hoy por hoy constituyen una esfera que engloba la totalidad de los procesos, hechos y fenómenos desde los niveles locales y regionales hasta el nivel más amplio de lo mundial pues todos ellos son, en sentido estricto, parte de las relaciones internacionales y, por lo tanto, objeto de estudio de Relaciones Internacionales.

\section{Ileana Cid Capetillo}




\section{EL DEBATE DEL MÉTODO EN LA DISCIPLINA DE RELACIONES INTERNACIONALES: ORDENANDO EL CAOS}

\section{Roberto Peña Guerrero*}

\section{Introducción: consideraciones preliminares}

Quiero iniciar este ensayo extendiendo un reconocimiento a todos los internacionalistas dedicados a la academia (a la docencia e investigación), que se han preocupado por el desarrollo científico de la disciplina de las Relaciones Internacionales y han dejado constancia de esa preocupación por escrito en alguna publicación, que haya contribuido al debate teórico-metodológico o simplemente haya estimulado su reflexión, sin importar si se promueve alguna teoría del conocimiento en particular.

Este reconocimiento lo extiendo, porque aquellos que han experimentado la necesidad de incursionar sobre los problemas teórico-metodológicos de la disciplina, se han visto obligados a ejercitar el pensamiento abstracto, en virtud de que el conocimiento propiamente científico se construye a partir de la triada cognoscitiva que va del nivel de lo concreto inmediato (fenomenológico o aparencial), al nivel de la abstracción (donde se construye la teoría) para dirigirse a lo concreto superado, con lo que se promueve el proceso de construcción científica, en el sentido en el que opera el vector epistemológico que va de lo abstracto a lo concreto superado, para comprobar o, en su caso desaprobar las hipótesis (ver esquema 1).

* Profesor titular del Centro de Relaciones Internacionales de la Facultad de Ciencias Política y Sociales de la Universidad Nacional Autónoma de México. Doctor en Relaciones Internacionales, Unión Europea y Globalización por la Universidad Complutense de Madrid. Profesor de las áreas de Teoría y Metodología y de Estudios Regionales (Unión Europea) en la misma especialidad. Ha participado en eventos académicos en México y en el extranjero. Tiene publicaciones en revistas especializadas y diversos libros colectivos. Sus más recientes publicaciones son: coordinación de libro México-Unión Europea. Asociación estratégica para la gobernabilidady la inclusión social, Plaza y Valdés-UNAM, México, 2008; coordinación del libro México-Unión Europea: políticas sociales y gobernabilidad, FCPyS, UNAM, México, 2010; así como tres cuadernos: Indicadores de Comercio e Inversión México-Unión Europea; Indicadores Políticos México-Unión Europea e Indicadores de Cooperación México-Unión Europea, editados por el Centro de Estudios Europeos de la FCPyS de la UNAM, México, 2012. 


\section{Esquema 1 Triada cognoscitiva}

Abstracción

(construcción teórica)

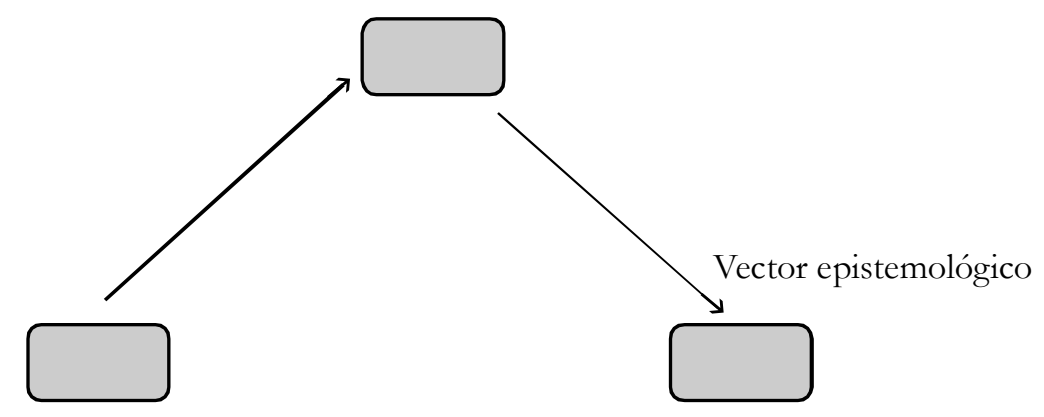

Concreto inmediato

Concreto superado

(Nivel fenomenológico o aparencial) (Esencia o especificidad de los fenómenos)

Fuente: elaboración propia.

Pero este ejercicio obligado del pensamiento abstracto, que es el que se requiere para abordar los problemas metodológicos a los que se enfrenta la explicación científica de los procesos históricos-sociales, es el medio no el fin, ya que si el internacionalista confunde el medio con el fin, no estaría contribuyendo a la disciplina de Relaciones Internacionales, sino a la filosofía de la ciencia en general, si es que sus aportaciones en este sentido fueran de trascendencia, como los estudios de Thomas Khun, quien de origen se graduó en física-teórica, pero por azares del destino incursionó en la filosofía de la ciencia y ahí destacó con su obra la Estructura de las Revoluciones Científicas. ${ }^{1}$

Bienvenidas todas las iniciativas que alimentan y promueven los debates teóricos-metodológicos de la disciplina de Relaciones Internacionales, sean idealistas o materialistas, en términos filosóficos, o provengan de alguna corriente teórica específica de la disciplina (utopista o liberal, realismo político, sociología histórica, marxista, sistemática, constructivista, etc.) Obviamente, nunca hay que olvidar que todos los debates en nuestra disciplina comparten, en última instancia, los mismos problemas metodológicos de todas las Ciencias Sociales.

\footnotetext{
${ }^{1}$ Thomas S. Kuhn, La estructura de las revoluciones cientificas, traduc. Agustín Contín, México,
} FCE, 1971, 320 pp. 
El DEBATE DEL MÉTOdo EN LA DisCiplina DE RELACIONES INTERNACIONALES: ...

También hay que reconocer que cada académico, cuando busca trascender el nivel fenomenológico o aparencial de su objeto de estudio, elabora su análisis y construye sus explicaciones desde las certidumbres que le brinda una metodología de estudio, la cual se sustenta en una determinada teoría del conocimiento. Esta certidumbre puede ser compartida por otros colegas, pero al final de cuentas el nivel de profundización y explicación científica de su objeto de estudio (fenómeno o proceso internacional específico) está determinado por la metodología de estudio utilizada, lo que se puede evaluar en el contexto de la parsimonia de niveles cognoscitivos, donde se percibe el grado de objetividad y profundidad de los análisis; es decir, si son más o menos científicos para explicar los objetos de estudio.

En el marco de estas reflexiones, nos centraremos en este ensayo en tres cuestiones que consideramos sustantivas: el problema de la metodología en nuestra disciplina, el método más científico y el problema de los paradigmas en la enseñanza de Relaciones Internacionales

\section{El problema del método en Relaciones Internacionales}

En 1976, hace 37 años presenté una ponencia en el Primer Coloquio Internacional de Primavera, en la que señalaba la confusión que existía en todo el mundo sobre el tema de los métodos de estudio en nuestra disciplina. Confusión que, desgraciadamente, no ha sido superada por muchos profesores, que la siguen reproduciendo en sus clases $y$, en consecuencia, trasmitida por generaciones a sus estudiantes.

En aquella ponencia, que fue publicada en la memoria del Primer Coloquio, ${ }^{2}$ destacaba que el carácter interdisciplinario de Relaciones Internacionales:

ha provocado que se confunda al método con las otras disciplinas (de las ciencias sociales) perdiéndose de perspectiva la razón de ser de cada ciencia, tratándolas de convertir en métodos en sí mismas. De tal manera, se afirma que existen diversos métodos para el estudio de las relaciones internacionales: el método jurídico, el histórico, el sociológico, el de la ciencia política, etcétera, hasta el grado de hablar en la actualidad de una metodología de las relaciones internacionales. ${ }^{3}$

\footnotetext{
${ }^{2}$ Roberto Peña Guerrero, "La alternativa metodológica para la disciplina de las Relaciones Internacionales: la dialéctica” en Estudio Científico de las Relaciones Internacionales, UNAM, FCPyS, México, 1978, pp. 141-143.

${ }^{3}$ Ibid., pp. 133-134.
} 
Resumiendo lo que señalaba en aquella ponencia: esa forma de buscar en cada disciplina de las ciencias sociales un método diferenciado, tiene su explicación por la manera en que algunos autores han explicado la evolución del estudio de las relaciones internacionales. Jean Siotis, ${ }^{4}$ por ejemplo, da por sentado que el método de la disciplina ha ido cambiando dependiendo de su evolución "científica"; así nos habla del método jurídico, el cual ha permanecido, desde el siglo XVI hasta nuestros días; después apareció en el siglo XIX el método historiográfico, que utiliza a las relaciones diplomáticas como fuente de conocimiento; el tercer método es el economicista, en donde el determinismo económico lo abarca todo, y, por último, el método de la ciencia-política que, según Siotis, es el que más ha brindado instrumentos metodológicos a Relaciones Internacionales, ya que las diferentes corrientes "teóricas" que se han desarrollado en la Ciencia Política han servido también como métodos.

Lo anterior es de especial observación en nuestra disciplina, porque lo más "normal" y recurrente es que muchos profesores consideren a las diversas escuelas o corrientes teóricas de Relaciones Internacionales como métodos en sí mismas. Por ello es común encontrarse con textos (libros y artículos), sin importar los tema u objetos de estudio, donde sus autores afirman que utilizan el método del realismo o neorrealismo político, o el de la sociología histórica, o el del conductismo, o el de la teoría general de sistemas, o el de la dependencia, o el del constructivismo social (la moda actualmente), etcétera.

También hay quienes se inclinan por el eclecticismo metodológico, ya sea porque perciben apenas la importancia de la metodología y buscan, basándose en los diferentes métodos, darle una apariencia científica a sus estudios, o bien porque consideran que el ser eclécticos facilita las investigaciones, lo que ha proliferado en los últimos años, ignorando las consecuencias que genera el eclecticismo, que provoca "rupturas epistemológicas" en los análisis.

Por último, se contribuye al desorden y, consecuentemente, al caos en los debates teórico-metodológicos en nuestra disciplina, cuando los profesores confunden las técnicas de investigación documental y los programas y sistemas estadísticos con métodos de estudio, o sea con teorías del conocimiento específicas que son las que integran propiamente las diversas corrientes metodológicas en las ciencias sociales y son las únicas que pueden ser denominadas como tales.

Reiterando lo que ya señalaba hace 37 años, no me cabe la menor duda de que

\footnotetext{
${ }^{4}$ Jean Siotis, "La Ciencia Política y el estudio de las Relaciones Internacionales" en Problemas de la ciencia contemporánea, México UNAM, FCPyS, Serie Estudio, 3, México, 1969, pp. 115-137.
} 
El Debate del método en la disciplina de ReLaciones INTERnacionales: ...

prevalece una confusión en nuestra disciplina sobre los métodos de estudio. Situación que también se presenta, en mayor o menor medida, en todas las demás ciencias sociales. Es decir, no es atributo sólo de Relaciones Internacionales.

Como respuesta a este caos y con el propósito de contribuir a su superación, consideramos procedente abordar a continuación ciertas precisiones básicas (que los estudiantes de la Licenciatura deberían dominar al concluir el segundo semestre de la carrera), sobre lo que estimamos debe entenderse por metodología o perspectiva metodológica en las ciencias sociales y, por ende, en Relaciones Internacionales; metodología que se delinea a través de los elementos centrales de toda teoría del conocimiento.

La aplicación de una determinada metodología para el estudio científico de cualquier proceso de la naturaleza y de la sociedad, conlleva toda una problemática de visión del mundo, de concepción de la realidad y de interpretación que de ésta haga el hombre. Todo método de investigación está sujeto a un substratum filosófico o perspectiva filosófica (ver esquema 2), que es donde se sustenta la esencia misma de las diversas teorías del conocimiento. Es decir, las distintas metodologías contienen un núcleo de carácter filosófico que, al mismo tiempo que delimita una concepción del mundo, establece los supuestos epistemológicos y los principios ontológicos que determinan la especificidad de cada método.

Decidirse por una determinada metodología, implica concebir al universo desde una perspectiva filosófica que condiciona toda la producción de

\section{Esquema 2}

Perspectivas filosóficas

Perspectivas
Filosóficas $\left\{\begin{array}{l}\text { Idealismo }\left\{\begin{array}{l}\text { Solipsista } \\ \text { Subjetivo } \\ \text { Realista } \\ \text { Dialéctico }\end{array}\right. \\ \text { Materialismo }\left\{\begin{array}{l}\text { Mecanicista } \\ \text { Organicista } \\ \text { Dialéctico }\end{array}\right.\end{array}\right.$

Fuente: elaboración propia. 
conocimientos que se realiza. Tal condicionamiento se debe, por un lado, a que los supuestos epistemológicos del método delimitan los parámetros por los que se encauzan los conocimientos que el hombre elabora y, por el otro, a que los principios ontológicos del mismo método, sus leyes, así como sus categorías y conceptos, se convierten en herramienta e instrumentos de análisis, por medio de los cuales el hombre logra la comprensión y la aprehensión abstracta de la realidad concreta que le rodea. En resumen, toda teoría de conocimiento alcanza tal rango y denominación, y se conforma en metodología específica, cuando integra tres ejes: el de los principios epistemológicos (visión del mundo), el de sus las leyes ontológicas (que se derivan de los principios), y el del aparato conceptual (categorías y conceptos que corresponden a los dos ejes anteriores). Ver esquema 3.

\section{Esquema 3}

Ejes de toda teoría de conocimiento=metodología

\begin{tabular}{ccc}
\multicolumn{3}{c}{ Ejes } \\
$\downarrow$ & $\downarrow$ & $\downarrow$ \\
Principios & Leyes & Aparato \\
Epistemológicos & Ontológicas & Conceptual
\end{tabular}

Fuente: elaboración propia.

De tal forma, toda metodología se inscribe en una determinada teoría del conocimiento, cuyos supuestos básicos están definidos por los principios epistemológicos que sustente cada una. ${ }^{5}$ En tales principios se fundamenta el substratum filosófico, la concepción del mundo que se adopta. Es desde este punto de donde queremos partir, ya que las diferentes corrientes metodológicas de las ciencias sociales se sustentan en alguna perspectiva filosófica o visión del mundo y, a su vez, las construcciones teóricas que buscan explicar un fenómeno o proceso histórico-social específico (sea del ámbito interno a las sociedades políticamente integradas o del ámbito de la sociedad internacional) adquieren su alcance y

\footnotetext{
${ }^{5}$ Como no es nuestra intención explicar cada uno de los principios epistemológicos que conforman a la teoría materialista del conocimiento dialéctico, estos se pueden ver en Agustín Cueva, "Sobre la filosofía y el método marxista" en Revista Mexicana de Ciencia Política, núm. 78, año xx, Nueva Época, UNAM, FCPys, México, octubre-diciembre de 1973, p. 125; y también en Peña Guerrero, op. cit.
} 
El DEBATE DEL MÉTOdo EN LA DisCiplina DE RELACIONES INTERNACIONALES: ...

profundidad analítica o científica en correspondencia con la teoría del conocimiento utilizada; es decir, con la corriente metodológica adoptada. Por eso, cuando se hace referencia a los debates teóricos sobre las diferentes explicaciones de los procesos históricos-sociales, lo adecuado es hablar de debates teórico-metodológicos, ya que el aspecto determinante del nivel de objetividad y profundidad científica de la explicación teórica de dichos fenómenos se encuentra en la metodología utilizada.

\section{E1 método más científico}

Las corrientes metodológicas se diferencian, en última instancia, por los resultados de objetividad y profundidad explicativa o científica que logran con respecto al objeto de estudio. De ahí que exista una parsimonia de niveles cognoscitivos, de menos a más profundos y científicos, de acuerdo al enfoque metodológico o teoría de conocimiento utilizada (ver esquema 4).

\section{Esquema 4 \\ Parsimonia de niveles cognoscitivos}

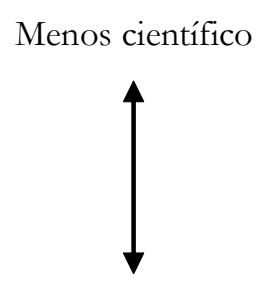

Más científico

\begin{tabular}{|c|}
\hline Idealismo solipsista \\
\hline Idealismo subjetivo \\
\hline Idealismo realista \\
\hline Idealismo dialéctico \\
\hline Materialismo mecanicista \\
\hline Materialismo organicista \\
\hline Materialismo dialéctico \\
\hline
\end{tabular}

Fuente: elaboración propia.

En este sentido, estimamos que el método científico más profundo es aquel que cubre determinados requisitos para cada uno de los ejes que integran su teoría de conocimiento, los cuales se expondrán a continuación de manera ordenada, por lo que iniciaremos en primer lugar con los principios epistemológicos, los cuales se centran en los siguientes aspectos: 
- La realidad concreta y objetiva, material, del mundo del cual formamos parte, se presenta independientemente de nuestro pensamiento. El mundo es material por naturaleza, todas las cosas que existen nacen de causas materiales, surgen y se desarrollan de acuerdo con las leyes del movimiento de la materia.

- La realidad inmediata percibida por el hombre es el resultado de una serie de interacciones materiales que se dan en los procesos de la naturaleza y la sociedad. Sin embargo, esta inmediatez de la realidad es únicamente la apariencia de los fenómenos que se presentan en la experiencia. El mundo de las apariencias, el mundo de la pseudo-concreción, el mundo del sentido común vulgar que distorsiona y mistifica la esencia misma de la existencia del hombre, debe ser superado; pero la única forma de superar la concepción del mundo superficial, es descubriendo el mundo real, el de la concreción, el de la esencia de los fenómenos, que se encuentra oculto en los fenómenos de la naturaleza y la sociedad.

- El ser humano debe esforzarse para descubrir la esencia de los fenómenos histórico-sociales, y "en virtud de que la esencia a diferencia de los fenómenos no se manifiesta directamente, y por cuanto el fundamento oculto de las cosas debe ser descubierto mediante una actividad especial, existen la ciencia y la filosofía. Si la apariencia fenoménica y la esencia de las cosas coincidieran totalmente, la ciencia y la filosofía serían superfluas". ${ }^{6}$

- Si buscamos la aprehensión del mundo real y concreto mediante el proceso teórico y el esfuerzo epistemológico, necesitamos de una metodología cuya dimensión nos permita descubrir la esencia de los fenómenos, así como también elaborar el conocimiento que del fenómeno y su esencia vayamos descubriendo.

- Si los procesos histórico-sociales se manifiestan en forma fenoménica, la esencia de los mismos, la cosa en sí, va a estar estructurada internamente. Y si esta estructura está en constante movimiento, en interacción con otras estructuras, inmersas en una totalidad concreta, la cual se desarrolla y cambia debido a sus contradicciones, que son el motor generador de todo lo existente, debemos abocarnos a utilizar la metodología científica que trata los procesos en sí, en sus cambios, con sus negaciones y contradicciones.

\footnotetext{
${ }^{6}$ Karel Kosik, Dialéctica de lo concreto, prólogo y traducción A. Sánchez -Vázquez, ed. Grijalbo, S. A., México 1967, p. 29. "Toda ciencia estaría de más, si la forma de manifestarse las cosas y la esencia de éstas coincidieran directamente", Marx, Carlos, El Capital, III, Sec. vII, cap. xxxIII, p. 757, traducción W. Roces, 3a., FCE, México 1965, citado en Kosik, op. cit.
} 
El debate del método en la disciplina de Relaciones Internacionales: ...

Es decir, hay que recurrir a la teoría del conocimiento del materialismo dialéctico que, por sus elementos y características, se convierte en un medio específico y básico en el proyecto de aprehensión de la realidad concreta que nos rodea.

- Por lo tanto, la apropiación que del mundo realice el ser humano es un esfuerzo del conocimiento humano por comprender la totalidad concreta de la estructura ontológica de la naturaleza y la sociedad. Es aquí donde el conocimiento lógico dialéctico sobre la realidad debe tratar de formular una proposición teórica que se aproxime lo más posible a la realidad en sí. Esto se sustenta en el principio de que "es el conocimiento el que coloca al mundo real como su objeto, que es desde entonces una formulación, una construcción, la construcción del objeto del conocimiento, distinto del objeto real". ${ }^{7}$ Dicho de otra forma, la proposición teórica, que es en sí la construcción del objeto del conocimiento, es la formulación lógica por medio de la cual se busca explicar la realidad concreta; realidad que mantiene su independencia en relación a la propia formulación.

- Así pues, la construcción del conocimiento se realiza a partir del objeto real de estudio. De aquí que el proceso de abstracción y los planteamientos teóricos (que buscan expresar lógicamente la estructura dialéctica de la naturaleza y la sociedad) estén condicionados por el objeto real, ya que en él se encuentran, complejamente relacionados, los elementos que hacen posible su existencia. Convertir la realidad concreta en objeto de estudio para formular la construcción lógica del conocimiento es una necesidad epistemológica, debido a que la "estructuración de lo real como objeto, lejos de ser un defecto, es el medio mismo por el cual opera el conocimiento científico". 8

- Aquí cabe señalar que la construcción del conocimiento es producto del proceso cognoscitivo que se genera a partir de la interacción entre el sujeto cognoscente y el objeto real de investigación. Este proceso cognoscitivo se sustenta en el principio de interacción y se caracteriza por respetar la existencia real y activa del sujeto y el objeto, a la vez que se acepta el hecho de que actúan el uno sobre el otro. La interacción se produce en el marco de la práctica social del sujeto que percibe al objeto en y por su actividad. ${ }^{9}$

\footnotetext{
${ }^{7}$ Miriam Limoeiro C., La ideología dominante, traducción Stella Mastrangelo, Ed. Siglo xxi. México, 1975, p. 29.

${ }^{8}$ Ibidem, p. 38.

${ }^{9}$ Cfr. Adam Schaff, Historiay verdad, traducción Ignasi Vidal, ed. Grijalbo, México, 1974, p. 86.
} 
- La forma de reproducir gnoseológicamente la realidad concreta, de crear el conocimiento que nos permita la apropiación del mundo real, tiene que ser llevada a cabo mediante un proceso de abstracción teórica, estableciendo una relación dialéctica entre lo racional del pensamiento y lo real y objetivo del mundo externo: todo lo racional es real y todo lo real es susceptible de ser cognoscible. ${ }^{10}$

- Pero ¿de qué caminos nos vamos a valer para lograr dicha reproducción? La realidad concreta "aparece en el pensamiento como proceso de síntesis, como resultado, no como punto de partida, aunque sea el verdadero punto de partida, y, en consecuencia, el punto de partida también de la intuición y de la representación. En el primer camino, la representación plena es volatizada en una determinación abstracta; en el segundo, las determinaciones abstractas conducen a la reproducción de lo concreto por el camino del pensamiento. (...) El método que consiste en elevarse de lo abstracto a lo concreto es para el pensamiento sólo la manera de apropiarse lo concreto, de reproducirlo como un concreto espiritual". ${ }^{11}$

- Este método corresponde a la teoría del conocimiento del materialismo dialéctico. Teoría que en el aspecto de la reproducción espiritual de la realidad, capta el doble carácter de la conciencia, que escapa tanto al positivismo como al idealismo, ya que la conciencia humana es "reflejo", y, al mismo tiempo, "proyección"; registra y construye, toma nota y planifica, refleja y anticipa; es al mismo tiempo receptiva y activa. ${ }^{12}$

- Objeto de la teoría del conocimiento es la reproducción racional de la realidad concreta; reproducción que se sustenta en una determinada concepción del mundo. La concepción del mundo del materialismo dialectico se fundamenta en la dinámica propia de la materia, en donde nada es inmutable, y define la dinámica misma del ser, su dialéctica, como la sustancia. La sustancia es el movimiento mismo de las cosas, fenómenos, o las cosas en movimiento. El movimiento de las cosas crea diversas fases, formas y aspectos que solamente son comprensibles como explicación de las "cosas mismas". 13

- Esta concepción descubre en la materia su sustancia, que es la que le va a

${ }^{10}$ Gramsci, op. cit., p. 39.

${ }^{11}$ Karl Marx, "Introducción general de la crítica de la economía política", Cuadernos de Pasado y Presente, núm. 1, traducción Manuel Murmis, et al., $7^{\mathrm{a}}$. ed., octubre de 1973, pp. 21-22.

${ }^{12}$ Cfr. Kosik, op. cit., p. 45.

${ }^{13}$ Ibid., p. 46. 
El debate del método en la disciplina de Relaciones Internacionales: ...

permitir transformarse y generar cosas nuevas, las cuales son la negación de la materia pasada. "Solamente una concepción de la materia que descubre en la materia misma la negatividad, es decir, la capacidad de producir nuevas cualidades y grados evolutivos más altos, permite explicar lo nuevo de un modo materialista como una cualidad del mundo material. ${ }^{14}$

- Por último, la teoría del conocimiento es fundamental en el proceso de las determinaciones abstractas y la reproducción espiritual de lo concreto, debido a que es el centro mediador activo de la oscilación dialéctica entre el contexto de la realidad y el contexto de la teoría. Dicho de otro modo, el método de estudio es el centro mediador activo de la oscilación entre realidad y abstracción; lo que hace que el problema fundamental del método sea la relación y posibilidad de transformar la totalidad concreta en totalidad abstracta. ${ }^{15}$ Esta transformación es la absolutización de la actividad de la teoría del conocimiento del materialismo dialéctico, que se opone a la concepción idealista hegeliana que opera al revés, ya que ésta considera en primer término a la "realidad abstracta" para después buscarle su esquema de la "realidad concreta"; es decir, de la necesidad de la diferencia llenada, lo que hace que las abstracciones puedan aplicarse a cualquier realidad. ${ }^{16}$

El segundo eje que abordaremos es el de las leyes ontológicas, cuyos aspectos se centran en la concepción de un mundo material estructurado dialécticamente, ya que éste, en su totalidad, es comprensible solamente a partir de la concepción dialéctica; pues la dialéctica no se conforma en razonamiento sino se sustenta en un mundo material. Aquí es importante realizar una observación acerca del mundo material y la dialéctica: las leyes de la dialéctica (la contradicción, la negación y los cambios cuantitativos a los cualitativos) están sujetos únicamente al mundo material, a las cosas y a los fenómenos. No existe nada en la naturaleza y en la sociedad que no esté en movimiento, en transformación o en constante interrelación a las demás cosas. Por eso las leyes generales más importantes del mundo material son la concatenación universal y el desarrollo, que constituyen al mismo tiempo el contenido fundamental de la dialéctica objetiva, es decir, de la dialéctica de los propios objetos materiales, de sus relaciones y procesos. Los aspectos a considerar en este eje son los siguientes:

${ }^{14}$ Ibid., pp. 47-48.

${ }^{15}$ Ibid., pp. 69-70.

${ }^{16}$ Cfr. Carlos Marx, Crítica de la Filosofía del Estado de Hegel, traducción Antonio Encinares, prólogo Antonio Sánchez Vázquez, ed. Grijalbo, Col. 70, núm. 27, México, 1968. 
- Las leyes del desarrollo del mundo material y concreto que nos rodea, tienen un carácter dialéctico y existen independientes por completo de la conciencia del hombre. Por ello, "las leyes de la dialéctica no son simples leyes del espíritu, sino de la naturaleza. No es el pensamiento el que da su propia forma a las cosas, el que las interpreta dialécticamente. A la inversa, porque la naturaleza es dialéctica, el pensamiento lo es también cuando refleja a la naturaleza correctamente, sin deformarla, sin simplificarla. ${ }^{17}$

- La dialéctica es inmanente a la materia por el hecho de que es en esta última donde se sustenta su razón de ser, el carácter ontológico de la misma dialéctica. En este sentido, el mundo material, determina la conformación de las leyes fundamentales de la dialéctica: la ley de la contradicción, la ley de los cambios cuantitativos en cualitativos y la ley de la negación. Estas leyes, que se encuentran concatenadas y en interacción, son parte misma de la totalidad concreta de la realidad, de la dialéctica de la naturaleza y la sociedad.

- El método dialéctico de investigación nos brinda, en sus categorías y leyes, la herramienta de análisis que permite aprehender la esencia misma de los procesos históricos-sociales. Categorías y leyes que nos proporcionan el instrumental gnoseológico, mediante el cual se capta la realidad en su totalidad concreta.

- Descubrimos las leyes de la dialéctica en el interior de los procesos y fenómenos histórico-sociales, al tratar de detectar la esencia de los mismos, su desarrollo y transformación. Cuando nos planteamos un determinado objeto de estudio y queremos explicar cómo y por qué surge, cómo y por qué se desarrolla y cómo y por qué se transforma, tenemos que recurrir al método del materialismo dialéctico, ya que, por sus leyes, este método logra captar en su totalidad concreta a los procesos y fenómenos.

- La potencialidad analítica de estas leyes está dada por su capacidad de ofrecer respuesta a una serie de cuestiones referentes a -cómo vamos a explicar- los fenómenos concretos mediante la abstracción teórica. Todo proceso surge, se desarrolla y transforma a partir de una serie de contradicciones, las cuales van a ser el motor generador de lo material. La ley de la unidad de los contrarios en las cosas, es la más importante de la dialéctica materialista. De tal forma, esta ley debe proporcionarnos los parámetros de análisis que todo conocimiento necesita para poder explicar

${ }^{17}$ Roger Garaudy et. al. Lecciones de filosofía marxista. Traduc. Luis Ramón Moroto, ed. Grijalbo, México 1965, pp. 286. 


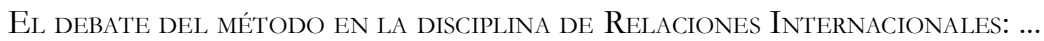

los procesos histórico-sociales. Esta ley nos sirve como uno de los instrumentos fundamentales de la estrategia metodológica a seguir.

- Si concebimos a la realidad como una totalidad concreta que tiene una estructura significativa, dicha estructura está determinada por las contradicciones existentes en ella. De aquí se deriva la relación dialéctica entre las contradicciones y la totalidad, es decir, la totalidad como realidad objetiva está conformada por las contradicciones. Las contradicciones objetivas, al reflejarse en el pensamiento, forman el movimiento de los opuestos en los conceptos, lo que promueve el desarrollo teórico y resuelve incesantemente los problemas del pensamiento humano. ${ }^{18}$

- La unidad de los contrarios en las cosas tiene un carácter universal y éste se sustenta en el hecho de que todas las cosas del mundo material existen porque contienen en sí contradicciones. "La universalidad o lo absoluto de las contradicciones tiene un doble significado. Uno es que la contradicción existe en el proceso de desarrollo de todas las cosas y el otro es que en el proceso de desarrollo de cada cosa existe, desde el comienzo hasta el fin, un movimiento de contrarios". ${ }^{19}$

- La unidad de los contrarios, la lucha de éstos en la naturaleza y la sociedad es el elemento dinamizador del movimiento y la transformación. En todo proceso natural o social existe una contradicción fundamental que es la que determina el aspecto cualitativo de cada uno de ellos. Aunada a esta contradicción coexisten una serie de contradicciones secundarias que forman el aspecto cuantitativo de los procesos. La relación e interacción entre estos dos aspectos, establece la ley de los cambios cuantitativos a los cualitativos o ley de la transformación.

- La cualidad de los procesos es la característica principal que permite diferenciarlos. Es la esencia de los mismos que nos permite delimitar el campo de estudio específico. Por su parte, el aspecto cuantitativo es el conjunto de elementos que existen como contradicciones secundarias en los procesos, las cuales, en su constante movimiento y transformación, inciden directamente en los cambios cualitativos de la naturaleza y la sociedad.

- Los cambios cuantitativos son aquellos que se dan en un proceso, pero éste no deja de ser lo que es. A diferencia, los cambios cualitativos son aquellos que se dan una sola vez y el proceso deja de ser lo que es, transformándose en un nuevo proceso con características esenciales diferentes al anterior.

${ }^{18}$ Ibid., p. 26.

${ }^{19}$ Ibid., p. 24. 
- La concepción dialéctica nos enseña que la materia se transforma, lo que significa el "nacimiento de formas que antes no existían, y la desaparición de fenómenos viejos; la sociedad esclavista cede su lugar a la feudal, etc. Se trata de transformaciones cualitativas y no sólo cuantitativas. Si observamos la realidad, vemos que en los fenómenos se producen cambios incesantes que, sin embargo, no hacen que el fenómeno deje de ser lo que es (...), se trata de cambios cuantitativos, por lo tanto. Sin embargo, la acumulación de tales cambios cuantitativos lleva a una situación en que se produce un cambio cualitativo. Dicho de otra forma: la acumulación de los cambios cuantitativos sólo puede realizarse hasta determinado límite; al rebasar éste, se produce un cambio cualitativo, un 'salto". ${ }^{20}$

- Toda transformación cualitativa supone un devenir de la lucha de contrarios. Durante este proceso y bajo determinadas circunstancias, la contradicción llega a un grado tal que se rompe su "equilibrio dialéctico. Se produce un cambio cualitativo, aparece un fenómeno nuevo que niega al anterior, pero no lo excluye. Es decir, el nuevo fenómeno, a la vez que mantiene elementos del que le precedió, contiene características nuevas, específicas". ${ }^{21}$ Aquí es donde adquiere significado la ley de la negación de la negación, debido a que el paso de una cualidad a otra nueva significa que la segunda va a negar a la primera.

- Por ejemplo, todo nuevo conocimiento es siempre perfeccionamiento de un conocimiento anterior, que se pone en duda, que se niega. ${ }^{22}$ La negación no puede ser pensada por una ampliación del conocimiento anterior y la complementariedad sólo puede ser vista a partir del pensamiento nuevo, que engloba al pensamiento que lo precedió. Se construye entonces una nueva aproximación a la realidad. No hay como elaborar el sistema nuevo por extensión del sistema anterior. Una vez construido aquel es que se puede comprender en él al pensamiento anterior, que es negado, pero no excluido, que pasa a encontrar nuevos límites dentro de los cuales sigue teniendo validez. Lo nuevo supera a lo antiguo y lo incluye en una perspectiva renovada. Aquí estamos en pleno dominio del conocimiento científico ya construido como tal. Sólo en este caso puede tener sentido la noción de complementariedad entre el conocimiento nuevo y el negado por él. ${ }^{23}$

${ }^{20}$ Juan Brom 0., Aspectos básicos del materialismo dialéctico, Edición del autor, México, 1970, p. 9.

${ }^{21}$ Ibid., p. 9.

${ }^{22}$ Miriam Limoeiro C., op. cit., p. 31.

${ }^{23}$ Ibid., p. 34. 
El debate del método en la disciplina de Relaciones Internacionales: ...

- Como ya se señaló, la ley de la negación es el resultado de los cambios cualitativos y, por lo tanto, producto de la lucha de contrarios. Sin embargo, nos hemos referido a esta ley como la ley de la negación de la negación, porque es una forma superior de la ley, ya que si observamos detenidamente una primera forma de existencia, ésta se desarrolló conformando su opuesto, el cual hace desembocar a una nueva existencia, que será la negación de la primera. A su vez, la nueva forma engendra su opuesto, el cual niega algo que de por si era ya una negación. Este proceso es el de la negación de la negación, en donde la negación última se emparenta con la primer forma; pero sobre un plano superior, conservando lo que ha sido adquirido desde el comienzo del proceso. ${ }^{24}$

- La concatenación de las leyes de la dialéctica determinan el carácter genéticodinámico del método de investigación. La génesis, desarrollo y transformación de los procesos de la naturaleza y la sociedad, implican, desde el punto de vista metodológico, la indagación de cómo se gesta el nacimiento de la realidad concreta y cuáles son las fuentes internas de su desarrollo y movimiento. Nosotros no podemos perder de perspectiva el carácter genético-dinámico de los procesos y fenómenos, debido a que es un supuesto de la comprensión racional del surgimiento de una nueva cualidad. ${ }^{25}$

- El carácter genético-dinámico de la ontología dialéctica es fundamental para el conocimiento del hombre. Si la estructuración y sistematización de las proposiciones teóricas se realizan a partir de la concepción de la teoría del conocimiento del materialismo dialéctico, y se aplican todas las herramientas que nos proporcionan sus categorías y leyes, vamos a obtener como resultado una elaboración epistemológica genética que nos permitirá mantener y proyectar el conocimiento científico en la misma praxis del hombre.

El tercer eje de la teoría de conocimiento es el del aparato conceptual, ya que la aprehensión de la realidad implica la formulación de hipótesis y la comprobación de las mismas para arribar a las tesis; proceso que requiere de un aparato conceptual que corresponda a las condiciones de existencia de los procesos histórico-sociales que seleccionamos como objetos de estudio. Es aquí donde la teoría de conocimiento o metodología encuentra la parte instrumental básica; es decir, las

${ }^{24}$ Cfr. Garaudy, et al., op. cit., p. 311.

${ }^{25}$ Cfr. Kosik, op. cit., p. 72. 
herramientas que le darán precisión, profundidad y trascendencia al proceso de construcción de los objetos de estudio. Los aspectos a considerar en este eje son los siguientes:

- El aparato conceptual es el núcleo fundamental de toda producción teórica, debido a que la formulación lógica de los objetos de investigación se estructura a partir de categorías científicas y conceptos genéricos u operatorios, los cuales, conjuntamente, le dan sentido y significado a las diversas propuestas teóricas que se van elaborando.

- Las categorías y conceptos genéricos u operatorios en la teoría del conocimiento del materialismo dialectico adquieren valor heurístico al referirse a condiciones de existencia concretas de los procesos históricosociales.

- Las precisiones conceptuales son un elemento básico que debe cubrir todo inicio de aprehensión y construcción de los objetos de estudio. Es decir, los profesores e investigadores tienen la obligación de definir los conceptos de los objetos de estudio que van a abordar, por lo que deben explicar qué van a entender por los términos centrales que integran el aparato conceptual correspondiente, ya que es a través del manejo correcto de este último, lo que nos permite conocer, explicar y aprehender de la manera más objetiva un fenómeno o proceso de la naturaleza o de la sociedad.

- El procedimiento para alcanzar una definición completa de los términos que utilizamos para identificar los elementos que integran los fenómenos y procesos histórico-sociales, es el del análisis de las dos esferas que contempla todo concepto: su intención y su extensión. La primera se refiere a las variables que conforman las características sustantivas que, en su conjunto, determinan la especificidad y cualidad del objeto de estudio, que la hace única y diferente a todas las demás "cosas". Por su parte, la extensión del concepto nos remite sólo a aquellas realidades o "cosas" a las que se puede aplicar dicho término, en tanto que tales realidades reúnen el conjunto de elementos que determinan la especificidad del concepto mismo.

- La determinación de cualquier concepto con rigor científico, se produce y se logra en conjugación con todos los conceptos que da cabida en los juicios que contiene su definición. Es decir, la determinación de un concepto específico implica un proceso cognoscitivo en el cual los propios juicios que hacen posible su existencia, están conformados por otros conceptos, desempeñando cada uno y simultáneamente la función de determinantes de los otros, al mismo tiempo que el concepto específico está determinado 


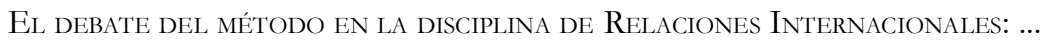

por ellos mismos. ${ }^{26}$ Por ejemplo, el concepto de totalidad concreta en la metodología del materialismo dialectico, se eleva a categoría científica al referirse a condiciones históricas de existencia, convirtiéndose en directriz heurística y principio epistemológico en el estudio, descripción, comprensión, ilustración y valoración de los sectores tematizados de la realidad social. ${ }^{27}$ Dicha categoría comprende la realidad en sus leyes internas y descubre, bajo la superficialidad y casualidad de los fenómenos, las conexiones internas necesarias como una unidad integrada por momentos contradictorios y complementarios entre si. Es decir, parte de la unidad de lo diverso y la síntesis de múltiples determinaciones. ${ }^{28}$

- El esfuerzo de rigor científico en las ciencias sociales, se enfrenta a ciertos problemas derivados de la transpolación mecánica de teorías y aparatos conceptuales, que son elaborados para determinadas realidades históricosociales, hacia otras realidades, sin considerar las especificidades concretas de estas últimas. El caso más común de esta transpolación mecánica es la que realizan algunos científicos sociales de los países subdesarrollados que adoptan las teorías y aparatos conceptuales elaborados en los países desarrollados, sin tomar en cuenta las diferencias estructurales y las necesidades histórico-sociales que prevalecen entre el mundo desarrollado y el subdesarrollado. De tal forma, dicha transpolación mecánica conduce a la inadecuación de los aparatos conceptuales, en detrimento del análisis objetivo. $^{29}$

- En el caso particular de la disciplina de las Relaciones Internacionales, esta inadecuación se presenta con mayor profundidad, por el hecho de que la mayor parte de la producción teórica y los correspondientes aparatos conceptuales, han sido elaborados en los centros académicos de los países desarrollados, principalmente en las universidades de Estados Unidos, las cuales buscan dar a sus teorías un aspecto de universalidad, que en la práctica son únicamente apreciaciones parciales de la realidad internacional, que sólo benefician los intereses de estos países y llegan, en la mayoría de los casos, a una apología de su sistema de valores socio-económicos.

- Esta situación nos obliga a abocarnos a la tarea de intentar una

${ }^{26} C f r$. Eli de Gortari. Introducción a la lógica dialéctica. Ed. Grijalbo, México, 1979, pp. 91-92

${ }^{27}$ Cfr., Kosik, op. cit., p. 56.

${ }^{28}$ Cfr., Ibid., p. 53.

${ }^{29}$ Cfr. Anouar Abdel-Malek, La dialéctica social, traducción Roberto Mesa, Ed. Siglo xxi, México, 1975, p. 39. 
reestructuración del aparato conceptual vigente en la disciplina de Relaciones Internacionales. Tarea que nos conduce a desplegar un esfuerzo doble: por un lado, el de creación o utilización de categorías científicas de análisis que nos permitan elaborar nuevas y más profundas proposiciones teóricas de la realidad internacional y sus procesos específicos y, por el otro, utilizar el aparato conceptual vigente, mediante la selección de conceptos, ya que en muchos de ellos "existen valores instrumentales que tienen que acogerse íntegramente para seguir elaborándose y refinándolos". ${ }^{30}$

\section{El problema de los paradigmas en la enseñanza de Relaciones Internacionales}

Este tema debería ser central en las revisiones periódicas de los planes de estudios de la Licenciatura, Maestría y Doctorado en Relaciones Internacionales, ya que la pregunta central es: ¿bajo qué paradigmas se están formando los internacionalistas en la Facultad de Ciencias Políticas y Sociales de la UNAM? De ahí la relevancia de la revisión y, en su caso, la reformulación de los paradigmas en la enseñanza de la disciplina de Relaciones Internacionales, tanto en el proceso de ajuste y adecuación epistemológica de las corrientes teórico-metodológicas y "modelos" explicativos de la realidad internacional, como del papel determinante que tales ajustes epistemológicos tienen en la enseñanza que de esta disciplina se realiza en las universidades a nivel nacional y mundial.

Un primer acercamiento al tema nos introduce de inmediato en la problemática de la reflexión teórica-metodológica y de la evolución científica de la disciplina de las Relaciones Internacionales. Problemática que hoy en día se redimensiona por los acelerados y radicales cambios que la sociedad internacional viene experimentando en las últimas dos décadas, cuyos efectos sociales, económicos, políticos, militares, culturales e ideológicos están generando un reacomodo integral de la distribución y correlación de fuerzas, tanto a nivel interno de los Estados, como en el ámbito propio de las relaciones internacionales.

Un segundo acercamiento al tema nos conduce a reflexionar sobre una preocupación profunda, compartida y generalizada por todos los científicos sociales interesados en los fenómenos internacionales, en torno a los derroteros que han seguido los paradigmas para comprender, explicar y tratar de influir en

${ }^{30}$ Antonio Gramsci, La política y el Estado moderno, traducción Jordi Solé Tura. Ed. Península. Barcelona, España, 1971, p. 43. 
El debate del método en la disciplina de Relaciones Internacionales: ...

la dinámica del cambio de la realidad internacional contemporánea. Dinámica que conlleva en su proceso viejos problemas que no se han resuelto y aún se han agravado, así como la aparición de nuevos fenómenos altamente complejos que requieren un tratamiento analítico y sistemático. Al conjugarse los viejos y nuevos problemas, se presenta una totalidad histórico-social única y multivariable, que requiere para su comprensión de paradigmas que respondan y se adecuen en términos cognoscitivos a las dimensiones y complejidades que está experimentando la estructura de la sociedad internacional a partir de los finales del siglo XX.

Los dos acercamientos iniciales al tema adquieren una nueva dimensión en el momento en que nos adentramos en la problemática de cómo se están preparando a los estudiantes en la carrera de Relaciones Internacionales en las universidades. Es decir, bajo qué paradigmas se encauza la enseñanza de la disciplina de las Relaciones Internacionales en las instituciones educativas. Este aspecto sustantivo es el que debe permear el debate del método en nuestra disciplina

De ahí que el esquema general de indagación se centre en las siguientes interrogantes:

- ¿Cuáles son los paradigmas dominantes en la enseñanza de la disciplina de Relaciones Internacionales en el mundo?

- ¿Cuál es la experiencia de las instituciones educativas en México, en cuanto a los enfoques paradigmáticos que prevalecen en la formación de los estudiantes?

- ¿Cómo se ha venido enseñando la disciplina de Relaciones Internacionales en la Universidad Nacional Autónoma de México, en particular en la Facultad de Ciencias Políticas y Sociales?

- ¿Cuál es la perspectiva de la enseñanza de la disciplina de las Relaciones Internacionales, ante lo que se ha denominado la apertura de las Ciencias Sociales?

- ¿Cuáles son las exigencias actuales del perfil profesional del internacionalista, que están demandando los mercados de trabajo, tradicionales y nuevos?

Estas interrogantes básicas deberían guiar los criterios para actualizar y, en su caso, reformular los planes y programas de estudio, traduciéndose ello en un perfil más acabado y fortalecido del egresado, en correspondencia con los cambios y mayores exigencias de los ámbitos laborales.

La revisión y, en su caso, la reformulación de los paradigmas en la enseñanza de la disciplina de las Relaciones Internacionales", nos lleva a replantear en forma 
diferente la problemática de los debates teórico-metodológicos contemporáneos en la disciplina, en la medida en que el propio término de paradigma y sus diferentes interpretaciones ubica la discusión en un terreno más polémico y reflexivo. Esta apreciación no es producto de la simple aceptación de una moda en la reflexión científica, promovida por los filósofos de la ciencia de corte neopositivista, quienes insisten en meter "en un mismo saco" los problemas metodológicos de las ciencias naturales y de las ciencias sociales, soslayando las diferencias cualitativas entre los dos ámbitos de la realidad y, por ende, de estudio de cada una de estas dos esferas. Por el contrario, su aceptación radica en que ha permitido abrir nuevos espacios de discusión, sustentados en una conceptualización renovada, que nos motiva a superar los monólogos academicis tas en que muchas universidades y centros educativos se han aferrado por largo tiempo.

No obstante el concepto de paradigma fue utilizado tradicionalmente, tanto por científicos sociales como por los de las llamadas ciencias naturales y exactas, para hacer referencia a las cosmovisiones y modelos teóricos existentes en sus respectivas áreas de estudio, no va a ser sino hasta la obra de Thomas S. Kuhn: La Estructura de las Revoluciones Cientificas, publicada en 1962, cuando tal concepto adquiere una presencia y dimensión diferente en la filosofía de la ciencia.

La pretensión de Kuhn (graduado en física teórica, pero interesado en la historia de la ciencia) fue la de explicar el proceso de las revoluciones científicas a partir de los cambios en los paradigmas dominantes, supuestamente en cualquier disciplina científica, pero tomando como centro rector de sus explicaciones la evolución de las ciencias físico-naturales. Su concepción es neopositivista y en las contadas ocasiones en que hace referencia a las Ciencias Sociales se mantiene a distancia, manifestando solamente sus dudas y desconocimiento sobre su problemática real.

Sin embargo, lo más seguro es que ni el propio Kuhn pensó en el impacto que sus hipótesis y tesis tendrían en la comunidad de los científicos sociales y, en forma especial, en los estudiosos de las relaciones internacionales. Se considere moda o no, es un hecho que a partir del segundo lustro de la década de los setenta, la obra de Kuhn ha tenido una influencia importante, como marco de referencia, para el análisis de la evolución científica de nuestra disciplina.

El primer problema que surge cuando abordamos el análisis de los debates teórico-metodológicos, concebidos como el enfrentamiento entre dos paradigmas, es la necesidad de tener una definición lo más exacta posible de lo que se entiende por paradigma. Al respecto, cabe hacer referencia a la investigación de Margaret Masterman, en la que demuestra que Kuhn utiliza el concepto de paradigma en 
El debate del método en la disciplina de Relaciones Internacionales: ...

por lo menos veintiún formas diferentes, ${ }^{31}$ por lo que en la posdata de la segunda edición de su libro, en 1969, el autor intenta definir el concepto bajo dos acepciones: por una parte, paradigma representa toda una constelación de creencias, valores y técnicas, etc. compartidos por los miembros de una comunidad científica. Por otra, denota una especie de elemento en esa constelación, referente a soluciones concretas a enigmas que, empleadas como modelos o ejemplos, pueden llegar a remplazar reglas explícitas como base para la solución de los restantes enigmas de la ciencia normal. ${ }^{32}$

Así, Kuhn denomina la primera acepción como "matriz disciplinaria" y a la segunda como "modelo" o "ejemplo compartido", el cual se refiere a cómo se educa a los futuros profesionales en una determinada disciplina. Estas interpretaciones no resuelven la confusión del concepto, pero le brindan elementos para definirlo como las suposiciones fundamentales que tienen los docentes e investigadores sobre el mundo que están estudiando. Tales suposiciones forman una representación del mundo, a partir de la cual se aborda el análisis de la realidad. En este sentido, paradigma se define como "visión del mundo", como una perspectiva intelectual más o menos sistemática, coherente y consistente de lo que es el universo (en el caso de nuestra disciplina, el universo de la sociedad internacional, sus fenómenos y procesos)..$^{33}$

Bajo estos términos, es necesario distinguir el significado de paradigma como "visión del mundo", entre los científicos sociales y los estudiosos de las ciencias naturales, ya que sus objetos de estudio difieren cualitativamente. No es lo mismo el físico-nuclear que trabaja a partir de un determinado paradigma de la física para desarrollar su práctica científica en un laboratorio (que mediante la observación y experimentación le permite obtener resultados tangibles), que un científico social, quien al sustentarse en un paradigma para sus investigaciones, no solamente está aceptando un modelo que le ayuda a explicar el fenómeno histórico-social que se ha abocado a estudiar, sino también, y es lo más relevante, está adoptando una concepción del mundo sustentada en una determinada perspectiva filosófica, a la cual le corresponde una teoría del conocimiento o metodología específica y singular que guía el propio proceso cognoscitivo.

De tal forma, cuando se habla de visiones o concepciones del mundo en las

${ }^{31}$ Cfr. Margaret Masterman, “The nature of a paradigm” en I. Lakatos y A. Musgrave (eds.) Criticism and the growth of knowledge, Cambridge University Press, England, 1970, pp. 59-89.

${ }^{32}$ Cfr. John A. Vásquez, El poder de la política del poder, traducción Ana Stellino, Ediciones Gernika S.A., México, 1991, pp. 17-31.

${ }^{33}$ Cfr. Ibid. 
ciencias sociales, en el sentido amplio de sistemas coherentes de ideas y valores, el problema de los paradigmas se redimensiona, porque conllevan en su estructuración implicaciones axiológicas, político-valorativas, de las propias teorías sociales.

Por lo tanto, el concepto de paradigma como visión del mundo de los científicos sociales y, en nuestro caso, de los internacionalistas, adquiere una connotación más profunda, en la medida en que al aceptar un paradigma se está comprometiendo uno con determinados valores $y$, por ende, con las teorías avocadas a mantener el statu quo, o bien las que tienden a promover el cambio.

Las dos acepciones que sobre el concepto de paradigma se han planteado, conforman en su interrelación un marco analítico de referencia de gran valor heurístico para estudiar las cosmovisiones bajo las cuales se están educando a los futuros profesionistas en la disciplina de Relaciones Internacionales en el mundo, en México y, particularmente, en la Facultad de Ciencias Políticas y Sociales de la UNAM.

Una educación científica implica, de acuerdo con Kuhn, la preparación del estudiante para resolver problemas. Es decir, el objetivo primordial del entrenamiento científico se concreta en la capacidad del estudiante para resolver problemas cuyas respuestas correctas ya se conocen. Tras esta filosofía de la educación enfocada a las ciencias físico-naturales, está la idea de que los estudiantes son capaces de llegar a la solución correcta de problemas viejos pero difíciles, con lo que van adquiriendo la habilidad para resolver problemas nuevos. La resolución de tales problemas inculca al estudiante un punto de vista del mundo, por lo que implícita o explícitamente va aceptando un paradigma determinado de la realidad profesional en la que está inmerso. ${ }^{34}$

Sin embargo, en el caso de las ciencias sociales y, en especial de la disciplina de las Relaciones Internacionales, esta filosofía de la educación tiene sus límites, en la medida de que sus objetos de estudio no pueden ser sometidos en la práctica a ensayos o experimentos de laboratorio, ya que la dinámica social se desdobla en escenarios donde los problemas a resolver tienen especificidades históricas y diferenciales que es imposible reducirlos a constantes permanentes cuya resolución no es física ni mecánica. Por lo tanto, la filosofía de la educación en ciencias sociales tiene otros matices, ya que si bien el objetivo de la preparación de futuros profesionistas es que adquieran los conocimientos, habilidades y destrezas para resolver problemas sociales, nacionales e internacionales, los paradigmas en los

${ }^{34}$ Cfr. Thomas S. Kuhn, op. cit., pp. 287-293. 
El debate del método en la disciplina de Relaciones Internacionales: ...

que son formados deben contemplar una formación abierta, plural y flexible que les permita resolver los problemas profesionales a partir de las características específicas y no repetibles de los fenómenos históricos sociales.

Si bien un aspecto básico de los debates sobre si la disciplina de las Relaciones Internacionales, en su esencia interdisciplinaria, debe ser una ciencia nomotética o ideográfica, es decir que tiende a la búsqueda de fenómenos recurrentes para el descubrimiento de leyes o estudie los fenómenos como hechos únicos y no repetibles, nos encontramos ante la necesidad de diferenciar los paradigmas de la disciplina en torno al debate señalado.

Si la disciplina se guiara por aquellos paradigmas de sustento nomotético, la filosofía de la educación de Kuhn tiene vigencia, pero en el caso de que tuvieran un sustento ideográfico tal filosofía sería inapropiada.

Dentro de esta línea de discusión, se proyecta la función trascendental que cumplen los profesores en la relación enseñanza-aprendizaje. Esta función está condicionada por el convencimiento y apego de los profesores a un paradigma determinado que es a través del cual encauzan su enseñanza, lo que determina al final de cuentas el perfil del egresado en Relaciones Internacionales. En este sentido, lo más deseable y apropiado sería que los profesores hicieran explícita su concepción del mundo y, por ende, su convencimiento por el paradigma que adoptan en la explicación de los fenómenos histórico-sociales internacionales. Un aspecto central que es determinante para hacer transparente dicha concepción, es el principio de lo que se debe entender por el fenómeno del cambio en la sociedad internacional.

Es obvio que ante la dinámica internacional siempre se haga referencia al cambio. Sin embargo, no queda clara la fundamentación teórico-metodológico que nos permita comprender el fenómeno del cambio en su totalidad concreta. Esto se debe a que prevalecen paradigmas que mantienen una interpretación lineal del cambio, que se percibe como una tendencia "darwiniana" de inicio, crecimiento, maduración y extinción de procesos, sin considerar las especificidades que se presentan en la dinámica social, cuya acumulación de cambios cuantitativos promueven un salto o cambio cualitativo, que implica una transformación radical de las estructuras sociales.

En síntesis, la revisión y reformulación de los paradigmas en la enseñanza de la disciplina de las relaciones internacionales está conduciendo a un reto intelectual de dimensiones insospechadas para quienes se dedican a la docencia e investigación, ya que tienen la responsabilidad de preparar a los estudiantes bajo una nueva perspectiva paradigmática integral. Esto se dice fácil pero es sumamente complejo, ya que equivale, para aquellos que han enseñado la disciplina bajo un 
determinado paradigma que sustenta su visión de la realidad internacional, a enfrentarse a la necesidad de reflexionar en términos cualitativos diferentes a su concepción tradicional y aceptar y asimilar una nueva visión del mundo. El aceptar un cambio de paradigma, significa una transformación de actitud profesional ante los objetos de estudio de la disciplina de Relaciones Internacionales. Ello implica avanzar por un camino arduo y difícil, pero es el único que permitirá romper inercias, superar estereotipos y promover el desarrollo científico de la disciplina. Como afirma Kuhn: "Sólo aquellos que han tenido el valor de observar que su propio campo (o escuela) tiene paradigmas, están capacitados para sentir que algo importante se sacrifica mediante el cambio". ${ }^{35}$

\section{Conclusiones}

Consideramos importante reiterar la relevancia científica del método del materialismo dialéctico para el estudio de los fenómenos internacionales, ${ }^{36}$ ya que éste se sustenta en el carácter fundamental que posee el proceso de producción de las condiciones materiales de vida, que es la base de la existencia social de los hombres y de las relaciones económicas, políticas, jurídicas, ideológicas, culturales, etc., o sea, superestructurales, que se dan en toda sociedad. Es esta concepción de la base material lo que nos permite tomar conciencia real de las instancias superestructurales y del movimiento histórico, que se derivan de las relaciones que contraen los individuos, los grupos y clases sociales y los Estados en un momento histórico específico.

Es esta base (infraestructura) la que permite el surgimiento y desarrollo de las relaciones internacionales. El tipo de las relaciones entre los Estados depende de la extensión del desarrollo de sus fuerzas productivas de cada uno de ellos, la división del trabajo y el intercambio interior. Y las contradicciones internas que se derivan de este desarrollo, se ensanchan en el ámbito externo, internacional, de las relaciones de producción secundaria y terciarias, y en general derivadas, transferidas, no primarias. ${ }^{37}$

${ }^{35}$ Ibid., p. 275.

${ }^{36} \mathrm{La}$ presencia de esta perspectiva es notable en enfoques recientes de nuestra disciplina como puede verse en: Stephen Hobden y Richard Wyn Jones, "Marxist Theories of International Relations" en John Baylis, Steve Smith y Patricia Owens, The Globalization of World Politics. An Introduction to International Relations, Oxford Univesity Press, Nueva York, 2008, pp. 144-159.

${ }^{37}$ Cfr., Carlos Marx y Federico Engels, La ideología alemana, traducción W. Roces. Ed. CID, México (s.f.) p. 20. 
El debate del método en la disciplina de Relaciones Internacionales: ...

Así pues, el desarrollo de la sociedad internacional tiene su base estructural en la producción material, en la internacionalización de las fuerzas productivas y en el intercambio económico, que en la etapa actual del capitalismo, denominada como globalización neoliberal, abarca al mundo en su totalidad. En la dinámica de las relaciones internacionales, además de la importancia vital de las relaciones económicas, existen otros factores como el político, el geográfico, el demográfico, etc. Pero éstos, a pesar de su carácter objetivo, no explican por sí solos el contenido de las relaciones internacionales entre Estados. Estos factores adquieren presencia histórico-social, en la medida en que se subsumen en la actividad social de la producción material.

Es aquí donde radica el potencial explicativo teórico metodológico de la concepción materialista dialéctica de la historia y la sociedad, porque a pesar de la peculiaridad y complejidad de la sociedad internacional, ésta se encuentra sujeta a las contradicciones generales del desarrollo social. No cabe duda de que las relaciones internacionales son un fenómeno social y que el análisis de éstas se debe llevar a cabo, en un primer momento, a partir de las relaciones económicas y su vinculación con los intereses de los grupos económicos dominantes en un momento histórico determinado. Esto nos permite, en un segundo momento, comprender las formas superestructurales que adquieren las relaciones internacionales políticas, jurídicas, ideológicas y hasta militares en un periodo histórico concreto.

\section{Fuentes}

Abdel-Malek, Anouar, La dialéctica social, traduc. Roberto Mesa, Siglo XXI, México, 1975.

Baylis, John, Smith, Steve y Owens, Patricia, The Globalization of World Politics. An Introduction to International Relations, Oxford Univesity Press, Nueva York, 2008, 680 pp.

Brom 0., Juan, Aspectos básicos del materialismo dialéctico, edición del autor, México, 1970.

Cueva, Agustín, "Sobre la filosofía y el método marxista" en Revista Mexicana de Ciencia Politica, núm. 78, año XX, Nueva Época, UNAM, FCPS, México, octubrediciembre de 1973.

Hobden, Stephen y Richard Wyn Jones, "Marxist Theories of International Relations", en Stephen Hobden y Richard Wyn Jones, The Globalization of World Politics. An Introduction to International Relations, Oxford University Press, Nueva York, 2008, pp. 144-159. 
Garaudy, Roger, et al., Lecciones de filosofía marxista, traduc. Luis Ramón Moroto, Ed. Grijalbo, México, 1965.

Gortari, Eli de, Introducción a la lógica dialéctica, Grijalbo, México, 1979.

Gramsci, Antonio, La política y el Estado moderno, traduc. Jordi Solé Tura, ed. Península, Barcelona, España 1971.

Kosik, Karel, Dialéctica de lo concreto, prólogo y traducción A. Sánchez -Vázquez, Grijalbo, México 1967.

Kuhn, Thomas S., La estructura de las revoluciones cientificas, traduc. Agustín Contín, FCE, México, 1971.

Limoeiro C. Miriam, La ideología dominante, traduc. Stella Mastrangelo, Siglo XXI, México, 1975.

Marx, Carlos, Crítica de la filosofía del Estado de Hegel, traduc. Antonio Encinares, prólogo Antonio Sánchez Vázquez, Grijalbo, colección 70, núm. 27, México, 1968.

Marx, Karl, "Introducción general de la crítica de la economía política", Cuadernos de Pasado y Presente, núm. 1, traduc. Manuel Murmis, et al., $7^{\mathrm{a}}$. ed., octubre de 1973.

Marx, Carlos y Federico Engels, La ideología alemana, traduc. W. Roces. ed. CID, México (s.f.).

Masterman, Margaret, "The nature of a paradigm" en I. Lakatos y A. Musgrave (eds.), Criticism and the growth of knowledge. Cambridge University Press, England, 1970.

Peña Guerrero, Roberto, "La alternativa metodológica para la disciplina de las Relaciones Internacionales: La dialéctica" en Estudio Cientifico de las Relaciones Internacionales, UNAM, FCPyS, México, 1978.

Schaff, Adam, Historia y verdad, traduc. Ignasi Vidal, Grijalbo, México 1974.

Siotis, Jean, "La ciencia política y el estudio de las Relaciones Internacionales" en Problemas de la ciencia contemporánea, Serie Estudio 3, UNAM, FCPyS, México, 1969.

Vásquez, John A., Elpoder de la política del poder, traduc. Ana Stellino, Ediciones Gernika, México, 1991. 


\section{Desarrollo de la SOCIEDAD INTERNACIONAL. OBjeto MATERIAL}

\section{David J. Sarquís*}

\section{Introducción: objeto material y objeto formal en relaciones internacionales}

Uno de los primeros aspectos que el aspirante a especialista en Relaciones Internacionales debe tener presente y analizar con todo cuidado para llegar a comprender con precisión la naturaleza de su propio trabajo es el de la doble acepción que tiene este concepto. En efecto, cuando hablamos de "relaciones internacionales", podemos, de hecho, estarnos refiriendo a dos cosas distintas que, por supuesto, están cercanamente interrelacionadas entre sí, pero que al mismo tiempo son claramente distinguibles la una de la otra y la diferencia no es cosa trivial.

Por un lado, en primera instancia podemos aludir con esta noción al conjunto de fenómenos sociales prácticos resultantes del flujo de interacción entre grupos humanos denominados naciones ${ }^{1}$ que podemos observar en un espacio geográfico e histórico determinado, tal como sugiere el sentido semántico estricto del término; pero, por otro, también nos podemos estar refiriendo al esfuerzo disciplinario dedicado al estudio de esos fenómenos que se observan en la práctica.

\footnotetext{
* Doctor en Relaciones Internacionales por la FCPYS de la UNAM. Docente-investigador de tiempo completo del ITESM-CEM. Miembro del SNI-1.

${ }^{1}$ Estrictamente hablando, la nación es una comunidad humana culturalmente integrada, la cual comparte en lo esencial sus valores y su historia. Como fenómeno de integración social emerge de las postrimerías de la Edad Media en Europa Occidental. No obstante, para poder hacer una revisión significativa de esta connotación del término necesitamos interpretarlo de manera flexible, entendiendo que la noción de nación se empleó en un contexto histórico concreto, porque era la forma de agrupación social más visible cuando empezó a dilucidarse teóricamente la interacción de grupos humanos políticamente independientes entre sí. La idea subyacente en relaciones internacionales no obstante es la de la interconectividad característica de unidades políticamente autónomas que pueden ser desde comunidades primitivas hasta pueblos o regiones, ya que sólo de este modo podemos ampliar el horizonte temporal de observación de nuestro objeto de estudio según veremos.
} 
Es decir, por un lado está la práctica social que se genera en el trato entre grupos humanos que son políticamente independientes y culturalmente diferenciados unos de otros (llamados naciones por razones históricas y de conveniencia) y por el otro está el esfuerzo de reflexión a través del cual los especialistas buscan dotar de sentido a ese conjunto de fenómenos sociales observables en la práctica. Obviamente, aunque podemos pensar en cada acepción por separado, el vínculo entre ellas es indisoluble, lo que significa que existe una influencia recíproca e inevitable entre ellas.

¿Y cuáles son los fenómenos sociales que se generan a través del trato que establecen entre sí estos grupos humanos políticamente independientes que dan pauta a nuestro objeto material de estudio? Pues de acuerdo a la experiencia histórica, los más comunes y visibles son las guerras, los tratados de paz, las alianzas, los fenómenos migratorios, la penetración cultural, la integración económica, las disputas territoriales, la creación de identidades frente al "otro", el aprovechamiento de los recursos naturales de una zona geográfica determinada, los impactos ambientales del desarrollo, en fin, todo aquello que contribuye de una u otra manera a forjar el concepto de una realidad internacional ${ }^{2}$ mediante intercambios políticos, económicos, jurídicos, culturales, etc. que trascienden fronteras ${ }^{3}$. Para poder estudiar todos estos fenómenos, los especialistas desarrollan teorías ${ }^{4}$ a través de las cuales intentan explicar lo que está pasando en los escenarios internacionales. ${ }^{5}$

La calidad de las teorías depende desde luego de la solidez de sus conceptos y de su poder explicativo, pero el punto de partida está en la naturaleza de las

\footnotetext{
${ }^{2}$ Realidad internacional podría ser, en efecto una primera aproximación a la definición de un objeto de estudio propio para Relaciones Internacionales. No obstante, el término puede resultar un tanto vago y habría que hacer precisiones puntuales sobre el mismo antes de poder usarlo de manera significativa.

${ }^{3}$ El concepto de frontera señala no sólo el límite geográfico sino también el histórico y el cultural que separa a un grupo humano de otro. Es importante porque permite establecer lo que viene a ser "interno" y lo que viene a ser "externo" a cada grupo y sugiere, ya de entrada, que la idea misma de relaciones internacionales involucra el encuentro y los intercambios entre distintos grupos humanos.

${ }^{4}$ Puede decirse que, en efecto, el estudio de la teoría está abocado al análisis y el entendimiento del objeto material, por lo que la vinculación entre ambos es necesaria e indivisible. Sin embargo, para fines didácticos y en razón de su complejidad, el estudio de la teoría merece un capítulo aparte.

${ }^{5}$ Este es otro concepto clave para los internacionalistas: se refiere al espacio histórico y geográfico en el que coexisten y establecen vínculos de diversos tipos grupos humanos políticamente independientes.
} 


\section{DesarRollo de la Sociedad internacional. Objeto material}

preguntas que se hacen sobre el objeto de estudio. ¿Qué es, en efecto, lo que se debe estudiar?, ¿cómo se le representa?, ¿qué significa?, ¿'es el resultado del azar u obedece a algún tipo de "regla" del devenir social?

Esto es lo que los especialistas han llamado la distinción entre relaciones internacionales como objeto material (un fenómeno observable en la praxis) y Relaciones Internacionales como objeto formal (el esfuerzo conceptual por aprehender el fenómeno antes mencionado). ${ }^{6}$ A través de sus intentos de respuesta a éstas y muchas otras interrogantes, los teóricos de las relaciones internacionales configuran conceptualmente, tanto el objeto material como el objeto formal al que están abocados.

La distinción no debe sorprendernos, igual diferencia existe prácticamente en todo el espectro de la ciencia: cada disciplina tiene su propio objeto de estudio, así, la física estudia la naturaleza, la biología estudia la vida como proceso, la química estudia formas de interacción entre materia y energía, etc. De hecho, tenemos que decir que para poder existir, una disciplina necesita primero haber identificado con toda claridad su objeto de estudio propio, en otras palabras, el segmento de la realidad al que estará abocado su esfuerzo cognoscitivo (su objeto material). Para ello es necesario que los estudiosos de área establezcan acuerdos claros sobre lo que van a estudiar, que definan dónde está el centro de su interés, en fin, cómo se van a representar eso que están estudiando, para ver qué nos pueden decir sobre él que no hayan dicho ya otras disciplinas. No hay pues desarrollo disciplinario posible en ausencia de un objeto de estudio claramente definido y delimitado, de ahí la importancia que tiene el que todos los analistas de las diversas áreas de la ciencia puedan identificar con absoluta puntualidad su objeto material de estudio.

El caso de las relaciones internacionales es un tanto complicado porque los internacionalistas usamos el mismo nombre para hablar del objeto de estudio y de la disciplina que debe abordarlo y esto suele crear confusión. Las otras disciplinas por lo general no tienen este problema ya que usan nombres distintos para distinguir el esfuerzo cognoscitivo como tal del objeto de estudio al que está abocado.

Hasta hace relativamente poco tiempo, la historia tenía el mismo problema que las relaciones internacionales, ya que el mismo concepto (historia) refería los dos ámbitos. Los historiadores, no obstante han avanzado en este terreno al establecer al pasado como objeto de estudio material de su disciplina, reservando

${ }^{6}$ Cfr. Rafael Calduch, Relaciones Internacionales, Ediciones Ciencias Sociales, 1991, especialmente. pp. 19-27. 
el nombre de historia para el esfuerzo disciplinario a través del cual se investiga el pasado, lo que evita importantes confusiones que los internacionalistas no han logrado resolver cabalmente todavía.

\section{Implicaciones de la conceptualización del objeto material}

Ahora bien, el problema del objeto de estudio no es sólo una cuestión terminológica. Esto significa que el tema de reflexión sobre el objeto material no se agota en la distinción entre la teoría y la práctica de las relaciones internacionales, de hecho el asunto es bastante más complejo.

No sólo se trata de identificar fenómenos sociales que el internacionalista debe explicar; se trata, sobre todo, de hacer explícita la distinción entre el proceso de observación y análisis de un objeto de estudio desde una perspectiva internacional, en relación con la observación y los estudios que podrían hacerse de estos mismos fenómenos desde cualquier otra matriz disciplinaria. ${ }^{7}$ En otras palabras, necesitamos reconocer como objeto material de estudio algo que ninguna otra disciplina esté ya abordando, de otra suerte, sólo estaríamos duplicando innecesariamente esfuerzos. Tenemos pues que identificar lo que es propio para el estudio del internacionalista y representárnoslo como objeto de análisis, tenemos que justificar que el análisis internacional como tal, tiene sentido y que el escenario internacional merece ser tratado como objeto de estudio aparte. Esto es así porque, en realidad, cuando nos representamos un objeto de estudio, ya estamos, de alguna manera sugiriendo la manera de interpretarlo y con ello, estamos gestando formas de actuar en el mundo.

De hecho, cuando estudiamos lo que ha sido el desarrollo disciplinario de Relaciones Internacionales ${ }^{8}$ nos vamos a encontrar precisamente con esta circunstancia de que, las dificultades de R.I. para consolidarse como disciplina

\footnotetext{
${ }^{7}$ Las matrices disciplinarias son de hecho puntos focales de reflexión sobre los problemas sociales y dan paso al surgimiento de las llamadas Ciencias Sociales, así la Ciencia Política, la Sociología, las Ciencias de la Comunicación, e incluso el Derecho, la Historia o la Filosofía como matrices disciplinarias reclaman su potestad para el análisis de segmentos específicos de la realidad internacional, lo cual, desde su punto de vista, haría prácticamente superflua la necesidad de una disciplina separada de Relaciones Internacionales.

${ }^{8}$ Para un recorrido histórico del desarrollo disciplinario de las relaciones internacionales, por lo menos en sus primeras etapas, es lectura obligada el trabajo de Emilio Cárdenas Elorduy, "El camino hacia la teoría de las relaciones internacionales: biografía de una disciplina", en Revista Mexicana de Ciencia Política, núm. 63, FCPYS, UNAM, México, 1971, pp. 5-23.
} 


\section{DesarRollo de la Sociedad internacional. Objeto material}

parten de la noción de que los fenómenos internacionales ya son abordados por otras matrices disciplinarias, incluso quizá desde una perspectiva más puntual (económica, jurídica, política, etc.) que la del supuesto “internacionalista” lo que, de ser cierto, haría innecesaria, según sus críticos, la existencia de una disciplina genérica o totalizante de las relaciones internacionales. Esto significa, en gran medida, que los internacionalistas no han sabido reconocer con claridad y expresar con precisión cuál es su objeto propio de estudio; cuál es el segmento de la realidad que ellos abordan y que, por lo menos desde alguna perspectiva singular, no es abordado por otros especialistas.

Prácticamente desde el inicio del esfuerzo reflexivo por crear la disciplina, al término de la Primera Guerra Mundial, ${ }^{9}$ el debate se ha centrado en este aspecto: todos los especialistas entienden que hay fenómenos transfronterizos (sobre todo guerras y procesos de paz, pero no exclusivamente) que generan algo que puede denominarse realidad internacional, ${ }^{10}$ pero no todos están de acuerdo en que debiera existir una disciplina autónoma para estudiarlos, precisamente porque, como objeto de estudio, las relaciones internacionales ya eran (y siguen siendo) estudiadas por otras matrices disciplinarias.

De este modo, Relaciones Internacionales como disciplina ha tenido que recorrer un largo camino durante la mayor parte del siglo XX para justificar su existencia; un camino que no ha estado exento de acalorados debates en torno a si debe existir o no una disciplina aparte, encargada del análisis de la realidad internacional (noción que, como hemos dicho, resulta harto vaga como para justificar la existencia de una disciplina nueva) sin que a la fecha se haya logrado un consenso universal en torno al tema. ${ }^{11}$

En el intento por justificar la existencia de una disciplina autónoma, algunos internacionalistas han argumentado que su perspectiva ofrece la única visión de conjunto basada en un esfuerzo multi e interdisciplinario de los procesos sociales,

\footnotetext{
${ }^{9}$ La mayoría de los especialistas reconoce hoy en día a la cátedra organizada por la Universidad de Aberystwyth en el país de Gales en 1919 como el inicio del desarrollo disciplinario de las R.I.

${ }^{10} \mathrm{La}$ idea de realidad internacional sugiere que hay un nivel o dimensión de la realidad social que no existe antes de que haya grupos humanos políticamente independientes unos de otros que entren en contacto entre sí. De este modo, sólo cuando esos grupos establecen interacción se puede empezar a hablar de una realidad internacional, en oposición a la idea de una realidad doméstica o interna, referida a lo que ocurre dentro de los límites interiores de cada frontera grupal.

${ }^{11}$ Seguramente el consenso universal será difícil (quizá incluso imposible) de alcanzar, pero cuando menos deberíamos aspirar a tener una comunidad epistémica fuerte y consolidada capaz de defender la idea de la autonomía disciplinaria de Relaciones Internacionales.
} 
lo que hace significativa la idea de una realidad internacional, cuestión que por cierto les ha merecido el apelativo despectivo de todólogos, sin que, por otra parte, contribuya de manera sustancial a justificar la idea de su autonomía disciplinaria.

Es por ello que resulta tan importante que los alumnos de esta área reflexionen detenidamente sobre la cuestión de su objeto de estudio propio desde el inicio de su carrera, es decir, que reconozcan con claridad el objeto material al cual van a estar abocados, ya que de otra suerte, difícilmente podrán desarrollar y consolidar su propia identidad profesional. Así que, en justicia, debe decirse que un estudiante del área incapaz de reconocer la diferencia entre las ri como objeto material y RI como objeto formal, no merece el nombre de internacionalista.

\section{Evolución histórica del objeto material}

La distinción entre objeto material y objeto formal no es ociosa; como fenómeno observable en la realidad (praxis) las relaciones internacionales se dan, desde nuestra perspectiva prácticamente de manera natural, incluso, podríamos decir, de manera obligada, a partir del contacto que por necesidad tienen que establecer las distintas naciones ${ }^{12}$ que comparten un espacio geográfico entre sí, ${ }^{13}$ incluso mucho antes de que alguien se dedique a reflexionar sobre esta situación. Así, puede afirmarse que el objeto material es anterior en el tiempo al objeto formal en relaciones internacionales y una vez que se configura el objeto formal empieza a incidir en la transformación consciente del objeto material.

No obstante, debe decirse que, para la mayoría de los especialistas contemporáneos, en sentido estricto, las relaciones internacionales son en realidad un fenómeno histórico con una línea cronológica relativamente corta y bien definida,

\footnotetext{
${ }^{12}$ Nuevamente, hay que enfatizar que empleamos en este momento el nombre de naciones de forma genérica para referirnos a grupos humanos políticamente independientes y culturalmente diferenciables entre sí. La nación, como tendrá que aprender todo internacionalista, es un modo de organización social histórica y geográficamente desarrollado en una etapa tardía de la experiencia europea: no todos los grupos humanos son o han sido naciones, aunque todos ellos generan interacción con "otros" dando pie al surgimiento de un nivel de realidad distinto de la realidad endógena que caracteriza a cada grupo humano. En ello radica la esencia de la idea de internacionalidad característica de la experiencia humana.

${ }^{13}$ Esto se debe, en esencia a que prácticamente no existen colectividades humanas en completo aislamiento. La experiencia demuestra que, aun en los espacios más recónditos del planeta, cuando llega la presencia humana, lo hace siempre manifestando una notable diversidad organizativa (siempre hay más de un grupo).
} 


\section{DesarRollo de la Sociedad internacional. Objeto material}

que apenas puede apreciarse con creciente claridad en la escena social global desde mediados del siglo XV, cuando empieza a gestarse una especie de "espíritu nacional" entre algunas de las comunidades ubicadas en el ámbito de Europa Occidental, las cuales finalmente cristalizan como proyectos sociales hacia principios del siglo XVII. ${ }^{14}$ En otras palabras, para la mayoría de los especialistas actuales, nuestro objeto propio de estudio (cualquier cosa que éste sea) no puede remontarse más allá del periodo del surgimiento de las naciones modernas y es este concepto un punto de partida clave para el análisis de lo internacional en el mundo moderno. El maestro Ortega y Gasset nos refiere sobre la cuestión de las naciones que,

debiera constar más al hombre medio culto que lo que llamamos estrictamente "naciones" no aparece plenamente en el área histórica hasta fines del siglo XVI y comienzos del XVII. Pero también viceversa, es preciso señalar que en torno a 1600, la realidad "naciones" se presenta ya con todos sus atributos íntegramente constituida. Los pueblos de Occidente habían llegado en su desarrollo a formarse una vida propia lo suficientemente rica, creadora y característica para que en esa fecha saltase a los ojos de cada uno que era diferente de los demás. (...) Esto nos descubre, de paso, que una nación no puede nunca ser una sola. $\mathrm{Al}$ estricto y no vago concepto de nación pertenece ineludiblemente la pluralidad. ${ }^{15}$

Dada su importancia, volveremos en seguida con el tema de la nación, sin embargo debemos recordar antes que, como esfuerzo disciplinario, Relaciones Internacionales sólo empieza a desarrollarse formalmente al término de la Primera Guerra Mundial, (es un fenómeno conceptual muy reciente) aunque, como ya también mencionamos, eso no significa ausencia total de reflexión sobre el fenómeno práctico de las relaciones internacionales procedente de fechas anteriores a ésa. Casualmente, algunos internacionalistas contemporáneos reconocen ya un importante antecedente de la reflexión teórica (que da paso a la formación de una disciplina) en torno al fenómeno internacional justamente en la obra del historiador ateniense Tucídides, ${ }^{16}$ y luego, en una sucesión de pensadores que atraviesan el espacio temporalidad del mundo antiguo y medieval hasta llegar a la era de la modernidad.

\footnotetext{
${ }^{14}$ La gestación de este espíritu nacional se observa ostensiblemente en Inglaterra y Francia, impulsadas a fortalecer su identidad propia, sobre todo a raíz del prolongado conflicto que las enfrenta por espacio de más de un siglo hacia fines de la Edad Media. Obviamente, la idea no es ajena a la necesidad del 'mercado ampliado' que según el análisis marxista requiere el desarrollo incipiente del capitalismo del siglo XVI.

${ }^{15}$ José Ortega y Gasset, Europa y la idea de nación, Alianza Editorial, 1985, pp. 50-51.

${ }_{16}$ Tucídides relata en La guerra del Peloponeso, el conflicto que enfrentó a la Liga de Delos liderada por la ciudad de Atenas contra la Liga del Peloponeso, dirigida por los espartanos y que
} 
El caso es, sin embargo, como ya hemos apuntado, que en términos generales los antecedentes de la reflexión teórica sobre la interacción internacional se habían recogido desde el ámbito particular de otras disciplinas, como el Derecho Internacional, la Historia Diplomática, la Economía Política o incluso la propia Filosofía y exclusivamente desde el ámbito de la tradición occidental, mientras que la historia de la disciplina empieza a vislumbrar ahora importantes antecedentes de reflexión teórica entre pensadores chinos e hindúes aún anteriores a la era cristiana. ${ }^{17}$

Desde esta perspectiva, en términos de nuestro objeto material, la cuestión de las civilizaciones anteriores a la modernidad se ha convertido en fechas recientes en tema de interés para la elaboración de la dimensión histórica en el estudio de las relaciones internacionales. ${ }^{18} \mathrm{El}$ caso griego, por ejemplo, es obviamente un caso histórico paradigmático pero controvertido, como todos los de la historia de la antigüedad para la disciplina de Relaciones Internacionales, porque aparentemente se alejan de la concepción clásica o rigorista de las relaciones internacionales como praxis, por la sencilla razón de que, como ya hemos dicho, las naciones rigurosamente consideradas no consolidan su presencia en el escenario mundial sino hasta mediados del siglo XVII de la era cristiana. La pregunta entonces es pertinente: ¿puede haber un objeto material de estudio de las relaciones internacionales en cualquier época anterior a la modernidad? De no ser así, el internacionalista debería quedar circunscrito a la especificidad de la historia universal reciente ${ }^{19}$ (digamos, a partir de mediados del siglo XVII y sólo desde una perspectiva eurocéntrica que coloca a la nación en el centro de la reflexión teórica), pero ello implicaría hacer caso omiso de toda la experiencia socio histórica anterior a estas fechas.

marca el fin de la era clásica en Grecia hacia el 404 a.C. Lo interesante de la reflexión en su relato es que resulta fácilmente asimilable a la noción de internacionalidad, en el sentido de espacio de interacción de comunidades políticamente independientes que es característico de los escenarios internacionales contemporáneos.

${ }^{17}$ Cfr. Donald Puchala, Theory and History in international relations, Routledge, London, 2003, pp. 174-185.

${ }^{18}$ En este sentido es particularmente relevante el trabajo de Adam Watson, The evolution of international society, Routledge, London, 2005 y la contribución de Barry Buzan \& Richard Little, International Systems in world history: Remaking the Study of International Relations, Oxford University Press, USA, 2000, 472 pp.

${ }^{19}$ De hecho, un enfoque así de rigorista tendría muchas dificultades para explicar dos aspectos fundamentales de la realidad internacional contemporánea: a) el papel del Estado como agente prioritario de la escena internacional y b) el surgimiento actual de las regiones como nuevas formas de agrupación social integradas, entre otras, por naciones. 


\section{DesarRollo de la Sociedad internacional. Objeto material}

En consecuencia, resulta de vital importancia repensar la cuestión del objeto material de las relaciones internacionales desde una perspectiva histórica de más largo plazo ya que, según reza el argumento tradicional, resulta, cuando menos, un abuso del lenguaje, referirnos a la interacción entre grupos humanos anteriores a la modernidad en términos de relaciones internacionales. ${ }^{20}$ Esto plantea un serio problema para cualquier intento de revisión histórica de largo alcance, ya que no permite explorar desde una perspectiva internacional el vasto expediente de la historia antigua y moderna hasta el advenimiento de las naciones propiamente dichas. Tal es el enfoque que podríamos llamar "restringido" en cuanto al nombre de nuestra disciplina, para el cual, puede haber interacción entre grupos humanos anteriores a la nación, pero ésta no debe confundirse con el tipo específico de intercambio entre las naciones propiamente dichas.

El razonamiento, como puede observarse, es perfectamente válido, pero claramente limitante en términos de vinculación de la experiencia histórica de largo alcance en materia de interacción entre colectividades políticamente autónomas (entre las cuales la nación es, en efecto, la más nueva, pero evidentemente no la única: hoy en día, por ejemplo, podemos afirmar que transitamos de la era de las naciones a la de las regiones, ${ }^{21}$ argumento que sin lugar a dudas tendríamos aún que sustentar). Después de todo, si los internacionalistas se interesan por fenómenos transfronterizos como las guerras, los tratados de paz, los procesos de integración, la formación de identidades grupales, el establecimiento de hegemonías, etc. (todos los cuales son de importancia capital en la configuración del objeto material de las R.I.), es claro que todos ellos tienen un expediente histórico de largo alcance, lo cual, por cierto no debe llevarnos a generalizaciones triviales. Es igualmente claro que cada etapa del desarrollo histórico de las relaciones internacionales posee su propia especificidad. Nuestro objeto material, en otras palabras, no carece de expediente histórico.

Si bien es cierto que el trabajo de la ciencia exige, entre sus premisas básicas, de la mayor precisión conceptual posible, también es cierto que normalmente el

${ }^{20}$ Cfr. Ekkehart Krippendorff, El sistema internacional como bistoria, traduc. Angelika Scherp, Fondo de Cultura Económica, México, 1975, especialmente pp. 9-22.

${ }^{21}$ En este sentido el autor japonés Kenichi Ohmae ha escrito dos obras que, aún bajo una óptica económica, comienzan a plantear este tema como un reto a Relaciones Internacionales. Véase Kenichi Ohmae, The Next Global Stage: Challenges and Opportunities in our Borderless World, Wharton School Publishing, Philadelphia, 2005 y The End of the Nation-State: the Rise of Regional Economies, Simon and Schuster Inc., New York, 1995. 
lenguaje es mucho más limitado que la realidad observable y que la costumbre hace ley. De este modo, el término relaciones internacionales, popularizado por Jeremy Bentham desde finales del siglo XVIII ha arraigado de tal manera entre el público general así como entre los estudiosos que, a pesar de las múltiples propuestas encaminadas a la búsqueda de una mayor precisión conceptual, ${ }^{22}$ hasta la fecha ha sido prácticamente imposible sustituirlo.

La noción inicial que sugiere este concepto, aunque es en gran medida nebulosa, permite incluso al observador no especializado intuir que, de una u otra manera se refiere al trato que diferentes naciones, países o grupos humanos socialmente organizados establecen entre sí. ${ }^{23}$

Sin embargo, con sólo ponderar esta intuición un poco podemos percatarnos de sus insuficiencias (¿qué es una nación o un país y cómo debe caracterizarse cada uno de ellos en el ámbito de su interacción con otros?, ¿cómo delimitamos en tamaño o funciones a los grupos humanos socialmente organizados para distinguirlos entre sí?, ¿cómo o en función de qué se elige un determinado curso de acción desde el interior de un grupo humano para relacionarse con los otros?) Todo lo anterior obliga, sobre todo en el ámbito de la academia, a preocuparnos por delimitar con mayor precisión cada uno de nuestros conceptos clave para el desarrollo disciplinario.

Esto significa tener que colocarnos en posición de delimitar con todo el rigor posible, qué es una nación o un país, qué son los grupos humanos socialmente organizados, u otras formas de organización humana, cómo se relacionan estos conceptos entre sí y con otros semejantes a ellos y cómo funciona el esquema de sus interacciones mutuas. Esto es fundamental para poder organizar, a partir de ahí la noción de un objeto material para la disciplina de Relaciones Internacionales.

Una vez que vamos precisando esto, puede llegar a decirse, en sentido estricto que, en efecto, relaciones internacionales propiamente dichas como objeto material

${ }^{22}$ Cfr. por ejemplo, Celestino Del Arenal, Introducción a las relaciones internacionales, Ed. Tecnos, Madrid, 1987, pp.16-20 o Leandro Rubio García, "La aprehensión de la escena internacional desde los asuntos mundiales hasta las relaciones internacionales" en Ileana Cid Capetillo, compiladora, Lecturas básicas para introducción al estudio de las relaciones internacionales, FCPYS/UNAM, 1999, pp. 117-132.

${ }^{23}$ Encuestas informales realizadas por alumnos del curso introductorio al estudio de las relaciones internacionales han revelado consistentemente que hasta en $90 \%$ de los casos, independientemente de su nivel de escolaridad, el entrevistado sospecha, por el puro nombre, que las relaciones internacionales tienen algo que ver con el trato que diversos países establecen unos con otros, quizá a través de la diplomacia o la política exterior, como hemos apuntado, pero no van mucho más allá de esa vaga intuición. 


\section{Desarrollo de la sociedad internacional. Objeto material}

serían un fenómeno histórico reciente y característicamente europeo porque, como señalamos, las naciones, como modo de organización social tienen apenas poco más de tres siglos de existencia y provienen de la experiencia concreta que significó la fragmentación de la Cristiandad al término de la Edad Media en el ámbito geográfico de la Europa Occidental y los países son entidades geográficas que surgen precisamente del desvanecimiento del antiguo orden medieval, justo cuando las naciones empiezan a consolidarse como proyectos socio-culturales, básicamente a consecuencia de las revoluciones burguesas, ya bien entrado el siglo XIX de la era actual.

Pero, entonces, como ya hemos inquirido ¿dónde queda toda la experiencia acumulada en cuanto a la interacción de distintos grupos humanos entre sí, en distintas latitudes del planeta con fecha anterior, por ejemplo, al siglo XVII?, $¿$ acaso no existe forma de vincular la experiencia humana anterior al siglo Xv con la contemporánea más allá de las vagas generalizaciones?, ¿no forma todo ese vasto horizonte histórico parte del objeto material de las relaciones internacionales? $?^{24}$

En consecuencia, nos parece necesario pensar en una concepción laxa o flexible del término "relaciones internacionales" para poder pensarlo históricamente a largo plazo, ya que no ha sido factible sustituirlo y así ampliar su alcance (sin perder su contenido) hasta abarcar un cúmulo de experiencias que incuestionablemente están ahí y pueden resultar sumamente provechosas para el analista del fenómeno internacional contemporáneo, en la medida que éste logra establecer conexiones significativas entre los distintos momentos históricos característicos de la evolución del gran sistema internacional, o más propiamente hablando, de los diversos sistemas internacionales históricos que han existido en el planeta al paso del tiempo.

Esta última reflexión nos sugiere además algo muy importante: el objeto material de estudio de las relaciones internacionales puede ser pensado en términos sistémicos, de este modo, podríamos decir que el objeto material de la disciplina es el sistema internacional en su conjunto y que el analista tiene que dilucidar su estructura, su funcionamiento, su comportamiento y su evolución. Ésta es, claro

${ }^{24}$ Krippendorf es de los partidarios de la postura restringida del término relaciones internacionales y sostiene enfático que prácticamente carece de sentido hablar del tema antes de la revolución industrial, pero curiosamente, cuando trata de explicar el advenimiento de ésta, tiene que remontarse a la época de las grandes exploraciones europeas que llevan a la conquista de América y el desarrollo del capitalismo. Me parece claro que si el autor quisiera explicar en turno esos hechos, tendría que ampliar el alcance de su mirada retrospectiva. 
está, una entre diversas propuestas para pensar nuestro objeto de estudio como internacionalistas, no es, evidentemente, la única, por lo tanto, el aspirante a especialista en el área tendrá que ponderar las bondades de considerar a su objeto de estudio como un sistema y compararlo frente a otras propuestas (que es justamente lo que debe hacerse en los cursos de teoría de las relaciones internacionales).

\section{La nación como objeto de estudio para los internacionalistas}

Podemos ahora regresar a considerar, por la importancia que tiene, el alcance del concepto de nación, primero para delimitar su contenido y luego para explorar las posibilidades de su conexión con el pasado; en particular, ese pasado tan significativo para la cultura occidental contemporánea que es el de la historia antigua y que hasta ahora, según la definición rigurosa más tradicional de las relaciones internacionales, no nos podíamos apropiar en toda su extensión los internacionalistas como parte de nuestro objeto propio de estudio.

Al hacerlo, vamos a ampliar el alcance de nuestro propio horizonte histórico para explorar un área que la propia historia apenas vislumbra como objeto de estudio, la de las relaciones internacionales y en la que ciertamente, historiadores e internacionalistas podemos conjugar esfuerzos para una mejor comprensión de la experiencia humana en su conjunto.

Nada hay, sin embargo, más engañoso que una definición excesivamente rigorista. Siempre se le encontrarán fallas que denotan su insuficiencia para abarcar la totalidad de los casos que supone comprender. El caso de la nación, que de alguna manera ya mencionábamos con anterioridad no es la excepción. A pesar de los múltiples intentos por definirla (y vaya que si han proliferado) siempre hay faltantes, siempre encontramos casos que caen fuera de la regla. No vamos entonces a emprender un análisis exhaustivo del concepto, porque no corresponde al interés directo de este trabajo y bien podría requerir de una extensión mucho más larga de la que ya hemos cubierto hasta ahora. Nos limitaremos entonces a considerarla, desde la perspectiva más general, simplemente como punto de partida para nuestra reflexión sobre el origen y alcance de las relaciones internacionales como fenómeno de la praxis social. No se trata de un reduccionismo simplista. La idea de la nación es compleja y requiere de un tratamiento extensivo y cuidadoso. También en este caso existe abundante literatura dedicada al tema. ${ }^{25}$

\footnotetext{
${ }^{25}$ Particularmente importante por su contenido es la obra de José Ortega y Gasset, op. cit., en
} 


\section{DesarRollo de la Sociedad internacional. Objeto material}

Para muchos especialistas, la idea formal de "la nación" se elaboró hacia fines del siglo XVIII (aunque otros señalan una proyección histórica de mayor alcance) y es, al mismo tiempo, señal inequívoca de la conciencia que algunas colectividades europeas han cobrado de sí mismas como colectividades ampliadas, en el sentido de haber incorporado a varios grupos otrora considerados como distintos, en base a instituciones comunes, fuerzas operativas conjuntas (como es el mercado) y a valores compartidos, normalmente por afinidad cultural, a la vez que un resultado de la reflexión de los enciclopedistas sobre las fuentes del poder social que legitiman las distintas formas de gobierno. Es interesante señalar también que, en el proceso, hay una concientización y concreción creciente de la idea de lo europeo en relación con las culturas que no lo son -los otros (chinos, indios, musulmanes, nativos americanos, etc.), en el lenguaje de Todorov. ${ }^{26}$

Así, por ejemplo, en contraposición con los defensores de las monarquías absolutas, fincadas en la tesis del derecho divino para gobernar, los filósofos de la razón argumentaron en favor de una concepción que ve al ejercicio del poder como una facultad que las autoridades sólo pueden ejercer de una manera socialmente aceptable cuando está basada en una especie de consenso generalizado que Rousseau llamó la voluntad general. Para el ginebrino, esta noción es de crucial importancia porque define la razón en la que se sustenta la idea misma de la formación de colectividades humanas, un proceso encaminado a superar los escollos de la vida no institucionalizada en la que el mayor riesgo de la subsistencia individual viene de la competencia natural con los 'otros'.

¿cómo es posible compaginar la libertad del hombre con las exigencias de la irrenunciable vida social, es decir, con la necesidad de someterse a un orden moral? Para Rousseau sólo existe una solución: aplicar fielmente el «Contrato Social». Por él, todos y cada uno de los individuos hacen entrega a la comunidad de todos sus derechos (en el sentido de pretensiones, reivindicaciones); como esta cesión se hace a la comunidad total y no a ninguna otra persona o grupo, la voluntad y los derechos de cada individuo no quedan sometidos a los de ningún otro, sino a la «Voluntad general» de esa persona colectiva de la cual él es una parte. Esa voluntad general busca siempre

\footnotetext{
la que el autor concibe a la nación como un grupo humano definido por un proyecto de vida compartido. Otro trabajo importante en la misma dirección es el de Rudolf Rocker, Nacionalismo y cultura, Alebrije, México, 1988; en la que se maneja la idea de nación como un modo de organización social alcanzado por los pueblos europeos en las postrimerías de la Edad Media.

${ }^{26}$ Cfr. Tzvetan Todorov, Nosotros y los otros, traducción Ministerio Francés Encargado de la Cultura y la Comunicación, Siglo XXI, México, 2000, especialmente pp. 203-208.
} 
el bien común, es decir, la defensa de la persona y de la propiedad de cada miembro, y, por tanto, lo mismo que buscaba cada uno de los individuos en el «estado de naturaleza». De esta forma, además de quedar garantizada la moralidad, cuando se obedece a la «Voluntad general», queda también garantizada la libertad individual, ya que se está obedeciendo a sí mismo. ${ }^{27}$

La noción es importante porque mete en escena a la gran masa amorfa de gente otrora contemplada desde una perspectiva social pasiva meramente como súbditos de un monarca, condición que la mayoría mantiene en el resto del mundo no europeo. Es justamente a partir de la idea de una voluntad popular que se va a ir conformando la idea de nación como un colectivo; un agregado social que representa la identidad de un grupo determinado y que define su estilo de vida y su manera de ser, (más allá de los vínculos étnicos, lingüísticos o religiosos que inicialmente vinculan a los colectivos humanos) lo que no sólo lo dota de coherencia y cohesión interna sino que además lo distingue de los demás (los otros) al exterior. Pero, ¿̇en qué sentido es distintiva la nación con respecto a formas anteriores de agrupación social?, ¿por qué no son los griegos, por ejemplo, o los romanos, los egipcios o los persas naciones propiamente hablando y, en todo caso, como debemos clasificarlos?

Como hemos señalado ya, la experiencia humana es ante todo grupal; difícilmente puede hablarse de manera significativa del ser humano fuera del contexto de algún grupo. Para poder existir, los grupos deben estar cohesionados. Las formas grupales anteriores a la nación lograban esa cohesión a través de distintos factores, el más antiguo era el vínculo sanguíneo, pero a medida que los grupos se hacen más grandes y complejos, la biología deja de un ser aglutinante efectivo, entonces los grupos tienen que desarrollar nuevos elementos de cohesión: claramente, el lenguaje, las costumbres comunes, la religión han jugado un importante papel histórico en ese sentido. Todo esto forma parte de la fenomenología social que configura el objeto material de las relaciones internacionales cuando elegimos pensar en nuestro objeto de estudio genérico como un sistema inter-nacional.

Durkheim reconoce la complejidad grupal creciente al establecer su distinción entre formas de solidaridad grupal mecánicas (basadas en el desempeño común de tareas colectivas) y formas de solidaridad orgánicas (basadas en la especialización), lo que de alguna manera da a la sociedad humana un carácter

\footnotetext{
${ }^{27}$ José Ocariz. Historia sencilla del pensamiento político: Rousseau. Recuperado el 11-01-2011 en: http://www.mercaba.org/Filosofia/rousseau_01.htm.
} 


\section{DesarRollo de la Sociedad internacional. Objeto material}

más social y menos biológico. ${ }^{28} \mathrm{La}$ nación fue hasta hace poco la forma más desarrollada de cohesión grupal (hoy en día se perfila sobre el escenario internacional el concepto de región, el cual apenas se está conceptualizando entre los especialistas) abarcando gente de distinto origen étnico, lingǘstico o religioso en un proyecto social común en el que la identidad global tiende a superar -no siempre con éxito- a la local. ${ }^{29}$

En un proyecto nacional consolidado, la gente se siente pues parte de una identidad más amplia que la de sus vecinos inmediatos (como sería, por ejemplo, el caso de las tribus). Los griegos no logran ese tipo de identidad ampliada porque la gente siempre es claramente más ateniense, espartana, tebana o corintia, etc. antes que griega o helena para decirlo con mayor propiedad.

Aunque existe la noción de heleno, que crea el trasfondo cultural de las polis y dota en alguna medida de identidad colectiva a las tribus griegas, ésta nunca fue lo suficientemente sólida como para superar la lealtad local, y mucho menos para sentar las bases de una autoridad central reguladora de todas las polis, situación que en gran medida caracteriza al sistema internacional contemporáneo. El único elemento que podía lograr la cohesión unificadora (la fuerza militar) está tan equilibrado en el ámbito de la cultura griega que, salvo en el caso de Alejandro Magno, sencillamente fue insuficiente para lograr un arreglo hegemónico duradero en el sistema griego. ${ }^{30}$

Ahondando en el tema de las naciones, me parece muy adecuada la propuesta de Anderson para abordar la problemática conceptual de la nación como: una comunidad política imaginada, inherentemente limitada y soberana. ${ }^{31}$ Es una idea interesante porque incluye los 3 ingredientes principales que necesariamente hay que abordar al pensar en las naciones: a) es una forma de agrupación humana,

28 "Solidaridad mecánica: es una solidaridad por similitud. Los miembros de una misma colectividad, se semejan porque experimentan los mismos sentimientos, porque se adhieren a los mismos valores, porque reconocen las mismas cosas sacras (...) Solidaridad orgánica: es contraria a la anterior, es aquella labor del consenso, es decir la unidad coherente de la colectividad, resulta de la diferenciación o se expresa en ella. Los individuos ya no son semejantes, sino diferentes; y hasta cierto punto precisamente porque son distintos se obtiene consenso." S/D. Émile Durkheim: Solidaridad, en: http://www.angelfire.com/planet/danielmr/Emile\%20Durkheim/ Solidaridad.htm rescatado el 14 de abril de 2011.

29 España puede ser considerada como un caso paradigmático en este sentido, ya que lo español no ha logrado un predominio contundente sobre lo vasco, lo catalán, lo gallego, etc.

${ }^{30}$ Es interesante observar, por ejemplo, que Agamenón, líder de la expedición contra Troya sólo es reconocido como primero entre pares.

${ }^{31}$ Benedict Anderson, Comunidades imaginadas: reflexiones sobre el origen y la difusión del nacionalismo, traducción L. Suárez, FCE, México, 2006, p. 23. 
(históricamente diferenciable de otras anteriores como el clan, la tribu o el pueblo), b) su condición delimitada nos lleva a tener que pensar en la cuestión de la otredad (ningún grupo social existe en aislamiento total, por lo que se es nacional de un grupo frente a quienes no lo son, lo que necesariamente da paso al surgimiento de lo internacional) y c) enfatiza el rasgo de la organización política propia como marca distintiva de cada grupo respecto a otras colectividades circunvecinas (tema que nos proyecta hacia la idea del Estado que trataremos más adelante), lo que le da derecho al establecimiento de su propio régimen político-normativo y le define como unidad: el Estado nacional frente a los otros.

De este modo, además de ser un concepto jurídico, la nación es también un concepto sociológico que nos refiere a una colectividad humana independiente de otras, en cuanto a que posee sus propias fuentes de coherencia interna ${ }^{32} \mathrm{y}$ desarrolla sus propios mecanismos de poder, que eventualmente llevan a la creación del Estado-nacional moderno, pero además, distinta de otras en cuanto a que, sobre la base de sus propias costumbres, tradiciones e historia, posee una identidad que le es característica y un proyecto de vida común que, en cierto sentido es único y le distingue de los otros, con quienes necesariamente debe interactuar. Históricamente, el proceso de interacción empieza con los vecinos inmediatos y progresivamente se extiende al paso del tiempo: hoy día tenemos por vez primera en la historia de la humanidad un sistema de alcance verdaderamente planetario y es este sistema (su dinámica de conjunto) lo que queremos entender.

En el grupo nacional, según hemos dicho, el vínculo sanguíneo como factor de aglutinación e identidad (característico de formas anteriores de agrupación) prácticamente ha desaparecido (no siempre del todo) y aunque la raza, la lengua, la religión y las tradiciones siguen jugando un papel vinculador importante, en sentido estricto han perdido su predominio en favor del estilo de vida compartido de la comunidad ampliada. En la nación, la mezcla de orígenes aumenta y, en consecuencia, la unidad del grupo pasa a convertirse en una función de sus valores

${ }^{32}$ El filósofo musulmán Ibn Jaldún escribió un monumental tratado en el siglo XIV de nuestra era que es antecedente indispensable para el desarrollo de una concepción sistémica que vincula a la historia y las relaciones internacionales como disciplinas de la complejidad. En esta obra, el autor desarrolla, entre otros, el concepto de asabiyya a través del cual explica justamente la cuestión de la unidad grupal y explora los elementos que dan coherencia a cada grupo humano. Esta noción es fundamental para la comprensión de la comunidad humana extendida (en su caso integrada obviamente por musulmanes) bajo el principio aglutinante del Islam (es decir la Umma, totalmente incomprensible desde una perspectiva no-sistémica). Ver Ibn Jaldún, Introducción a la historia universal, traducción Juan Feres, FCE, México, 1997. 


\section{DesarRollo de la Sociedad internacional. Objeto material}

comunes efectivamente compartidos, es decir, de su cultura. Tan importante como esto puede ser para la cohesión interna de los grupos humanos (absolutamente necesaria para garantizar su sobrevivencia) el fenómeno tiene importantes consecuencias para el mundo externo: los otros se convierten automáticamente en rivales y ésta es una característica perdurable de la realidad internacional de todos los tiempos; una realidad que ningún estudioso del área puede ignorar.

El proceso de configuración de naciones es, como hemos dicho, históricamente muy reciente y característicamente europeo occidental, pero los grupos políticamente independientes genéricamente hablando son tan antiguos como el hombre mismo. Anderson señala atinadamente, sin embargo, que a pesar de lo reciente que puede parecer el fenómeno de construcción de naciones y nacionalidades a los ojos de los historiadores, la mirada subjetiva de los nacionalistas actuales le da al asunto de la nacionalidad una proyección temporal de mucho mayor alcance. ${ }^{33}$

Es por eso que en la actualidad tendemos a pensar en diversos grupos humanos como naciones, cuando en realidad no lo fueron: los griegos, los romanos, los judíos, por sólo nombrar algunos que en términos antropológicos son más bien pueblos, y el análisis de la diferencia específica entre pueblos y naciones forma parte del objeto material de las relaciones internacionales y nos ayuda a comprender mejor la forma como se integran distintos sistemas internacionales en épocas diferentes.

Más aún, la cuestión terminológica se complica porque prácticamente todas las naciones hoy conformadas en el escenario internacional tienden a apropiarse del pasado histórico lejano de la región geográfica que habitan, así por ejemplo, los mexicanos contemporáneos reclaman como parte de su historia nacional el legado de todos los pueblos prehispánicos de la región, desde los olmecas hasta los aztecas, cuestión que desde luego no está exenta de controversia porque orilla a algunos a pensar en esos pueblos como antiguos mexicanos.

Una nación, por cierto, puede o no tener éxito en su intento por organizar su propio esquema de poder, cuando lo logra, puede llegar a convertirse en un Estado-nación, ${ }^{34}$ por mérito propio pero cuando no, normalmente queda

${ }^{33}$ Ibid., p. 22.

${ }^{34}$ En este sentido, debe señalarse que la experiencia del Estado nacional es fundamentalmente europea en su origen y que sólo a partir del siglo XIX se exporta la idea de que el resto del mundo podría organizarse siguiendo este patrón, el cual pocas veces se ha seguido con facilidad en otras latitudes. 
subordinada a la autoridad central de otra nación, en virtud de lo cual pasa a formar parte constitutiva de algún Estado multinacional. ${ }^{35}$ Retomaremos la cuestión del Estado un poco más adelante, pero antes vale la pena observar que el ideal wilsoneano de "cada nación con su propio gobierno en su propio territorio" ha sido mucho más difícil de llevar a la práctica de lo que su entusiasta enunciado parecía sugerir y es en gran medida responsable de muchos de las grandes tragedias sociales del siglo XX (la limpieza étnica, por ejemplo).

La experiencia humana es, como ya hemos dicho, fundamentalmente grupal; Aristóteles lo tenía muy claro cuando definió al hombre como el "animal político". En función de ello, cuando revisamos la evolución de nuestra especie, siempre encontramos alguna forma de organización colectiva a la cual hacer referencia para enmarcar las vicisitudes individuales.

En este sentido, es claro que el concepto de nación, a pesar de lo novedoso que pudiera parecer hacia fines del siglo XVI, tiene ya importantes antecedentes históricos de largo alcance, por la sencilla razón de que la propia supervivencia de nuestro género ha dependido de nuestras capacidades de asociación, por lo tanto, siempre vamos a tener que estudiar al hombre como parte de algún grupo, por más que los individualistas exacerbados pretendan negarlo. Además, siempre tendremos que contextualizar la historia de cada grupo humano vis a vis su relación con otros grupos, lo que da sentido a la noción de internacionalidad en su sentido más amplio, como la condición producida por el encuentro (incluso casual) de grupos humanos obligados a coexistir en un espacio histórico y geográfico determinado y que es tan característica de la historia de nuestra especie en su conjunto.

La forma más antigua de asociación humana de la que se tiene noticia, incluso anterior al período en el que propiamente dicho se inicia el registro de la historia (y que hoy en día estudia la antropología) es el caso de la comunidad primitiva. ${ }^{36}$ La evidencia señala que originalmente se trataba apenas de algo más que una banda de homínidos superiores dedicados a la recolección y la caza menor (inclusive, más bien al rescate de los despojos que dejaban las grandes fieras). El

\footnotetext{
${ }^{35}$ El caso kurdo ilustra bien esta situación; su población se encuentra distribuida a lo largo de partes del territorio de Irán, Iraq, Turquía y Siria y aún cuando su presencia en estos territorios data de hace siglos, nunca se han podido conformar como Estado-nación. Sin embargo, el caso del Kurdistán-iraquí destaca por ser una región autónoma con parlamento, presidente y constitución propia.

${ }^{36}$ Aunque ya casi inexistente en la actualidad y ciertamente muy influidas por su contacto con la civilización, todavía se encuentran algunos ejemplos de esta forma de organización social, por ejemplo, entre los bosquimanos de Australia y algunos grupos de las islas polinesias.
} 


\section{DesarRollo de la Sociedad internacional. Objeto material}

principal factor aglutinador entre ellos era el vínculo sanguíneo, el cual les permitía reconocerse como miembros del mismo grupo y a la vez, diferenciarse de otros, lo que a su vez les permitía sumar esfuerzos en la lucha por la subsistencia. Su modo característico de ser ha sido ampliamente descrito por F. Engels en Los origenes de la familia, la propiedad privada y el estado.

De conformidad con el precepto que señala que el cambio cuantitativo implica cambios cualitativos, puede asumirse que en cuanto esos grupos estuvieron en posición de crecer, es decir, en cuanto aumentó el número de integrantes del grupo, bien fuese porque las condiciones así lo permitieron o porque se fusionaron con otros grupos, lo cierto es que, aún cuando cada una de ellos puede seguir siendo considerado como colectividad humana, de hecho pasaron a ser algo distinto de las comunidades primitivas y se convirtieron de manera progresiva en hordas, tribus, clanes, fratrias, pueblos etc., ${ }^{37}$ y así sucesivamente hasta llegar a ser las modernas naciones que actualmente pueblan nuestro planeta. Una concepción de esta naturaleza implica el tener que pensar el conjunto de la experiencia humana desde una perspectiva predominantemente internacional (en el sentido laxo del término) toda vez que las propias historias locales se definen, por lo menos en alguna medida, en función de la relación con los otros.

Debe hacerse notar que, en efecto, cada nuevo nombre de las modalidades de asociación colectiva implica nuevas condiciones de asociación, es decir, transformaciones en la naturaleza misma del grupo, sus reglas de convivencia, sus formas de gobierno etc., esto significa básicamente su adaptación a nuevas condiciones de existencia y finalmente, su evolución. Además genera, sin duda, nuevas especificidades, pero no elimina en su totalidad las semejanzas que vinculan a los distintos grupos humanos. Aunque, como ya señalamos esto no quiere decir, en manera alguna que todos los grupos hayan evolucionado en la misma dirección y, mucho menos, que, en esencia, todas las formas de agrupación humana de la comunidad primitiva a la nación sean lo mismo. La evolución no es un proceso lineal y cada de esas agrupaciones humanas tiene sus especificidades, las cuales definen los rasgos distintivos de su época y de sus relaciones internacionales.

\footnotetext{
${ }^{37}$ La reflexión sobre las causas que permitieron este incremento poblacional es muy abundante y llena las páginas de diversos textos de historia y antropología. Se mencionan, entre otras, la creciente capacidad de adaptación de los seres humanos, mayor disponibilidad de recursos, progreso tecnológico, nuevas habilidades, entre otras. Ortega y Gasset nos recuerda que, "la tribu es una idea peculiar de sociedad que posee sus precisos atributos, por lo pronto, la colectividad en cuestión procede genealógicamente de ciertos antepasados comunes a todos o a la mayor parte de sus miembros. Antes de la idea de tribu hubo la idea de horda, como luego ha habido muchas otras ideas de sociedad” op. cit., p. 54 (énfasis añadido).
} 
Pero tampoco quiere decir que las nuevas pierdan toda forma de vinculación o conectividad con sus precedentes.

En otras palabras, todas las colectividades sociales comparten la característica común de ser versiones de agrupación humana y, por ello, todas están estructuralmente vinculadas, pero cada una de ellas tiene rasgos propios que la hacen distintiva. Los pueblos por ejemplo, son modos de organización social en los que la lengua, la religión o la raza son todavía elementos sustantivos para determinar los niveles de pertenencia al grupo y definir las lealtades de los individuos. La nación se define más en términos culturales.

Esto significa que cada grupo que va surgiendo tiene nuevos factores de aglutinación, modos de organización económica, política y social y, sobre todo, modos de interacción con los otros; en fin cada uno de ellos representa un nuevo modelo cultural y proyecto de vida que además debe relacionarse con los extranjeros. Por eso, al analizarlos, se puede adoptar la doble perspectiva de la búsqueda de aquello que tienen en común entre sí y el señalamiento de aquello que los separa y diferencia, o cada uno de estos enfoques por su propio lado.

Así, desde un punto de vista laxo o flexible, y a falta de mejores opciones conceptuales, me parece que el término de relaciones internacionales puede aceptablemente ampliarse para abarcar el flujo de interacción que establecen entre sí diversos grupos humanos, dependientes de su propio poder político a lo largo de la historia; es decir, con su propio centro de autoridad constituido, aun cuando subsiste la necesidad de caracterizarlo en su especificidad. De esta manera, el internacionalista moderno puede expandir enormemente su horizonte de reflexión temporal si, en lugar de pensar exclusivamente en la relación entre naciones, piensa en la interacción entre colectividades políticamente autónomas y busca entre ellas, cualquiera que sea su ubicación histórica o geográfica, en primer término, los denominadores comunes a lo largo de la historia, para posteriormente concentrarse en la especificación de las diferencias que las separan (aunque obviamente, de conformidad con lo que hemos señalado, tales diferencias no las desconectan del todo de formas previas de organización colectiva). ${ }^{38}$

Un enfoque de esta naturaleza permite no sólo apreciar la evolución conjunta del género humano desde la perspectiva integral de sus procesos de dispersión-

\footnotetext{
${ }^{38}$ Ciertamente que uno de los mayores retos para el internacionalista contemporáneo estriba precisamente en entender el traslape actual de diversas formas de organización social, que sobreviven aún junto a la nación; grandes extensiones del planeta son aún completamente tribales en plena era de la red, mientras que en otras empieza a dibujarse un proyecto de organización social supranacional, el de las regiones.
} 


\section{DesarRollo de la Sociedad internacional. Objeto material}

aglutinamiento cohesión-fragmentación progresivos por todo el planeta y el desarrollo de sus diversos polos de crecimiento civilizador, sino además, también posibilita de manera simultánea el análisis de los procesos de interacción que históricamente se han ido dando entre ellos: un flujo continuo de relaciones regido por una dinámica específica, en la que los principios de la auto organización, la adaptación, la competencia entre las partes, la cooperación, la especialización y la co-evolución ${ }^{39}$ juegan un papel central, que adicionalmente, por contraste entre ellas, vuelve significativo el análisis de cada momento particular en la historia de las formas de agrupación entre los hombres y la relación entre ellas.

\section{E1 Estado como objeto de estudio para las relaciones internacionales}

Otra noción fundamental para la reflexión del internacionalista en la configuración de su objeto material es la referente al Estado. Como ya habíamos señalado, en su acepción clásica, la idea misma de relaciones internacionales es virtualmente inseparable de la del Estado-nacional. Esto nos exige pues explorar el contenido $\mathrm{y}$ alcance de este otro concepto.

Prácticamente desde sus orígenes como disciplina, la idea de las relaciones internacionales como fenómeno práctico se encuentra estrechamente ligada a la misma del Estado. Es justamente por ello que muchos especialistas, incluso hoy en día, ven a Relaciones Internacionales como una sub-disciplina de la Ciencia Política y además, que el paradigma más difundido y más influyente en los medios académicos para su estudio se llama precisamente "estato-céntrico".

Vincular el estudio de las relaciones internacionales (como fenómeno práctico) a la aparición del Estado tiene su lógica; es una lógica restringida (en el sentido de que sólo se aboca al análisis de una dimensión de lo internacional), pero al fin, lógica. Bajo esta óptica, el surgimiento de las relaciones internacionales sólo puede ser concomitante al surgimiento del Estado porque es éste el que monopoliza de manera preferente las relaciones con el exterior [de hecho, con otro(s) estado(s)]. Incluso, desde una perspectiva todavía más rigorista, relaciones internacionales propiamente dichas sólo podría haber en el contexto del mundo moderno, con la aparición de las naciones por un lado como ya hemos señalado, pero del Estado moderno por otro, lo cual produce ese nexo inexorable que los especialistas más

39 Todas estas son propiedades sistémicas; para una mejor comprensión de lo que ellas significan, ver David Sarquís, Relaciones internacionales: una perspectiva sistémica, M. A. Porrúa, México, 2005, esp. capítulo 2, "El mundo visto como un sistema”, pp. 101-165. 
ortodoxos ven como único objeto de estudio apropiado para Relaciones Internacionales (como disciplina): el Estado-nacional y su interacción con otros estados nacionales, lo que de hecho prácticamente imposibilita la consideración de Relaciones Internacionales como disciplina autónoma ya que, a partir de esta perspectiva, queda irremediablemente sometida a la tutela matricial de la Ciencia Política. ${ }^{40}$

La propuesta, insisto, no carece de sentido, sólo que produce un ámbito de reflexión excesivamente limitado y restringido que se congestiona con el estudio de la especificidad del modelo euro-céntrico de las relaciones internacionales surgido de la experiencia y de la reflexión sobre los fenómenos internacionales tal como se daban en el contexto de la Europa Occidental hacia fines del Medioevo ${ }^{41}$ pero además, se (auto) limita al ámbito de lo estatal. Es un enfoque tan concentrado en el estudio del árbol que sencillamente no puede ver el bosque en el que está inserto ese árbol.

En la perspectiva que propongo:

- la idea de Estado no puede confinarse exclusivamente a la era moderna, (si bien es cierto que el Estado moderno posee su propia especificidad),

- la fenomenología internacional no puede limitarse a su manifestación a través del Estado (que es sólo un caso particular en un universo mucho más amplio de interacción entre grupos políticamente autónomos),

- las relaciones internacionales (siempre en un sentido laxo del término, como interacción entre grupos humanos políticamente autónomos) en la práctica anteceden a la creación del Estado y son de hecho una de las razones por las que éste se constituye, ${ }^{42}$

${ }^{40}$ Esta es una definición típica a la vez que distorsionante de Relaciones Internacionales: "Las RI constituyen una disciplina que forman parte de las ciencias políticas y que se centran en las relaciones entre los estados y entre los estados y otras instituciones que forman parte del sistema internacional. Se trata de un campo interdisciplinario donde se combinan la política, el derecho, la economía y la historia, por ejemplo.”S/D. Definición de Relaciones Internacionales en http://definicion.de/relaciones-internacionales/ rescatado el 7 de julio de 2011.

${ }^{41}$ Es, de hecho, un modelo que ya estaría perdiendo vigencia -o relevancia analítica- en el mundo contemporáneo con la aparición de múltiples actores no estatales sobre el escenario internacional y la creación de "regiones".

${ }^{42}$ Este enfoque concuerda plenamente con Oppeheimer, para quien: "El estado, totalmente durante su surgimiento y casi totalmente durante sus primeras fases de desarrollo es una institución social impuesta por un grupo de hombres victoriosos ante otro grupo derrotado, con el único objetivo de reglamentar el dominio del vencedor sobre el vencido y de defenderse de las revueltas interiores así como de los ataques externos. En términos teleológicos, tal dominio no tenía ningún 


\section{DesarRollo de la Sociedad internacional. Objeto material}

- además, las relaciones internacionales (con mayor o menor intensidad) son una constante de las relaciones humanas históricas en el nivel de las colectividades, no importa cuán homogéneo llega a ser un sistema social integrado por grupos políticamente autónomos, siempre subsiste en él la sombra de la otredad.

Este esquema parte de la idea que ve el origen del hombre moderno (es decir, específicamente el homo sapiens) en algún lugar del África sudoriental hace apenas unos doscientos mil años y un proceso gradual de dispersión de estos hombres por el planeta a través de la bipartición repetida de grupos humanos viajando en todas direcciones hasta ocupar los más remotos rincones del planeta hace apenas unos cien mil años. Es justamente este proceso de bipartición y expansión el que genera la condición de internacionalidad, de la que ya hemos hablado, como ese espacio o nivel de la realidad social en el que ocurre la interacción humana grupal que genera el fenómeno práctico de las relaciones internacionales en su sentido más laxo.

Ya ocupado el planeta en su totalidad, el proceso continuo de crecimiento demográfico generado por el progreso de nuestra especie, intensifica las interacciones y la reunificación grupal (no siempre de manera voluntaria ni pacífica) progresiva de los grupos que originalmente se dispersaron por todas partes y que hoy forman la familia humana. ${ }^{43}$ La condición de internacionalidad a la que me he referido en repetidas ocasiones se gesta en cada proceso de partición de los grupos humanos, creando el fenómeno de la otredad, indispensable de las relaciones internacionales, mismas que surgen a partir de la interacción que aquellos más primitivos establecen entre sí debido a la inexorable influencia mutua que reciben de ella.

Ciertamente, a la luz de las diferencias grupales surgidas del proceso de dispersión, así como de la especificidad de las historias locales, podemos preguntarnos con entera propiedad si es válida una historia incluyente de la experiencia humana en su conjunto desde una sola y única narrativa articulante.

otro propósito que la explotación económica de los vencidos por los vencedores”, Franz Oppenheimer, The State. Free Life, New York, 1975 p. 8. Disponible en: http://www.franzoppenheimer.de/state0.htm\#Introduction_b.

${ }^{43} \mathrm{El}$ proceso es explicado en detalle por Brian Fagan en The journey from Eden: the peopling of our world, Thames \& Hudson, London, 1990, donde nos dice: "A pesar de nuestras diferencias externas en el tono de piel, forma del cabello y tamaño, todos los seres humanos modernos tenemos un ancestro común relativamente reciente en África. Y si los genetistas actuales no se equivocan, entonces tenemos un punto de origen reciente en la historia y luego una historia de dispersión por el planeta” (p. 41). 
La pregunta no es nueva, la plantea con toda claridad Mann en el primer tomo de Las fuentes del poder social, y asimismo, la responde de manera contundente con un sí rotundo. ${ }^{44} \mathrm{El}$ argumento es relativamente sencillo; una narrativa de esta naturaleza:

presupone un contacto cultural continuo entre grupos, basado en una conciencia de que, pese a las diferencias locales, todos los seres humanos forman una sola especie, se enfrentan con determinados problemas comunes y pueden aprender soluciones los unos de los otros. ${ }^{45}$

Pero esto no excluye el modelo del análisis histórico discontinuo y fragmentado. Por supuesto que a lo largo de la historia, el fenómeno internacional irá adquiriendo matices propios que singularizan los distintos periodos históricos dándole a cada uno su especificidad. A todo lo largo del tiempo y del espacio habrá, por lo tanto, semejanzas y diferencias características de cada periodo y de cada región, y si bien es cierto que los analistas pueden privilegiar unas u otras, ello no debería implicar la negación de cualquiera de ellas. En una perspectiva sistémica integral deben contemplarse ambas: la historia como ruptura y singularidad y la historia como continuidad y regularidad. No son enfoques mutuamente excluyentes, a pesar de la visión rigorista de la lógica aristotélica o de las apariencias.

En relación con el concepto del Estado, coincido plenamente con el enfoque que plantea Marquardt en su Historia Universal del Estado cuando nos dice que no parte de un concepto moderno del Estado como idea objetiva e inmutable:

Como común denominador del término genérico 'Estado' se quiere entender aquí una organización jurídico-política duradera con una extensión supra-local y algún grado de complejidad social que coordina la convivencia humana en el interior y brinda protección militar y diplomática frente al exterior. ${ }^{46}$

Este enfoque es importante porque incluye, como vemos, el aspecto que más

${ }^{44}$ Michael Mann, Las fuentes del poder social, I, traducción Pepa Linares Alianza Universidad, Madrid, 1991, p. 60 y ss.

${ }^{45}$ Ibidem.

${ }^{46}$ Bernd Marquardt, op cit., p. 7. Obviamente, la protección militar y diplomática frente al exterior adquiere características distintivas con el surgimiento del Estado como entidad jurídico-política. El punto que he querido enfatizar, no obstante es que las relaciones internacionales (siempre en un sentido laxo) no sólo tienen que ver con protección militar y diplomática, incluyen procesos mucho más amplios y no siempre "formales" en el sentido de estar coordinados por un Estado. 


\section{Desarrollo de la sociedad internacional. Objeto material}

ha interesado a los internacionalistas clásicos, el de la relación con el exterior. Mann nos ofrece una versión un poco más detallada, pero en absoluta consonancia con la anterior:

Mi definición provisional se deriva de Weber: El Estado es un conjunto diferenciado de instituciones y de personal que incorporan la centralidad, en el sentido de que las relaciones políticas irradian hacia afuera para abarcar una zona territorialmente demarcada, sobre la cual reivindica el monopolio de la formación vinculante y permanente de normas, respaldado por la violencia física. ${ }^{47}$

Ciertamente hay autores que, con justificada razón, objetan el énfasis que tradicionalmente se ha puesto desde la ciencia política en la función reguladora (y monopolizadora) de la violencia por parte del Estado, toda vez que, dicen, la teoría del conflicto tiende a minimizar la función mediadora, conciliadora e incluso estabilizadora del aparato estatal. Fried, por ejemplo, ve al Estado como:

una colección de instituciones y agencias especializadas, algunas de carácter formal y otras informal que mantienen un orden estratificado. Usualmente, su punto de concentración son principios básicos de organización: jerarquía, diferentes grados de acceso a recursos básicos, obediencia a funcionarios, y defensa de un área. El estado debe mantenerse así mismo tanto externa como internamente. ${ }^{48}$

Elman Service, por su parte, reconoce la importancia que tiene para el funcionamiento del Estado tanto el uso como la mera amenaza de uso de la fuerza pública, no obstante recalca la importante función que tiene, por ejemplo el uso de la autoridad (prestigio) para convidar a la acción social sin necesidad de aplicación de la fuerza. ${ }^{49}$ Evidentemente ambos enfoques pueden ser sustentados por la experiencia, depende básicamente de cuál de ellos se quiera enfatizar como prioritario en el contexto de una visión paradigmática específica; a final de cuentas, ambos enfoques (el de la teoría del conflicto y el de la mediación) tienen validez y explican aspectos observables en el surgimiento, configuración y funcionamiento del Estado. Como atinadamente explican Johnson y Earle:

Estas dos vertientes teóricas no son mutuamente excluyentes; de hecho identifican dos procesos interdependientes. Por un lado, los Estados nacen del conflicto y la dominación;

${ }^{47}$ Michael Mann, op. cit., p. 64.

${ }^{48}$ Morton Fried, op. cit., p. 235.

${ }^{49}$ Elman Service, Los orígenes del Estado y de la civilización. El proceso de evolución cultural, Alianza Editorial, Madrid, 1984, p. 33. 
un grupo étnico se convierte en élite gobernante de un gran imperio, y las instituciones imperiales operan para mantener y fortalecer este dominio. Por otra parte, los Estados se desarrollan y funcionan bajo ciertas condiciones básicas que al mismo tiempo permiten el control económico y requieren de administración central; las poblaciones locales son vinculadas en términos económicos al Estado a través de una cuidadosamente manejada dependencia que es consecuencia de una intensificación a largo plazo de la economía de subsistencia. ${ }^{50}$

Explicar las razones que finalmente conducen al surgimiento del Estado es una tarea relativamente simple desde un punto de vista sistémico, aduciendo precisamente las necesidades de organización interna de los grupos sociales propiciada por el incremento en su complejidad y los requerimientos de coordinación para responder a los retos externos. Tal es el código básico de configuración estatal. Por supuesto que cada grupo lo va a hacer en su contexto propio y en función de sus características singulares, lo que dará al fenómeno de creación de Estados toda su complejidad individual. Kemp, por ejemplo, coincide plenamente con el enfoque sociológico sobre el surgimiento del Estado:

El hombre ha reconocido al estado como entidad abstracta sólo desde la época de la Grecia Clásica. Pero su verdadera historia se remonta mucho más atrás. Si retrocedemos en el tiempo hasta llegar a las primeras civilizaciones, de las cuales una es Egipto, podremos observar que los elementos fundamentales de los estados modernos ya se hallaban presentes y funcionaban con vigor, aunque no hubiera una conciencia objetiva de lo que todo ello implicaba. (...) Las ideas y las prácticas que asociamos a épocas más recientes fueron grabadas en un núcleo que, en el fondo, no ha cambiado desde la aparición de los primeros estados en el mundo antiguo. El estudio de la historia antigua pone al descubierto este núcleo y, de este modo, la esencia de la vida moderna. ${ }^{51}$

Liverani describe un proceso de características más generales que de hecho aplica a todo el contexto del Mediterráneo oriental durante la edad del bronce antiguo. Al hablar de la revolución urbana de este periodo, el autor relata la forma en la que la agricultura facilita la creación de excedentes alimentarios que permiten el surgimiento de grupos dedicados a tareas especializadas que, en gran medida, facilitan el desarrollo del Estado. Éste, al parecer, logra monopolizar los medios de producción de estos grupos de especialistas quienes, en consecuencia se verán obligados a trabajar para lo que el autor llama la "gran organización"

${ }^{50}$ Allen Johnson \& Tomothy Earle, The evolution of human societies: from foraging group to agrarian state, Stanford University Press, Stanford, 2000, p. 305.

${ }^{51}$ Barry Kemp, El antiguo Egipto: anatomía de una civilización, Crítica, Barcelona, 2004, p. 27. 


\section{DesarRollo de la Sociedad internacional. Objeto material}

que los convierte en lo más selecto de la población, aunque los mantiene virtualmente como "siervos" del rey. El resto de la población se dedica a faenas agrícolas y en ese sentido mantiene un cierto margen de libertad, que de hecho es relativa ya que todo el ciclo productivo está supeditado a la acción supervisora del Estado. ${ }^{52}$

Marquardt enlista las teorías concretas a las que aduce la Ciencia Política para explicar el fenómeno con mayor detalle en términos de control de la violencia doméstica, y contención de la exterior, búsqueda del bienestar común, organización contractual para el logro de objetivos colectivos, concreción de la madurez espiritual del un pueblo o desarrollo de instrumentos de control para la lucha de clases. ${ }^{53}$ No es necesario repetir la explicación aquí, sólo tener en mente que, en efecto, con la aparición del aparato estatal hay una evolución cualitativa muy importante en las relaciones internacionales porque, a partir de ella, la interacción entre los grupos tiene un aspecto "formal", digamos institucionalizado que se canaliza predominantemente a través de los órganos del Estado (pero que de ninguna manera agota ahí el ámbito de la interacción posible entre los grupos humanos).

Por supuesto que el surgimiento del Estado está lejos de ser un acontecimiento repentino o mecánico a lo largo del planeta. Tampoco su desarrollo, ni su funcionamiento constituyen algo uniforme, de tal suerte que sigue siendo ilusorio pensar que, al comprender la forma como se desarrolló un Estado particular, se tiene ya la clave para comprender el desarrollo de todos los Estados a nivel planetario; indudablemente, cada uno tiene sus características propias que le confieren su distintiva singularidad histórica. Aunque tampoco podría negarse que se han adquirido claves importantes para la comprensión general del proceso a través del análisis histórico comparativo que también revela la presencia de importantes semejanzas vinculantes entre procesos de construcción estatal a lo largo del tiempo.

La idea de una estructura reguladora de la vida social al interior de los grupos humanos y coordinadora de su actividad frente al exterior tiene sus propios matices en cada uno de los lugares donde se concreta y es responsabilidad del especialista de cada región caracterizar las singularidades del proceso que estudia.

La paradoja radica, quizá, en el hecho de que el proceso de singularización no elimina por completo ni la posibilidad, ni la utilidad de la generalización, al

\footnotetext{
${ }^{52}$ Mario Liverani, El antiguo Oriente, traducción Juan Vivanco, Critica, Barcelona, 1995, p. 100

${ }^{53}$ Marquardt, op. cit., p. 47 y ss.
} 


\section{DAVID J. SARQuís}

contrario, si está bien realizado, el análisis puede contribuir enormemente a enriquecer el enfoque generalizador. El problema está, sin embargo, en el hecho de que muchos especialistas, una vez alcanzado el nivel de la especialización, simplemente niegan el valor, siquiera parcial de la generalización.

Marquardt nos presenta el siguiente esquema general referente al desarrollo evolutivo del Estado, ${ }^{54}$ mismo que pretende ser aplicable (como regularidad sociológica) a la mayoría de los casos histórico-singulares.

El proceso evolutivo señalado por el autor se basa en la idea de un aumento gradual (que no necesariamente uniforme) de la complejidad social derivado principal pero no exclusivamente, del aumento cuantitativo de los grupos y de sus capacidades en el intento por responder a sus necesidades básicas en la lucha cotidiana por la sobrevivencia.

Según este modelo, ese crecimiento cuantitativo traería aparejada, al mismo tiempo la obligación de contar con mayores recursos para alimentar, vestir y dar habitación al grupo y, por lo tanto, la necesidad de una organización política más eficiente (quizá por ello, monopolizada), lo que gradualmente iría mejorando las capacidades tecnológicas de los grupos a la vez que definiendo y consolidando las jerarquías grupales.

Ello requeriría, entre otras cosas, no sólo de la capacidad para implementar la jerarquización, sino, sobre todo, de elementos ideológicos consistentes para justificarla. Como puede apreciarse, hay todo un conjunto de circunstancias que se van conjugando para hacer posible la evolución de la organización política entre los seres humanos. No es posible, por lo tanto, atribuir a una sola de estas variables todo el peso causal del análisis para explicar sus resultados. Como tampoco es posible hacer una generalización absoluta del proceso. Marquardt nos sugiere ciertas tendencias históricas. Nos corresponde a nosotros ponerlas a prueba en casos histórico concretos.

Desde una perspectiva generalizadora podemos ciertamente apreciar que el proceso de surgimiento de los Estados es entonces lento y ofrece algunas características comunes en diversos puntos del planeta. Éstas pueden sintetizarse de alguna manera observando que, en efecto, la sociedad humana es originalmente igualitaria, gradualmente se empieza a estratificar hasta que finalmente queda jerarquizada de manera institucional.

El cambio empieza a generarse, como han explicado Service y Fried, ${ }^{55}$ cuando en el seno de la sociedad igualitaria se empiezan a conceder privilegios y

${ }^{54}$ Véase Tabla 1.

${ }^{55}$ Ver, Elman Service, op. cit, esp. cap. 4 pp. 90-122 y Morton Fried, op. cit, pp. 182-185. 
Desarrollo de la sociedad internacional. Objeto material

Tabla 1

Evolución de la organización política entre los seres humanos:

Tendencias históricas

\begin{tabular}{l|l}
\multicolumn{1}{c|}{$\begin{array}{c}\text { Aumento de la complejidad } \\
\text { civilizatoria }\end{array}$} & Etapas de la organización política \\
\hline $\begin{array}{l}\text { 1. Cazadores y Recolectores } \\
\text { Sistema de energía solar no modelado } \\
\text { Al menos dos millones de años }\end{array}$ & Grupos nómadas pequeños \\
\hline $\begin{array}{l}\text { 2. Sociedades Agrarias Simples } \\
\text { Sistema de energía solar modelado con }\end{array}$ & $\begin{array}{l}\text { 1era Fase: comunidades locales } \\
\text { leña como transmisor primario de }\end{array}$ \\
energía (renovable) & \\
Desde aprox. 10,000 años a.C. & 2da Fase: Jefaturas tribales locales \\
\hline 3. Civilizaciones Agrarias & 1era Fase: Reinos Dinásticos \\
Sistema de energía solar modelado con & Primera transición básica hacia el \\
leña como transmisor primario de & Estado \\
energía (renovable) & Sub-fases: \\
Mayor grado de complejidad & Principados regionales (aldeas) \\
Desde aprox. 3,000 a.C. & Principados regionales (ciudades) \\
& Reinos supra-regionales \\
& 2da Fase: Estados de paz interna \\
& Segunda transición básica hacia el \\
& Estado \\
\hline 4. Culturas Industriales & 3era transición básica de la historia del \\
Sistemas de energía fósil (crecimiento & Estado. \\
de cantidad, pero no renovable) & Revolución de la soberanía \\
Desde aprox. 1800 d.C. (Revolución & Estado constitucional republicano \\
Industrial) & democrático \\
\end{tabular}

Fuente: Marquardt, Bernd, op. cit, p. 8.

distinciones a ciertos individuos por diversas razones que están más allá del interés directo de este estudio pero que establecen rangos diferenciables entre los individuos. De ahí transitamos hacia las jefaturas de jerarquía que controlan regiones y poblaciones más amplias, aunque básicamente a través de los mismos mecanismos que los empleados por las sociedades igualitarias. Con el crecimiento 
demográfico implícito en el camino hacia la sociedad estatal se va a requerir de instituciones regionales especializadas que faciliten las tareas de administración y control. Como explican Johnson y Earle, la sociedad estatal va a requerir de una organización militar más sofisticada, responsable de proyectos de conquista, defensa o control interno así como de una burocracia capaz de administrar eficientemente los recursos que se ponen a su alcance, así como manejar los flujos de información que le permitan mantener el control y equilibrio social. Adicionalmente, el control estatal también se apoya en la religión que lo santifica. La sociedad está cada vez más estratificada, las relaciones directas de parentesco son menos importantes para efectos políticos y los efectos del proceso civilizador (escritura, urbanización, comercio, etc.) se hacen cada vez más evidentes. ${ }^{56}$

Entendido entonces como estructura de poder para el control de las distintas formas de agrupación humana que han existido al paso del tiempo, es claro que el fenómeno del Estado es tan antiguo como la historia. Su condición genérica no cambia, pero sus modalidades específicas sí, la forma de organizarse, justificarse y ejercer el poder sí van variando conforme cambia la sociedad, de ahí que no resulte ni extraño ni equívoco hablar del Estado moderno y pretender caracterizarlo en su singularidad. Esto es algo que, por supuesto, todos los internacionalistas deberán hacer en su oportunidad; entender la naturaleza, el funcionamiento, la estructura, el comportamiento y la evolución del Estado es fundamental para su profesión. Pero es sobre todo la cuestión del reto que implica la convivencia con otros Estados, las condiciones en que ésta se da, los factores que entran en juego, etc. lo que más debe importarnos como internacionalistas. Es, por supuesto muy importante entender que:

El Estado moderno se origina por determinados cambios económicos y sociales que ocurrieron en Europa entre los siglos XVI y el xviII. Su nacimiento se encuentra en la época del Renacimiento en Europa, escenario de importantes cambios en su ordenamiento político. Paulatinamente, surge entre las comunidades un sentimiento de identificación cultural y nacional en un territorio con fronteras determinadas y con un gobierno que dirige los destinos del pueblo. Los monarcas interesados en concentrar el poder en su persona negocian con los señores feudales ayudados por lo burgueses, tranzando derechos individuales sobre sus feudos a cambio de importantes privilegios. De este modo el concepto feudal de lealtad es reemplazado por el de autoridad y obediencia, propios de un Estado con poder centralizado. ${ }^{57}$

${ }^{56}$ Ver, Johnson y Earle, op. cit, p. 304.

${ }^{57}$ Angélica Sanabria Caballero, Factores de influencia de formación del Estado moderno, recuperado el 07 de julio de 2011 de http:/ / www.alipso.com/monografias/estado_moderno/ 


\section{DesarRollo de la Sociedad internacional. Objeto material}

Pero es incluso más importante, desde una perspectiva internacional, entender al Estado como piedra angular del desarrollo de la dinámica internacional. Si bien es cierto que su exclusividad como actor del escenario internacional es ampliamente cuestionada hoy en día, jamás podrá negarse su importancia en este contexto, así:

Aunque el siglo xx ha sido escenario del nacimiento de muchas instituciones internacionales, el Estado soberano sigue siendo el componente principal del sistema político internacional. Desde esta perspectiva, un Estado nace cuando un número suficiente de otros estados lo reconocen como tal. En época moderna, la admisión en la Organización de las Naciones Unidas (ONU) y en otros organismos internacionales proporciona una constancia eficiente de que se ha alcanzado la categoría de Estado. ${ }^{58}$

Esto sugiere, evidentemente, que la dinámica de lo internacional (aunque dependiente en gran medida de la acción del Estado) es de hecho mucho más compleja que la mera interacción estatal y aunque todavía hay muchos autores y escuelas de pensamiento que siguen enfocándose en esa parte de la realidad internacional para una definición del objeto material en relaciones internacionales (lo que necesariamente se refleja en sus consideraciones teóricas) también es cierto que ha crecido el número de especialistas que trabajan con una representación más compleja del escenario internacional, al que consideran de manera provechosa como un sistema.

\section{El sistema internacional como objeto de estudio en las relaciones internacionales}

A la luz de las reflexiones anteriores podemos ahora reconsiderar de manera genérica el problema del objeto material de las relaciones internacionales. Ya lo hemos dicho con anterioridad, desde nuestra perspectiva, el sistema internacional constituye la representación más provechosa de la realidad internacional, ahora intentaremos explicar qué significa esto y en qué consisten sus bondades.

En términos generales la idea de un sistema se ha manejado en el lenguaje popular como cualquier conjunto de elementos interrelacionados entre sí pero claramente distinguibles unos de los otros. Así definida, la noción de sistema carece prácticamente de utilidad o interés para la ciencia, aunque ciertamente no

\footnotetext{
${ }^{58}$ Racini, Alexander, Los hechos y el Derecho, recuperado el 08 de julio de 2011 de: http:// www.lhdtv.info/2009/09/que-es-el-estado-y-cuales-son-sus.html.
} 
deja de ser un concepto conveniente en su uso corriente por la enorme cantidad de situaciones que permite referir en la vida diaria, incluso con su evidente falta de rigor. ${ }^{59}$

El desarrollo de una perspectiva sistémica como instrumento metodológico para cualquier rama disciplinaria en el ámbito de la ciencia exige, sin embargo, una más cuidadosa elaboración conceptual a efecto de permitir el logro de mayor precisión a la hora de articular un discurso significativo en la exploración de nuestro objeto de estudio. Si vamos a tratar de representarnos al objeto de estudio como un sistema, que es el punto de partida en el análisis sistémico, tendremos, sin duda, que empezar por definir con más claridad qué entendemos por sistema y explicar cómo es que esta noción puede aplicarse a todo lo largo y ancho del espectro disciplinario, proporcionando de este modo un lenguaje común para el esfuerzo que sugiere la interdisciplinariedad y que exige cada disciplina.

No es éste, desde luego, el lugar para entrar a ese análisis detallado, ${ }^{60}$ pero si vale la pena hacer, por lo menos una pequeña acotación inicial: la concepción sistémica parte de una ontología que asume al universo como una totalidad interconectada en todos sus múltiples y variados aspectos. Una totalidad que puede concebirse como un proceso en devenir continuo y causalmente estructurado pero, al mismo tiempo, como una colección de fases discontinuas con sentido propio.

Es además una totalidad dinámica en la que lo observado nunca es algo fijo y definido de una vez por todas y para siempre sino que se encuentra en constante devenir; es algo, pero sólo de manera temporal porque siempre se está convirtiendo en algo nuevo. Además puede decirse que, desde esta perspectiva, todo lo que es (y en lo que deviene) procede justamente de la interacción entre los componentes del sistema. La teoría sistémica es, desde este punto de vista, un esfuerzo intelectual que busca ocuparse de la realidad en su doble dimensión de ser y devenir como producto de la interrelación. De esta manera, tanto la estructura como las funciones o el comportamiento de un sistema son tan relevantes como su dinámica de cambio para el observador que lo estudia.

En el plano internacional, un sistema se integra, en primer término, con la

${ }^{59}$ La conveniencia en el uso del concepto se nota con facilidad en la aceptación tan extendida que tiene hoy en día tanto en el lenguaje coloquial como entre las más diversas disciplinas del quehacer científico. Todo mundo habla de sistemas, pero pocos lo hacen con el rigor que exige la filosofía de sistemas de perfil y aspiraciones científicas.

${ }^{60} \mathrm{El}$ análisis detallado de la concepción sistémica aparece en David Sarquís. Relaciones internacionales: una perspectiva sistémica, op. cit. 


\section{DesarRollo de la Sociedad internacional. Objeto material}

presencia de grupos humanos políticamente independientes y culturalmente diferenciables unos de otros y en seguida, mediante la interacción que dichos grupos establecen entre sí. Dado que cada uno busca ante todo su propia supervivencia, es normal que los primeros contactos entre ellos estén basados en la desconfianza, incluso que ésta propicie la hostilidad. Pero eso no significa que estos grupos estén impedidos de tratarse de otro modo. De hecho, es históricamente demostrable que en muchos casos prevalece la cooperación, sin que por ello desaparezca totalmente la competencia, más aún, puede argumentarse de manera significativa que es en gran medida el espíritu de cooperación el que finalmente ha hecho posible el proceso civilizador a lo largo de la historia.

La tendencia sistémica en la historia es hacia la fusión de estos grupos en unidades mayores, prácticamente hasta homogeneizar el contexto regional en el que se desempeñan. Pero ningún proyecto de conformación sistémica es perene; ya lo dijo Duroselle: Todo imperio perecerá. ${ }^{61} \mathrm{El}$ hecho de que las unidades mayores estén conformadas por las partes que se fusionaron para crearlas implica que, de una u otra forma, seguirá habiendo resistencia a la homogeneización total (porque las partes siempre tienen intereses propios). Esto llevará finalmente a una ruptura sistémica que de hecho sólo marca el inicio de un nuevo ciclo.

Para efectos de una concepción sistémica de la realidad internacional de largo alcance histórico necesitamos entonces asumir:

a) que los sistemas internacionales (en sentido laxo) se gestan a partir de la presencia de grupos humanos políticamente autónomos en espacios compartidos, ${ }^{62}$

b) que la convivencia obligada les lleva al establecimiento de vínculos que se mueven en el espectro competencia-cooperación y lleva gradualmente a la fusión de estos grupos en entidades mayores con un sincretismo que transforma las estructuras grupales en todas sus dimensiones,

c) que la integración implica etapas de desarrollo sistémico que se caracterizan por el surgimiento de principios guía de la conducta de las partes en el sistema, (en este caso, los grupos humanos) los cuales permiten el esta-

${ }^{61}$ J. B. Duroselle, Todo imperio perecerá, traducción Abdiel Macías Arvizu, Fondo de Cultura Económica, México, 1998.

${ }^{62}$ En su origen histórico remoto la diversificación de los grupos humanos y su expansión por el planeta es un proceso que se gesta en las necesidades de supervivencia de una especie unitaria que nace en el sudeste de África hace más de 2 millones de años y de ahí emigra gradualmente hasta ocupar la totalidad del planeta. 


\section{DAVID J. SARQuís}

blecimiento de un orden sobre la base del cual crecen las estructuras del sistema y se definen las funciones de sus partes,

d) que la duración del orden así establecido en el sistema permite la configuración de un bloque histórico, es decir un segmento temporal durante el que prevalece cierto orden reconocible que da identidad y significado al sistema,

e) que la realidad sistémica es inherentemente dinámica, motivo por el cual los bloques históricos nunca permanecen estáticos. Es nuestra responsabilidad como historiadores señalar (y justificar) las fronteras temporales de los bloques históricos caracterizados por su orden distintivo que vamos reconociendo al examinar el pasado en su dimensión internacional,

f) que la tendencia sistémica es transitar hacia niveles de creciente complejidad al ir fusionando a los grupos humanos en colectividades de mayor envergadura. De este modo se van gestando, primero las confederaciones y luego los imperios, aunque la ruta en cada caso está siempre llena de sorpresas y posibilidades.

Desde una perspectiva sistémica, entonces, se puede tratar de entender los hechos internacionales en su singularidad, a partir de las tendencias sistémicas generales de las que nacen. Por ejemplo, hoy en día se habla mucho de la globalización y se considera como un fenómeno único, característico de nuestro tiempo, propiciado por la expansión del capitalismo, el desarrollo tecnológico y su impacto en el sector del transporte y las comunicación, lo que ha hecho, finalmente, del capitalismo el único sistema de alcance verdaderamente planetario. En consecuencia, a partir de tal enfoque no habría antecedente histórico con el cual contrastarlo o desde el cual explicarlo. Si consideramos, en cambio que:

la globalización implica la expansión, intensificación así como el incremento en la velocidad en los flujos de gente productos e ideas que dan forma al mundo. Integra regiones y continentes, comprime el tiempo y el espacio, promueve la imitación y provoca la resistencia. ${ }^{63}$

Entonces dejamos abierto el margen como para repensarla en términos de un proceso sistémico de largo alcance histórico en el que luego tendríamos que

${ }^{63}$ A. G. Hopkins, Global history: interactions between the universal and the local, Palgrave, New York, 2006 p. 3. 


\section{Desarrollo de la sociedad internacional. Objeto material}

diferenciar, precisando los factores que en cada caso promueven la expansión, la intensificación, etc. (en el caso del sistema internacional contemporáneo son claramente la ampliación del capitalismo y el desarrollo científico y tecnológico, pero en épocas anteriores los factores serían otros). Esto nos permitiría entender con mayor facilidad que aún en su singularidad histórica, el fenómeno de la globalización está paradigmáticamente relacionado con fenómenos similares que expresan la naturaleza inherentemente sistémica de todo escenario internacional. Del mismo modo, en cada caso habría que definir con precisión el alcance del concepto 'mundo'. ${ }^{64}$

En otras palabras, desde una perspectiva sistémica se puede apreciar que cada evento singular tiene una interconexión sistémica con el resto de la realidad y (aún en su unicidad) constituye una expresión fractal ${ }^{65}$ en la construcción de lo real. Según ésta, la realidad se auto reproduce siguiendo un código básico de "instrucciones" que dictan sus componentes básicos repitiendo formas elementales que se replican de forma incesante, a la manera de nuestro propio código genético.

Entre los aspectos que me parecen especialmente valiosos del enfoque histórico desde una perspectiva sistémica en relaciones internacionales me gustaría enfatizar los siguientes:

- Destaca la unidad subyacente en la diversidad de la historia humana y establece una interconexión que justifica la idea de una historia universal que involucra como partícipes activos a todos los grupos humanos.

- Permite flexibilizar el concepto de relaciones internacionales para ampliar su alcance y así poder abarcar la experiencia de comunidades soberanas (políticamente autónomas) del pasado pre-moderno.

\footnotetext{
${ }^{64} \mathrm{Si}$ bien es cierto que hoy día el proceso tiene -por primera vez en la historia- un alcance planetario, es claro que no siempre ha sido así; el 'mundo homérico' era, por supuesto, mucho más pequeño, no obstante, igual representó un espacio temporal gradualmente homogeneizado a partir de la aparición de la cultura micénica hasta dar paso al universo helenizado de Alejandro Magno.

${ }^{65}$ La idea de la expresión fractal está relacionada con la noción de que la naturaleza misma se auto-reproduce siguiendo patrones de regularidad constantes. "Un fractal es un objeto geométrico cuya estructura se repite en diferentes escalas. Esta estructura puede ser generada por un proceso recursivo o iterativo capaz de producir estructuras similares independientemente de la escala de de la teoría del caos, la cual se basa en una interconexión que se manifiesta en acontecimientos aparentemente aleatorios”, Jesús Manuel García Muñoz, Fractales, recuperado el 26 de julio de 2011 de: http:/ / www.enelnombredetux.com/project.php?project=fractales.
} 
- También permite consolidar la idea del bloque histórico como un momento sistémico específico en el proceso evolutivo global de la humanidad vista en su conjunto y su complemento, la idea del orden internacional como el conjunto de principios guía que, de manera implícita o explícita orientan el comportamiento de los actores internacionales de cada bloque histórico concreto.

- Obliga a una reflexión detenida sobre los procesos de cambio que alteran la estructura básica o el comportamiento del sistema internacional en un momento dado y que abren el tránsito histórico de un orden internacional a otro.

- Despliega la posibilidad del análisis comparativo entre distintos momentos históricos del sistema internacional, posibilitando así el reconocimiento de las semejanzas que los unen, pero también el de las diferencias que los separan, lo cual a su vez permite la caracterización singularizada de cada bloque histórico o fase por la que transita el sistema internacional, lo que a su vez facilita la comprensión de los patrones de regularidad de los escenarios internacionales históricos.

- Sugiere la necesidad de un análisis multivariable de la realidad internacional en oposición al tipo de análisis que privilegia la idea de factores exclusivos determinantes (unilineales) de la realidad internacional.

- Eso, en su conjunto, nos brinda una mejor idea de la dinámica que mueve a los sistemas internacionales en su dimensión histórica, permite su caracterización y explica su evolución.

Sobre esta base es posible hoy día sugerir que la internacionalidad, en su sentido laxo (interacción entre colectividades humanas políticamente autónomas y medio en el que ésta se desarrolla) es inherente a la condición humana y que, por lo tanto, toda experiencia civilizadora se ha dado en el marco de un contexto internacional, es decir, un medio social creado por la interacción de grupos políticamente autónomos.

Obviamente, no todos los sistemas internacionales funcionan del mismo modo. A partir de algunos elementos y reglas de operación básicas, cada uno de ellos crece en direcciones distintas. No obstante, tenemos elementos suficientes para sugerir una tipología elemental según la cual, los sistemas internacionales históricos se pueden mover en tres ámbitos característicos o transitar por tres fases en su evolución:

a) el de la anarquía (escenarios fragmentarios)

b) el de las reglas mínimas comunes (confederaciones) 
c) el de la integración homogeneizante. (imperios)

El problema fundamental aquí se vuelve, por supuesto, el de la reconstrucción histórica de cualquier caso con el que tratamos de ilustrar esta tipología. Aún cuando se disponga de material para iniciar el proceso, debe tomarse en cuenta que, la idea misma de un sistema internacional de otra época que no sea la actual es prácticamente inexistente (aunque ya existen algunos antecedentes importantes) por tanto, el modelo sistémico tiene primero que ser elaborado, con el riesgo evidente de estar proyectando características del escenario actual hacia el pasado de manera indiscriminada. Ciertamente se corre el riesgo de sólo: "reformular la evidencia para generar una versión disfrazada del surgimiento de Occidente y su menos afortunado corolario: la caída de todos los demás". ${ }^{66}$

En ese aspecto nunca se puede ser suficientemente cuidadoso.

\section{A manera de conclusión}

El estudio del objeto material de las relaciones internacionales puede parecer innecesariamente complicado, especialmente al inicio de la carrera, no obstante, la experiencia demuestra la enorme importancia que tiene en la formación de los internacionalistas. Difícilmente se puede llegar a ser un buen internacionalista sin antes haber identificado con toda claridad nuestro objeto material de estudio, ya que de ello depende el desarrollo de nuestra propia identidad profesional.

En la elaboración de este trabajo hemos sugerido que una primera aproximación a la idea de nuestro objeto material podría ser la noción de realidad internacional, la cual, a pesar de su vaguedad indica ya la presencia de un ámbito o dimensión de la realidad social que posee su propia especificidad. Ahora bien, ¿de dónde procede esta especificidad y cómo podemos caracterizarla?

En un segundo momento de la reflexión sobre el tema hemos dicho que la realidad internacional se genera a través de la interacción entre grupos humanos políticamente independientes y culturalmente diferenciables (lo cual ciertamente incluye, pero no se limita al caso de las naciones) los unos de los otros. Esto nos revela la importancia que tiene en la historia misma de la humanidad la noción de la otredad, que incluye, como un apartado especial a la noción de extranjero.

A continuación señalamos que la realidad internacional puede ser representada en la mente de los investigadores de diversas maneras: en un extremo del espectro

\footnotetext{
${ }^{66}$ Hopkins, op. cit., p. 4.
} 
de las representaciones podemos encontrar a un conjunto de grupos humanos que tienen sentido socio-histórico por sí mismos y que se desenvuelven en un espacio histórico y geográfico singular como unidades autónomas que discrecionalmente deciden actuar frente a otros grupos humanos con los que comparten su espacio vital. En el otro extremo podemos visualizar una red de interacción social que produce un sistema internacional (el cual representa algo más que la mera suma mecánica de sus partes). ${ }^{67}$ Ese sistema tiene, de alguna manera una especie de vida propia que necesariamente influye en el desempeño de cada uno de sus componentes. El sistema desarrolla así su estructura, sus funciones y su comportamiento, todo lo cual condiciona su evolución. Así, cada sistema posee un orden propio que le es característico y que constituye un objeto de estudio propio para cualquier observador que decide enfocarlo, presumiblemente, un internacionalista.

La forma de representarse al objeto material es entonces de crucial importancia, ya que ella nos orilla de manera natural no sólo a pensar sobre el objeto de estudio, sino a actuar con relación a él.

Así, por ejemplo, quienes conciben a los agentes del escenario internacional en términos aislados tienden a privilegiar la idea de una soberanía definida por un interés nacional propio, cuya defensa constituye el eje rector de toda acción internacional. En cambio, quien ve al escenario internacional como una red de diversos agentes necesariamente interconectados creando un sistema puede argumentar más fácilmente en torno a la necesidad de la tolerancia y la cooperación para una mejor convivencia.

En fin, esto constituye el núcleo duro de los debates teóricos que deben analizarse como un capítulo aparte en el entramado genérico de las relaciones internacionales.

\section{Fuentes}

Anderson, Benedict, Comunidades imaginadas: reflexiones sobre el origen y la difusión del nacionalismo, FCE, México, 2006.

\footnotetext{
${ }^{67}$ Esta idea aparece ya claramente sugerida en Elizabeth Brooks, "Bolas de billar, telarañas y remolinos: el estado actual de la teoría de las relaciones internacionales en Estados Unidos” en Revista Mexicana de Ciencias Políticas y Sociales, año xxvII, nueva época, FCPYS, UNAM, México, abril-septiembre de 1981, pp. 57-77.
} 


\section{DesarRollo de la Sociedad internacional. Objeto material}

Buzan, B. \& Little, R., International Systems in world history, Oxford University Press, Oxford, 2000.

Calduch, Rafael, Relaciones Internacionales, Ediciones Ciencias Sociales, Madrid, 1991.

Cárdenas Elorduy, Emilio, "El camino hacia la teoría de las relaciones internacionales: biografía de una disciplina", Revista Mexicana de Ciencia Política, núm. 63, FCPS, UNAM, México, 1971.

Del Arenal, Celestino. Introducción a las relaciones internacionales. Tecnos, Madrid, 1987.

Duroselle, J. B., Todo imperio perecerá, traducción Abdiel Macías Arvizu, FCE, México, 1998.

Fagan, Brian, The journey from Eden: the peopling of our world, Thames \& Hudson, London, 1990.

Fried, Morton, The evolution of political society, Random House, New York, 1967.

García Muñoz, Jesús Manuel, Fractales, http:// www.enelnombredetux.com/ project.pnp?project $=$ Fractales

Hopkins, A. G., Global history: interactions between the universal and the local, Palgrave, New York, 2006.

Ibn Jaldún, Introducción a la historia universal, FCE, México, 1997.

Johnson, Allen \& Earle, Timothy, The evolution of human societies: from foraging group to agrarian state, Stanford University Press, Stanford, 2000.

Kemp, Barry, El antiguo Egipto: anatomía de una civilización, Crítica, Barcelona, 2004.

Krippendorff, Ekkehart, El sistema internacional como historia, FCE, México, 1975. Liverani, Mario, El antiguo Oriente, Critica, Barcelona, 1995.

Mann, Michael, Las fuentes del poder social, I, Alianza Universidad, Madrid, 1991.

Marquardt, Bernd, Historia Universal del Estado, La carrera editores, México, 2009.

Ocariz, José, Historia sencilla del pensamiento político: Rousseau, en http:// www.mercaba.org/Filosofia/rousseau_01.htm

Ohmae, Kenichi, The Next Global Stage: Challenges and Opportunities in our Bordeless World, Wharton School Publishing, Philadelphia, 2005.

Ohmae, Kenichi, The End of the Nation-State: the Rise of Regional Economies, Simon and Schuster Inc., New York, 1995.

Oppenheimer, Franz, The State, Free Life, New York, 1975 en http:// www.franz-oppenheimer.de/state0.htm\#Introduction_b

Ortega y Gasset, José, Europa y la idea de nación, Alianza Editorial, Madrid, 1985. 
Puchala, Donald, Theory and History in International Relations, Routledge, London, 2003.

Racini, Alexander, Los hechosy el Derecho, en http://www.lhdtv.info/2009/09/ que-es-el-estado-y-cuales-son-sus.html

Rocker, Rudolf, Nacionalismo y cultura, Alebrije, México, 1988.

Rubio García, Leandro. "La aprehensión de la escena internacional desde los asuntos mundiales hasta las relaciones internacionales" en Cid Capetillo, Ileana, compiladora, Lecturas básicas para introducción al estudio de las relaciones internacionales. FCPyS/UNAM, México, 1999.

S/D. Definición de Relaciones Internacionales en http://definicion.de/ relaciones-internacionales /

S/D. Émile Durkheim: Solidaridad en: http://www.angelfire.com/planet/ danielmr/Emile\%20Durkheim/Solidaridad.htm

Sanabria Caballero, Angélica, Factores de influencia de formación del Estado moderno, en http://www.alipso.com/monografias/estado_moderno/

Sarquís, David, Relaciones internacionales: una perspectiva sistémica, M. A. Porrúa, México, 2005.

Service, Elman, Los orígenes del Estado y de la civilización. El proceso de evolución cultural. Alianza Editorial, Madrid, 1984.

Todorov, Tzvetan, Nosotros y los otros, Siglo XXI, México, 2000.

Watson, Adam, The evolution of international society, Routledge, London, 2005. 


\section{UNA MIRADA A LA DISCIPLINA DE RELACIONES INTERNACIONALES}

\section{Mayra López Díaz}

\section{Introducción}

Revisar la historia de la ciencia es uno de los ejercicios más apasionantes para cualquier interesado en el tema, pues se corrobora que la espiral del conocimiento no se detiene y que aparece en el mismo momento en que el ser humano se ubica sobre la faz de la Tierra hace aproximadamente 250000 años, pues justo allí, la marcha del reloj del conocimiento se activó, evidenciándose la necesidad del ser humano de y sobre el conocer.

La intención del presente capitulo es ofrecer al lector una breve aproximación a la evolución de los estudios sobre lo internacional, a partir de la disciplina de Relaciones Internacionales y sus antecesoras, es decir, se abordará el desarrollo disciplinar intentando separar el objeto material (objeto de estudio) del objeto formal (disciplinas, teorías, conceptos, etc.), sólo para facilitar el análisis pues estamos ciertos de que la explicación de las transformaciones científicas tienen una estrecha vinculación con la correlación de fuerzas políticas, sociales, económicas y culturales.

Asimismo, en este capítulo, antes de entrar en la materia que nos ocupa, consideramos necesario tomar como punto de partida la explicación de la ciencia en general y, posteriormente, de las ciencias sociales, pues es en el marco de estas últimas, donde se da el surgimiento disciplinar de Relaciones Internacionales y la expansión de la misma en México y el mundo.

\footnotetext{
* Licenciatura y maestría en Relaciones Internacionales por la FCPYS, UNAM. Profesora del área de Teoría y Metodología en la misma especialidad. Ha participado en eventos académicos en México y en el extranjero. Tiene publicaciones en revistas especializadas y diversos libros colectivos. Su libro más reciente es Aportaciones teóricas de la escuela estadounidense a Relaciones Internacionales, FCPYS, UNAM, México, 2010.
} 


\section{De la Ciencia y las Ciencias Sociales}

Un individuo al nacer, inicialmente manifiesta la inquietud por conocer a través de la autoexploración, conforme va creciendo expande su necesidad e intenta explorar el entorno. Si esto mismo, lo trasladamos a la historia de la humanidad, entonces nos daremos cuenta que algo similar le sucedió al hombre primitivo, al intentar definirse a sí mismo y posteriormente entender y explicar los fenómenos de la naturaleza, tan sólo con la observación.

La dicotomía hombre-naturaleza mostraba la forma en que los fenómenos naturales, tales como el rayo, atemorizaban al ser humano, lo cual manifestaba la supremacía de la naturaleza sobre la especie humana. Al paso del tiempo, el hombre ha intentado en múltiples ocasiones invertir esta relación, siendo él quien domine. En ciertas situaciones lo ha conseguido, sin embargo, el ilimitado alcance de su contraparte le recuerda de vez en vez que esto no es posible o no de forma permanente.

Y así, en esta estrecha relación encontramos que el hombre aventaja a los animales por una sencilla razón, la diferencia antropológica, que está dada porque el hombre busca conocer y explicar y no sólo interactuar con la naturaleza, ${ }^{1}$ por ello,

el conocimiento del transcurso regular de las estaciones y de lo que causa las tempestades y los eclipses solares y lunares les quita su carácter de amenazador, liberando -al menosun poco al hombre frente a la naturaleza. Reprime los demonios y los dioses, en beneficio del conocimiento de causa y efecto. Con base en eso, se podría definir [...] la ciencia como la búsqueda sistemática de los vínculos entre las causas y los efectos, entre la esencia y la apariencia. Esta separación y la falta de identidad entre la apariencia y la esencia hace posible que exista la ciencia. ${ }^{2}$

Dicha ciencia tuvo una evolución y transformación, lo que fue evidenciando su reproducción en "círculos cerrados", en un primer momento al servicio del rey o emperador o papa y después, en pos de diversos intereses. Así, ciencia y

\footnotetext{
1 "Mientras los animales inferiores sólo están en el mundo, el hombre trata de entenderlo; y, sobre la base de su inteligencia imperfecta, pero perfectible del mundo, el hombre intenta ensoñarse de él para hacerlo más confortable. En este proceso, construye un mundo artificial: ese creciente cuerpo de ideas llamado 'ciencia', que puede caracterizarse como conocimiento racional, sistemático, exacto, verificable y por consiguiente falible. Por medio de la investigación científica, el hombre ha alcanzado una reconstrucción conceptual del mundo que es cada vez más amplia, profunda y exacta." Mario Bunge, La ciencia, su método y su filosofía, Nueva Imagen, Buenos Aires, 2000, p. 9.

${ }^{2}$ Ekkehart Krippendorff, Las relaciones internacionales como ciencia. Introducción, traducción Angelika Scherp, FCE, México, 1993, p. 15.
} 
religión estuvieron unidas, los asesores del "príncipe", por llamarlos de alguna manera, eran quienes detentaban este conocimiento y regularmente eran clérigos o intelectuales con una tradición importante dentro de la corte o gobierno, tal y como sucedía en la Antigüedad en diversas partes del orbe.

Muestra de ello es lo sustentado por James Allen Smith en su texto Intermediarios de ideas, donde señala que la tradición del asesoramiento es típicamente occidental, hecho que no indica exclusividad geográfica, y que con base en ella se preparaba a los más jóvenes de las casas reales para desempeñar su papel de líderes. Algunos de los nombres más destacados de esta relación asesor-asesorado, son:

Aristóteles [...] [como] tutor del joven Alejandro; Séneca [...] [de] Nerón; Gerbert de Aurillac fue maestro [...] de [...], Otto III, [...] [y] de [...], Roberto Capeto; Thomas Hobbes se ocupó de la educación del joven príncipe de Gales que se convertiría en Carlos II y el cardenal Mazarino [...] de Luis XIV."’3

Lo anterior permite entrever que el poder como el conocimiento se controlaron y concentraron, como ya se mencionó, en grupos selectos o círculos cerrados, tal como sucede hoy con el conocimiento -que es el tema que nos ocupa-, en las comunidades científicas donde para que exista un intercambio de ideas es necesario un lenguaje común. ${ }^{4}$

De regreso al proceso que sigue la historia de la ciencia, vale la pena resaltar que cada cambio de paradigma ${ }^{5}$ está ligado a la modificación del cómo hacer y cómo allegarse conocimiento, como menciona Immanuel Wallestein en su libro La historia de las ciencias sociales, con el Renacimiento, se abrió

la posibilidad de reconocer la verdad por medio de la racionalidad, por la racionalidad de sus individuos. Así, las leyes naturales, descubiertas y no inventadas por los filósofos,

${ }^{3}$ James Allen Smith Intermediarios de ideas. Los "Grupos de Expertos" (think tanks) y el surgimiento de la nueva elite política, traducción Cristina Piña, Grupo Editorial Latinoamericano, Buenos Aires, 1994, p. 15.

${ }^{4}$ En el caso de nuestra disciplina el lenguaje común incluirá conceptos como: Estado-Nación, relaciones internacionales, relaciones interestatales, sociedad internacional, sistema internacional, escena o escenario internacional, ámbito internacional, estudios internacionales, entre muchos otros que se van sumando a la lista a lo largo del tiempo.

${ }^{5}$ Para Thomas Kuhn, el paradigma por "una parte representa toda una constelación de creencias, valores, técnicas y demás, compartidos por miembros de una comunidad. Por otra, denota una especie de elementos en esa constelación, soluciones concretas o enigmas, que pueden llegar a reemplazar reglas explícitas como base para la solución de los restantes enigmas de la ciencia normal", citado en John A. Vasquez, Elpoder de la política del poder, traducción Ana Stellino, Ediciones Gernika, S. A., México, 1992, p. 18. 
fueron un encuentro del conocimiento racional. [Mientras que] la Reforma instó en el acceso directo del individuo a Dios y a lo bueno sin intermediarios, sin el clero. Esta idea de que es posible para todo el mundo acceder directamente a la verdad y a lo bueno fue evidentemente un cambio muy importante, un desafío para las autoridades existentes. ${ }^{6}$

Claramente, el acceso al conocimiento no se amplió a todos los individuos de la faz de la Tierra, si no a unos cuantos que demostraron tener capacidad para asimilar y perpetuar el mismo. Esto también se tradujo en la ampliación paulatina de los círculos de conocimiento y poder sin llegar nunca a ser masivos, de allí la expansión de comunidades científicas y de universidades tal como hoy las conocemos, ${ }^{7}$ pues el teólogo y el filósofo de poco a poco se fueron transformando en científicos sin que ninguna de estas dos figuras desapareciera de la composición social, al adaptar su forma de explicar la realidad.

Con el avance de la ciencia, la filosofía y la teología pasaron a segundo plano, pues el científico se casó con la idea de que él era el único detentador de la verdad, y se concentró en el desarrollo científico-tecnológico sin tener en consideración otros aspectos de la vida, por ello Levi-Strauss en su texto Raz̧a e historia señala que:

El Occidente, a pesar de ser el amo de las máquinas, tiene conocimientos muy elementales del uso de las fuentes de energía de esa máquina, la más desarrollada de todas, que es el cuerpo humano. [...], así como [....] de la relación entre el cuerpo y el espíritu, el Oriente y el Extremo Oriente tienen una ventaja de varios milenios sobre el Occidente. Han producido los extensos sumarios teóricos y prácticos del yoga hindú, las técnicas respiratorias chinas y la gimnasia de los órganos maorí. ${ }^{8}$

Así, la ciencia se fue convirtiendo en un cuerpo teórico de conocimiento estructurado, sistematizado e integrado que permite ofrecer a través de las diferentes disciplinas una explicación y aprehensión de la realidad con un sesgo importante, pues hay conocimientos que no han sobrevivido ante la concentración

${ }^{6}$ Immanuel Wallestein, La historia de las ciencias sociales, UNAM/Centro de Investigaciones Interdisciplinarias en Ciencias y Humanidades, México, 1997, p. 10.

${ }^{7} \mathrm{El}$ término Universidad proviene del latín universitas que significa gremio o corporación y hacía referencia al gremio de estudiantes o maestros. Vale la pena aclarar que la Universidad como tal aparece en la Edad Media y se consolida al final de ésta, pues se conjugan los gremios de estudiantes y profesores, pero además se establecen los grados académicos. Pero, sin duda, son el Renacimiento y la Reforma los dos momentos que permiten su mayor expansión y alcance.

${ }^{8}$ Claude Lévi-Strauss, Rasse und Geschichte, Francfort del Meno, 1972, p. 43. Citado en Krippendorff, op. cit., p. 19. 
del conocimiento en unas manos. Al fijar la atención en la ciencia, las universidades cobran mayor importancia, debido a que constituyen los espacios idóneos para la generación de conocimiento porque existe el intercambio de ideas entre pares y ello permite erigir a la razón como el eje rector de todo estudio, principio enarbolado por la Ilustración.

De acuerdo a lo anterior es que se produce la división inevitable de la ciencia en natural, filosófica y humanística, dicho divorcio nos lleva a tener un siglo XIX con dos culturas: la filosófica-humanista (que en sí misma sufrió una escisión desde antes) y la natural. ${ }^{9}$ En medio de estas dos grandes corrientes se ubicaron los partidarios de la ciencia social que intentaban el establecimiento de leyes o generalidades del comportamiento social, lo cual desembocó en la aparición de múltiples disciplinas interesadas en el estudio de este campo que buscaban impulsarlo desde una forma objetiva de explicar la realidad. ${ }^{10}$ Lo anterior porque debía soslayarse que el hombre, en estricto sentido el investigador, es al mismo tiempo el objeto a investigar y que su propia investigación está sujeta a juicios apreciativos, los cuales quedaban ocultos en el ámbito de lo privado y fuera de la reflexión científica. ${ }^{11}$

Sin embargo y aun cuando la intención era crear ciencias que explicaran lo social, la llamada ciencia social pasó por altibajos importantes, pues se argumentó que, en estricto sentido, no puede ser considerada ciencia y que si se tomaba como tal, dónde se ubicaría. En este mismo tenor, habría que definir si sería una ciencia social o varias ciencias sociales.

Otra de las complicaciones que se presentaron fue la de definir cuál o cuáles disciplinas aplicarían el método de la ciencia social, si es que existía, y cuáles se dedicarían a la enseñanza en las universidades. Esto por supuesto llevó a otra discusión, no menos importante, no obstante casi de inmediato se empezaron a perfilar diferentes nombres y disciplinas, sobresalieron de ellas: "historia, economía, sociología, ciencia política y antropología". ${ }^{12}$ Desde luego, no fueron las únicas, pero si las que en el momento resultaban mucho más explicativas y de mayor tradición para el estudio propio de lo social.

Es indiscutible, que las transformaciones en las comunidades científicas, están vinculadas o sustentadas en la evolución y cambio de las potencias de la época,

${ }^{9}$ Cfr. Wallerstein, op. cit., p. 11-12.

${ }^{10}$ Cfr. Immanuel Wallerstein (coord.), Abrir las ciencias sociales. Informe de la Comisión Gulbenkian para la reestructuración de las ciencias sociales, Siglo XXI Editores, México, 1999, p. 16.

${ }^{11}$ Cfr. Krippendorff, op.cit., p. 21.

${ }^{12}$ Wallerstein, Abrir las ciencias sociales, op.cit. p. 17. 
que requerían la explicación de los fenómenos sociales que en ese momento se estaban gestando a nivel local o internacional. Por tanto, las principales potencias se involucraron en el proceso y la generación de conocimiento, tal fue el caso de Gran Bretaña, Francia, las Alemanias, las Italias y Estados Unidos.

Al llegar el siglo XX todo se transformó, prácticamente las potencias europeas cedieron la estafeta a Estados Unidos porque ellas estaban en una activa participación en la Primera Guerra Mundial y en todos los conflictos que le antecedieron, hecho que al final puso de manifiesto la necesidad de crear una disciplina que explicara los sucesos internacionales. Más tarde, ya hacia finales de la Segunda Guerra Mundial y en años posteriores, la Organización de Naciones Unidas a través de la UNESCO se vio en la necesidad de terminar con el añejo debate sobre el estado de las ciencias sociales y definirlas como tales.

Es hasta entonces cuando las ciencias sociales empiezan a tener un avance más significativo manteniendo un status diferenciado del resto de la ciencia. Sin embargo hacia principios del siglo XXI y en

opinión del sociólogo portugués [...] de Sousa Santos, las ciencias sociales contemporáneas se hallan frente al desafío de generar una segunda ruptura epistemológica. Si la primera ruptura realizada en los siglos XVIII y XIX, se hizo frente a la "doxa" de los saberes tradicionales, la segunda debe hacerse frente a la primera, es decir, frente a la jerarquía de los conocimientos planteada por la episteme moderna. Lo cual significa que el reto mayor de las ciencias sociales no es ya distanciarse de las otras epistemes - con el propósito de garantizar una mayor objetividad del conocimiento- sino acercarse a ellas. ${ }^{13}$

\section{El estudio de lo internacional}

Tradicionalmente, cuando se presenta un parte-aguas histórico siempre se alude a un antes y un después del suceso. Lo mismo pasa en las disciplinas o en las ciencias, como hemos visto hasta ahora. Relaciones Internacionales no es la excepción y su historia o desarrollo está dividido en una etapa científica y otra pre-científica, lo cual demuestra la relevancia que han tenido los asuntos internacionales o extranjeros a lo largo de la historia de la humanidad.

La denominada etapa pre-científica tiene su inicio, aproximadamente, en el siglo XVII y son dos disciplinas: el Derecho y la Historia, las que se disputan la

\footnotetext{
${ }^{13}$ Santiago Castro Gómez, Freya Schiwy y Catherine Walsh "Introducción”, en Santiago Castro Gómez, Freya Schiwy y Catherine Walsh (editores) Indisciplinar las ciencias sociales. Geopolitica del conocimiento y colonialidad del poder. Perspectiva desde lo andino, Universidad Andina Simón Bolivar, Ediciones Abya-Yala, Ecuador, 2002, p. 12.
} 
primacía en el estudio. De hecho es muy difícil definir cuál de las dos inició el estudio, pues ambas han existido desde la Antigüedad y han dado cuenta de las relaciones y fenómenos que se presentaban entre los Estados nación de la época, pues de acuerdo a "Stanley Hoffmann, 'el análisis metódico de las relaciones entre los Estados ha estado durante largo tiempo, por decirlo de alguna manera, ahogado por la historia de estas relaciones y por el estudio de las normas jurídicas que tratan de ordenarlas". ${ }^{14}$

Sin embargo, iniciaremos nuestro recorrido por esta etapa pre-científica con el Derecho Internacional, el cual se nutre de la visión universalista de los teólogos -juristas españoles, el derecho de gentes o ius gentium y el derecho naturalderecho de todo el género humano sea cristiano o no. Los principales representantes son: Francisco de Vitoria, Hugo Grocio, Samuel Puffendorf, Christian Wolff y Emer Vattel. Los tres últimos fueron quienes propusieron una secularización del derecho, para que fuera aplicado independientemente de la pertenencia a una religión. ${ }^{15}$

Gracias a la secularización del derecho, se creó la doctrina positiva del derecho natural que favoreció la aplicación y reconocimiento del mismo en diferentes instrumentos jurídicos, tales como los tratados en los que se incluyó el principio de pacta sunt servanda, lo que promovió paulatinamente la desaparición o asimilación del derecho de gentes.

En el siglo XVII, Vitoria y Suárez sistematizaron y elaboraron instrumentos jurídicos que regularan las relaciones entre los estados, pues aun no era posible separar la filosofía y la teología del derecho. Sin embargo, el derecho después de la aparición y formación del Estado-Nación ${ }^{16}$ en 1648, luego de la firma del tratado de Paz de Westfalia que ponía fin a la Guerra de los Treinta Años, debía transformarse por la existencia de dos nuevos tipos de relaciones, por un lado, las que se presentaban al interior del Estado después de la formación de un pacto social que mantenía unidos a los ciudadanos y, por otro, las que se daban entre los mismos Estados con derechos y obligaciones similares.

${ }^{14}$ Stanley Hoffman "Théorie et Relacions Internationales”, Revue Française de Science Politique, vol. XI, nº 2, 1961, 1961, p. 414. Citado en: Esther Barbé, Relaciones Internacionales, Edit. Tecnos, Madrid, 1995, p. 27.

${ }^{15}$ Cfr. Antonio Truyol. La sociedad internacional. España, Alianza Editorial, 1974, p. 71-72.

${ }^{16}$ El Estado-Nación tiene tres elementos básicos: territorio, población y gobierno. Se debe recordar que el concepto de Estado hace alusión a una cuestión política vinculada con el gobierno, pues éste ultimo es el que representa al Estado que es considerado un ente abstracto. Mientras que, el concepto de Nación está directamente vinculado a una conformación social representada por la población. 


\section{Imagen 1}

\section{Firma del tratado de Paz de Westfalia}

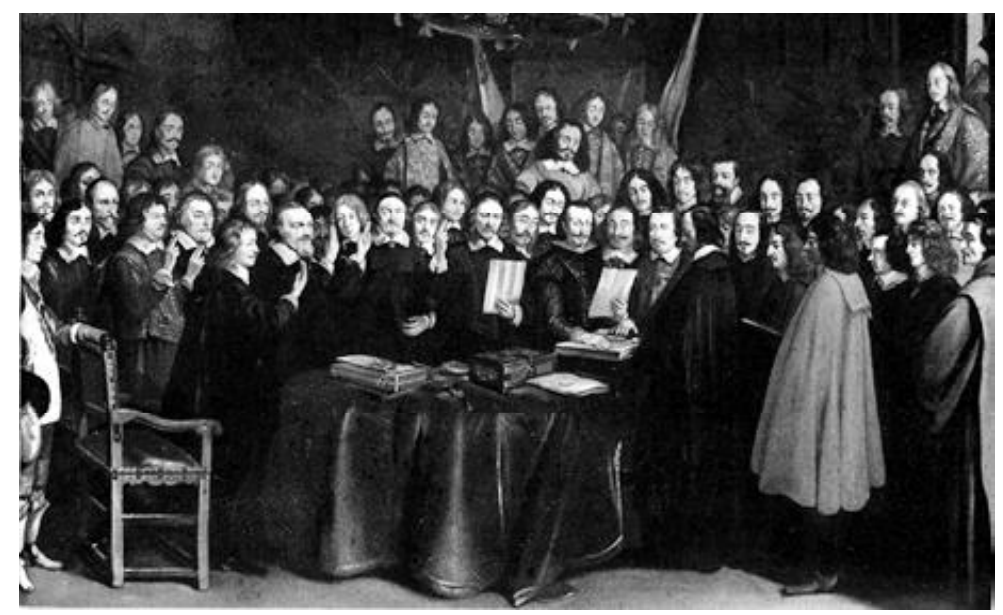

Fuente: http://www.larouchepub.com/spanish/anteriores/2005/Vol XXIInum06.html

Luego del establecimiento de las primeras reglas de convivencia, a nivel internacional se mantuvo el concepto de comunidad con el cual se reflejaba la fuerte carga teológica y filosófica que aun arrastraba el derecho y que innegablemente lo estaba sumiendo, paulatinamente, en un letargo. La visión jurídica de la realidad empezó a ser rebasada porque las relaciones no se sustentaban en las buenas intenciones y la buena voluntad.

No obstante, dicho enfoque se perpetuó durante todo el siglo XIX dando bastante peso a las corrientes positivistas que apoyaban la exclusividad del Estado, dejando de lado las nuevas perspectivas políticas, económicas y sociales, que cada vez influían con más fuerza en la sociedad internacional y en las propias competencias del derecho internacional. Para Emilio Cárdenas una de las grandes aportaciones de esta etapa fue que el derecho diplomático logró regular las relaciones entre las potencias europeas a partir del Tratado de Viena en 1815, lo cual significó un avance en materia de legislación internacional. ${ }^{17}$

Como podemos observar, la no adaptación del derecho internacional a las

${ }^{17}$ Cfr. Emilio Cárdenas Elorduy, "El camino hacia la teoría de las relaciones internacionales (biografía de una disciplina)", en Revista Mexicana de Ciencias Políticas, FCPyS, UNAM, México, enero-marzo 1971, p. 8. 
nuevas realidades ${ }^{18}$, donde ya no se regulaban relaciones entre cristianos y paganos, lo llevó a convertirse en una disciplina obsoleta para mediar las relaciones internacionales y, por ende, quedó rebasada para dar explicación a la Primera Guerra Mundial y a los conflictos posteriores a ésta, aunque sin desaparecer por completo. El enfoque ético en Relaciones Internacionales resurge sólo a partir del fin de la Segunda Guerra Mundial con la creación de la Organización de Naciones Unidas, organismo que velaría por el respeto y establecimiento de un marco jurídico para la sociedad internacional.

Como bien señaló Stanley Hoffmann, las relaciones internacionales han estado plagadas de estudios jurídicos e históricos, por lo tanto, ahora es el turno de la historia, como una de las disciplinas que dieron forma a la etapa pre-científica de Relaciones Internacionales.

La historia ha jugado un papel fundamental para todo científico social, por ser considerada como el laboratorio para analizar la realidad. Sin embargo, la relevancia de la historia está presente desde la Antigüedad con los griegos quienes creían que el destino del hombre, o sea la historia, estaba en manos de los dioses. Dicha concepción ha quedado plasmada en una gran cantidad de textos épicos de la época y que hoy sirve como base para determinar que la historia es una narración de hechos pasados de los hombres.

Así, la Historia como disciplina se encargó de los asuntos internacionales al igual que el Derecho Internacional a partir del siglo XVII con la Historia de los Tratados - que fue considerada como auxiliar del Derecho- y hacia el siglo XIX con la Historia Diplomática. Evidentemente, el nacimiento de la Historia de los Tratados está ligado al sistema de Estado europeos surgido de la Paz de Westfalia y a la Historia Diplomática que encontró su mayor auge antes y durante la Primera Guerra Mundial.

Como se ha mencionado ya, la Historia de los Tratados se desarrolló, de alguna forma, a la sombra del Derecho, pues únicamente se consideró que daba cuenta de las relaciones políticas entre los Estados debido a que éstos utilizaban

${ }^{18}$ De hecho, esta no adaptación obedece, según el propio Emilio Cárdenas a tres factores fundamentales: "Primero: [...] optimismo excesivo es típico del espíritu general de esa época. (...). Segundo: el alto grado de sistematización y conceptualización que había logrado el derecho internacional público [que] se presentaba a los ojos de los observadores como instrumento eficaz para estudiar las relaciones entre las naciones. (...). Tercero: la actitud internacional. Es característico de esa etapa la tendencia a formular juicios morales siempre favorables a todas las acciones internacionales y a juzgar severamente todas aquellas actitudes nacionalistas que tenían algún efecto en la política exterior extranjera. (...)" Ibid., pp. 9-10. 
los tratados para concluir una guerra o firmar una alianza bélica. ${ }^{19} \mathrm{Al}$ final, los tratados han constituido una fuente importante para analizar las relaciones interestatales, pero también para la formación de los nuevos representantes de los Estados.

Justo en esta etapa, el Derecho y la Historia se dedican como disciplinas científicas a la regulación y estudio de las relaciones internacionales sobre la base de los Estados europeos. Sin embargo, durante el siglo XVIII, es la Historia la que sobresale debido a los movimientos de la Ilustración y la llegada del Siglo de las Luces en los cuales se necesitaba una ciencia capaz de dar cuenta de lo sucedido durante la evolución y progreso de la humanidad.

Hacia el siglo XIX es la Historia Diplomática la que toma fuerza pues no sólo ofrecía historiografía sino el desarrollo de las acciones diplomáticas. De hecho, Antonio Truyol señala que "en términos generales, cabría afirmar que en la génesis de las relaciones internacionales como disciplina autónoma o diferenciada ha correspondido a la historia diplomática un papel de primer plano". ${ }^{20}$

El Congreso de Viena (1814-1815), es el mejor ejemplo de la cita anterior, en él se negoció la paz de las potencias victoriosas en busca de reafirmar el Antiguo Régimen frente al fenómeno revolucionario que en ese momento ponía en tela de juicio el status quo de Europa. Esta negociación se apoyó en paralelo en la denominada Santa Alianza, promovida por los imperios más conservadores: Rusia, Prusia y Austria, que buscaban salvaguardar sus intereses a toda costa.

Es así como observamos que hasta este momento, tanto el derecho como la historia se concentraron en el estudio y regulación de las relaciones europeas, lo cual evidencia las perspectivas eurocéntrica y, por otro lado, estatocéntrica, ya que a pesar de la existencia de otras zonas geográficas, los únicos Estados considerados a cabalidad eran los europeos.

Una vez avanzado el siglo XIX, la sociedad internacional fue sufriendo modificaciones, las cuales en buena medida no fueron dilucidadas por los historiadores y diplomáticos de la época en el afán de mantener el equilibrio de poder en Europa. Sin considerar que, con ello, estaban cometiendo el mismo

\footnotetext{
${ }^{19}$ Hecho con el cual podemos comprobar que la dicotomía siempre presente en las relaciones internacionales es la paz y la guerra, y que sus dos representantes son el soldado y el diplomático, tal y como lo señala Raymond Aron en su texto Pazy Guerra entre las Naciones. Desde luego, es importante reconocer que conforme va evolucionado el enfoque teórico de Relaciones Internacionales, la dicotomia se transforma ahora puede ser entendida desde una perspectiva de conflicto y cooperación, pero al final la misma esencia.

${ }^{20}$ Antonio Truyol. La teoría de las relaciones internacionales como sociología. $2^{\mathrm{a}}$ ed., Alianza Editorial, Madrid, 1973, p. 64.
} 


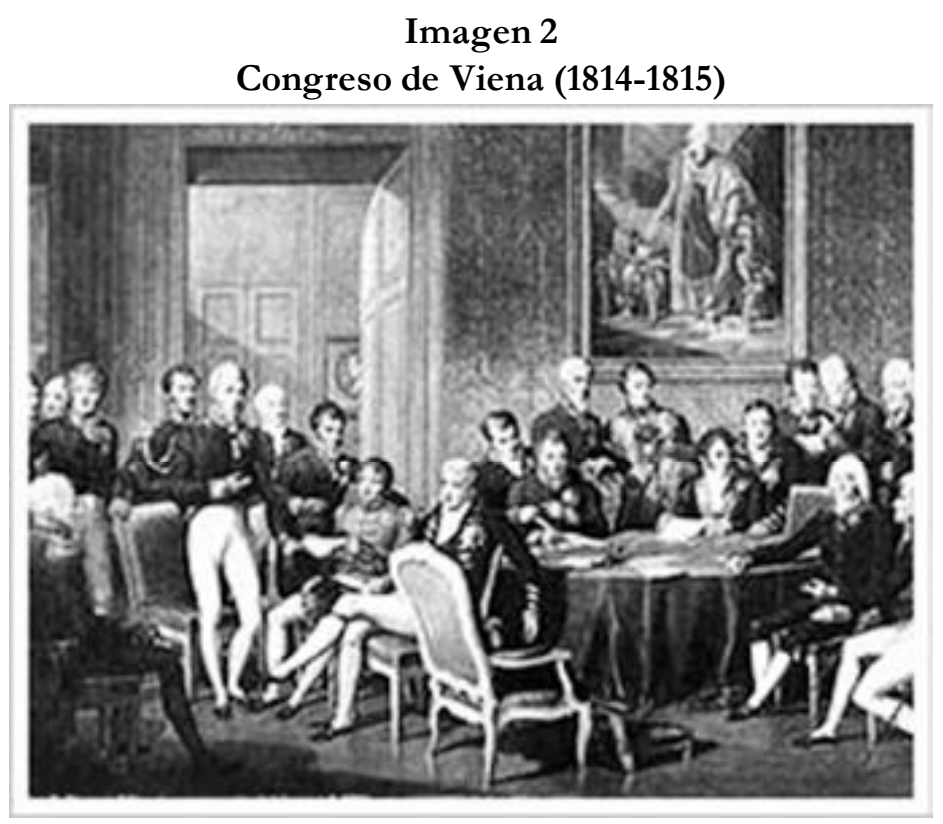

Fuente:http:/ / recursostic.educacion.es/kairos/web/ensenanzas/bachille rato/espana/img/imagenes_comentadas/emergente_congreso deviena.html

error que los juristas, ya que estaban dejando de lado aspectos políticos, económicos y sociales que concernían a la sociedad en su conjunto y no sólo a las potencias. Lo anterior dio como consecuencia la imposibilidad de construir un marco conceptual que apuntalara el inicio de la teorización para explicar las relaciones internacionales y obviamente, tampoco se presentó como una herramienta consistente para analizar la Primera Guerra Mundial.

Pese a las deficiencias antes planteadas, la Historia Diplomática paulatinamente se fue transformando en Historia de las Relaciones Internacionales, gracias a los estudiosos franceses y españoles que retomaron mucha de su riqueza explicativa considerándola como "un estudio científico de los fenómenos internacionales para llegar a descubrir los datos fundamentales y los datos accidentales que las rigen". ${ }^{21}$ Lo anterior permite que esta historia siga explicando la realidad internacional durante buena parte del siglo XX, de forma autónoma a la disciplina de Relaciones Internacionales.

${ }^{21}$ J. B. Duroselle, "L'étude des Relations Intenationales. Objet, Méthode, Perspectives", Revue Française de Science Politique, vol. II, no 4, 1952, p. 683. Citado en: Esther Barbe, op.cit., p. 28. 
Aun cuando existe una estrecha vinculación entre la historia diplomática y la diplomacia, es necesario un tratamiento por separado debido a que la diplomacia, como tal, constituye un ejercicio político más que un mero recuento de los hechos. El diplomático es el representante de un gobierno, el cual le confiere facultades para tomar decisiones y representarlo, por tanto a su actividad se le denomina Diplomacia.

La Diplomacia en cuanto tal, al igual que las dos disciplinas antes abordadas: el Derecho y la Historia, tiene antecedentes en la Antigüedad. De la misma forma que la Historia, la Diplomacia está vinculada a los dioses y semidioses, desde un aspecto mitológico, en donde

el dios Hermes simboliza para los antiguos las cualidades del encanto, la marrullería y la trampa. [Dicho mito se sustenta en que] el mismo día en que nació, robó cincuenta cabezas de ganado a su hermano Apolo y luego (después de esconder las vacas en una cueva) se volvió a dormir tranquilamente en su cuna. Zeus aplaudió con calor esa prueba de habilidad de Hermes y le empleó desde entonces en el desempeño de las misiones diplomáticas más delicadas, entre ellas el asesinato de Argos. ${ }^{22}$

Más tarde, se consideró que el origen de la diplomacia tenía una raíz religiosa, ya que los ángeles habían sido los primeros mensajeros entre el cielo y la Tierra. ${ }^{23}$ Esta explicación fue aceptada debido a la fuerte influencia que la religión tenía en la definición y conformación europea de la época previa a la aparición del Estado-Nación.

Ahora bien, si nos remontamos a lo que en la práctica se conoce como la visión amplia de las relaciones internacionales, es decir que éstas existen como tal a partir de la presencia de los primeros grupos que poblaron la Tierra y que tuvieron contacto, entonces, podemos afirmar que la diplomacia es tan antigua como la humanidad misma. Sin embargo, se torna harto difícil constatarlo, pero lo que sí es posible confirmar es que en las civilizaciones egipcia, griega y romana existían embajadores o heraldos y más aun en los siglos XIII y XIV entre las ciudadesestado italianas.

Por supuesto, las actividades prestadas por esto personajes carecían del cuerpo sistematizado de reglas y categorías que se lograrían posteriormente gracias al derecho y la historia de los tratados. Hecho que se consumó en su totalidad con el ya citado Congreso de Viena, donde para firmar la paz se reunieron los

${ }^{22}$ Harold Nicolson, La diplomacia. $3^{\mathrm{a}}$ ed., Traduc. Adolfo Álvarez Buylla, Fondo de Cultura Económica, México, 1994, p. 23.

${ }^{23}$ Cfr. idem., p. 22. 
diplomáticos y estadistas más prominentes de la época a quienes interesaba mucho poner fin al descrédito y desequilibrio existente de los cuerpos diplomáticos.

Así, el

Reglement de 19 de marzo de 1815 y las normas subsiguientes del Congreso de Aquisgrán, establecieron finalmente los servicios diplomáticos y la representación de las potencias sobre una base de común acuerdo. Se definieron cuatro categorías de representantes, a saber: 1) embajadores y legados y nuncios papales; 2) enviados extraordinarios y ministros plenipotenciarios; 3) ministros residentes; 4) encargados de negocios. ${ }^{24}$

Lo anterior fomentó que cada Estado, incluso la misma iglesia, creara un ministerio independiente de relaciones exteriores y un cuerpo diplomático. Así, la Diplomacia, se convirtió en la responsable de estudiar y explicar las relaciones internacionales de la época y sobre todo de mantener la paz sustentada en la historia y el derecho. Motivo por el cual, al igual que ellas, se convirtió en una disciplina anticuada, incapaz de adaptarse a los cambios de finales del siglo XIX, lo que provocaría la firma de múltiples tratados secretos violando y desconociendo los acuerdos del Congreso de Viena que permitían el equilibrio de poder en Europa.

Dichos tratados secretos son parte de las causas para el estallido de la Primera Guerra Mundial que, aunados a la necesidad de ampliar los mercados y las fuentes de abastecimiento de materias primas, crearon una rivalidad tal que en 1914 se formaron dos bandos militares: 1) la "Entente" integrada por Francia, Rusia y Gran Bretaña y 2) la "Triple Alianza" de la cual eran parte Alemania, AustriaHungría e Italia. La guerra inició so pretexto del asesinato del archiduque Francisco Fernando I de Austria en Sarajevo, capital de Bosnia.

El desarrollo de esta Primera Guerra Mundial es casi por todos conocido y de fácil consulta en los libros de Historia. Sin embargo, cabe mencionar que este primer conflicto a escala mundial puso al descubierto un sinnúmero de anomalías que se venían arrastrando en la relación entre los Estados europeos, pues en varias ocasiones se rechazó el fin de la guerra con la esperanza de obtener un resultado más ventajoso para cada uno de los involucrados de acuerdo al bando al que pertenecían.

Por tanto, no es casualidad que en los años previos al conflicto mismo se haya buscado dar una explicación al acontecer internacional y se hayan creado dos instituciones de investigación directamente interesadas en los estudios sobre la

${ }^{24}$ Ibid. p. 35. 
Imagen 3

Asesinato del Archiduque Francisco Fernando I

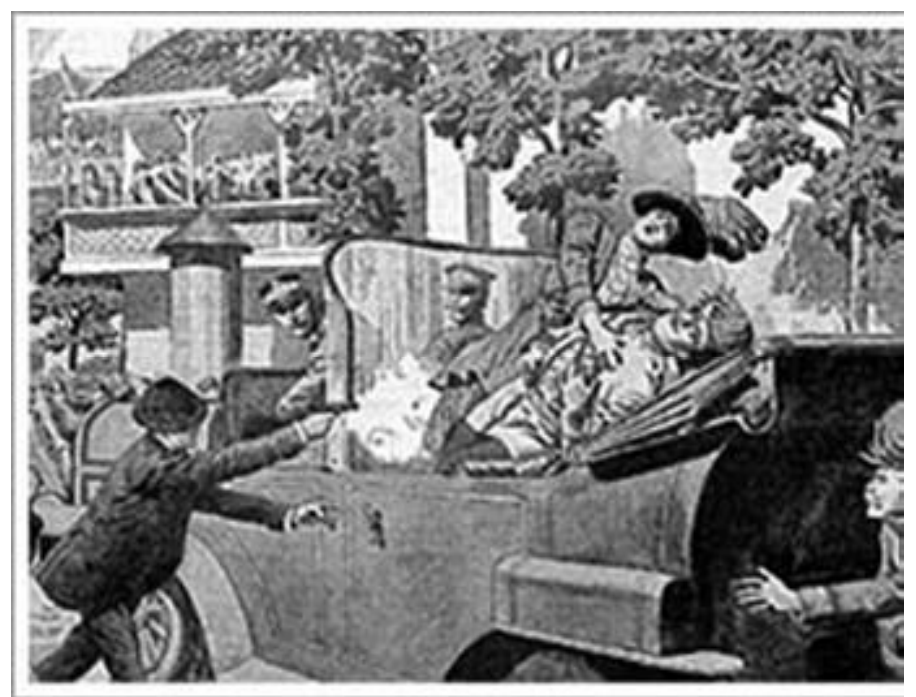

Fuente: http:/ / recursostic.educacion.es/kairos/web/ensenanzas / bachillerato/mundo/img/f_asesinato.jpg

paz. Por un lado la Carnegie Endowment for International Peace que apareció en 1910 y que ha utilizado como medio de difusión su Revista International Conciliation, y por el otro, la World Peace Foundation.

Asimismo, durante los años previos al fin de la Primera Guerra Mundial, la inquietud por dar una solución a la guerra y consumar la paz llevaron a la publicación de tres textos fundamentales que pusieron de manifiesto la necesidad de crear una disciplina encaminada al estudio de lo internacional. El primero fue el de Paul Reinsch intitulado World Politics at the End of Nineteenth Century en 1900; el segundo, An Introduction to the Study of International Relations en 1916: y el tercero Imperialismo. Fase superior del capitalismo de Lenin, el cual apareció en 1917. ${ }^{25}$

En este escenario,

Wilson, presidente de Estados Unidos, proclama a principios de 1918 sus 'Catorce Puntos', que piden la abolición de la diplomacia secreta, la libertad de los mares, y el libre comercio, el arreglo libre e imparcial de los problemas coloniales (sin establecer la autodeterminación para los pueblos sujetos), la restauración de los países europeos ocupados, y la organización

${ }^{25}$ Cfr. Barbé, op. cit., p. 24. 
de una Sociedad de Naciones. Estos puntos, presentados como de interés general, facilitaban la expansión comercial de Estados Unidos. ${ }^{26}$

Los 14 puntos de Wilson fueron bien acogidos por algunos, pero otros decidieron no considerarlos en su momento sino hasta tiempo después, una vez firmado el Tratado de Paz de Versalles y acordada la creación de la Sociedad Naciones -antecedente inmediato de la Organización de Naciones Unidas.

A lo anterior se sumó la puesta en marcha de la Royal International Society en Londres y el Council on Foreign Relations en Nueva York, instituciones que sirvieron de inspiración para la creación de otras en diferentes partes de Europa y sobre todo en Estados Unidos, este último creador prototípico de los denominados think tanks, tal y como los conocemos actualmente.

Es entonces, a partir de la Primera Guerra Mundial cuando la figura del asesor o consejero vuelve a tomar relevancia debido a su participación en las negociaciones y, sobre todo, con la creación de instituciones expresas para su actividad que le permitirían tener una mayor proyección y alcance a la hora de tomar decisiones. Probablemente esto marcó la transición del asesoramiento individual al colectivo.

\section{Imagen 4}

Firma del Tratado de Paz de Versalles

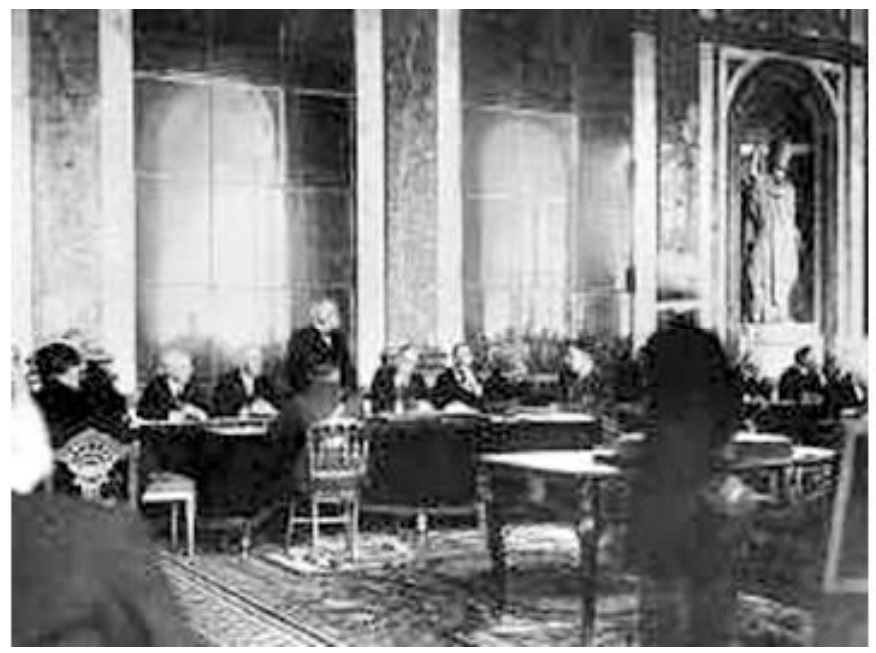

Fuente: http://clio.rediris.es/udidactica/IGM/images/firmaversa lles.jpg

${ }^{26}$ Juan Brom, Esbozo de historia universal, Editorial Grijalbo, México, 1991, p. 202. 
En este contexto, se manifiesta la necesidad de crear una disciplina capaz de explicar la realidad internacional con nuevas dimensiones y actores, pues aunque ya había algunas que se dedicaban a dicho estudio, sus enfoques habían quedado completamente rebasados y la toma de decisiones ya no estaba sólo en manos de los gobiernos sino también en manos de una incipiente opinión pública dispuesta a involucrarse en el proceso y presionar a nivel internacional para la erradicación de la guerra. Por ello es que algunos autores sostienen que la teorización en relaciones internacionales no es responsabilidad puramente intelectual y gubernamental, sino que se debe permitir el involucramiento de otros actores. ${ }^{27}$

A partir de lo anterior, se promueve la impartición de la primera cátedra denominada "Woodrow Wilson" de Política Internacional a cargo de Alfred Zimmern en la Universidad de Aberyswyth en el País de Gales en 1919, anunciándose con ello, el nacimiento de Relaciones Internacionales como disciplina encargada del estudio de lo internacional. ${ }^{28}$

Sin importar el nombre que tomara, Relaciones Internacionales en ese momento debía enfrentar el mismo problema que las otras ciencias sociales y es que su objeto de estudio no es algo tangible a diferencia de las ciencias naturales que cuentan con campos bien definidos. Además, las mismas Relaciones Internacionales no son las que proveen del campo de estudio sino los estudiosos y los practicantes de éstas. ${ }^{29}$ A propósito de esto se crea una disputa importante, pues la realidad internacional parece ser muy amplia, lo mismo es jurídica, económica, social, política, etc. y entonces Relaciones Internacionales se dedicaba a estudiar todo, sólo que en el plano internacional.

Lo anterior parece tener una similitud, por cierto, algo burda, a un pastel, pensando que éste es la realidad. Una vez que tenemos esa realidad es necesario dividirla para ser estudiada y enseñada por las diferentes ciencias y disciplinas, lo cual nos lleva a partir en rebanadas el pastel. Antes de hacer las rebanadas lo primero que regularmente hacemos es cortar un círculo en el centro del pastel y después procedemos a hacer las correspondientes divisiones en partes más o

${ }^{27}$ Cfr. W. C. Olson y A. J. R., Groom, International Relations. Then and Now, Harper Collins, Londres, 1991, p. 47.

${ }^{28}$ El término internacional ha sido utilizado a lo largo del trabajo, pero es justo con la aparición de la disciplina de Relaciones Internacionales cuando toma mayor relevancia y es necesario explicar que fue acuñado por Jeremy Bentham en 1780, el cual se refiere a la suma de la historia diplomática y de la política exterior de los estados

${ }^{29}$ Cfr. Chris Brown y Kirsten Ainley, Understanding International Relations, Fourth Edition, Palgrave Macmillan, Estados Unidos, 2009, pp. 2-3. 
menos iguales. Algo parecido fue lo que se hizo cuando aparece a la escena disciplinaria Relaciones Internacionales (Figura 1).

Figura 1

\section{La realidad divida en disciplinas}

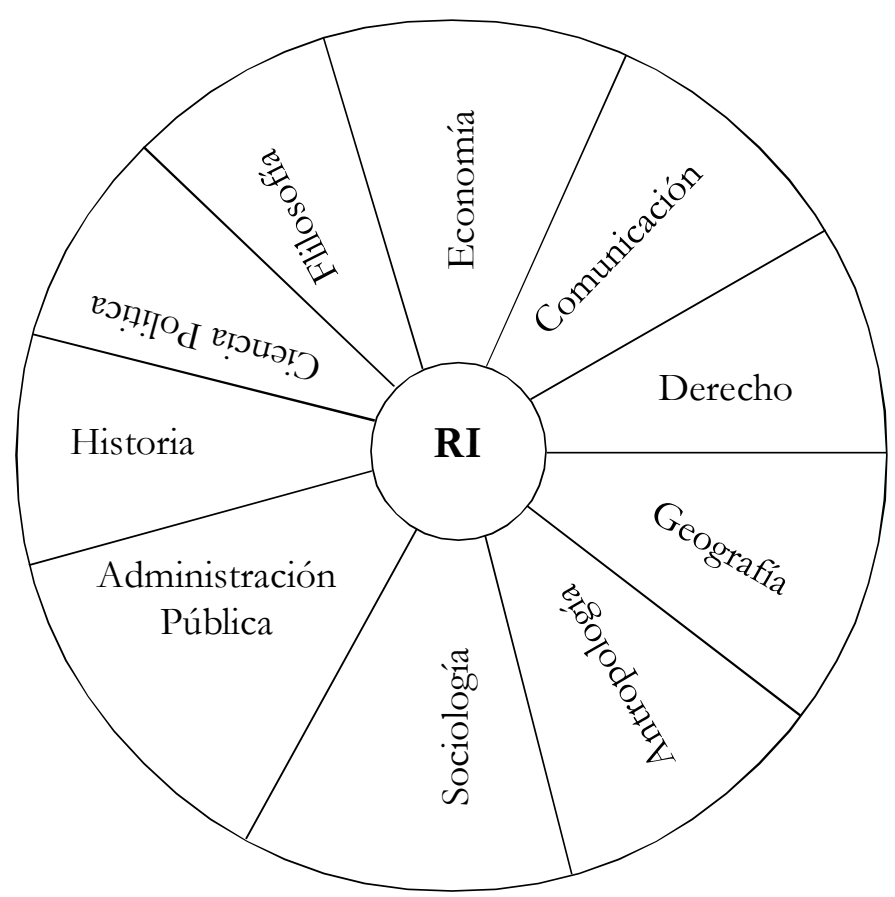

Fuente: Creación propia con base en la reflexiones de autores como Roberto Mesa, Rafael Calduch, Mario Amadeo texto que pueden ser revisados en el libro de Ileana Cid Capetillo (comp.) Lecturas básicas para introducción al estudio de Relaciones Internacionales. Facultad de Ciencias Políticas y Sociales, UNAM, 1998, 285 pp. el cual también se encuentra disponible en: http://ciid.politicas.unam.mx/ basicasri/

Definitivamente, a la distancia mencionar la situación anterior parece muy sencillo, sin embargo en su momento y hasta muy entrado el siglo XX marcó el tenor de la discusión entre los estudiosos de los asuntos internacionales y de otras disciplinas, pues, sobre todo, los politólogos, sociólogos y juristas pretendían adjudicarse el estudio de lo internacional y la creación, dentro de su disciplina, de la rama de las relaciones internacionales. Lo que evidentemente no permitía la autonomía de Relaciones Internacionales y la hacía aparecer como "todóloga". 
En buena medida, la situación anterior quedó salvada por el carácter intermulti-transdisicplinario de Relaciones Internacionales. Sin embargo, algunos estudios están fuertemente permeados por la influencia de la Sociología y la Historia, como es el caso de los franceses que se basan mucho en la denominada Sociología Histórica o en la Historia de las Relaciones Internacionales, antes mencionadas. En el caso de los estudios realizados en España, podemos identificar la inclinación hacia lo jurídico debido a la relación con el Derecho Internacional. Para los anglosajones, léase ingleses y estadounidenses, la vertiente política es la de mayor peso.

Ante esto último es importante señalar que, de forma natural, Relaciones Internacionales tiene una fuerte relación con los estudios politológicos que a su vez han sido ampliamente desarrollados en Estados Unidos por múltiples razones, entre ellas porque dicho Estado se convirtió en el garante del mundo luego de que Gran Bretaña, paulatinamente, le transfiriera la estafeta, tanto en materia de seguridad como académica. Con base en lo anterior, Stanley Hoffmann justifica y afirma que nuestra disciplina es una ciencia americana. ${ }^{30}$

Con el inicio de la etapa científica era necesario cumplir con la rigurosidad de toda ciencia o por lo menos de toda disciplina. Por un lado, construir un cuerpo teórico y, por el otro, diseñar planes de estudio independientes de las disciplinas que reclamaban como área de investigación lo internacional. ${ }^{31}$

El primer intento para crear un cuerpo teórico, ${ }^{32}$ se hizo desde la perspectiva idealista, que partía del paradigma estatocéntrico sobre los principios del liberalismo en donde su sustento era la idea de que la naturaleza humana es buena y que dicha bondad se traduce en el progreso de la sociedad. Para los liberales la conducta humana malvada, tal como la injusticia o la guerra, es reprobable y producto de instituciones corruptas que han desviado su misión, sin embargo, asume que no es posible evitarla pero si atenuarla, de tal suerte que, se logren las reformas institucionales necesarias para el bien común. ${ }^{33}$

${ }^{30}$ Cfr. Stanley Hoffmann, "An American Social Science: International Relations” en James Der Derian (ed.), International Theory. Critical Investigations, New York University Press, New York, 1995, pp. 225-227.

${ }^{31}$ Sobre este punto se ahondará en el apartado siguiente, denominado De México y el mundo, porque en él abordaremos la forma en que se fueron creando en distintas latitudes, las escuelas o institutos para formar a los especialistas en lo internacional.

${ }^{32} \mathrm{El}$ cual parte de la idea de que: "Una teoría es un conjunto de propuestas y conceptos tendientes a explciar fenómenos al hacer explícitas las relaciones entre los conceptos manejados; el fin ultimo de una teoría es predecir un fenómeno", Karen Mingst, Fundamentos de la Relaciones Internacionales, Colección Estudios Internacionales, CIDE, México, 2009, p. 111.

${ }^{33}$ Cfr. ibid., pp. 116-117. 
La fase idealista normativa [...] [respondía entonces] tanto al contexto internacional como al intelectual, que [...] [llevó al] fin de la Primera Guerra Mundial. Esta guerra había demostrado a los estudiosos que la diplomacia europea secreta resultaba ineficiente para mantener la paz y el orden internacionales. Además, las pérdidas humanas habían creado una opinión pública internacional partidaria de la erradicación de la guerra como medio de seguridad colectiva. ${ }^{34}$

Dicha seguridad debería estar garantizada por las instituciones, por ello, la creación de la Sociedad de Naciones generó optimismo al sentar las bases para preservar la paz sustentada en dos ejes fundamentales: 1) la defensa de la moral internacional y 2) el desdén del equilibrio del poder, la carrera armamentista, el uso de la fuerza y de los tratados secretos. Sin embargo, ni los principios constitutivos del liberalismo ni la concepción de la realidad planteada por el mismo, tuvieron la suficiente fuerza para cohesionar y conducir a la sociedad internacional a una correlación de fuerzas que garantizara el mantenimiento de la paz.

Durante el periodo de entre guerras que va de 1919 a 1939, aparece una visión que busca normar los sucesos internacionales más que explicarlos. Dicha perspectiva se sustenta en elementos históricos, jurídicos y éticos, lo cual es tangible en el manejo del discurso aunque, obviamente se trata de una política de poder encubierta, que es bien descrita por E.H. Carr en su libro La crisis de los veinte años, ${ }^{35}$ en donde plantea el debate suscitado entre idealismo (también conocido como utopismo o liberalismo) y una nueva visión que estaba siendo planteada por autores como Reinhold Niebur, a la cual se le denominó realismo.

A diferencia del idealismo, el llamado realismo partía de la idea de que la naturaleza humana era malvada y que existe una constante lucha por la sobrevivencia, pues según Thomas Hobbes el hombre es el lobo del hombre. ${ }^{36}$ Asimismo, el realismo intenta ubicarse en el ser y no en el deber ser como lo hacen otras teorías que pretenden normar más que explicar la realidad; por supuesto, esto no implica que al interior del Estado no exista un aparato jurídico que regule las relaciones entre los ciudadanos y que al exterior del mismo no existan reglas de convivencia en la anarquía existente.

\footnotetext{
${ }^{34}$ Mayra López Díaz, Aportaciones teóricas de la escuela estadounidense a Relaciones Internacionales, Facultad de Ciencias Políticas y Sociales, UNAM, México, 2010, p. 36.

${ }^{35}$ E. H. Carr, La crisis de los veinte años (1919-1939), traducción Emma Benzal Alonso, (con prólogo de Esther Barbé), Los Libros de la Catarata, Madrid, 2004, 321 pp.

${ }^{36}$ Esta idea es posible revisarla con amplitud en la obra completa de Thomas Hobbes, Leviatan, FCE, México, 2008.
} 
Lo anterior, de alguna forma, fue considerado como el elemento perfecto para dotar de cientificidad a la disciplina, al despojarse de juicios de valor y, sobre todo, de las visiones juridicistas que tradicionalmente habían permeado el estudio de la realidad internacional, las cuales aun contenían una fuerte carga teológica y filosófica.

El realismo, entonces, encontró a su máximo representante en Hans J. Morgenthau, quien se encargó de sistematizar las ideas realistas y de utilizarlas para dar una explicación a la realidad internacional. Lo anterior lo hizo en su obra escrita en 1948, Política entre las naciones, la cual históricamente ha sido la más estudiada por los interesados de los asuntos internacionales, ${ }^{37}$ pues se trata del fundamento de la teoría realista, pero también del punto clave que justifica y consolida a cabalidad la política exterior estadounidense y la existencia de la disciplina de Relaciones Internacionales al dotarla de un cuerpo teórico basado en la razón que la llevará a la objetividad que, a su vez, paulatinamente contribuiría a la conformación de una agenda de investigación.

El realismo durante el debate con el idealismo, logró el consenso entre estudiosos y políticos, respecto a tres ideas fundamentales, por un lado, erigió al Estado como el actor principal; por otro, estableció que la política interna y la externa son dos esferas separadas y, por último, demostró que las relaciones internacionales constituyen una lucha por el poder y por la paz. ${ }^{38}$

De alguna forma, las ideas anteriores habían estado ya presentes en el estudio de la realidad internacional, pues tanto el idealismo como el realismo partían del paradigma estatocéntrico. Asimismo, se había identificado ya que existía una dicotomía conformada por la paz y la guerra -entendiéndose esta última como la obtención del poder a través del uso de la fuerza si fuera necesario. Lo único que en todas las discusiones anteriores no se había dilucidado con claridad era la separación entre las esferas políticas, nacional e internacional, pues ante esto sólo se había planteado que a partir de la aparición del Estado-Nación era necesario regular dos tipos de relaciones, las de los ciudadanos -al interior del Estado- y las concernientes a los Estados en la interacción con otros. Mientras que el idealismo sostenía que son las organizaciones internacionales las que deben ocuparse de la política internacional para evitar la guerra.

\footnotetext{
${ }^{37}$ Ver John A. Vásquez, El poder de la politica del poder, traducción Ana Stellino, Ediciones Gernika S. A., México, 1991, 408 pp.

${ }^{38}$ Cfr. Vasquez, op. cit., p. 39 o bien, revisar el texto completo de Hans J. Morgenthau, Politica entre las naciones. La lucha por el podery la paz, edición revisada por Kenneth W. Thompson, traducción Herber W. Olivera, 2a. ed., Grupo Editor Latinoamericano, Argentina, 1986, 729 pp.
} 
Las ideas anteriores están contenidas en los denominados Seis principios del realismo político que señalan que: 1) La naturaleza humana no ha variado y se sustenta en leyes objetivas producto de la política y la sociedad. 2) La política internacional obedece al interés definido en términos de poder. 3) El poder es una categoría de análisis universal sujeta al contexto. 4) Los principios morales universales no pueden ser aplicados a los actos de los Estados debido a que la realidad es cambiante y lo que en algún momento es adecuado en otro parece no serlo. 5) Las aspiraciones morales de una nación no necesariamente se corresponde con los preceptos morales. 6) El realismo político mantiene la autonomía y supremacía de la esfera política, sin embargo, no ignora otros pensamientos distintos al político porque se apoya en el pluralismo de la naturaleza humana, es decir, que en el hombre confluyen las manifestaciones económica, política, moral, etc. ${ }^{39}$

Ante este panorama, todo parecía estar casi solucionado para la disciplina, no obstante aparecieron algunos estudiosos que cuestionaron la cientificidad aportada por el realismo, pues tomar como base la razón no era suficiente para hablar de una ciencia. Debemos recordar que, en estricto sentido, entre otras cosas la ciencia es aquella que aplica el método científico para explicar la realidad, entonces, ante esta perspectiva, Relaciones Internacionales carecía de él.

Es así como una corriente, también partidaria del paradigma estatocéntrico, pues no refutaba los tres elementos fundamentales del realismo -abordados ya en su momento-, propuso incorporar al estudio de los asuntos internacionales algunos modelos de análisis que incluyeran variables cuantitativas y que básicamente provenían de disciplinas como Matemáticas, Psicología, Economía, Ciencia Política y hasta Lingüística, que después fueran explicadas haciendo uso de la Estadística. A estas nuevas propuestas se les denominó en su conjunto revuelta conductista y estuvo en gran efervescencia durante toda la década de los años sesenta.

Los modelos que aparecieron fueron: la Teoría de los Juegos, la Teoría de la Negociación Internacional, la Teoría del Conflicto, las Técnicas de Simulación, la Teoría de las Comunicaciones, la Teoría de Sistemas, entre otras. Con estos modelos se propició en la disciplina una mayor interdisciplinariedad pues se incorporaron muchos más elementos de teorías y metodologías ajenas a la misma; el uso del análisis comparativo y las técnicas de investigación, recolección y

${ }^{39}$ Cfr. Hans J. Morgenthau, op. cit., pp. 12-26. 
almacenamiento de datos (bases de datos) que favorecían el rigor científico. ${ }^{40}$

Durante poco más de tres décadas, el realismo se convirtió en el eje rector del debate en Relaciones Internacionales, estableciendo el denominado mainstream que cobijaba el estadio de ciencia normal que se había presentado en la disciplina y que además era auspiciado por Estados Unidos por convenir así a sus intereses. Sin embargo, el dinamismo social superó por mucho a las explicaciones tradicionales que ofrecía el realismo y a los mismos modelos cientificistas, abriéndose la necesidad de una reformulación sobre la forma de estudiar la realidad.

Es la década de los años setenta y a la par de sucesos como: la prolongación de la guerra de Vietnam, la confrontación Norte-Sur, la proliferación de armamentos, los conflictos en Medio Oriente, los modelos económicos de sustitución de importaciones en América Latina, entre otras cosas, cuando el Estado como ente monolítico de la realidad internacional empieza a ser cuestionado como actor principal, lo que da como resultado la aparición de nuevos actores, tales como: las empresas transnacionales (ET) y las organizaciones no gubernamentales (ONG)

Ante el despertar del denominado Tercer Mundo, las aportaciones para explicar la realidad desde otra perspectiva empiezan a cobrar importancia y son la Dependencia y el Imperialismo, los que ofrecen algunas alternativas de análisis centrándose en la explicación del capitalismo y el proceso de industrialización que se ha vivido. Ambas visiones demuestran que los rezagos de los países del sur o Tercer Mundo son producto exclusivo del desarrollo desigual y combinado del capital, de la división internacional del trabajo y de las diferentes formas de explotación. Estos fenómenos que se identifican de forma global se reproducen también al interior de los Estados, existiendo una polarización entre la población pues hay grupo de pobres extremadamente pobres y de ricos exageradamente ricos.

Frente este panorama, aparece una propuesta denominada Interdependencia que intenta sistematizar los postulados hasta ese momento presentados por idealismo, realismo y cientificismo, pues la suma de los tres tomaría en cuenta al Estado, a la organización internacional (otros actores) y además se tendrían otros métodos para analizar la realidad porque, como señalan Keohane y Nye, el

poder de las naciones - aquella secular piedra basal de analistas y estadistas- se ha tornado más elusivo: "los cálculos de poder son más difíciles y engañosos de cuanto eran en otras

${ }^{40}$ Cfr. Luis Alberto Padilla, Teorías de las Relaciones Internacionales. La investigación sobre la pazy el conflicto, IRIPAZ, Guatemala, 1992 p. 112. 
épocas." [...] [y ahora nos movemos] "interdependiente en economía, en comunicaciones y en el campo de las aspiraciones humanas". ${ }^{41}$

Es así como, la aparición de una concepción transnacional marcó un cambio en el discurso porque "la política mundial y el comportamiento de los Estados [que modifican] las acciones gubernamentales también influyen en los modelos de interdependencia". ${ }^{42}$ Dicha modificación resquebraja uno de los consensos logrados por el realismo, referente a que las esferas de política interna y externa están separadas y que además existe una jerarquización en torno a los temas de la agenda internacional, siendo los político militares, los que encabezan la lista.

De acuerdo a los múltiples cuestionamientos presentados al realismo, tanto desde el exterior como desde su interior, éste se ve en la necesidad de renovarse y afianzar sus principales ideas -con ciertas adecuaciones- y entonces acepta que el Estado como actor unitario y racional se desenvuelve en un medio anárquico en el cual para sobrevivir necesita de la autoayuda (self help), es decir, tener pleno conocimiento de sus capacidades para poder tomar decisiones, debido a que ha habido un cambio en el sistema y no un cambio de sistema porque existen varios elementos que deben ser asumidos y tratados a nivel estatal y no por otros actores. Kenneth Waltz -discípulo de Morgenthau- es quien se encarga de hace esta defensa y renovación del realismo.

Una vez implementadas las transformaciones en el sistema, la visión idealista o liberal debe revisarse también, de lo contrario quedará fuera de la reflexión teórica. Así, hacia principios de los años 80, identificamos tres propuestas fundamentales para el estudio de lo internacional: neo-realismo, neo-idealismo ó neo-liberalismo y neo-marxismo (Teoría Social Crítica y Sistema Mundial Moderno). Sin embargo, este último quedó de lado en el debate, debido a que se fue transformando en lo que Ole Weaver llama un debate interparadigmático ${ }^{43} \mathrm{O}$ en otros términos, iniciaba el tercer debate, que giraba básicamente en torno a la concepción del Estado, la aparición de otros actores, la anarquía, tan sólo por mencionar algunos temas.

De hecho, lo que sucede en este punto es que después del debate, la llamada neo-neo síntesis, que no es más que la conclusión de que, tanto neo-liberalismo

${ }^{41}$ Robert O. Keohane y Joseph S. Nye, Poder e interdependencia. La política mundial en transición, traducción Herber Cardoso Franco, Grupo Editorial Latinoamericano, Buenos Aires, 1988, p. 15.

${ }^{42}$ Idem., p. 18.

${ }^{43}$ Cfr. Ole Waever, "The rise and fall of the inter-paradigm debate", en Smith, Steve et al. (edits.), International Theory: Positivism and Beyond, Cambridge University Press, 1996, pp. 149-185. 
como neo-realismo, están analizando la misma realidad, pero desde ángulos diferentes. A propósito de lo anterior, David A. Baldwin identifica que existen seis tópicos fundamentales que caracterizan el acercamiento entre ambas teorías, los cuales a continuación se señalan:

1) La naturaleza y consecuencias de la anarquía, siendo los neo-realistas quienes la ven como llevadera más que los neoliberales, debido a los matices que presente el comportamiento del Estado. 2) La cooperación internacional, ambas visiones coinciden en que la cooperación internacional es posible pero difieren en la facilidad y probabilidad de que ésta ocurra. 3) Las ganancias absolutas o relativas. Las primeras son buscadas por el neo-liberalismo y las segundas por el neorealismo. Sin embargo, la discusión lleva a concluir que la división entre ambas es poco clara porque las ganancias relativas se obtienen a través de la negociación y las absolutas en condiciones específicas, lo que dificulta determinar en qué condiciones se obtendrán. 4) La prioridad de las metas del Estado, ambas visiones coinciden en que la seguridad nacional y el bienestar económico son importantes, pero difieren en la jerarquía que ocupan. Los neo-realistas le dan más peso al aspecto político (seguridad), mientras que los neo-liberales se interesan por estudiar la economía política para lograr la cooperación. 5) Los neo-realistas dan mayor énfasis a las capacidades que a las intenciones, mientras que los neo-liberales se inclinan por estas últimas. 6) Los regímenes y las instituciones son dos alternativas para aminorar la anarquía, sólo que los neo-liberales señalan que las instituciones son más significativas para la política mundial debido a que han sido más difundidas; mientras que, los neo-realistas son partidarios del desarrollo de los regímenes porque las instituciones sólo mitigan la anarquía a través de la cooperación interestatal. ${ }^{44}$

Como podemos observar, durante casi toda esta década de los ochenta, el debate entre neo-liberales y neo-realistas fue bastante álgido, sin embargo, la realidad no se detiene y no podía esperar a que estas dos visiones llegaran a conclusiones y acuerdos que le permitieran explicarla. Por ello, durante la Convención de la International Studies Association, Robert O. Keohane, en su carácter de presidente de la misma (1988-1989), afirmó que estaba apareciendo una serie de visiones disidentes a las posturas tradiciones, las cuales podrían ser concentradas bajo el nombre de reflectivistas, dentro de las cuales señaló a autores como: Hayward Alker, Richard Ashley, Friedrich Kratochwil y John Ruggie,

${ }^{44}$ Cfr. David A. Baldwin, "Neoliberalism, Neorealism and World Politics", en Baldwin, David A. (editor), Neorealism and Neoliberalism: The Contemporary Debate, Columbia University Press, New York, 1993, pp. 4-8. 
quienes tenían en común: a) su desconfianza hacia los modelos científicos para el estudio de la política mundial, b) una metodología basada en la interpretación histórica y textual y c) la insistencia en la importancia de la reflexión humana sobre la naturaleza de las instituciones y sobre el carácter de la política mundial. ${ }^{45}$

El reflectivismo entonces abarca las teorías feminista, crítica, posmoderna, normativa, entre otras, que parten de los postulados arriba señalados. Así, se presenta una escisión teórica entre teorías racionalistas (neo-liberalismo y neorealismo, principalmente) y las teorías reflectivistas (antes mencionadas). Situación que da cabida a la aparición del constructivismo social, visión que intenta vincular ambas teorías e introduce el término de agente para sustituir el de actor, preferido por la corriente tradicional, asimismo, dicen que la anarquía no es una realidad pre-existente que se les impone a los Estados sino que es lo que ellos mismos construyen, pues al final las relaciones en la sociedad internacional son construcciones derivadas de las prácticas sociales dentro de ella. ${ }^{46}$

Toda la discusión entre racionalistas y reflectivistas se lleva a cabo durante los años 90 y se prolonga hasta el siglo xxI, pues muchas de las nuevas visiones tenían un desarrollo incipiente, por lo menos en la disciplina de Relaciones Internacionales, y ello las ha obligado a demostrar su capacidad explicativa en el ámbito internacional. Ante este hecho, algunos autores, tradicionalmente, racionalistas han dado su voto de confianza a las novedosas maneras de estudiar el mundo y por supuesto, han logrado más adeptos.

\section{De México y el mundo}

Una vez revisada la evolución de la ciencia y las ciencias sociales en general y de Relaciones Internacionales en particular, vale la pena remitirnos a la forma en que la disciplina fue instaurada en México y el mundo, al crearse espacios dentro de las universidades o nuevas instituciones.

En México, las

${ }^{45}$ Cfr. www.cedep.ifch.ufrgs.br/Textos_Elet/pdf/Salomon.pdf y Steve Smith, "New Approaches to International Theory" en Baylis, John and Smith, Steve (eds.), The Globalization of World Politics. An Introduction to International Relations, Great Britain, Oxford University Press, 1997 y en ediciones más recientes.

${ }^{46}$ Cfr. Alexander Wendt, "Anarchy is What States Make of it: The Social Construction of Power Politics" en James Der Derian (editor), International Theory. Critical Investigations, New York University Press, USA, 1995. 
instituciones estatales y universitarias en el proceso de desarrollo de las ciencias sociales después de la Revolución [tuvieron sin duda un papel fundamental, tal y como se puede observar a continuación]: el Instituto de Arqueología, fundado en 1917 y cuyo primer director fue Manuel Gamio; el Instituto de Investigaciones Sociales de la UNAM, fundado en 1930 durante el periodo de Ignacio García Téllez como rector; El Colegio de México, surgido en 1940 de la iniciativa de Alfonso Reyes y Daniel Cosío Villegas, quienes reunieron a un nutrido grupo de intelectuales republicanos españoles llegados al país durante la Guerra Civil en España; el Instituto Nacional de Antropología e Historia (INAH) y el Instituto Nacional Indigenista (INI), fundados respectivamente en 1939 y 1948 por Alfonso Caso, y el Fondo de Cultura Económica que, bajo la dirección de Daniel Cosío Villegas, publicó importantes traducciones de los autores fundamentales de las ciencias sociales a partir de 1934. José Luis Reyna (2007) se ha referido a este proceso, que se dio de la mano de las grandes agencias estatales, justamente como el de la 'institucionalización de las ciencias sociales'.

La otra parte de este camino recorrido por las ciencias sociales en la primera mitad del siglo xx fue la correspondiente a la profesionalización, es decir, la apropiación -el monopolio, dicen algunos autores (Sciulli, 2005)- de un conjunto de conocimientos y competencias por una comunidad reconocida y claramente identificada respecto a otras. El primer paso se dio con la creación de tres escuelas de estudios superiores: la Escuela Nacional de Economía impulsada en 1935 por Enrique González Aparicio, la Escuela Nacional de Antropología e Historia surgida en 1942 de un acuerdo entre el Instituto Politécnico Nacional y el INAH, y la Escuela Nacional de Ciencias Políticas y Sociales de la UNAM (ENPCS), creada por el rector Luis Garrido a iniciativa de don Lucio Mendieta y Núñez en 1953. Unos años más tarde se fundó la Escuela Superior de Economía en el Instituto Politécnico Nacional (Ludlow, 2003). Con todas ellas se abrió a las nuevas generaciones la posibilidad de realizar una carrera profesional especializada en el estudio de la cultura, la economía, la sociedad y la política. ${ }^{47}$

Es así que, el fin de la Segunda Guerra Mundial marcó grandes transformaciones en la enseñanza de las ciencias sociales y en especial de Relaciones Internacionales, pues en todo el mundo aparecieron diversas instituciones que se enfocaron en la enseñanza o capacitación de sus cuerpos diplomáticos basadas en la disciplina antes mencionada, desde luego, dependiendo del lugar tomaba un nombre distinto pero la esencia era fundamentalmente la misma,

cultivar la ciencia de las relaciones humanas, [...] fomentar la amistad entre los pueblos, promoviendo el mutuo entendimiento. [...] fortaleciendo las instituciones para que no se repitiera una nueva guerra. Con ese motivo la UNESCO preparó, en 1948, las bases para

${ }^{47}$ Cristina Puga, "Ciencias Sociales. Un nuevo momento" en http://www.scielo.org.mx/ scielo.php?pid=S0188-25032009000500005\&script=sci_arttext Consultado 30 de julio de 2012. 
una conferencia internacional que se celebró en septiembre de 1949 y en donde se fundó la Asociación Internacional de Ciencia Política (IPSA). [...] La conferencia buscaba dos objetivos: la promoción de la paz mundial y el fortalecimiento del desarrollo intelectual de la Ciencia Política pues ya desde la preparación del congreso se había planteado la necesidad de que se desarrollaran enfoques, métodos, técnicas y terminología propios. ${ }^{48}$

Como podemos observar, la conferencia del 49, buscaba la consolidación disciplinar de Ciencia Política y en el caso de México, también dio origen a la Escuela Nacional de Ciencias Políticas y Sociales ${ }^{49}$ que abrió sus puertas el 25 de julio de 1951 ofreciendo cuatro carreras: Ciencia Política, Ciencias Sociales, Ciencias Diplomáticas y Periodísmo. Siendo éste el inicio de la carrera de Ciencias Diplomáticas, que inicialmente tenía, dentro de su mapa curricular, múltiples

\section{Imagen 5}

\section{Sede la UNESCO en París}

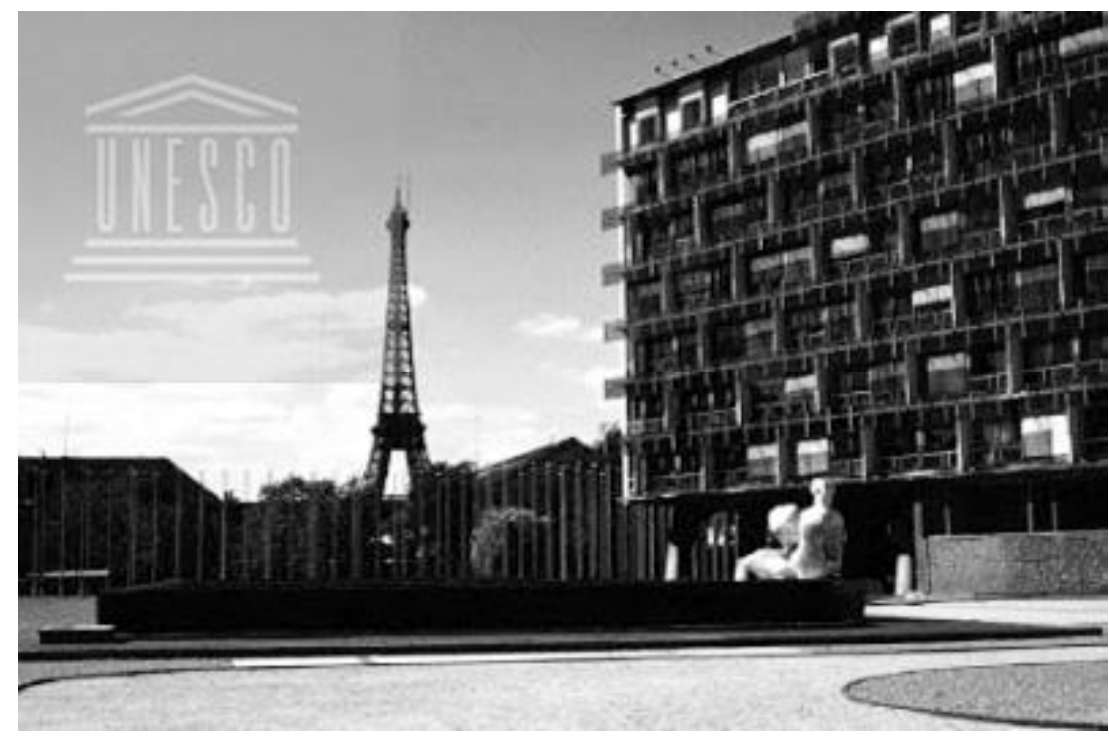

Fuente: http://3.bp.blogspot.com/_e5weBB72AS8/SefestXv2wI/AAAAAAAAArg/ AF_hDNjJLIE/s400/une390-2.jpg

${ }^{48}$ Enrique Suárez-Iñiguez " "La Ciencia Política mexicana y el Centro de Estudios Políticos", en http://www.politicas.unam.mx/carreras/cp/ Consultado el 30 de julio de 2012.

${ }^{49}$ Para lo cual se tomó como modelo la London School of Economics and Political Science, el Institut d'Estudes Politiques de la Universidad de París y la École de Sciences Politiques de la Universidad de Lovaina, siendo esta última la más influyente en todo el proceso. 
materias relacionadas con el Derecho, ${ }^{50}$ pues inicialmente dentro de la Universidad Nacional Autónoma de México, la Facultad de Derecho se encargaba del estudio de las Ciencias Sociales, dotándolas de una perspectiva jurídica.

Después de la Segunda Guerra Mundial y de la conferencia convocada por la UNESCO, diversos países dieron impulso a la formación de instituciones que les permitieran contar con un cuerpo diplomático capacitado, lo cual queda perfectamente demostrado en la cita siguiente de un texto del Instituto Matías Romero de Estudios Diplomáticos de México, donde se hace alusión a diferentes países e instituciones:

El Colegio de Asuntos Exteriores de la República Popular de China (1955) forma, capacita y actualiza a sus servidores públicos del ramo, motivo por lo cual cuenta con una licenciatura y una maestría, además de cursos breves.

En España opera la Escuela Diplomática (1942), administrada por el Ministerio de Asuntos Exteriores y la Universidad Complutense de Madrid. Su objeto es la preparación de los candidatos al servicio que presentan exámenes de oposición. ${ }^{51}$ Su vecina Francia, posee la mejor y más prestigiada institución de formación de servidores públicos del mundo: la Escuela Nacional de Administración (1945), que tiene la peculiaridad de contener, dentro de su programa académico general, un subprograma relativo a los servidores de lo exterior. Los egresados, según su rendimiento escolar, se incorporan a la administración pública y, en su caso, al Ministerio de Asuntos Extranjeros.

Italia, por su parte, cuenta con la Sociedad Italiana para la Organización Internacional (1944) para los graduados universitarios en relaciones internacionales o para quienes están vinculados con las comunidades europeas. Otorga certificados y diplomas a quienes cursan sus programas de preparación y formación en diplomacia.

En Alemania existe el Centro de Formación y Capacitación del Ministerio de Asuntos Exteriores (1950), creado para administrar los procedimientos de selección de los aspirantes al Servicio Exterior, amén de impartir cursos de capacitación respectivos.

\footnotetext{
${ }^{50}$ Se puede revisar el mapa curricular presentado en el capítulo XII. El Instituto Matías Romero de Estudios Diplomáticos, p. 334, en www.bibliojuridica.org/libros/4/1821/23.pdf Consultado el 30 de julio de 2012.

${ }^{51}$ Cabe señalar que en España desde 2011 ya existe un programa de licenciatura en Relaciones Internacionales en la Facultad de Ciencias Políticas y Sociología de la Universidad Complutense de Madrid, creado por la iniciativa del Dr. Rafael Calduch Cervera y un grupo de profesores de esa Facultad y de la Sección Departamental de Derecho Internacional Público y Relaciones Internacionales de la Facultad de Ciencias de la Información.
} 
Finalmente, la Organización de las Naciones Unidas tiene en el Instituto de Capacitación e Investigación (1965) un centro al servicio de las personas provenientes de los países subdesarrollados que se incorporan a ella. Expide certificados a quienes cursas sus programas de capacitación. También cuenta con un programa de investigación sobre sí misma y sus problemas. ${ }^{52}$

Como se presentó en la cita anterior, los Estados tomaron conciencia de la importancia de crear instituciones dedicadas expresamente al estudio de lo social y en particular de lo internacional. En el caso de México, aun cuando existía ya la

\section{Imagen 6}

\section{Sede original del Instituto Matías Romero}

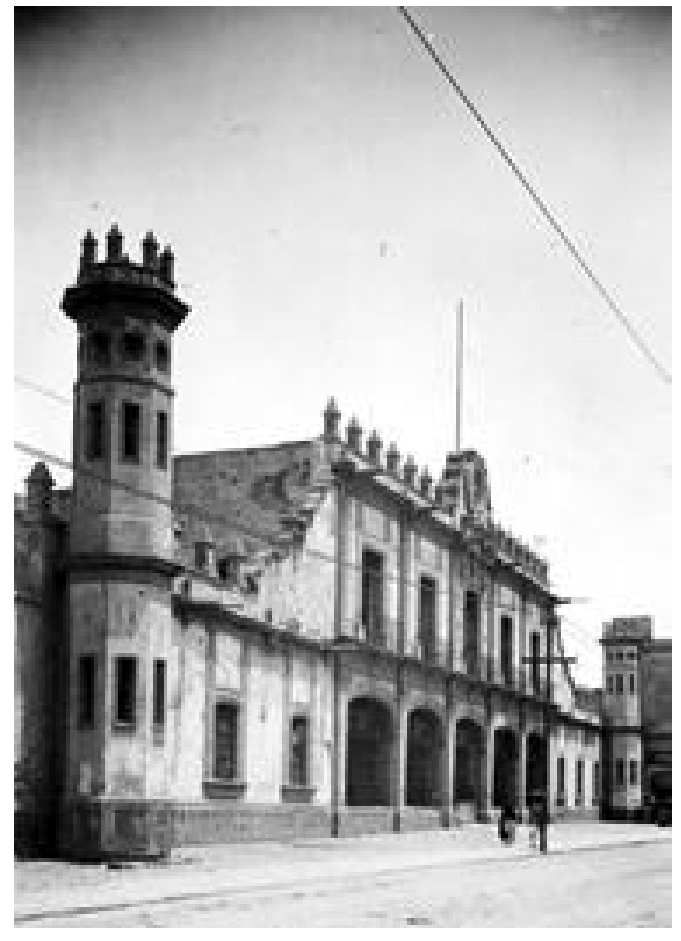

Fuente: http://2.bp.blogspot.com/-Jdo2ZOOoRr0/ Tg4kVLnxPWI/AAAAAAAAZwc/mblTI9vn QTU/s1600/Garita \%2Bde\%2BPeralvillo\% 252C\%2BAduana $\% 2 \mathrm{Bdel} \% 2 \mathrm{BPulque.jpg}$

${ }^{52}$ Capítulo XII, El Instituto Matías Romero de Estudios Diplomáticos, p. 332, en www.bibliojuridica.org/libros/4/1821/23.pdf Consultado 30 de julio de 2012. 
carrera de Ciencias Diplomáticas que posteriormente se transformó en Relaciones Internacionales (1967), ${ }^{53}$ la inclinación por la rama diplomático consular dentro de la misma Universidad (UNAM), era muy escasa, por lo que la formación de especialistas en esta área se dejó de lado para empezar la instrucción en diferentes áreas del quehacer internacional.

Así, mientras la UNAM y otras escuelas de Ciencias Políticas y Sociales en el país continuaban con la enseñanza de las diferentes disciplinas. El 14 de diciembre de 1974 se fundó el Instituto Matías Romero de Estudios Diplomáticos (IMRED) bajo la tutela de la Secretaría de Relaciones Exteriores para formar a sus propios servidores. La formación en el instituto como tal, prepara a los servidores públicos en temas diplomáticos, asuntos consulares y administrativos.

En su origen, el Instituto fue constituido para desempeñar las siguientes obligaciones:

- Capacitar y actualizar a los miembros del Servicio Exterior.

- Fungir como centro de investigación de alto nivel sobre cuestiones internacionales y realizar labores de divulgación referentes a la política exterior, así como de intercambio con organismos, asociaciones e instituciones afines.

- Integrar una biblioteca especializada en temas relativos al derecho internacional, historia diplomática, política internacional y método diplomático.

- Coordinar las labores del laboratorio de idiomas.

- Apoyar a la Comisión Consultiva de Ingreso en la organización y ejecución de los concursos públicos de ingreso al Servicio Exterior. ${ }^{54}$

A últimas fechas, las funciones del instituto se han concentrado sobre el último punto referente a los concursos y a la elaboración de un programa de capacitación para los nuevos miembros. Mientras que, la Facultad de Ciencias Políticas y Sociales de la UNAM, continúa siendo una oferta de gran calidad para los interesados en formarse como expertos en los temas internacionales, ya que cuenta con una amplia oferta educativa a distintos niveles, tales como: licenciatura, maestría y doctorado; hecho que la coloca a la vanguardia frente a otras instituciones nacionales.

${ }^{53}$ A partir de esta fecha se elaboró un nuevo plan de estudios para ofrecer materias más enfocadas a la interdisciplinariedad de Relaciones Internacionales. Posteriormente, el plan de estudios sufrió modificaciones importantes en 1976, 1997 y la más reciente en 2005 con el afán de cubrir las exigencias de un mundo en constante transformación.

${ }^{54}$ Ibid., p. 337. 
UnA MIRADA A LA DISCIPLINA DE RELACIONES InTERNACIONALES

\section{A manera de conclusión}

Definitivamente, para el estudioso de los asuntos internacionales es fundamental acercarse y conocer el desarrollo disciplinar de Relaciones Internacionales porque es a partir de ello que se identifica su origen y vinculación con otras disciplina. Hecho que a lo largo del tiempo la han dotado de un carácter interdisciplinario, que hoy, lejos de poner en tela de juicio su validez y especificidad, le permiten una adaptación natural ante las propuestas interdisciplinarias que se han identificado como el camino a seguir por las Ciencias Sociales.

Por otro lado, el recorrido a lo largo de la historia de la disciplina permite constatar que su desarrollo está íntimamente vinculado con las dos guerras mundiales. La primera marcó su aparición y la segunda su consolidación, evidentemente, no fueron sólo las guerras en sí mismas sino todos los elementos involucrados en el proceso que pusieron de manifiesto la necesidad de contar con una disciplina dedicada a estudiar lo internacional y que, en un primer momento, formara a los cuerpos diplomáticos de los diferentes Estados.

Asimismo, se da cuenta que desde el siglo XIX se hizo patente la urgencia de regular y sistematizar la actuación de los diplomáticos, posteriormente, se hizo indispensable que además de tener conocimientos de lenguas extranjeras, historia, lógica, retórica, etc., el representante del Estado en el exterior fuera parte de un cuerpo diplomático y, de ser posible, tuviera una formación disciplinar vinculada con los temas internacionales, lo que lo investiría de saberes y un lenguaje particular.

A lo largo de este capítulo, se ha observado también la existencia de los paradigmas que han dado origen a diversas teorías, las cuales constituyen hoy el sustento teórico de la disciplina y la posibilidad del debate continuo para generar conocimiento y ofrecer a Relaciones Internacionales muchos más elementos para continuar explicando la dinámica realidad internacional.

\section{Fuentes}

Baldwin, David A., "Neoliberalism, Neorealism and World Politics", en Baldwin, David A. (editor), Neorealism and Neoliberalism: The Contemporary Debate, Columbia University Press, New York, 1993.

Barbé, Esther, Relaciones Internacionales, Edit. Tecnos, Madrid, 1995.

Brett, E. A., Reconstructing Development Theory. International Inequality, Institutional Reform and Social Emancipation, Palgrave Macmillan, Great Britain, 2009. 
Brom. Juan, Esbozo de historia universal, Editorial Grijalbo, México, 1991.

Brown, Chris and Ainley, Kirstein, Understanding International Relations, fourth edition, Palgrave Macmillan, China, 2009.

Cárdenas Elorduy, Emilio, "El camino hacia la teoría de las relaciones internacionales (biografía de una disciplina)", en Revista Mexicana de Ciencias Politicas, FCPyS, UNAM, México, enero-marzo 1971.

Carr, E. H., La crisis de los veinte años (1919-1939), traducción Emma Benzal Alonso (con prólogo de Esther Barbé), Los Libros de la Catarata, Madrid, 2004.

Castro Gómez, Santiago, Freya Schiwy y Catherine Walsh (editores), Interdisciplinar las ciencias sociales. Geopolitica del conocimiento y colonialidad del poder. Perspectiva desde lo andino, Universidad Andina Simón Bolívar, Ediciones AbyaYala, Ecuador, 2002.

Hobbes, Thomas, Leviathan, FCE, México, 2008.

Hoffman, Stanley, "An American Social Science: International Relations" en James Der Derrian (ed.), International Theory. Critical Investigations, New York University Press, New York, 1995.

Keohane, Robert O, y Joseph Nye, Poder interdependencia. La politica mundial en transición, traducción Herber Cardoso Franco, Grupo Editorial Latinoamericano, Buenos Aires, 1988.

López Díaz, Mayra, Aportaciones teóricas de la escuela estadounidense a Relaciones Internacionales, Facultad de Ciencias Políticas y Sociales, UNAM, México, 2010.

Mingst, Karen, Fundamentos de las Relaciones Internacionales, Colección Estudios Internacionales, CIDE, México, 2009.

Morgenthau, Hans J., Politica entre las naciones. La lucha por el poder y la paz, edición revisada por Kenneth W.Thompson, traducción Herber W. Olivera, $2^{\mathrm{a}}$. ed., Grupo Editor Latinoamericano, Argentina, 1986.

Nicolson, Harold, La Diplomacia, $3^{\mathrm{a}}$. ed., traducción Adolfo Álvarez Buylla, Fondo de Cultura Económica, 1994.

Olson, W.C. y A. J. R. Groom, International Relations. Then and Now, Harper Collins, Londres, 1991.

Padilla, Luis Alberto, Teorías de las Relaciones Internacionales. La investigación sobre la pary el conflicto, IRIPAZ, Guatemala, 1992.

Puga, Cristina, "Ciencias Sociales. Un nuevo momento", en http:// www.scielo.org.mx// scielo.php?pid=SO188-25032009000500005\&script =sci_arttext

Smith, James Allen, Intermediarios de ideas. Los "Grupos de Expertos" (think tanks) y el surgimiento de la nueva elite política, traducción Cristina Piña, Grupo Editorial Latinoamericano, Buenos Aires, 1994. 
Smith, Steve, "New Approaches to International Theory" en Baylis, John and Steve Smith (eds.), The Globalization of World Politics. An Introduction to International Relations, Oxford University Press, Great Britain, 1997.

Suárez Iñiguez, Enrique, "La Ciencia Política mexicana y el Centro de Estudios Políticos”, en http://www.politicas.unam.mx/carreras/cp

Truyol y Serra, Antonio. La teoría de las relaciones internacionales como sociología, $2^{\mathrm{a}}$. ed., Alianza Editorial, Madrid, 1973.

Vasquez, John A., El poder de la política del poder, traducción Ana Stellino, Ediciones Gernika S.A., México, 1991.

Wallerstein, Immanuel, La historia de las ciencias sociales, UNAM / Centro de Investigaciones Interdisciplinarias en Ciencias y Humanidades, México, 1997.

Wallerstein, Immanuel (coord.), Abrir las ciencias sociales. Informe de la Comisión Gulbenkian para la reestructuración de las ciencias sociales, Siglo XXI Editores, México, 1999.

Weaver, Ole, "The rise and fall of the inter-paradigm debate", en Smith, Steve, et al. (edits.), International Theory: Positivism and Beyond, Cambridge University Press, 1996.

Wendt, Alexander, "Anarchy is What States Make of it. The Social Construction of Power Politics", en James Der Derian (editor), International Theory. Critical Investigations, New York University Press, USA, 1995. 
110 BLANCA 


\section{LOS PROTAGONISTAS DE LAS RELACIONES INTERNACIONALES}

\section{Ileana Cid Capetillo*}

\section{Introducción}

En la disertación sobre los protagonistas de las relaciones internacionales nos encontramos, de entrada, con una distinción que será importante para dar respuesta a qué entes debemos considerar como tales. De un lado está la aceptación consensuada de que la sociedad internacional ${ }^{1}$ que se constituye como el objeto de estudio de nuestra disciplina es aquélla que se materializó a partir de 1648 y, de otro, la también asunción de que la hoy reconocida Ciencia Social denominada Relaciones Internacionales tiene su formal concreción en 1919. Tenemos, entonces, dos problemas distintos pero necesariamente interrelacionados: uno de carácter ontológico y el otro de naturaleza gnoseológica.

En el primer caso (el ontológico) observamos el desarrollo de una realidad que a lo largo de casi 370 años se ha ido ampliando hasta abarcar la totalidad del mundo y complejizando en sus elementos y en las relaciones que entre ellos se producen pero que, paradójicamente, en su esencia sigue mostrando los rasgos que la definen y que han sido recogidos en la caracterización de un estado "westfaliano" tal y como surgió a raíz de la conclusión de la guerra de 30 años

* Profesora titular de Relaciones Internacionales de la Facultad de Ciencias Políticas y Sociales de la Universidad Nacional Autónoma de México. Doctora en Relaciones Internacionales, Unión Europea y Globalización por la Universidad Complutense de Madrid. Profesora del área de Teoría y Metodología en la misma especialidad. Ha participado en eventos académicos en México y en el extranjero. Tiene publicaciones en revistas especializadas y diversos libros colectivos. Sus libros más recientes son Ileana Cid Capetillo, Beatriz Nadia Pérez R. y Cuauhtémoc V. Pérez Llanas (coordinadores), Las políticas de migración de la Unión Europea, Centro de Estudios Europeos, FCPYS, UNAM, México, 2012. Y Daniel Añorve Añorve, Ileana Cid Capetillo y Ana Teresa Gutiérrez del Cid (coeditores), Los BRICS entre la multiploaridad y la unipolaridad en el siglo XXI, FCPYS, UNAM - Universidad de Guanajuato, México, 2012.

1 “'El adjetivo 'internacional' (que se aplicó por primera vez en el ámbito jurídico) es relativamente moderno: se debe al polifacético filósofo empirista Jeremías Bentham, que en sus Principios de Moral y de Legislación (1780), al referirse al law of nations (equivalente inglés del droit de gens, Völkerrecht o derecho de gentes) sostuvo que sería más correcto denominarlo internacional law, por aplicarse a las relaciones que establecen entre sí los diversos cuerpos políticos”, Antonio Truyol y Serra, La sociedad internacional, Alianza Universidad, Madrid, 1974, p. 18. 
que asoló a Europa entre 1618 y 1648. Es decir que esta sociedad internacional que tantos retos plantea a los estudiosos que se proponen entenderla es fundamentalmente la misma que acompañó a la extensión del capitalismo que desde Europa se expandió (con momentos de avance y otros de aparente retroceso, a veces percibidos por la sociedad como de larga duración pero que en la línea del tiempo de la historia son en realidad apenas pequeñas etapas que, aunque dejan su huella en la composición social, no han logrado producir una desviación definitiva del modelo original, hasta ahora) y continúa haciéndolo demostrando la fuerza de su capacidad de absorción de otras realidades locales o incluso regionales o continentales.

Empíricamente se constata que esta sociedad internacional tiene como elemento definitorio principal el de su naturaleza anárquica puesto que nunca se ha llegado a constituir un poder central que gobierne bajo un único esquema político jurídico a la totalidad que abarca. Es evidente, entonces, que las experiencias supranacionales han sido y son básicamente limitadas tanto en el tiempo como en el espacio. En este sentido, la composición del sistema a raíz de todos los drásticos cambios que se han vivido en las recientes décadas, especialmente por los efectos que la globalización le impone, estaría caracterizada como neo westfaliana pues hablar de una sociedad post westfaliana supondría la superación de su característica principal (la anarquía) que indudablemente pervive hasta la actualidad. ${ }^{2}$

Es, entonces, una sociedad básicamente igualitaria, en la que, bajo supuestos jurídicos, todos sus integrantes, representados en la figura del Estado Nación, tienen la misma composición y naturaleza, con el consabido atributo o atribución de soberanía lo que les impide reconocer a una autoridad superior por encima de ellos. Sin embargo, es evidente que los participantes de la sociedad internacional se escalonan en una estricta jerarquía que se superpone a las atribuciones que les otorga el derecho internacional y ella se deriva del poder que cada uno detenta

\footnotetext{
2 "En síntesis, ni el pacto Briand-Kellog, ni las Naciones Unidas han logrado, hasta la fecha, suprimir la característica específica del sistema internacional que los filósofos y los juristas de siglos anteriores definieron con el término de estado de naturaleza. Este estado se contrapone al estado civil o de sociedad, el cual presupone la presencia de tribunales y policía. La sociedad internacional carece de un equivalente a los tribunales, y si las Naciones Unidas quisiera someter a una de las grandes potencias a su dominio, la acción policial provocaría una gran guerra. Asimismo, la carta de las Naciones Unidas reconoce explícitamente la 'igualdad soberana' de los Estados y los diplomáticos jamás han definido el 'crimen internacional' por excelencia: la agresión.” Raymond Aron, “¿Qué es una teoría de las Relaciones Internacionales?, Revue Francaise de Science Politique, Vol. XVII, núm. 5, octubre de 1967, pp. 837-861, traducción David Sarquís, ITESM, Campus Monterrey, México, primavera de 1998, p. 6.
} 
en relación con los demás.

El carácter hobbesiano de esta sociedad es de naturaleza ontológica pues la anarquía se ha manifestado como producto de la formación de las unidades políticas orgánicamente diferenciadas que en su constitución y reproducción generaron las condiciones para que privara tal anarquía. Es decir que en la formación del Estado Nación la afirmación, defensa y reproducción de sus componentes centrales (gobierno, población y territorio) que entrañan la obligada referencia de la soberanía se reproducen en una relación inversamente proporcional al carácter anárquico de la sociedad internacional: a Estados más sólidos les corresponde necesariamente un entorno político que acentúa su atomización.

En efecto, las sociedades nacionales a lo largo de los recientes cuatro siglos han tenido como preocupación prioritaria la seguridad, el mantenimiento y la consolidación de su propio Estado que, además, se reserva el monopolio del uso legal y legítimo de la violencia.

A partir de 1648, con la paz de Westfalia, se inicia el proceso de internacionalización que va a alcanzar su plena realización a finales del siglo XIX y principios del XX. Se señala 1648 como un parte-aguas histórico, porque marca el nacimiento del Estado-nación como gran y primordial actor de las relaciones internacionales. De acuerdo a Juan Carlos Pereira, esa fecha corresponde también a la formación del primer sistema internacional de la era moderna, cuyos principios básicos eran:

a) El respeto a los límites territoriales de los Estados.

b) La igualdad soberana de los Estados.

c) La no intervención en sus asuntos internos.

d) Los tratados debían ser observados y cumplidos por los Estados (la aplicación del principio pacta sunt servanda).

e) Los conflictos relativos al orden de paz debían ser resueltos por medios pacíficos, especialmente a través de la negociación político-diplomática.

f) El Estado víctima de una violación del orden establecido podía recurrir a la guerra contra el agresor y debería contar con el apoyo de otros Estados.

g) Una guerra iniciada sin causa justa sería contraria a Derecho, por lo que los Estados partes en los tratados de paz deberían hacer frente conjuntamente contra el perturbador del orden establecido. ${ }^{3}$

${ }^{3}$ Juan Carlos Pereira (coord.), Historia de las relaciones internacionales contemporáneas, Ariel Historia, Barcelona, 2001, pp. 40-41. 
Durante los más de 270 años que transcurren entre la formal constitución de la sociedad internacional en 1648 y el nacimiento en 1919 de la disciplina que la tiene como objeto central de estudio, el concierto de las naciones se establece mediante la acción de los Estados que se van incrementando numéricamente al mismo tiempo que, en su figura de Estado Nación, se extienden de sus límites europeos originales para asentarse en América, Asia y África reproduciendo los elementos formales que le son atribuidos desde su constitución inicial. Pero el carácter protagónico central del Estado es desde entonces cuestionado y la fecha de 1919 marca también la conformación de otro actor que desde entonces ha demandado un lugar que en cierta forma le contiende al Estado, sobre todo porque es el que le puede imponer límites a sus excesos como el Leviatán en que se erigió y se colocó por encima de la sociedad en franca autonomía respecto a ella, a pesar de que es la que lo creó para asegurar su pervivencia. La organización internacional como ideal para coadyuvar al sano cauce de los asuntos mundiales tiene en la Sociedad de las Naciones (que originalmente reúne en su seno a 42 países del mundo) su primera expresión que va a ser sucedida en 1945 por la Organización de las Naciones Unidas (que al iniciar la segunda década del siglo xxi tiene 193 miembros). Tenemos así disciplinarmente el debate por el reconocimiento de cuál de los dos actores (el Estado y la organización internacional) debe ser considerado como el prioritario.

El idealismo que acompaña al nacimiento de Relaciones Internacionales con una visión juridicista y, por lo tanto normativa, arraigada en el "deber ser", se inclina por la aceptación de la organización internacional y pugna por la necesidad de contribuir a su fortalecimiento para asegurar el cauce pacífico de los asuntos mundiales y como la única posibilidad de limitar las condiciones que facilitan el advenimiento de las guerras. El realismo político, en cambio, a raíz del primer gran debate que se suscita en la disciplina en medio de la segunda guerra mundial y que impone su visión al concluir ésta subraya los límites del idealismo manifiestos en la crisis de 1929-1933, la extensión de las políticas agresivas y expansionistas de las grandes potencias y, principalmente, el estallido de la segunda gran conflagración que involucra a la gran mayoría de los países, todo lo cual le permite sustentar que las relaciones internacionales son básicamente relaciones de lucha por el poder.

A lo largo del siglo XX la disciplina se desarrolló vigorosamente, en cabal correspondencia con la maduración y complejización de la sociedad internacional que se amplía extensivamente y se profundiza intensivamente -en una evolución horizontal y vertical-, de tal manera que produjo una multiplicidad de teorías, corrientes analíticas y propuestas conceptuales que pueden desconcertar al 
estudiante lego de la disciplina pero que realmente se aglutinan en dos grandes visiones: la positivista y la no positivista. El main stream que se arraiga decididamente en la academia anglo sajona, ${ }^{4}$ con un eje indiscutible en las universidades y centros de estudio de Estados Unidos se alinea definitivamente en la primera visión con una orientación típicamente funcionalista. Así, desde la década de los cuarenta se impone el predominio del realismo que con la revolución cientificista en la década de los sesenta y setenta se ve enriquecido con las propuestas de la teoría de los juegos, la toma de decisiones, la teoría de los sistemas, la negociación internacional, la teoría del conflicto, las investigaciones para la paz y muchas otras que no atentan contra la esencia del realismo pero que señalan las anomalías científicas y, por lo tanto, hacen invaluables aportaciones de carácter metodológico que rescatan del positivismo en su preocupación por alcanzar la consolidación de la disciplina con sustento en la aplicación del método científico. Entre las visiones no positivistas avanzan de manera muy sólida la teoría de la dependencia y la teoría del imperialismo que son las únicas que efectivamente cuestionan la visión positivista al partir de una concepción opuesta del mundo. Los principales señalamientos que se hacen desde esta perspectiva para entender las leyes y desarrollo de la sociedad internacional son atendidos por dos autores ${ }^{5}$ que hacen un esfuerzo por superar las anomalías del realismo político y que plantean la teoría de la interdependencia compleja que posibilita la rearticulación del paradigma estatocéntrico.

${ }^{4}$ No se incluyen aquí (pocos estudiosos lo hacen, precisamente por el predominio que tiene la academia estadounidense) el importante desarrollo de la Sociología Histórica que se arraiga preferentemente en Europa, con la notable excepción de Stanley Hoffman quien fue discípulo de Raymond Aron y logra introducir y dar a conocer el pensamiento de éste en Estados Unidos. Véase Raymond Aron. "Conflicto y guerra desde el punto de vista de la sociología histórica" en Stanley Hoffman, comp., Teorías contemporáneas sobre Relaciones Internacionales, traducción M. D. López Martínez, Edit. Tecnos, Madrid, 1963, pp. 239-256. Hay, sin embargo, una larga lista de autores que ofrecen diferentes perspectivas desde la Sociología Histórica, empezando con el trabajo pionero, publicado en Inglaterra en 1941, de Georg Schwarzenberger, La política del poder, traducción Julieta Campos y Enrique González Pedrero, Fondo de Cultura Económica, México, 1960. Otros autores importantes son Marcel Merle, Sociología de las relaciones internacionales, traducción Roberto Mesa, Alianza Universidad, Madrid, 1986. En España varios autores destacados incluyen a Rafael Calduch Cervera, Relaciones Internacionales, Ediciones Ciencias Sociales, Madrid, 1991, quien explícitamente señala: "La forma de razonamiento que resulta imprescindible para el internacionalista consiste en el pensamiento dialéctico. El modelo metodológico [...] lo aporta la sociología histórica."

${ }^{5}$ Robert O. Keohane y Joseph S. Nye, Poder e interdependencia. La politica mundial en transición, traducción Herber Cardoso Franco, Grupo Editor Latinoamericano, Buenos Aires, 1988, 305 pp. 


\section{Ileana Cid Capetillo}

A esta recomposición del realismo político en la teoría de la interdependencia le corresponden una serie de cambios en la sociedad internacional que van a desembocar en el proceso de globalización que hoy caracteriza a la etapa actual del desarrollo del capitalismo y que ha sido acompañado de una multiplicidad de explicaciones sobre lo internacional.

Sin pretender en ningún sentido citar la totalidad de las teorías internacionales emanadas a partir [de la última década del siglo xx], las más importantes han sido las siguientes: desde la perspectiva positivista se encuentran el conductismo (behaviorismo), funcionalismo, la teoría sistémica, regímenes internacionales, neorrealismo, materialismo histórico, neoliberalismo institucional, etc., mientras que desde la visión post-positivista se incluye el neomarxismo, feminismo, constructivismo y postmodernismo. ${ }^{6}$

Como ya he señalado en otro lugar, la distinción entre las distintas propuestas analíticas se encuentra en la manera que dan respuesta a las preguntas centrales de nuestro objeto de conocimiento, puesto que

En la base de toda construcción teórica de Relaciones Internacionales hay implícita o explícitamente un punto de partida originado por tres cuestionamientos centrales: ¿quiénes hacen las relaciones internacionales?, ¿qué tipo de relaciones establecen? y ¿̇en qué espacios estructurales interactúan? La primera se refiere a los protagonistas o entes que promueven las relaciones internacionales; la segunda busca identificar los nexos societales que establecen entre sí y la tercera da cuenta de los ámbitos en los que los protagonistas se interrelacionan.

Haciendo una revisión de las corrientes de pensamiento que han influido en nuestra disciplina, la respuesta a la segunda pregunta se ha abordado solamente mediante uno de tres concepto generalmente aceptados: los actores, los sujetos o los agentes internacionales. Desde nuestra apreciación apuntamos que, sin embargo, a estos conceptos no se les ha definido explícitamente su intensión (la definición del objeto y el señalamiento de los elementos que lo caracterizan como único y que lo distinguen de otros que pudieran parecérsele) y que más bien las

${ }^{6}$ Juan Pablo Prado Lallande, “Teorías positivistas y críticas de las Relaciones Internacionales: Realismo y Constructivismo en la Cooperación Internacional” en Paulino Ernesto Arellanes Jiménez, Teorías de Relaciones Internacionales y Aplicación Práctica, Tomo II, Benemérita Universidad Autónoma de Puebla, México, 2009, p. 32.

${ }^{7}$ Ileana Cid Capetillo, "La discusión sobre los actores en el escenario internacional" en Política y Cultura, núm. 10, Universidad Autónoma Metropolitana-Xochimilco, México, verano de 1998, pp. 47-60. 
teorías se han abocado a enlistar aquellos entes o protagonistas que son reconocidos como participantes en la sociedad internacional, es decir que solamente se plantea de manera reiterada la extensión del concepto.

\section{Conceptos: actor, sujeto, agente}

El estudio de las relaciones internacionales suele hacerse en uno u otro de dos niveles: el del sistema internacional y el de las unidades que lo componen. Cada uno de ellos plantea sus propias dificultades pero aquí sólo nos limitaremos a intentar una explicación sobre cómo se han entendido esas unidades y de qué manera se les ha conceptualizado. Es importante dejar clara la idea de que a pesar de que en todos los casos estamos hablando de los protagonistas que participan en las relaciones internacionales, el background teórico analítico ha conducido a los estudiosos a percibirlos de diferente manera. De ahí las distintas denominaciones que reciben según cada corriente. Vale la pena advertir aquí que el uso indistinto de estos conceptos como si se tratara de sinónimos sí conduce al eclecticismo en virtud de que se arraigan en visiones del mundo diferentes e incluso opuestas y que al vincularse con todo el corpus conceptual adquieren una

\section{Tabla 1}

Actor, sujeto, agente

\begin{tabular}{|l|l|l|l|l|}
\hline Concepto & \multicolumn{1}{|c|}{ Espacio } & \multicolumn{1}{|c|}{$\begin{array}{c}\text { Corriente de } \\
\text { estudio }\end{array}$} & \multicolumn{1}{|c|}{ Visión } & \multicolumn{1}{|c|}{$\begin{array}{l}\text { Supuestos } \\
\text { principales }\end{array}$} \\
\hline Actor & $\begin{array}{l}\text { Sociedad } \\
\text { Sistema }\end{array}$ & $\begin{array}{l}\text { Idealismo } \\
\text { Realismo } \\
\text { Interdependencia } \\
\text { Neos }\end{array}$ & $\begin{array}{l}\text { Positivismo } \\
\text { Funcionalismo }\end{array}$ & $\begin{array}{l}\text { Unitario } \\
\text { Racional } \\
\text { Individual }\end{array}$ \\
\hline Sujeto & $\begin{array}{l}\text { Formación } \\
\text { económico } \\
\text { social } \\
\text { Sistema } \\
\text { Mundo }\end{array}$ & Marxismo & $\begin{array}{l}\text { Materialismo } \\
\text { histórico } \\
\text { dialéctico }\end{array}$ & $\begin{array}{l}\text { Colectivo } \\
\text { Referencia } \\
\text { de clase }\end{array}$ \\
\hline Agente & $\begin{array}{l}\text { Sistema } \\
\text { internacional }\end{array}$ & Constructivismo & Eclecticismo & $\begin{array}{l}\text { Ejerce una } \\
\text { agencia }\end{array}$ \\
\hline
\end{tabular}

Fuente: elaboración propia. 


\section{Ileana Cid Capetillo}

lógica particular con consecuencias analíticas para la explicación de la totalidad de las relaciones internacionales.

Como ya hemos señalado reiteradamente, ${ }^{8}$ el concepto de actor se deriva directamente de la ciencia de la Sociología en donde el predominio de las corrientes funcionalistas ${ }^{9}$ lo ha impuesto a tal grado que prácticamente se le da por común y acríticamente aceptado y ha pasado a ocupar un lugar indiscutido tanto en el discurso académico como en el lenguaje cotidiano. En realidad este concepto se define en relación con otros ${ }^{10}$ que permiten identificar la extensión del mismo y que son: el papel (rol) que desempeñan a partir del status que ocupan dentro del grupo social al que pertenecen en el escenario en que existen y participan, de acuerdo a una relación funcional pues en caso contrario provocan una anomia que origina una disfunción que rompe el equilibrio de la sociedad y que debe ser corregida. La concepción que priva en esta propuesta es de carácter atomista pues se considera al individuo como la unidad última del conjunto.

Dentro del análisis de las relaciones internacionales se han adoptado las propuestas de los principales teóricos de la Sociología como Max Weber, Emile Durkheim y Talcott Parsons, entre otros, aunque generalmente no se hace referencia explícita a sus obras, de las cuales emanan las ideas centrales. Los autores de nuestra disciplina que aluden al concepto de actor de relaciones internacionales tienden a concentrarse en el señalamiento de quiénes consideran que deben ser reconocidos como actores más que en explicar por qué deben ser considerados como tales. La excepción la encontramos en Rafael Calduch, quien nos indica que debemos considerar como tales "a aquéllos grupos que gozan de una capacidad efectiva para generar y/o participar en unas relaciones internacionales con otros grupos que pertenecen a la misma sociedad internacional," al mismo tiempo que "la capacidad de generar o participar en

\footnotetext{
${ }^{8}$ Ileana Cid Capetillo y Pedro González Olvera. "Los sujetos de las relaciones internacionales", en Relaciones Internacionales, núms. 33-34, UNAM, Facultad de Ciencias Políticas y Sociales, Centro de Relaciones Internacionales, México, julio-diciembre de 1984, pp. 127-130. Así como, Ileana Cid Capetillo, "La discusión sobre los actores en el escenario internacional" en Politica y Cultura, núm. 10, Universidad Autónoma Metropolitana-Xochimilco, México, verano de 1998, pp. 47-60.

${ }^{9}$ Rafael Calduch Cervera, Relaciones Internacionales, Ediciones Ciencias Sociales, Madrid, 1991, p. 105.

${ }^{10} \mathrm{Al}$ estudiante que se inicia en el estudio de esta materia, siempre le resulta curioso, por decir lo menos, que el lenguaje utilizado provenga de las artes escénicas. Como en el teatro, el actor actúa (plays) un papel (rol) que le es asignado para representarlo en el escenario (stage), la actuación (performance) del actor -valga la redundancia- es calificada según la manera en que se despliega, según se produzca más o menos apegada al papel asignado.
} 
relaciones que son internacionalmente significativas". ${ }^{11}$ De entrada, cabe señalar, como ya lo hicimos en otro lugar,

que los actores internacionales son aquellos grupos de poder público (estatal) o privado, cuyas acciones tienen repercusiones económicas, políticas, sociales o culturales a nivel internacional y que tienen como condición el reconocimiento de otros actores tanto en lo referente a su naturaleza, como a su capacidad de acción y a su influencia. Para considerarse como tales, deben contar con capacidad de tomar decisiones que comprometan a otros grupos sociales, económicos o políticos y que incidan tanto dentro como fuera de su propia organización. ${ }^{12}$

Tradicionalmente, las relaciones que se pueden estimar como significativas en el nivel internacional están vinculadas con los problemas de la guerra y la paz, que marcan la ecuación básica en nuestra disciplina, en la cual el orden de los factores sí altera el producto: los realistas privilegian el análisis de la guerra mientras que los idealistas dan énfasis a la desiderata de la paz. Por lo tanto, para los primeros, el actor primario de las relaciones internacionales es el Estado que actúa con base en su interés nacional y participa en la lucha por el poder, mientras que los idealistas aspiran a la edificación de organismos internacionales que impongan límites al egoísmo del Estado y contribuyan a la generación de condiciones que limiten las causas del conflicto.

En las corrientes teóricas que revisan el realismo y el idealismo clásicos, sobre todo a raíz de que se perciben cambios importantes en las relaciones internacionales desde la década de los setenta del siglo XX, se reconoce el protagonismo que empiezan a tener otros "actores", la mayor parte de ellos de naturaleza privada, es decir no necesariamente gubernamentales. Se incluyen, así a las empresas transnacionales y a las organizaciones internacionales no gubernamentales (ONG), entre otros señalados de manera más efímera o menos consistente, pero que incluso se van personificando como alguna de estas categorías. A partir de entonces, la literatura empezará a hablar de ellos como "nuevos" actores de las relaciones internacionales aunque realmente no aparecieron por generación espontánea, ya existían, lo novedoso es que su protagonismo se hace más consistente, más visible, debido a que van adquiriendo fuerza y multiplicando su número.

En este orden de ideas, tenemos una distinción primaria entre actores públicos y actores privados. Los unos están representados por los estados y las organizaciones internacionales

${ }^{11}$ Idem., pp. $105-106$.

${ }^{12}$ Cid Capetillo, "La discusión sobre...", op. cit. 
gubernamentales y los otros por las empresas transnacionales, las organizaciones internacionales no gubernamentales, las asociaciones políticas, religiosas, culturales o sociales. A aquéllos les corresponde la personificación de la sociedad política y a éstos la de la sociedad civil. ${ }^{13}$

El concepto de sujeto de relaciones internacionales se deriva del propuesto en el materialismo histórico dialéctico a partir de la noción de sujeto de la historia, siendo el hombre como ser social, es decir inserto en la estructura de clases de cada sociedad particular, el que por medio de la praxis tiene la capacidad de incidir en su conglomerado social al mismo tiempo en que es determinado por las relaciones vigentes en ella. Se trata de una relación dialéctica de múltiples determinaciones, en la cual la realidad social está caracterizada por la lucha que sostienen las clases sociales dominantes y dominadas entre sí y que en última instancia se constituye en el "motor de la historia" en donde las condiciones de carácter económico (la propiedad de los medios de producción y el desarrollo de las fuerzas productivas) determinan en última instancia la forma de organización política (la superestructura) y, por lo tanto, con base en ella se construye el Estado. En la época de la modernidad representado por el Estado Nación capitalista que es la forma que pervive hasta la época actual. En este sentido, los actores primarios serían las clases sociales y el Estado sería un producto de ellas y, por lo tanto, un actor secundario.

Para ubicarnos en el nivel internacional podemos decir que indudablemente el protagonismo del Estado es incuestionable e incluso podemos aceptar que hay otros sujetos que realmente despliegan un protagonismo visiblemente amplio pero esta visión del mundo nos obligaría a no perder de vista que los intereses que los mueven son aquellos de las clases sociales, a las cuales representan (en última instancia).

Para identificar a los sujetos de las relaciones internacionales es conveniente recordar la lista de características que nos permiten seleccionar aquellos que realmente pueden ser reconocidos como tales respecto de otros que tienen una escasa posibilidad de "incidir de manera eficiente en la sociedad internacional":

1. Dentro de la totalidad en que se inscriben, se encuentran jerarquizados según el lugar que ocupan.

2. Mediante su praxis logran trascender los límites de la formación económico social local o nacional.

3. Tienen la capacidad de participar organizadamente en la vida económica y

${ }^{13}$ Idem. 
en los procesos jurídico-políticos e ideológicos de la sociedad (en general).

4. En su praxis social implementan y utilizan diferentes mecanismos para hacer prevalecer sus intereses.

5. Tienen una acción continua y prolongada en el desarrollo histórico.

6. Desarrollan nuevas actividades que se agregan a las primarias y que imponen una práctica novedosa. ${ }^{14}$

Por último, consideraremos a los agentes en la interpretación que sobre los protagonistas de relaciones internacionales ofrece el constructivismo al que incluimos aquí a pesar de que "no es una teoría sustantiva de RI, [sino que] se trata más bien de un marco analítico para estudiar la política mundial". ${ }^{15}$ Desde ahora anotamos que hemos clasificado esta corriente de pensamiento como ecléctica pues explícitamente afirma que deriva de las aportaciones del "trabajo de pensadores como Emile Durkheim, Jürgen Habermas, Karl Marx, Max Weber y Ludwig Wittgenstein", 16 lo cual resulta sorprendente pues todos ellos tenían concepciones del mundo distintas e incluso contrapuestas y porque los cuerpos analítico conceptuales que elaboraron son francamente incompatibles.

Sin embargo, al tratar de hacer un conceso, la perspectiva constructivista parte de la idea de que la anarquía es el elemento clave para entender por qué las relaciones en el medio internacional son conflictivas y de poder, y es que a falta de un ente regulador de las relaciones internacionales, los agentes actúan creando construcciones sociales a partir de las cuales las identidades y los intereses se modifica.

Los constructivistas relacionan el concepto de agente con el Estado, pues aun cuando la creación de éste ha sido fuertemente cuestionada por ellos, en el ámbito internacional es el que se encarga, junto con las instituciones, de las interacciones entre los participantes de la anarquía.

\section{Debates sobre actores tradicionales, nuevos y emergentes}

La denominación de "nuevos actores" quizá no es la más apropiada puesto que todos ellos tienen una larga historia que algunos autores rastrean incluso a etapas

${ }^{14}$ Cid Capetillo y González Olvera, op. cit., p. 130.

${ }^{15}$ Arturo Santa Cruz (Ed.), El constructivismo y las relaciones internacionales, Centro de Investigación y Docencia Económicas, México, 2009, p. 10.

${ }^{16}$ Idem., p. 9. 


\section{Ileana Cid Capetillo}

anteriores a la contemporánea pero al utilizarla se hace referencia al destacado protagonismo que han adquirido en la actualidad y que ha conducido a muchos analistas y observadores a sugerir que incluso compiten con las actividades del Estado. Por tal motivo puede ser más apropiado referirnos a ellos como actores no estatales o privados.

En la red de protagonistas que hoy despliegan su acción en la escena internacional encontramos un número creciente de órganos, organismos, grupos o asociaciones que tienen una ocupadísima agenda de reuniones a lo largo del año, en las que se discuten desde los temas más acuciantes de la sociedad internacional hasta otros de aparente menor importancia pero que deben ser concertados por las partes interesadas. Nos estamos refiriendo a formas de organización intergubernamental como el G20, el G8 o las conferencias que se articulan fuera del esquema de la ONU y que en una primera aproximación pueden ser percibidas como "nuevos actores internacionales" pero que en realidad no deben ser, en un sentido estricto, considerados así pues son foros deliberativos sin capacidad para tomar decisiones vinculantes para sus integrantes, carecen de una estructura formal y su composición numérica es reducida en relación a la totalidad de la sociedad internacional y cambia de acuerdo a distintas condiciones que prevalecen en cada momento [por ejemplo, en la reunión Cumbre del G20 en Los Cabos, México participaron alrededor de 24 países].

Se trata, entonces de escenarios (para seguir con el lenguaje teatral) en los que del elenco de actores internacionales se convoca a una lista conveniente de acuerdo al montaje que se programe. Pero los actores son y siguen siendo los Estados a través de su representación en los gobiernos, materialmente personificados en los gobernantes (jefes de Estado y de gobierno).

Las instituciones intergubernamentales, tanto los organismos internacionales como los procesos de institucionalizaciones regionales y mundiales, pueden ser agrupadas en otro eje de análisis, pero no visualizadas como actores similares.

Se derivan directamente del Estado y contribuyen a la organización de la política internacional, pero no son sus responsables directas. ${ }^{17}$

Evidentemente, esta conclusión no es aceptada por todos los estudiosos de las relaciones internacionales. Una visión distinta a la expuesta considera que:

\footnotetext{
${ }^{17}$ Alfonso Sánchez Mugica, "El teatro sin autor. La actualidad de la perspectiva teórica de los actores" en Paulino Arellanes Jiménez (coord.), Escenarios, actores y conflictos internacionales, Grupo Editorial Patria, México, 2008, p. 88.
} 
La celeridad e intensidad de los cambios derivados del proceso de globalización, así como la multiplicidad de actores y foros de negociación simultáneos, han introducido transformaciones profundas en la orientación, en el diseño y en la instrumentación de las relaciones internacionales en el momento actual que impedirían una visión tan restrictiva de los actores en el ámbito internacional. ${ }^{18}$

En este sentido, es conveniente dejar abierta la discusión y, en todo caso, que sea el estudioso quien defina su propia perspectiva para lo cual será interesante observar la manera cómo evolucionan estos foros.

\section{Actores tradicionales. El Estado}

A lo largo de la pervivencia del sistema internacional correspondiente al desarrollo del capitalismo y de la modernidad, todavía no acabada, es comúnmente aceptado que el actor primordial, el más relevante por su acción y capacidades, es el Estado (en su formato de Estado-Nación), debido, principalmente, a la presencia de la anarquía que se constituye como el determinante central de ese sistema. A pesar de los importantes cambios que se han suscitado desde la constitución del sistema de Westfalia, es evidente que no han sido suficientes para transformarlo en uno nuevo, distinto, con leyes de funcionamiento opuestas a las que a pesar de todo siguen en vigor. Nos encontramos, entonces todavía inmersos en un contexto en donde sigue privando básicamente la explicación que Thomas Hobbes ${ }^{19}$ planteó visionariamente desde que se empezaba a conformar: una sociedad (de ninguna manera una comunidad), ${ }^{20}$ que está históricamente marcada por la lucha por el poder, en la cual se impone por la fuerza la parte que lo concentra y que, por lo tanto, está caracterizada por el egoísmo (no otra cosa es el self help o autoayuda que proclaman los realistas).

\footnotetext{
${ }^{18}$ Gustavo Palomares Lerma, "Actor internacional/ International Actor/ Acteur International, en Juan Carlos Pereira (coord.), Diccionario de Relaciones Internacionales y Politica Exterior, Ed. ArielMinisterio de Defensa, Madrid, 2008, p. 4.

${ }^{19}$ Thomas Hobbes, Leviatan, FCE, México, 2008, 618 pp.

${ }^{20}$ La distinción entre comunidad (Gemeinschaft) y sociedad (Gesellschaft) fue planteada originalmente por Fernand Tönnies. Para el sociólogo alemán, la diferencia dependía del grado de cohesión y cooperación que se alcanzara en cada una. "La sociedad internacional, desde estas aproximaciones, sería una sociedad y no una 'comunidad', y dependería de la cooperación limitada y condicional de sus miembros, cuya primera fidelidad es a las partes constituyentes y no al proyecto global.”, Palomares Lerma, op. cit., p. 5.
} 
Esta sociedad se constituye a partir de que el hombre supera el "estado de naturaleza" que caracterizaba a la sociedad primitiva, buscando una forma de organización que le garantizara las condiciones de vida, principalmente su seguridad y su supervivencia. A lo largo de la historia de la humanidad, las sociedades se han dado distintas formas de organización política en las que se nota una tendencia a su ampliación y extensión: de la familia se pasa al clan, de ahí a la tribu, al Estado esclavista, al Estado feudal, ${ }^{21}$ hasta, finalmente, constituir el Estado Nación. ${ }^{22}$ La posibilidad de que aparezcan en un sentido completo las relaciones internacionales se produce por la confluencia de distintos factores como son el desarrollo del capitalismo, la modernidad, la ampliación del mundo a todos sus confines por el "descubrimiento" y la colonización de territorios extraeuropeos, así como la acción de una clase social protegida por un Estado que garantiza la consecución de sus intereses (de ambos).

Como otras formas de organización política, los referentes que componen el Estado Nación están constituidos por un gobierno, un territorio y una población. Como afirma Jacques Huntzinger:

Bajo múltiples facetas, el Estado existe desde la sedentarización de los grupos sociales, en tanto que establecen un poder político bajo una población al interior de un territorio dado. Los tres elementos que constituyen, tanto a los ojos de los juristas como a los de los sociólogos, los criterios constitutivos del Estado son: el príncipe, el territorio y la población. Estos tres elementos constitutivos del Estado se van a encontrar juntos en las ciudades, los principados y las monarquías, así como en los estados modernos y contemporáneos. Desde que la humanidad se organiza en sociedades distintas, establece a los estados. Pero, en el curso de la historia, el carácter de cada uno de los elementos constitutivos y sus combinaciones son muy variados. ${ }^{23}$

Sin embargo el protagonismo del Estado Nación ha sido cambiante, según lo exija la economía capitalista: casi de acuerdo a la teoría del péndulo, se transcurre

${ }^{21} \mathrm{O}$, en las sociedades no originalmente occidentales como las americanas y las asiáticas a otras formas de Estado propias de lo que el marxismo denominó "el modo de producción asiático".

${ }^{22}$ Para una explicación más concisa, ver en este mismo libro el capítulo de David J. Sarquís, "Desarrollo de la sociedad internacional. Objeto material", y de manera más amplia: David J. Sarquís Ramírez, La dimensión histórica de las relaciones internacionales, Grial Selections, México, 2012, 508 pp.

${ }^{23}$ Jacques Huntzinger, “L'Universalization de l'Etat Nation” en Ileana Cid Capetillo, compiladora, Lecturas básicas para introducción al estudio de las relaciones internacionales, FCPYS, UNAM, México, 1999, traducción libre. 
de una etapa de menor intervención estatal y mayor libertad de las fuerzas del mercado (liberalismo), tal como lo planteara Adam Smith, a otra caracterizada por un Estado fuerte e intervencionista para controlar los excesos del mercado (intervencionismo), de acuerdo a lo resumido por John M. Keynes, cuyo tránsito se produce cuando las condiciones del modelo se agotan y se pasa a una etapa superior (neoliberalismo o neokeynesianismo) que parece reproducir el modelo original pero que siempre contiene elementos originales que lo hacen parecer "lo mismo pero diferente".

La novedad en la forma moderna del Estado es otorgada por la soberanía, de ahí que la cualidad de la sociedad internacional es que está integrada por Estados soberanos, con igualdad jurídica y, por lo tanto, cimentado en el principio jurídico según el cual cada uno de ellos ejerce el control absoluto en su interior, mismo que no puede ser violentado por injerencias externas. ${ }^{24}$

Entre las atribuciones del Estado, coincidimos con Raymond Aron en que la más relevante es que posee el monopolio legal y legítimo de la violencia pues de otra manera no podría garantizar su soberanía y la seguridad del conglomerado al que representa. He aquí la diferencia entre el poder que ejerce al interior de su sociedad y aquél con el que se enfrenta en el ámbito externo. En vista de que la soberanía del Estado supone que no puede reconocer un poder superior por encima de él mismo, en las relaciones internacionales cada Estado se ve compelido a recurrir a la fuerza frente a sus pares en caso de percibir una amenaza o ser agredido de alguna forma. Así, nos dice Aron:

He elegido, según dije, en Pazy Guerra entre las Naciones, el otro aspecto de la alternativa. He buscado aquello que constituye la especificidad de las relaciones internacionales o interestatales y he creído encontrar ese rasgo específico en la legitimidad y la legalidad del recurso a la fuerza armada por parte de los actores. Entre las civilizaciones más desarrolladas, las relaciones internacionales son las únicas entre el cúmulo de relaciones sociales que admiten la violencia como algo normal [incluso permitido, aunque siempre bajo las condiciones que impone el Derecho Internacional en los rubros del Derecho de Guerra -jus belli y jus ad bellum]. ${ }^{25}$

\footnotetext{
${ }^{24}$ La sociedad internacional ya reconoce como inviolables los principios de autodeterminación de los pueblos [de tal manera que sólo ellos deciden la forma de organización política de acuerdo a su naturaleza e intereses]; la no intromisión en los asuntos internos [el Derecho Internacional se ha visto obligado a implementar políticas ad hoc para intervenir cuando por "razones humanitarias" la comunidad mundial busca proteger a sociedades amenazadas por conflictos internos]; la solución pacífica de las controversias, etc., que tienen como objetivo facilitar la convivencia entre naciones.

${ }^{25}$ Aron, “¿Qué es una teoría...”, op. cit., p. 5, corchetes añadidos.
} 
Debemos subrayar otras atribuciones del Estado que nos permiten fundamentar la idea de que su papel como actor internacional de ninguna manera puede ser competido por ninguno otro de los que son actualmente incluidos en las listas sugeridas en la literatura actual de Relaciones Internacionales. Entre dichas atribuciones están:

- La capacidad exclusiva de declarar la guerra y concertar la paz.

- La facultad de suscribir tratados con sus pares, mediante los cuales se compromete al conjunto de la sociedad y sus órganos de gobierno.

- La competencia para emitir moneda de curso legal.

- El cobro de impuestos con la finalidad de cubrir los gastos de administración gubernamental, la inversión social y, en última instancia, la procuración en la distribución de la riqueza.

- La autoridad para hacer cumplir la ley, impartir justicia y sancionar su transgresión.

- La posibilidad de participar en formas de organización internacional, incluso aquellas que puedan pretender la promoción de alguna forma de "supranacionalidad", lo cual necesariamente deriva del carácter soberano del Estado que tiene la potestad de ingresar por su propia voluntad y retirarse cuando considera que las condiciones ya no son las adecuadas a sus intereses o cuando las circunstancias cambian (Rebus sic stantibus).

Para abundar más y en la defensa de esta idea, autores como Oran Young, tomando en consideración nociones como soberanía y territorialidad, como atributos principales del Estado, sostienen que :

1) la propia noción de la política internacional supone el postulado del Estado nación como la unidad fundamental de las relaciones internacionales; 2) el Estado ha sido la máxima referencia de las lealtades humanas históricamente; 3 ) el derecho internacional considera al Estado como el principal sujeto de la normatividad jurídico-internacional en base a su entidad soberana; 4) el carácter de los miembros de las organizaciones internacionales está reservado a los Estados; 5) el Estado ha adquirido mayor legitimidad a causa del proceso descolonizador en África y Asia. ${ }^{26}$

Jacques Huntzinger explica la manera como desde su aparición, el Estado, como forma de organización política, se ha extendido por todo el mundo y cuando

${ }^{26}$ Citado en Celestino del Arenal, Introducción a las relaciones internacionales, México, Rei, 1996, p. 325. 
se produce el surgimiento de uno nuevo por un proceso de independencia de un territorio o de secesión de otro mayor, no se opta por una forma distinta sino que adopta la que se ha impuesto consuetudinariamente en la sociedad internacional. Esto puede tener una explicación en el hecho de que la lógica de las relaciones internacionales implica necesariamente la interacción entre pares por lo que la existencia de uno, sólo es objetivamente posible una vez que los otros le conceden el reconocimiento que, desde 1936, fue definido por el Instituto de Derecho Internacional como

el acto libre por el cual uno o varios Estados verifican la existencia sobre un territorio determinado de una sociedad humana políticamente organizada, independiente de cualquier otro Estado existente, capaz de observar las prescripciones del Derecho Internacional, y manifiestan consiguientemente su voluntad de considerarlo como miembro de la Comunidad Internacional. ${ }^{27}$

No nos detendremos en el problema del reconocimiento de Estados porque lo que nos interesa aquí es recalcar que la sociedad internacional solamente se extiende al conjunto o suma de Estados que la integran, que son reconocidos por su pares y que, por lo tanto, son partícipes de pleno derecho de las organizaciones que se constituyen como foros de negociación y concertación internacionales. ¿Hasta dónde se extiende la sociedad internacional? El Diccionario de Relaciones Internacionales y Politica Exterior la mide de la siguiente forma:

[El] proceso de universalización en el curso del siglo xx muestra una pauta de crecimiento continuo. En 1900 existían 46 Estados y tras la Primera Guerra Mundial y durante la posguerra aumentarían a 64. En 1960, cuando prácticamente se había consumado la emancipación de Asia y el norte de África, el número se había elevado a 131 y en 1980 a 190. Finalmente, los efectos de las Revoluciones de 1989 y el final de la Guerra Fría, en concurrencia con el auge de los etnonacionalismos, conducirían a un incremento del número de Estados y territorios autónomos, que en el año 2005 ascenderían a $227 .^{28}$

Como dato interesante, podemos señalar que al año 2012, la Organización de Naciones Unidas cuenta con 193 miembros, mientras que el Comité Olímpico Internacional aglutina a 204 integrantes.

Permítasenos ahora hacer una digresión necesaria, especialmente dirigida a

${ }^{27}$ Citado en Yaelle Cacho Sánchez, "Reconocimiento de Estados / Recognition of States / Reconnaissance des États" en Pereira, Diccionario..., op. cit., p. 843.

${ }^{28}$ José Luis Neila Hernández, "Estado-Nación / Nation State / État-Nation" en Pereira, Diccionario..., op. cit., p. 378. 
los estudiantes que recién se inician en el conocimiento de las relaciones internacionales. Como ya dijimos, es un hecho que, dentro de nuestra disciplina, el Estado, ${ }^{29}$ en su forma de Estado Nación, ocupa un lugar preponderante como actor de las relaciones internacionales. Sin embargo, es frecuente que el estudiante incurra en la equivocación de confundir Estado con gobierno o, aún más, tomarlos como sinónimos. Por ello es conveniente que, partiendo de la concepción clásica o tradicional de la noción de Estado, reconozcamos al gobierno como uno de sus elementos constitutivos (junto con la población y el territorio) y precisemos que en la sociedad moderna adopta diferentes variantes en el mundo.

En este sentido es importante hacer, como lo hizo Rousseau, una distinción entre Estado (que se caracteriza por la voluntad general, suprema y soberana) y gobierno (que comprende a los que la comunidad elige para cumplir esa voluntad).

La posibilidad de constituir diferentes formas de gobierno es planteada o reconocida desde Aristóteles, para quien existen formas de gobierno puras e impuras, en donde las primeras se caracterizan porque el gobernante demuestra interés por su pueblo y, por ende, por su bienestar, mientras que las segundas lo hacen por desarrollarse dentro de un sistema corrupto y por el escaso o nulo interés del gobernante por sus gobernados.

Es bien sabido que Aristóteles reconoce tres formas de gobierno puras:

- Monarquía, que es el gobierno de un solo individuo.

- Aristocracia, dentro de la cual el gobierno recae en manos de un grupo de representantes de una clase dominante.

- Democracia, que implica que el gobierno es conducido por una mayoría donde se observa la participación del pueblo en los asuntos públicos.

Para él mismo, las tres formas de gobierno impuras son:

- Tiranía, que es el gobierno de un individuo denominado tirano, que no demuestra interés alguno en el bienestar de su población.

29 "Según el gran economista liberal, Adam Smith, un Estado sólo funciona y es exitoso si tiene el poder exclusivo sobre la seguridad interna (policía, sistema judicial), externa (militar) y la infraestructura básica (que incluye también educación y salud).” Thomas Cieslik, “¿Es el Estado de Bienestar europeo un modelo para México? La inclusión social como elemento de la política exterior de la Unión Europea”, en Roberto Peña Guerrero (coordinador), México-Unión Europea. Asociación estratégica para la gobernabilidad y la inclusión social, UNAM - Plaza y Valdés, México, 2008, p. 68. 
- Oligarquía, el gobierno de un grupo de representantes que utilizan sus privilegios al tener una posición social relevante.

- Demagogia, que es el gobierno de una mayoría no representativa. ${ }^{30}$

Paolo Biscaretti nos ofrece un criterio más actual sobre la clasificación de las formas de gobierno, el cual está constituido por la determinación del órgano competente para trazar la dirección política general, es decir, la orientación en particular que presentan el Ejecutivo y el Legislativo. Según esto, se identifican tres formas de gobierno, con sus respectivas derivaciones:

- Constitucional pura, que puede ser una monarquía o república, pero donde es el Jefe de Estado -rey o presidente- quien define la dirección política general, apoyándose en ministros que políticamente son responsables sólo ante el propio Jefe de Estado.

- Constitucional parlamentaria, que puede ser una monarquía o una república, en donde la referida competencia no corresponde al Jefe de Estado, sino a los ministros, quienes son responsables ante el Parlamento que es, en última instancia, el encargado de certificar la dirección delineada por el gobierno.

- Constitucional directorial, que es el tipo republicano y que recuerda la experiencia del Directorio francés de 1795. En este caso la dirección del órgano dictatorial recae en varios ministros quienes, reunidos en colegio, ejecutan las funciones del Jefe de Estado. Actualmente este modelo es aplicado únicamente en Suiza. ${ }^{31}$

En la mayor parte de los autores encontramos una coincidencia en el sentido de que hay dos formas clásicas de gobierno que son la monárquica y la republicana. Por tanto, es importante considerar la definición conceptual de cada una de ellas a fin de entender el comportamiento de los Estados a partir de su sistema gubernamental y de los órganos que lo componen.

La monarquía es el régimen de un solo individuo, sea rey, príncipe, emperador, sultán, emir, duque o algún otro que se abroga las atribuciones del gobierno. Literalmente quiere decir "gobierno de uno solo", 32 aunque esta definición

\footnotetext{
${ }^{30}$ Eduardo López B., Manual de derecho positivo mexicano, Ed. Trillas, México, 1996, p. 86.

${ }^{31}$ Paolo Biscaretti, Introducción al derecho constitucional comparado, Fondo de Cultura Económica, México, 1996, p. 155.

${ }^{32}$ Julio Tobar D., Elementos de Ciencia Política, Universidad Católica de Ecuador, Ecuador, 1958, p. 256.
} 


\section{Ileana Cid Capetillo}

únicamente sería válida en su versión absoluta o autocrática, no en la constitucional en la cual "el monarca reina pero no gobierna" 33 sino que actúa como el poder moderador entre el gobierno y el parlamento. Usualmente la monarquía es hereditaria aunque puede darse el caso de que el monarca sea elegido para serlo de por vida. Dentro de esta forma de gobierno encontramos tres variantes:

- Monarquía absoluta, en cuyo caso el monarca está por encima de la ley en virtud de que él es la ley misma, por lo que ejerce el poder de manera absoluta e ilimitada sin estar sujeto a ningún control. Históricamente en este caso, el monarca no era responsable ante autoridad alguna y transmitía su investidura de manera hereditaria dentro de una sucesión dinástica.

- Monarquía constitucional, en donde el rey, como Jefe de Estado, se apoya en una constitución que rige sus poderes: a su lado se ubican otros órganos o entes, como las asambleas legislativas, que ejercían junto con el monarca el poder gubernamental de acuerdo con una base jurídica paritaria.

- Monarquía parlamentaria, cuya característica principal radica en que el parlamento tiene injerencia en los asuntos de gobierno. Se presenta así la división entre Jefe de Estado, el monarca, y Jefe de Gobierno, el primer ministro. En este caso, las funciones del monarca se restringen a las de tipo protocolario, aunque también coordina a los tres poderes estatales y representa a su Estado en asuntos internacionales. Por su parte, el primer ministro dirige la política del Estado. El parlamento usualmente es bicameral y la constitución marca la pauta para el funcionamiento del sistema.

Por otra parte, la república es la forma de gobierno representativo en donde el poder reside en el pueblo, personificado por un jefe supremo llamado presidente. Aquí, el pueblo decide libremente y elige con cierta periodicidad a los funcionarios del gobierno, visualizados como sus representantes. En la antigüedad, las repúblicas eran lo suficientemente pequeñas para ser gobernadas directamente por los ciudadanos, en las repúblicas modernas se hace indispensable delegar los poderes: el legislativo conformado por un grupo de representantes que se constituyen en un congreso; el ejecutivo encabezado por un presidente o un primer ministro y el judicial que vigila el respeto al orden constitucional. Esta división de poderes está pensada también como una manera de garantizar un equilibrio de fuerzas y la participación de la sociedad en las tareas básicas del gobierno.

\footnotetext{
${ }^{33}$ Manuel Osorio, Diccionario de las Ciencias Jurídicas, Políticas y Sociales, Ed. Heliasta, Argentina, 1990 , p. 469.
} 
Ahora bien, de acuerdo al carácter, atribuciones y situación dentro del juego de las fuerzas políticas del Jefe de Estado o Presidente de la República, del Parlamento o Congreso y del Gabinete o Ministerio, podemos encontrar las siguientes variantes de repúblicas que no necesariamente se dan en su forma pura sino que pueden presentarse de manera cruzada o combinada:

- Democrática, reconocida por su carácter popular, orientada al servicio de las aspiraciones de su sociedad y garantizada en sus expresiones jurídicas. Normalmente la democracia se garantiza por la vía indirecta, pues los representantes de las principales funciones públicas son designados por el cuerpo electoral, mediante la libre elección de aquéllos a los que van a representar. En esta forma de gobierno se encuadra adecuadamente la frase de Lincoln de que es "el gobierno del pueblo, por el pueblo y para el pueblo". ${ }^{34}$

- Federal, organizada por la vía del federalismo que supone un fraccionamiento del poder público entre una representación nacional autoritaria en asuntos de importancia general y ante las demás naciones y un ejercicio territorial interno.

- Parlamentaria, en cuyo caso, la existencia de un parlamento uni o bicameral supone que es éste el que posee la supremacía de los destinos nacionales por la necesidad de que el poder ejecutivo cuente con mayoría parlamentaria para ejercer sus funciones.

- Popular, generalmente asumido por gobiernos de corte socialista en donde el calificativo alude a la participación de las masas, bajo la dictadura del proletariado y regidas por un partido único.

- Presidencialista, de carácter eminentemente representativo, en donde el presidente concentra las funciones de jefe de Estado, jefe de gobierno y jefe del partido político mayoritario, situación que queda ilustrada por la frase "gobierno de un hombre electo por el pueblo". ${ }^{35}$ Asimismo, posee poderes efectivos, como cabeza del Ejecutivo, que le permiten oponerse a iniciativas legislativas del Congreso o Parlamento, pero no obligarlo a dimitir, aun con mayoría hostil, hasta que termine su mandato.

- Socialista, en la que se proclama el colectivismo en cuanto a los medios de producción y cambio. La propiedad de los medios de producción recae en el Estado y se gobierna con un partido único.

${ }^{34}$ Citado por Tobar, op. cit., p. 263.

${ }^{35}$ Biscaretti, op. cit., p. 156. 
- Unitaria, ofrece una estructura fundamental del Estado, dentro del régimen democrático, conservando la unidad y uniformidad administrativa, con leyes y códigos únicos para la nación.

Por otra parte, existen otras formas de gobierno que están menos extendidas por el mundo pero que representan variaciones interesantes que finalmente inciden en la política internacional.

- El principado es el gobierno que se encuentra encabezado por un príncipe cuya sucesión se da por vía hereditaria.

- El sultanato encuentra en el sultán (término árabe equivalente a monarca o soberano) a su gobernante. Se presenta en países de tradición mahometana.

- El emirato es un sistema de gobierno regido por un emir, con la ayuda de un gabinete designado por él. No hay partidos políticos y en la mayoría de los casos no existe un sistema legal de sufragio.

- El ducado responde a una circunscripción territorial de las monarquías, a cuyo frente históricamente se encontraba un duque que ejercía señorío sobre las tierras y jurisdicción sobre sus vasallos. En este caso, el duque ejerce las funciones de jefe de Estado. Esta forma de gobierno está prácticamente extinta pues sólo se presenta en el caso de Luxemburgo.

En materia política, vale la pena señalar la antigüedad de las constituciones vigentes en el mundo. Algunos estados no tienen, debido a que son monarquías en las que el rey no se sujeta a ningún marco jurídico nacional. Sin embargo, la mayor parte si la tienen, en algunos casos son muy actuales pues se trata de naciones formadas en las últimas décadas, pero hay otros en que las constituciones datan de más de cien años, tal es el caso de Estados Unidos, que tiene la constitución más antigua del mundo (1789). Otros ejemplos son Argentina (1853), Canadá (1867), Bélgica (1831), Luxemburgo (1868), Noruega (1814), Suecia (1809), Suiza (1874) y Tonga (1875).

Es evidente que al analizar la presencia de los Estados en las relaciones internacionales contemporáneas, para clasificarlos y diferenciar su actuación y su participación en los asuntos mundiales, debemos tomar en cuenta muy diversos elementos, como son: los geográficos (ubicación, recursos naturales, clima, hidrografia, orografía, por ej.), los económicos (balanza de pagos, producto interno bruto, tasas de interés, grado de desarrollo), los culturales o los tecnológicos, entre otros. En síntesis "el Estado es la combinación de un pueblo y un suelo, que presenta una efigie propia, auténtica, inconfundible y con una peculiar 
idiosincrasia". ${ }^{36}$ En un sentido más organizado y siguiendo los planteamientos teóricos de la geopolítica, el poder (y, diríamos nosotros, la naturaleza) de los Estados se define a partir de los siguientes elementos:

- La superficie de su espacio territorial (tamaño, configuración, forma de fronteras, etc.).

- La situación con respecto a las comunicaciones marítimas (litoral, flota mercante, poder naval), tanto en un sentido positivo como en uno negativo, es decir si no los posee.

- La posición geográfica absoluta y relativa.

- Los cambios operados en la situación mundial o regional, debidos al aumento o disminución en el poder en una o varias naciones.

- Los antecedentes de las pasadas cuestiones histórico-geográficas y el papel que ellas representaron en la política exterior.

- La capacidad de investigación técnica-científica, potencial industrial, recursos financieros y balance comercial.

- La competencia entre los estados por lograr una firme base de sustentación en el orden regional o mundial (político, económico o ideológico).

- La tendencia hacia estructuras internacionales más amplias, determinadas por el proceso de formación de bloques, integraciones regionales o continentales.

- El factor poblacional como elemento valorizador dado por la calidad, cantidad relativa, cultural y distribución demográfica.

- El tiempo político que se considera. ${ }^{37}$

Ahora bien, un elemento que es particularmente interesante es el que se refiere a la composición étnica dentro de las naciones que integran a cada uno de los estados.

Se ha subrayado que, hoy en día, es más común encontrar la diversidad o composición multiétnica en las sociedades nacionales que una pretendida homogeneidad "nacional", de ahí que podemos afirmar que la integración de una sociedad radica en elementos de cohesión políticos, económicos y culturales (tanto de carácter objetivo como subjetivo) más que en una homogeneidad derivada de características de tipo racial o étnico. A título de ejemplo, podemos

${ }^{36}$ Héctor Gómez Rueda, Teoría y doctrina de la Geopolitica, Ed. Astrea, Buenos Aires, 1977, p. 62.

${ }^{37}$ Idem., pp. 17-18 


\section{Ileana Cid Capetillo}

mencionar el caso de México, en donde la presencia de numerosos grupos indígenas, con culturas, lenguas, tradiciones y formas de trabajo muy diversas, enriquecen el mosaico social de nuestra nación, así encontramos la siguiente distribución de etnias en el territorio mexicano:

Baja California: cochimi, paipia, kumiami, yuma. Coahuila: kikapú. Chiapas: ahuteco, cakchiquel, chicomulcelteco, kanjobal, ketchi, lacandón, mame, matocintlico, solteco, teco, tzetzal, tzotzil, tojolabal. Chihuahua: rarámuri, (tarahumara). Estado de México: matlazinca, tlahuica-ocuitleco. Guanajuato: chichimeca. Nayarit: cora. Michoacán: purépecha. Oaxaca: chatino, cuicateco, chinanteco, chocho, huave, ixateco, papabuco. Quintana Roo: ixil, quiché. Sinaloa: mayo. Sonora: cahíta, pápago, yaqui, cúcapa, kiliwa, seri. Veracruz: popoluca, tepehua. Durango y Nayarit: wirráriga (huichol). Chiapas y Veracruz: zapoteco. Campeche, Yucatán, Quintana Roo: maya. Chihuahua y Sonora: guarijio, opata, pima. Estado de México, Guerrero, Jalisco, Michoacán, Oaxaca, Puebla y Veracruz: náhuatl. Oaxaca y Tabasco: chontal. Quéretaro y San Luís Potosí: pame. Estado de México, Hidalgo y Veracruz: otomí. Guerrero, Oaxaca y Puebla: mixteco. Guerrero y Oaxaca: amuzgo. Oaxaca y Veracruz: totonaca. Chiapas y Veracruz: zoque. ${ }^{38}$

En conclusión, si la noción de actor de relaciones internacionales en las visiones clásicas se ha reservado primordialmente para el Estado, no cabe duda de que en un escenario internacional cada vez más complejo se han venido incorporando otros actores públicos y privados con un creciente protagonismo que nos obliga a considerarlos. ${ }^{39}$

\section{Las organizaciones internacionales gubernamentales}

A pesar de que los autores y estudiosos en general del Derecho Internacional (en donde el capítulo dedicado a las organizaciones internacionales es especialmente importante) hacen un recuento histórico que puede remontarse a varios siglos atrás, para efectos de nuestra materia vamos a afirmar que éstas sólo tienen existencia como actores de las relaciones internacionales a partir del siglo XX. No desconocemos la importancia de otras formas que pudieron presentarse en el pasado pero son antecedentes que no han adquirido las determinaciones que

${ }^{38}$ Chayo Uriarte de Atilano, "Pueblos indios. Esperanza de paz" en Sumario de El Informador, Guadalajara, Jal., México, 29 de julio de 2000, p. 10.

${ }^{39}$ Cfr. Philippe Marchesin, Introduction aux Relations Internationales, Editions Karthala, Paris, 2008, pp. 71-83. 
definen a la totalidad moderna ni en composición, ni en funciones y tampoco en efectos. ${ }^{40}$

En todo caso, los antecedentes más cercanos de las actuales organizaciones internacionales se remontan a 1874, cuando se creó la Unión Postal Universal, en 1875 se estructura la Unión Telegráfica Universal y en 1905 se funda el Instituto Internacional para la Agricultura, que más tarde se concretaría en la FAO (Organización de Naciones Unidas para la Alimentación y la Agricultura).

Pero en el siglo XX se produce el primer gran experimento que pretendía alcanzar una organización con vocación universal. ${ }^{41} \mathrm{Al}$ concluir la Primera Guerra Mundial, en los tratados de paz que se firmaron, el 28 de junio 1919 en París, se incluyó el Pacto que daba vida a la Sociedad de Naciones (SDN), con sede en Ginebra, la cual inició sus trabajos el 15 de noviembre de 1920 con la participación de 42 Estados. ${ }^{42}$ Ya en esta organización se delinea la estructura orgánica que se mantiene como base de todas las que se integran después de esa fecha: una Secretaria General, una Asamblea General y un Consejo, además de otros componentes que pueden variar.

La SDNestaba compuesta por:

la Asamblea, integrada por representantes de todos los Estados miembros en pie de igualdad, (...) el Consejo, que comprendía miembros permanentes y no permanentes, que en conjunto fueron ocho en principio, y luego, once, (además) había una Secretaría permanente, ${ }^{43}$ con el secretario general a la cabeza. En cambio, el Tribunal Permanente

${ }^{40}$ En materia de Derecho Internacional, Alfred Verdross afirma que: "Antes de la S.d.N y de la O.N.U. no había órganos internacionales universales, pues la antigua comunidad internacional no estaba organizada, careciendo, por tanto, de órganos centrales (...)", y más adelante reitera: "Órganos internacionales de carácter político sólo existen desde la fundación de la S.d.N, es decir, desde que se intentó organizar la comunidad internacional sobre una base universal (...)", en Derecho Internacional Público, traducción Antonio Truyol y Serra, Biblioteca Jurídica Aguilar, $5^{a}$. ed., 1972, pp. 274 y 277, énfasis en el original.

${ }^{41} \mathrm{La}$ vocación universal de la SDN desde el principio fue incumplida. Estados Unidos nunca ingresó pues el Congreso le negó a Woodrow Wilson la ratificación del Tratado de Versalles. Originalmente Alemania, Turquía y la unss no formaron parte de la organización aunque más tarde se incorporaron por un breve lapso debido a que fueron castigados por sus políticas agresivas en el periodo de entreguerras. México, debido a la inestabilidad interna producto de la Revolución, no entró originalmente pero mediante una resolución del 8 de septiembre de 1931, unánime aceptada por la Asamblea General, fue reconocido como miembro original.

${ }^{42}$ http://www.ecured.cu/index.php/Sociedad_de_Naciones\#Estructura Página consultada el 22 de agosto de 2012.

${ }^{43}$ Los Secretarios Generales de la SDN fueron: Sir James Eric Drummond (Reino Unido) 1920-1933, designado de antemano por el Tratado de Versalles; Joseph Avenol (Francia) 19331940; y Seán Lester (Irlanda) 1940-1946. 
de Justicia Internacional (actual tribunal Internacional de Justicia) no era órgano suyo, sino un tribunal ajeno a la Sociedad y fundado por un tratado colectivo autónomo." Además, en materia de "fomento de la cooperación internacional, (...) disponía de muchas comisiones y organizaciones técnicas, permanentes y no permanentes." ${ }^{4}$

La vida institucional de la SDN se prolongó de 1920 a 1946, cuando fue sucedida por la Organización de Naciones Unidas (ONU). Durante ese tiempo tuvo un total de 63 Estados miembros, de los cuales sólo 31 fueron permanentes. ${ }^{45}$ En los análisis de política internacional se señala con insistencia el fracaso político que se hizo evidente con la manifestaciones de descontento de los países revisionistas que quedaron inconformes con las estipulaciones de los tratados de paz de París, la extensión de las políticas agresivas e intervencionistas de las potencias, la formación de alianzas militares y todo lo demás que condujo al estallido de la Segunda Guerra Mundial. Sin embargo, poco se han analizado los avances que en materia de cooperación se lograron y que contribuyeron a sentar las bases de la atención que se les brindaría después.

Al finalizar la Segunda Guerra Mundial, con sustento en la correlación de fuerzas que se delineó como consecuencia del triunfo de las Potencias Aliadas con Estados Unidos a la cabeza, se instituyeron tres regímenes internacionales que permitirían implantar una cierta gobernanza en el mundo: el régimen político (con la ONU como coordinadora general), el régimen económico (con base en el sistema de Bretton Woods) y el régimen militar (con la OTAN, los pactos regionales y los pactos bilaterales bajo la hegemonía de Estados Unidos, frente a la Organización del Pacto de Varsovia bajo la égida de la Unión de Repúblicas Socialistas Soviéticas). En este rubro, al plantear las organizaciones internacionales nos vamos a concentrar en el modelo que ofrece la ONU para entenderlas como actores internacionales.

La Organización de Naciones Unidas se fundó a raíz de la Conferencia de San Francisco realizada del 25 de abril al 26 de junio de 1945 e inició formalmente el 24 de octubre de ese mismo año, "con 51 Estados miembros de los que 20 eran latinoamericanos y 3 africanos". ${ }^{46}$ Su estructura básica está integrada por seis órganos principales:

${ }^{44}$ Verdross, op. cit., pp. 427 y 428 . Énfasis en el original.

${ }^{45}$ http://www.ecured.cu/index.php/Sociedad_de_Naciones\#Estructura Página consultada el 22 de agosto de 2012.

${ }^{46}$ Francesc Granell Trías, "Organización de las Naciones Unidas (ONU)/United Nations Organization (UNO)/Organisation des Nations Unies (ONU)", en Pereira, Diccionario..., op. cit. p. 697. 
- La Asamblea General “es el órgano deliberante en el que están representados todos los Estados miembros, cada uno con un voto" " ${ }^{77}$ Su trabajo se organiza en seis comisiones: 1. Desarme y Seguridad; 2. Económica y Financiera; 3. Humanitario, social y cultural; 4. Política y de descolonización; 5. Administrativa y Presupuestaria; y, 6. Jurídica.

- El Consejo de Seguridad (CSONU) integrado por cinco miembros permanentes (China, Estados Unidos, Francia, Reino Unido y Rusia), más diez no permanentes, electos por la Asamblea para periodos de dos años.

- El Consejo Económico y Social (ECOSOC) “compuesto por 54 miembros con mandatos de tres años, es el órgano coordinador de la labor económica y social de las Naciones Unidas y de los Organismos, agencias e instituciones especializadas" ${ }^{48}$ del sistema.

- El Consejo de Administración Fiduciaria integrado por los cinco miembros permanentes del CSONU, atiende el proceso hacia la independencia o logro de un gobierno propio de los territorios en fideicomiso.

- La Corte Internacional de Justicia integrada por 15 magistrados con mandatos de nueve años con posibilidades de renovación. ${ }^{49}$

- La Secretaría a cuyo frente se encuentra el Secretario General de la ONU, quien, a propuesta del CsONu, es nombrado por la Asamblea General para periodos de cinco años renovables. Desde la fundación de la ONu y hasta la fecha, han ocupado ese alto cargo: Trygve Lie (1946-1953), Dag Hammarsksjöld (1953-1961), U Thant (1961-1971) Kurt Waldheim (1971 1981), Javier Pérez de Cuellar (1981-1991), Boutros Boutros-Ghali (19921997), Kofi Annan (1997-2006) y, actualmente, Ban Ki-moon (desde 2007). ${ }^{50}$

La Organización de Naciones Unidas, a lo largo de sus casi 70 años de vida, sin que se logre avanzar en la reforma que se viene demandando desde hace dos décadas, sí ha cambiado sustancialmente y sobre todo, ha crecido considerablemente pues se ha visto en la necesidad de afrontar los temas novedosos que van surgiendo en la agenda internacional, con lo cual, ha implementado Altos Comisariados, Conferencias, Agencias y Programas con

${ }^{47}$ Idem, p. 697.

${ }^{48}$ Idem., p. 598.

${ }^{49}$ Fuera del esquema de UN pero con vínculos se encuentran el Tribunal Penal Internacional para la ex Yugoslavia (1993), el Tribunal Internacional para Ruanda (1994) y el Tribunal Penal Internacional (1996) que tiene un Acuerdo de Vinculación con la ONU. Cfr., idem., p. 699.

${ }^{50} \mathrm{Idem}$. 
estructura propia (incluso burocracias y presupuesto) que han vuelto de la ONU más un sistema de organizaciones que una particular en sí misma. Su actual estructura, es sumamente compleja y extensa. ${ }^{51}$

Los análisis que se han realizado alrededor del tema de la necesaria reforma, han sacado a la luz los problemas que la aquejan: precariedad presupuestal, existencia de una enorme burocracia, órganos que se superponen, multiplicación de funciones entre ellos de cara a insuficiencia (o ineficacia) en los canales de comunicación interinstitucional, estructuras obsoletas (como el Consejo de Administración Fiduciaria) que atendían tareas que ya no se corresponden con los asuntos de la realidad internacional actual, entre otros.

Sin embargo, debe señalarse que la ONU, a pesar de las limitaciones que tiene, ha contribuido de manera efectiva al mantenimiento de la paz en el mundo y al desarrollo de la cooperación internacional en todas sus facetas.

Para centrarnos en nuestro tema, la organización internacional como actor de relaciones internacionales, reúne una serie de condiciones que la diferencian de otros entes que puedan ser considerados como tales. Entre ellas, las más relevantes son:

- Se crean con la determinación de tener una permanencia definitiva y de largo plazo.

- Están integradas por los Estados que gozan de la plenitud de sus derechos y del reconocimiento de sus pares. Son ellos los que son admitidos como miembros de derecho pero delegan su representación en los funcionarios gubernamentales (diplomáticos), previa acreditación, en pleno ejercicio.

- Básicamente son organizaciones internacionales intergubernamentales por lo que están enmarcadas en el conjunto de organizaciones de carácter público, aunque su acción se ubica en el nivel internacional.

- Su fundación se establece a partir de un pacto o carta constitutivos ${ }^{52}$ en el que se puntualizan los considerandos, los antecedentes, los objetivos y propósitos, así como la definición y atribuciones de los órganos que integran su estructura.

- Aunque la organización internacional tiene una sede permanente que es decidida por sus miembros fundadores, no tiene en sentido estricto un

${ }^{51}$ Véase: Sistema de las Naciones Unidas, [en línea] Dirección URL: http://www.onu.cl/ onu/wp-content/uploads/2011/05/organigrama- \{cONU-1024x658.png

${ }^{52}$ En relación con el Pacto de la SDN, dice Alfred Verdross que "fue, en realidad, la primera constitución de la comunidad internacional en sentido formal”, op. cit., p. 427. Énfasis en el original. 
referente territorial -como el del Estado-y, por ello, el país anfitrión, acorde al Derecho Internacional, reconoce la extraterritorialidad que implica que la propia legislación nacional no aplica en esos límites.

- El presupuesto requerido para la administración y el cumplimiento de sus tareas depende de las aportaciones de sus integrantes, puesto que no tiene forma de adquirir ingresos propios.

- Hasta ahora no existe una organización internacional que tenga capacidad coercitiva, es decir que pueda imponer sanciones "penales" a los trasgresores de la ley internacional. ${ }^{53}$

La paradoja de las organizaciones internacionales radica en que su relativa autonomía siempre es dependiente de la buena voluntad de sus miembros que, debemos recordar, tienen la plena capacidad soberana, mientras que su existencia es imprescindible pues son los foros por excelencia en que los Estados pueden encauzar todos los asuntos de conflicto (guerra) y cooperación (paz) que se suscitan en la sociedad internacional. Como afirman Keohane y Nye:

$[\ldots]$ la existencia de canales múltiples lleva a predecir un diferente y significativo papel para los organismos internacionales en la política mundial. Los realistas alineados en la tradición de Hans J. Morgenthau habían descrito un mundo en el que los Estados, al actuar en pos del interés propio, luchaban por 'el poder y la paz'. Los problemas de seguridad predominan; la guerra es una constante amenaza. En un mundo así se puede suponer que los organismos internacionales han de cumplir una función secundaria, ya que se encuentran limitados por la rara congruencia de tales intereses. Por lo tanto, los organismos internacionales son claramente periféricos en la política mundial. Pero en un mundo de múltiples problemas imperfectamente relacionados, en el cual las coaliciones son transnacionales y transgubernamentales, el papel potencial de las instituciones internacionales para la negociación política ha crecido enormemente. Ellas contribuyen, en particular, a establecer la agenda internacional, actúan como catalizadores para la formación de coaliciones y como escenario para iniciativas políticas y vinculación de los Estados débiles. ${ }^{54}$

${ }^{53}$ La Corte Penal Internacional sólo puede enjuiciar a individuos que han cometido crímenes graves contra la humanidad. Sin embargo, debe reconocerse que "es complementaria respecto de las jurisdicciones nacionales, de modo que sólo podrá conocer de un asunto cuando el Estado con jurisdicción sobre éste no quiera o no pueda conocer del mismo, o cuando ejerza su jurisdicción sobre el caso, pero de modo inadecuado para el interés de la justicia." Carmen Quesada Alcalá, "Corte Penal Internacional / International Criminal Court / Court Pénale Internationale" en Pereira, Diccionario..., op. cit., p. 246.

${ }^{54}$ Keohane y Nyre, op. cit., p. 47. 
Queda claro que la organización como actor internacional tiene una presencia indiscutida y que, además, juega un papel muy importante en la vida internacional, sobre todo porque es la única vía para imponer límites al poder y a la acción egoísta del Estado. Por esa razón, y porque los integrantes de la sociedad internacional reconocen su contribución y las ventajas de su existencia, desde su surgimiento en los inicios del siglo $\mathrm{XX},{ }^{55}$ se ha multiplicado considerablemente su número:

De acuerdo con el Anuario de Organizaciones Internacionales correspondiente a 2004/ 2005 publicado por la Unión de Asociaciones Internacionales, existen en la actualidad 245 organizaciones internacionales intergubernamentales fruto de convenciones mundiales de las cuales una es de carácter general (Naciones Unidas), 34 son organizaciones de carácter universal, 33 de carácter intercontinental y 177 de carácter regional, existiendo también otros 1,743 organismos internacionales y regionales intergubernamentales de otro carácter. ${ }^{56}$

\section{Organizaciones internacionales no gubernamentales}

En la sociedad internacional del último tercio del siglo XX se hizo notorio el incremento y el protagonismo de las ONG, sobre todo provocado por un contexto dominado por políticas neoliberales que alejaron a los Estados de la atención de problemas que afectan a las poblaciones y al medio ambiente. En ese momento se buscaba elevar las voces de la sociedad civil para demandar soluciones o alternativas a temas de pobreza, salud, género, comercio justo, justicia, cultura, educación y, de manera muy destacada, preservación de especies, uso de suelos, conservación de recursos, entre muchos más.

La ONG es una forma de organización que específicamente se enmarca en el rubro de lo social pues surge de manera independiente a cualquier pacto gubernamental (con lo que se deslindan de lo propiamente político o público) o acuerdo empresarial (económico o privado) y tiene su modelo o antecedente más relevante en la creación de la Cruz Roja o de la Media Luna Roja Internacional.

En la actualidad hay un número creciente de ONG, de muy diferentes tamaños

\footnotetext{
${ }^{55}$ Para mayor información sobre el desarrollo histórico y las competencias de las organizaciones internacionales gubernamentales, ver: Daniel Dormoy, "Les Organisations Internationales" en Frédéric Charillon, Les Relations Internationales, La Documentation Francaise, Paris, 2006, pp. 6974.

${ }^{56}$ Granell Trías, op. cit., p. 711.
} 
y capacidades, además de que se sigue diversificando la temática que atienden, prácticamente es imposible dar una definición precisa de un conglomerado tan heterogéneo, sin embargo, en términos generales, entre sus características más generales encontramos las siguientes:

a) Son organizaciones estables con un grado mínimo de estructura, personalidad jurídica y capacidad legal de acuerdo con la normativa vigente. b) Están integradas por ciudadanas y ciudadanos asociados a partir de unas convicciones y motivaciones compartidas a favor de la cooperación y la solidaridad. Son por tanto una parte del llamado Tercer Sector o 'Sector Social', es decir, una expresión particular del movimiento asociativo voluntario de la sociedad civil. c) Son organizaciones sin ánimo de lucro empresarial, personal o grupal. La totalidad de los ingresos obtenidos debe dedicarse a sus proyectos de desarrollo, educación y sensibilización, exceptuando los necesarios para el funcionamiento de la organización. d) Se dedican a canalizar recursos hacia los países del Sur mediante la realización de proyectos de desarrollo o la respuesta ante situaciones de emergencia. (...) e) Se nutren de recursos económicos aportados por donaciones privadas y/o subvenciones públicas, así como del trabajo voluntario (a veces parcialmente profesionalizado) de sus colaboradores. f) Tienen autonomía institucional y decisoria respecto a cualquier instancia gubernamental, intergubernamental o cualquier otra ajena a la organización. En particular son entidades independientes de los Gobiernos, no surgen a instancias de éstos, ni, por tanto, han de defender los mismos intereses, lo cual no significa que no reciban financiación de las Administraciones públicas o que no puedan realizar acciones conjuntas. ${ }^{57}$

Pero no todas las ONG que aparecen en los medios, que tienen un protagonismo o, incluso, que reciben apoyo económico gubernamental o privado, gozan de una cualidad que solamente les concede la ONU, a través del ECOSOC y que casi podríamos decir que equivale al reconocimiento de su existencia, de acuerdo a la normativa derivada de la Resolución 1996/31, de 1996.

El ECOSOC reconoce tres tipos de entidades consultivas, de acuerdo al nivel de participación que se les concede:

Estatus general: se aplica a las ONG grandes internacionales cuyos intereses abarcan la mayor parte de la agenda del Consejo Económico y Social. Ellos pueden hablar ante los delegados, hacer declaraciones de hasta 2.000 palabras, e introducir temas en la agenda. Las ONG deben proporcionar un informe cuadrienal con un resumen de sus contribuciones a la ONU.

${ }^{57}$ José Luis Sotillo Lorenzo y Raquel Martínez-Gómez López, “Organizaciones No Gubernamentales / Non-Governamental Organizatios / Organisation Non Gouvernamentale”, en Pereira, Diccionario, op. cit., p. 717. 
Estatus especial: se refiere a las ONG con "competencia especial en algunos ámbitos de actividad del Consejo. Las ONG deben proporcionar un informe cuadrienal, pero no pueden incluir temas en la agenda. Sus declaraciones escritas no deben acceder las 500 palabras.

Estatus roster: concierne a ONG con uno o varios temas específicos. Pueden asistir a las reuniones, pero no pueden hablar o hacer declaraciones. ${ }^{58}$

El ECOSOC tiene muy bien regulado el procedimiento para que las ONG pueden adquirir el carácter de entidades consultivas. Los requisitos básicos consisten en que las solicitantes deben desarrollar actividades "relevantes a la labor" del mismo ECOSOC; acreditar "por lo menos dos años de existencia reconocida oficialmente"; tener una sede fija; una estructura representativa; autoridad para hablar en nombre de sus miembros; contar con "un mecanismo de toma de decisiones democrático" y de rendición de cuentas; y, además, "ser independientes de las estructuras gubernamentales y los fondos públicos". 59

La fuente oficial de ECOSOC informa que se suman más de 2,719 ONG con reconocimiento como entidades consultivas, clasificadas en aquellas que "se interesan en la mayor parte de las actividades del Consejo", las que tienen "competencia especial en áreas específicas" y las "que ocasionalmente pueden efectuar aportes a la labor del Consejo". ${ }^{60}$

Sin duda alguna, en el futuro presenciaremos la persistencia en el incremento de ONG, sin embargo es conveniente señalar que muchas de las que aparecen periódicamente tienen una existencia efímera, adoptan temas de manera oportunista, no pueden acreditar los requisitos resumidos por el ECOSOC y, por lo tanto, tampoco se toman la molestia de solicitar su registro.

\section{Empresas multi y transnacionales}

El cuestionamiento a la idea de que el Estado era no sólo el actor principal en relaciones internacionales sino prácticamente el único por las atribuciones que le corresponden y que no pueden ser competidas por otros entes de influencia

\footnotetext{
${ }^{58}$ Consejo Económico y Social (ECOSOC), en http:/ / www.un-ngls.org/spip?page=article= 1519 Página consultada el 25 de agosto de 2012.

${ }^{59}$ Idem., Así como "Número record de ONGs buscan participación en la ONU", Nueva York, 31 de enero de 2011, en http://www.un.org/es/development/desa/news/ecosoc/recordnumber-of-ngos-seeking-participation-in-the-un.html Página consultada el 25 de agosto de 2012.

${ }^{60}$ Consejo Económico y Social (ECOSOC) en http://www.cinu.org.mx/onu/estructura/ ecosoc.htm\#ong Página consultada el 22 de agosto de 2012.
} 
mundial empezó a ser revisada a raíz del creciente protagonismo que empezaron a adquirir las grandes empresas que trascienden los límites del mercado nacional en el que surgen e incursionan en otros mediante el comercio, la inversión directa y el establecimiento de filiales que reproducen sus esquemas productivos. Aunque en un sentido laxo se pueden encontrar antecedentes de este tipo de internacionalización de las empresas -algunos incluso anteriores al surgimiento del capitalismo, alrededor del siglo XV-, para los efectos de nuestra indagación, nos limitaremos a la etapa más reciente de su desarrollo, pues es la que motiva la apreciación de que se han constituido en actores internacionales, que arranca con la expansión del capitalismo en su etapa industrial y que, como apunta Rafael Calduch Cervera, puede ser apreciado en tres etapas: el periodo de aparición de las empresas multinacionales (1860-1914), la etapa de su consolidación (19141945) y la de su universalización (1945-1990). ${ }^{61}$

Pero es a partir de la década de los 60 del siglo xx que tal tipo de empresa tiene una espectacular presencia en la economía internacional, con lo que también despliega una considerable influencia en la política y en la sociedad, por lo que se convierte en un destacado objeto de observación para entender la manera como se va desarrollando el capitalismo en el mundo con cambios importantes que se proyectan desde la economía pero que impactan a las demás esferas en procesos de crecimiento y crisis que son promovidos por el desarrollo de las fuerzas productivas, así como por el efecto de los avances en la ciencia y la tecnología, que anticipan el arribo de la globalización en la que adquieren todas las connotaciones que hoy resultan tan normalmente apreciadas como la cotidianidad del capitalismo: concentración del capital, monopolio del know how en la producción y en la administración, división geográfica del proceso productivo, el empleo aleatorio o selectivo de mano de obra de acuerdo a su capacitación y a su costo, independientemente de su ubicación geográfica,

Desde los estudios pioneros de Christian Palloix ${ }^{62}$ en la década de los setenta hasta la gran mayoría de la bibliografía de Relaciones Internacionales, se pasa a considerarla como un actor destacado, aunque cabe señalar que bajo diferentes denominaciones, como empresas internacionales, multinacionales, transnacionales o supranacionales ${ }^{63}$ que frecuentemente producen confusión pero que son utilizados por muchos autores prácticamente como sinónimos, pues al revisar

${ }^{61}$ Rafael Calduch, Relaciones Internacionales, Edit. Ciencias Sociales, Madrid, 1991, pp. 302-309.

${ }^{62}$ Christian Palloix. Las firmas multinacionales y el proceso de internacionalización, traducción José Luis Alonso, Siglo XXI de España Editores, Madrid, 1975, 350 pp.

${ }^{63}$ Rafael Calduch, op. cit., p. 310. 
múltiples definiciones nos damos cuenta de que hacen referencia al mismo ente. Nosotros distinguimos entre empresa multinacional y transnacional pues en la experiencia latinoamericana se han impulsado proyectos de carácter multinacional pero público, en los que participan gobiernos de distintos países que aportan capital, tecnología y trabajo en una determinada rama productiva para eficientar el proceso y contribuir a la cooperación entre los países, un ejemplo es la Naviera Multinacional del Caribe (NAMUCAR) que está integrada por Costa Rica, Cuba, Jamaica, México, Nicaragua, Panamá y Venezuela desde el 28 de mayo de 1975 a iniciativa del Sistema Económico Latinoamericano (SELA). Por otra parte, consideramos que el término empresa transnacional goza hoy día de una mayor aceptación.

Una definición clara y sencilla de empresa transnacional es aquélla que señala que "es un sistema de producción o prestación de servicios, integrado por unidades localizadas en distintos países, que responden a estrategias centralmente planificadas en una casa matriz cuyo control se basa prominentemente, aunque no de manera exclusiva, en la propiedad de todo o parte del capital social de las subsidiarias y que, a su vez, es poseída y dirigida por ciudadanos del país donde la matriz tiene su domicilio". ${ }^{64}$ En la actualidad este tipo de empresa despliega su acción tanto en las actividades extractivas, como en las productivas y en las de servicio.

Algunas de las características de las empresas transnacionales son:

- Su presencia en diferentes regiones geográficas del mundo. Si bien en las primeras etapas de su desarrollo se destaca con insistencia su origen en los países occidentales industrializados y desarrollados, al revisar las listas de las empresas más grandes del mundo nos percatamos que ya algunas de ellas provienen de países de otros continentes como América Latina y Asia, con la particularidad de que se comportan exactamente igual que sus predecesoras e igualmente generan críticas y actitudes de rechazo por las prácticas contrarias a los intereses de los países en que se asientan. ${ }^{65}$

- La cantidad de recursos económicos que poseen. Se ha comparado en múltiples ocasiones el enorme capital que manejan algunas empresas que

${ }^{64}$ Jaime de Pablo Valenciano, "Empresa multinacionales/Transnacionales / Multinational/ Transnational Compañy / Entreprise Multinationales/Transnationale”, en Pereira, Diccionario..., op. cit., p. 341.

${ }^{65}$ Es interesante reflexionar sobre el caso del conflicto entre Cemex y el gobierno de Venezuela que condujo a la expropiación en 2008. 
con facilidad superan el producto interno bruto de algunos países pequeños o incluso de la suma de varios de ellos.

- Una estrategia de internacionalización a través del establecimiento de filiales, franquicias, colocación de acciones y valores en bolsas de valores de diferentes países, establecimiento de alianzas estratégicas, fusiones, deslocalización y fragmentación de la producción.

Un punto que es interesante señalar es que la empresa trasnacional actúa básicamente en el mercado, su racionalidad es de carácter económico y su influencia política la ejerce sobre los Estados, es decir que ella misma no despliega actividades políticas sino que lo hace a través de los gobiernos empleando diversos medios que van desde los abiertos, como el cabildeo (lobbying), hasta los encubiertos como el soborno. Así, a pesar de que en las últimas décadas se ha hablado mucho de la superposición de la lógica del mercado sobre la sociedad política, la crisis tan profunda por la que está atravesando el capitalismo de los centros más desarrollados está demostrando que lo que desarregla la empresa lo tiene que arreglar el Estado, pues sólo éste puede garantizar el reparto de la riqueza. Lo que estamos presenciando, en pocas palabras, es el fracaso del neoliberalismo y su incapacidad de cumplir con sus principales promesas.

Por otra parte, debe destacarse que la empresa transnacional no es sujeto de derecho internacional y que los avances que éste ha logrado para regular muchos de los aspectos de las relaciones internacionales siguen presentando un vacío en lo que refiere a este ente. En la literatura sobre el tema se señalan los intentos que se han producido por alcanzar una normatividad que regule sus actividades, ${ }^{66}$ pero la conclusión es que hasta la fecha

no existe un Código Global que regule la conducta de las transnacionales y al contrario, su poder se ha incrementado y expandido por todo el mundo. Si bien es cierto que existieron esfuerzos por controlar su gestión [...] éstos no prosperaron y los que existen se encuentran en calidad de recomendaciones o sólo a nivel regional, pero a falta de un carácter legal y de obligatoriedad internacional, las empresas transnacionales seguirán conduciéndose con sus propias reglas. ${ }^{67}$

${ }^{66}$ Ver Blanca Teresa Ortega Elizalde, Expansión internacional y reconcentración regional de la gran empresa mexicana: casos de grupo Cemex, Grupo Vitro y Grupo Carso, tesis de licenciatura en Relaciones Internacionales, FCPYS, UNAM, México, 2010.

${ }^{67}$ Idem., p. 24. 


\section{Ileana Cid Capetillo}

\section{El individuo}

Desde hace mucho tiempo, en algunos estudios de nuestra disciplina se ha sugerido la consideración del individuo como actor de las relaciones internacionales, bajo la óptica del protagonismo que puede alcanzar y su capacidad para incidir tanto en la política como en la economía y en la sociedad, ya sea en un sentido positivo como en uno negativo. Sin embargo, se deben tomar en cuenta algunos factores que no han sido suficientemente discutidos.

Se habla de "el individuo" como un genérico que solamente se personifica en casos específicos, de tal manera que no todos los individuos son susceptibles de tener un protagonismo en la política, en la economía o en la sociedad internacionales. Cuando alguno lo despliega lo hace siempre como referente o en representación de un Estado, ${ }^{68}$ de un organismo internacional, de una empresa transnacional o de una asociación civil o religiosa. De tal manera que no hablamos de "el individuo" sino de personalidades que destacan por su capacidad política, ideológica, económica o social. ${ }^{69}$

Su participación es efímera si se compara con la duración del largo proceso de la historia, es cierto que puede ser perpetuada por sus seguidores pero normalmente lo hacen de una manera desvirtuada del original pues aquéllos acoplarán sus ideas, su ejemplo o su ideología a sus propios intereses según las condiciones cambiantes en que las aplican.

La mejor manera de evaluar su desempeño es poniéndolo en referencia con el Estado, la empresa, la asociación, la comunidad religiosa o la organización a la que pertenecen de donde derivan su acción. En virtud de que no existen valores universales generalmente aceptados, la acción de un individuo puede ser vista por su comunidad como heroica mientras que otra la vería incluso como criminal.

Evidentemente, cuando los medios de comunicación reseñan la actividad desplegada por un personaje en una cumbre internacional se concentran en la actuación de los individuos pero no como tales sino como jefes de Estado o de gobierno, como directores de empresas o como funcionarios internacionales. Sin embargo, debemos reconocer que el "cargo" hace muchas veces al personaje,

\footnotetext{
${ }^{68}$ Precisamente en este sentido lo estudia Duroselle en uno de los trabajos más citados entre quienes estudian este tema, en la parte en que analiza al Hombre de Estado, en Pierre Renouvin y Jean Baptiste Duroselle, Introducción a la política internacional, traducción Manuel Camacho de Ciria. Ed. RIALP, 1968.

${ }^{69} \mathrm{El}$ materialismo histórico dialéctico se distancia de esta visión propia de las visiones positivistas al considerarlo como sujeto histórico y por lo tanto con un referente social, o sea como parte de una clase.
} 
quien tiene los reflectores mientras dure aquél. Hace muy poco tiempo Nicolás Sarkozy era, junto con Angela Merkel, uno de los puntales de la política de la Unión Europea, tan compenetrados en sus planes que se hablaba de la fórmula "Merkozy"; al ganar François Hollande las elecciones francesas ese dúo se desintegró y, con él, se tambalean sus propuestas más firmes. Por supuesto estamos hablando de políticos que actúan conforme a las normas democráticas de sus sociedades y que aceptan el término de su mandato cuando la legislación y un proceso electoral marcan el traslado del poder a un nuevo mandatario. No es el caso de individuos que se perpetúan en el gobierno y que incluso lo heredan a sus descendientes, constituyendo verdaderas dinastías como la de Duvallier, en su momento, en Haití, o la de Kim Il Sung en Corea del norte.

Sin embargo, quizá debemos reconocer que en el ámbito económico puede ser más prolongada la acción de individuos que se convierten en la personificación misma de cambios tecnológicos y marcan toda una etapa de la historia por predominar en procesos productivos de punta dependiendo de la etapa del capitalismo: Henry Ford o Rockefeller en el auge de la industrialización frente a Bill Gates o Carlos Slim en la globalización en donde el sector de servicios es el predominante en la economía mundial.

A pesar de lo señalado hasta aquí, debemos reconocer que muchos autores de nuestra disciplina sí consideran al individuo como un actor internacional, aún en el caso de reconocer las limitantes arriba señaladas. Así, Rafael Calduch afirma que

En efecto, el individuo en tanto que productor o consumidor, como agente comunicante o como miembro de la opinión pública, como elector o como candidato político, como turista o como terrorista, para utilizar los propios términos de Rosenau, constituye un sujeto activo de la vida internacional operando en el específico marco de sus capacidades, poderes o competencias individuales que son, al mismo tiempo, también sociales. ${ }^{70}$

\section{Actores atípicos o disfuncionales}

Para concluir este capítulo, es interesante hacer algunos señalamientos sobre un tipo de actores cuya presencia causa en los tiempos recientes una especial atención. Nos referimos a aquellos que pueden ser considerados como atípicos o disfuncionales al sistema, al impulsar acciones que contravienen las prácticas

aceptadas y las normas vigentes de la sociedad internacional, no sólo en un sentido

${ }^{70}$ Calduch, op. cit., p. 361. 
retador sino, sobre todo, agresivo y violento poniendo en peligro la paz y la estabilidad internacional.

Nos adentramos en este punto debido a que en muchas ocasiones, en el salón de clases surge el debate acerca de cómo debemos considerar a los grupos organizados que desarrollan actividades relacionadas con el crimen o con el terrorismo (por cierto, difíciles de deslindar), las cuales tienen una incidencia importante en las relaciones internacionales. Este planteamiento surge de consideraciones que, a pesar de ser evidentes, debemos plantear aquí. Como que son organizaciones cuyas acciones trascienden los límites de la sociedad de origen para trasladarse a ámbitos regionales y mundiales; poseen una estructura organizativa bastante integrada, en la que priva una sólida jerarquía que es reconocida y respetada por sus integrantes; en su interior existen normas, reglas, principios e incluso valores que son observados por la totalidad; cuentan con ramales o células que se ubican en diferentes contextos regionales o mundiales; acumulan cuantiosos recursos que en ocasiones pueden competir o rebasar a aquellos de los que dispone un Estado; establecen vínculos con otros actores internacionales para facilitar el cauce de sus acciones.

Con todo, no podemos desconocer que por ser organizaciones que se mueven al margen de la ley (nacional e internacional), aunque sus acciones inciden en las relaciones internacionales, lo hacen en un sentido negativo y disfuncional al sistema. Entre otras razones, porque los Estados tienen que dirigir una parte considerable de su acción para combatirlos; en el esfuerzo se invierten cantidades considerables del presupuesto tanto de los propios Estados como de organizaciones internacionales; desquician a las sociedades y las desvían de sus objetivos de bienestar, de desarrollo y de paz al provocar guerras y conflictos, más o menos prolongados en el tiempo y extendidos en los territorios; modifican las economías de los países al introducir cantidades superlativas de dinero que busca convertirse en capital (mediante el lavado) a través de la inversión bancaria o inmobiliaria con afectaciones o desequilibrios que afectan al consumidor de base; al vincularse con otros entes gubernamentales, trasnacionales e internacionales, promueven la corrupción, el compromiso disfuncional ante el cumplimiento de la ley; lesionan a sectores importantes de la sociedad (principalmente a los jóvenes) e introducen prácticas y valores nocivos y que se van arraigando a tal grado que son difíciles de combatir. ${ }^{71}$

${ }^{71}$ Para una visión más detallada de su estructura, funcionamiento y efectos que llevan a hablar de una "mundialización criminal", véase: Yann Braem, "Les Acteurs Illégaux: Le Devéloppement de la Criminalité Internationale” en Frédéric Carillon, op. cit., pp. 99-104. 


\section{A manera de conclusión}

El tema de los protagonistas de relaciones internacionales es absolutamente central para la comprensión de la totalidad que nos proponemos estudiar. No basta con intentar identificar los procesos que caracterizan a la sociedad en un momento histórico determinado si no identificamos a los entes que los impulsan y a los que finalmente se les imponen en una relación dialéctica.

Los asuntos que se ubican en la agenda internacional son múltiples y tan variados como el movimiento del capital, el desarrollo de la economía, las innovaciones tecnológicas, las modificaciones del mercado, el combate al narcotráfico, los movimientos de liberación nacional, la negociación y concertación de acuerdos, convenios y tratados, la creación de zonas de libre comercio, la formación de alianzas políticas y militares, el deterioro del medio ambiente, la conservación de los recursos naturales, la realización de procesos electorales en un país, los movimientos migratorios, la extensión o el combate a la pobreza, las modificaciones de la demografía, la realización de reuniones o cumbres internacionales, en fin, las políticas exteriores de los Estados y tantos otros temas que ocupan la atención de la opinión pública y que son objeto de noticias en los medios de comunicación.

Sin embargo, se corre el riesgo de caer en la reificación del análisis si todos esos temas los cosificamos sin ver que son producto de la acción de entes concretos que los impulsan y los hacen posibles en determinado momento y que al mismo tiempo se constituyen en elementos que condicionan su vida y su acción. Sin duda alguna, hay una relación dialéctica al ser interdependientes el protagonista y sus condiciones por la capacidad de influirse de manera recíproca.

\section{Fuentes}

Arenal, Celestino del, Introducción a las relaciones internacionales, Rei, México, 1996. Aron, Raymond, "Conflicto y guerra desde el punto de vista de la sociología histórica" en Stanley Hoffman, comp. Teorías Contemporáneas sobre Relaciones Internacionales, traduc. M. D. López Martínez, Edit. Tecnos, Madrid, 1963.

Aron, Raymond, “¿Qué es una teoría de las Relaciones Internacionales?, Revue Francaise de Science Politique, Vol. XVII, núm. 5, octubre de 1967, pp. 837-861, traduc. David Sarquís, ITESM, Campus Monterrey, México, primavera de 1998.

Bauer, Raymond, Ithiel de Sola Pool y Lewis Dexter, American Business and Foreign Policy, Atherton, Nueva York, 1963. 
Biscaretti, Paolo, Introducción al derecho constitucional comparado, Fondo de Cultura Económica, México, 1996.

Braem, Yann, "Les Acteurs Illégaux: Le Devéloppement de la Criminalité Internationale" en Frédéric Charillon, Les Relations Internationales, La Documentation Francaise, Paris, 2006, pp. 99-104.

Cacho Sánchez, Yaelle, "Reconocimiento de Estados/Recognition of States /Reconnaissance des États" en Juan Carlos Pereira (coord.), Diccionario de Relaciones Internacionales y Politica Exterior, Ed. Ariel - Ministerio de Defensa, Madrid, 2008.

Calduch Cervera, Rafael, Relaciones Internacionales, Ediciones Ciencias Sociales, Madrid, 1991.

Charillon, Frédéric, Les Relations Internationales, La Documentation Francaise, Paris, 2006, 208 pp. Charillon, Frédéric, Les Relations Internationales, La Documentation Francaise, Paris, 2006, 208 pp.

Cid Capetillo, Ileana y Pedro González Olvera, "Los sujetos de las relaciones internacionales" en Relaciones Internacionales, núms. 33-34, UNAM, Facultad de Ciencias Políticas y Sociales, Centro de Relaciones Internacionales, México, juliodiciembre de 1984, pp. 127-130.

Cid Capetillo, Ileana, "La discusión sobre los actores en el escenario internacional" en Política y Cultura, núm. 10, Universidad Autónoma MetropolitanaXochimilco, México, verano de 1998, pp. 47-60.

Cieslik, Thomas, "¿Es el Estado de Bienestar europeo un modelo para México? La inclusión social como elemento de la política exterior de la Unión Europea” en Roberto Peña Guerrero (coordinador). México-Unión Europea. Asociación estratégica para la gobernabilidad y la inclusión social, UNAM - Plaza y Valdés, México, 2008.

Consejo Económico y Social (ECOSOC), en http://www.cinu.org.mx/onu/ estructura/ecosoc.htm\#ong

Consejo Económico y Social (ECOSOC), en http://www.un-ngls.org/ spip?page $=$ article $=1519$

Del Arenal, Celestino, Introducción a las relaciones internacionales, Rei, México, 1996.

Dormoy, Daniel, "Les Organisations Internationales" en Frédéric Charillon. Les Relations Internationales, La Documentation Francaise, Paris, 2006, pp. 69-74.

Gómez Rueda, Héctor, Teoría y doctrina de la geopolítica, Ed. Astrea, Buenos Aires, 1977.

Granell Trías, Francesc, "Organización Internacional / International Organization / Organisation Internationale”, en Juan Carlos Pereira (coord.), Diccionario de Relaciones Internacionales y Política Exterior, Ed. Ariel - Ministerio de 
Defensa, Madrid, 2008.

Hobbes, Thomas, Leviatan, FCE, México, 2008.

Huntzinger, Jacques, "L’Universalization de l'Etat Nation" en Ileana Cid Capetillo, compiladora, Lecturas básicas para introducción al estudio de las relaciones internacionales, FCPyS, UNAM, México, 1999.

Keohane, Robert O. y Joseph S. Nye, Poder interdependencia. La politica mundial en transición, traduc. Herber Cardoso Franco, Grupo Editor Latinoamericano, Buenos Aires, 1988, 305 pp.

López B., Eduardo, Manual de derecho positivo mexicano, Ed. Trillas, México, 1996.

Marchesin, Philippe. Introduction aux Relations Internationales, Editions Karthala, Paris, 2008, 224 pp.

Neila Hernández, José Luis, "Estado-Nación / Nation State / État-Nation", en Juan Carlos Pereira (coord.), Diccionario de Relaciones Internacionales y Política Exterior, Ed. Ariel - Ministerio de Defensa, Madrid, 2008.

Organización de Naciones Unidas, "Número record de ONGs buscan participación en la ONU”, Nueva York, 31 de enero de 2011, en http:// www.un.org/es/development/desa/news/ecosoc/record-number-of-ngosseeking-participation-in-the-un.html

Ortega Elizalde, Blanca Teresa, Expansión internacionaly reconcentración regional de la gran empresa mexicana: casos de grupo Cemex, Grupo Vitro y Grupo Carso, tesis de licenciatura en Relaciones Internacionales, FCPyS, UNAM, México, 2010.

Osorio, Manuel, Diccionario de las Ciencias Jurídicas, Políticas y Sociales, Ed. Heliasta, Argentina, 1990.

Palloix, Christian, Lasfirmas multinacionales y elproceso de internacionalización, traduc. José Luis Alonso, Siglo XXI de España Editores, Madrid, 1975.

Palomares Lerma, Gustavo, "Actor internacional/ International Actor/ Acteur International, en Juan Carlos Pereira (coord.), Diccionario de Relaciones Internacionales y Política Exterior, Ed. Ariel - Ministerio de Defensa, Madrid, 2008.

Pereira, Juan Carlos (coord.), Historia de las relaciones internacionales contemporáneas, Ariel Historia, Barcelona, 2001.

Prado Lallande, Juan Pablo, "Teorías positivistas y críticas de las Relaciones Internacionales: Realismo y Constructivismo en la Cooperación Internacional" en Paulino Ernesto Arellanes Jiménez, Teorias de Relaciones Internacionales y Aplicación Práctica, Tomo II, Benemérita Universidad Autónoma de Puebla, México, 2009.

Quesada Alcalá, Carmen, "Corte Penal Internacional / International Criminal Court / Court Pénale Internationale" en Juan Carlos Pereira (coord.), Diccionario de Relaciones Internacionales y Política Exterior, Ed. Ariel - Ministerio de Defensa, Madrid, 2008. 
Renouvin, Pierre y Jean Baptiste Duroselle, Introducción a la política internacional. traduc. Manuel Camacho de Ciria, Ed. RIALP, 1968.

Sánchez Mugica, Alfonso, "El teatro sin autor. La actualidad de la perspectiva teórica de los actores" en Paulino Arellanes Jiménez (coord.), Escenarios, actoresy conflictos internacionales, Grupo Editorial Patria, México, 2008.

Santa Cruz, Arturo (ed.), El constructivismo y las relaciones internacionales, Centro de Investigación y Docencia Económicas, México, 2009.

Sarquís Ramírez, David J., La dimensión histórica de las relaciones internacionales, Grial Selections, México, 2012.

Sotillo Lorenzo, José Luis y Raquel Martínez-Gómez López, “Organizaciones No Gubernamentales / Non-Governamental Organizatios / Organisation Non Gouvernamentale" en Juan Carlos Pereira (coord.), Diccionario de Relaciones Internacionales y Política Exterior, Ed. Ariel - Ministerio de Defensa, Madrid, 2008.

Tobar D., Julio, Elementos de Ciencia Política, Universidad Católica de Ecuador, Ecuador, 1958.

Truyol y Serra, Antonio, La sociedad internacional, Alianza Universidad, Madrid, 1974.

Uriarte de Atilano, Chayo, "Pueblos indios. Esperanza de paz" en Sumario de El Informador, Guadalajara, Jal., México, 29 de julio de 2000.

Valenciano, Jaime de Pablo, "Empresa multinacionales/Transnacionales / Multinational/Transnational Compañy / Entreprise Multinationales/ Transnationale" en Juan Carlos Pereira (coord.), Diccionario de Relaciones Internacionales y Politica Exterior, Ed. Ariel - Ministerio de Defensa, Madrid, 2008.

Verdross, Alfred, Derecho Internacional Público, traduc. Antonio Truyol y Serra, Biblioteca Jurídica Aguilar, 5a. ed., 1972. 


\section{FACTORES, PROCESOS Y TEMAS DE LA AGENDA INTERNACIONAL}

\section{Teresa del Socorro Pérez Rodríguez}

\section{Introducción}

El estudio de los "factores" o "fuerzas" en Relaciones Internacionales es uno de los temas menos trabajados en la literatura de la disciplina; sin embargo, su relevancia en el análisis es fundamental, en tanto que éstos son los que determinan, a través de la interacción que generan entre los actores, la toma de decisiones y de ello las acciones de éstos en el ámbito internacional.

En el análisis de las relaciones internacionales, la interacción de los actores es determinada por diversos elementos que incluso influyen de manera importante en el funcionamiento de la sociedad internacional. Para autores como Marcel Merle, los factores son el producto de la interacción de las iniciativas de operadores individuales y colectivos; ${ }^{1}$ para otros, como Jean Baptiste Duroselle, los factores son "fuerzas" que no se ven pero cuyos efectos inciden, y en la mayoría de los casos determinan, las acciones de los actores, por lo tanto, se perciben sus efectos, siendo determinantes en la dinámica y funcionamiento de la sociedad internacional, pero sólo pueden ser reconocidos como autónomos al integrar la dimensión histórica. ${ }^{2}$ Es decir, sólo se les identifica con claridad una vez que ha pasado el tiempo.

El análisis de los factores nos permite entender las interacciones y posibilidades que ordenan el juego de los actores. La multiplicidad de acciones que se

\footnotetext{
* Profesora de Relaciones Internacionales en la Facultad de Ciencias Políticas y Sociales de la UNAM, en las áreas de Teoría y Metodología y de Estudios Regionales. Ha participado en eventos académicos en México y en el extranjero. Tiene publicaciones en diversos libros colectivos. Entre sus publicaciones más recientes se encuentra "La Directiva Europea de Retorno y el debate competencias-actores en el proceso de integración", conjunto con Guillermo Navarrete Herrejón, en Ileana Cid Capetillo, Beatriz Nadia Pérez Rodríguez y Cuauhtémoc Pérez Llanas (coordinadores), Las politicas de migración de la Unión Europea, Centro de Estudios Europeos, FCPYS, UNAM, México, 2012.

${ }^{1}$ Véase Marcel Merle, Sociología de las relaciones internacionales, traducción de Roberto Meza, Alianza Editorial, España, $7^{\mathrm{a}}$. Edición, 1995, p. 162.

${ }^{2}$ Véanse Marcel Merle, Idem., y Jean-Baptiste Duroselle, Todo imperio perecerá. Teoría sobre las relaciones internacionales, FCE, México, 1998, p. 154.
} 
entrecruzan, van desde la movilidad social, los desequilibrios económicos provocados por los flujos de capitales, la aceleración de los intercambios sociales y de la información por los cambios y avances tecnológicos, entre otros, que determinan el entorno en el que se mueven los actores.

Por lo tanto, podemos ubicar a los factores como ese entorno en el que se desarrollan los actores, que incide en las decisiones y determina sus interacciones, pero que, como señala Duroselle, no son visibles sino que lo que se percibe son sus efectos. Los analistas coinciden en que los factores que inciden en la sociedad internacional son el geográfico, demográfico, económico, técnico e ideológico.

Otro autor que habla sobre las fuerzas internacionales y su importancia en la definición del devenir internacional es Antonio Truyol y Serra, ${ }^{3}$ sin embargo, él ubica a las fuerzas internacionales como los grupos sociales que por su fuerza, magnitud o importancia pueden, en un momento determinado, intervenir en la toma de decisiones y en la política internacional, modificando la decisión y acción de los Estados; tal es el caso de las asociaciones económicas privadas, grupos de presión o lobbies. Por lo tanto, para Truyol, las fuerzas internacionales son físicamente identificables como grupos cuya capacidad para expandirse y alcanzar sus objetivos incide en la toma de decisiones de los actores.

\section{Factor Geográfico o las fuerzas de la naturaleza}

Como ya hemos mencionado, Merle y otros autores ubican el factor geográfico en el análisis de la realidad internacional, en tanto que Duroselle habla de las fuerzas de la naturaleza. El empleo del término "fuerza" de Duroselle nos remite a la idea de que estamos hablando de algo que no se ve sino que sólo se percibe y sus efectos son los que determinan las interacciones de los actores en cuestión; en tanto que el término "factor" hace referencia a uno de los elementos que, junto con otros, inciden en las decisiones de los actores y por tanto determinan sus interacciones. Por lo tanto, este último resulta ser más neutro frente al de "fuerza", el cual conlleva cierto grado de obligatoriedad y por tanto de impotencia por parte de los actores para reaccionar ante tales condiciones. Por ello, nos inclinamos más por el uso del término "factor", sin embargo, en el caso de la naturaleza o el factor geográfico, en efecto, el término de "fuerza" parece adecuado en tanto que de inicio este elemento no puede modificarse en su totalidad.

\footnotetext{
${ }^{3}$ Véase Antonio Truyol y Serra, La sociedad internacional, Sexta reimpresión de la segunda edición, Alianza Editorial, Madrid, 2008.
} 
FACTORES, PROCESOS Y TEMAS DE LA AGENDA INTERNACIONAL

El desenvolvimiento de las sociedades en el mundo resulta de la influencia de algunos aspectos que en ocasiones no son tomados en cuenta, como el clima, el relieve, los recursos naturales y las condiciones del suelo entre otros. No es sino hasta finales del siglo xIX cuando a través de una iniciativa impulsada por Friedrich Ratzel $^{4}$ que se considera la influencia de la naturaleza sobre las sociedades, permitiendo realizar un estudio más amplio de las mismas, no sólo de las actuales, sino también de aquellas que tuvieron un papel preponderante tiempo atrás. ${ }^{5}$

La Geografía Política es una de las ramas que interviene de manera significativa en el factor geográfico; su objeto de estudio son las relaciones entre los elementos geográficos, demográficos, económicos, culturales y políticos del Estado con las políticas para promover la unidad, la seguridad y la prosperidad.

Es importante señalar que para el factor geográfico no sólo resulta primordial la ubicación de un Estado, sino también la manera en la que éste utilice dicha posición y los recursos con los que cuenta. Para ello, es necesario identificar algunos elementos como el clima, ya que de acuerdo a las condiciones climáticas que se presenten es como será el comportamiento del hombre; por ejemplo, en las zonas áridas los asentamientos humanos son escasos y pequeños, sobre todo porque la vegetación de estos lugares es mínima. En las zonas cálidas, a diferencia de las anteriores, la vegetación es más rica, sin embargo también existe la presencia de un gran número de enfermedades que aquejan a la población.

El clima influye directamente en las formas de vegetación que se presentan en un país y ésta, a su vez, incide en las actividades económicas presentes, de ahí que resulte importante analizar el clima como uno de los factores primordiales en las sociedades humanas. La abundancia de los recursos como la vegetación, permite a un Estado proveer a sus sociedades de alimentos necesarios para no depender de Estados extranjeros y de esta manera mantenerse aislados económica y políticamente.

El estudio de la geografía política es otro de los elementos que no puede olvidarse pues, como ya se señaló, no sólo se enfoca a la situación geográfica, sino que también involucra otros aspectos que permiten entender el comportamiento de los Estados. Al respecto, es necesario hablar de aquellos países en los que existe una ruta natural de tránsito, ya que de ser así, pueden utilizar la fuerza para impedir que cualquier otro Estado haga uso de dicho territorio. De esta manera, quien pretenda cruzar o hacer uso del territorio estará

\footnotetext{
${ }^{4}$ Esta iniciativa comienza a partir de la publicación de su obra Politische Geographie

${ }^{5}$ Rubio García Leandro, Más sobre las Relaciones Internacionales: ciencias auxiliares e ideología y objetividad en http://www.cepc.es/rap/Publicaciones/Revistas/13/RPI_135_083.pdf
} 
obligado a pagar un impuesto, beneficiando de manera significativa la economía del país. Cuando un Estado logra la posesión de un territorio, desde el cual se permita vigilar y mantener un control mediante el impedimento de la libre circulación marítima, o de alguna otra índole, dicho Estado tendrá una ventaja tanto económica como política con respecto a los demás países.

En la actualidad, la tecnología y las comunicaciones han permitido salvar ese hecho, a través del transporte aéreo, por ejemplo; sin embargo, existe otro tipo de situaciones en las que el problema del tránsito sigue estando vigente; como ejemplo podemos citar el caso del gas natural que Rusia vende a los países europeos y que debe ser transportado atravesando a Ucrania, país que se beneficia al contar con el recurso; sin embargo, si la decisión de Rusia fuera trasladar el gas por otra ruta, Ucrania perdería su ventaja comparativa y dejaría de beneficiarse del recurso.

Otro caso que podemos mencionar con respecto a Rusia es el de la provincia de Kaliningrado, la cual se encuentra separada del resto del país por sus fronteras con Polonia y Lituania. Si bien Lituania formó parte de la Unión Soviética y por tanto Kaliningrado no estaba separado del resto del país, en 1991, Lituania se independizó de la URSS y se adhirió a la Unión Europea en 2004, dividiendo a Rusia y dejando esa provincia separada del resto, situación que obliga a que los ciudadanos de Kaliningrado requieran de visado para trasladarse a cualquier otra provincia de su propio país, Rusia. En este ejemplo, el tránsito de personas, vehículos, etc., por tierra beneficia a Lituania y Letonia como países fronterizos, por el cobro de peajes o bien el consumo que pueda existir en el traslado hacia Rusia. El caso de Kaliningrado resulta ser interesante, ya que es la salida de Rusia al Báltico y durante la época soviética representaba un puerto de entrada para muchos productos, a partir del ingreso de los países Bálticos (Lituania, Letonia y Estonia) a la OTAN y a la Unión Europea, los vínculos entre Kaliningrado y Rusia se han dificultado, particularmente en el comercio, sin embargo, éste se incrementó hacia los países de la Unión Europea.

Desde una perspectiva tradicional, la condición insular de algunos países podía definir en mucho su situación internacional. Las ventajas para el Estado insular estarían definidas por las rutas marítimas y aéreas, fundamentales para el comercio, y la posibilidad de convertirse en bases militares en periodos de guerra. Las desventajas se centran en la dependencia de productos extranjeros para abastecer a la población tanto de alimentos como de productos manufacturados. Si bien en un momento en el que el desarrollo de la tecnología y de las comunicaciones y transportes ha evolucionado a tal grado de facilitar la intercomunicación y por tanto disminuir las condicionantes físicas para los Estados, aún podemos ubicar casos en los que la condición insular benefició o perjudicó a un país. El caso más 
representativo del siglo XX fue el bloqueo económico que se realizó a Cuba tras la crisis de los misiles en 1962-1963; situación que condicionó el desarrollo de la isla y su abastecimiento fue muy limitado. Su condición insular ubicó a Cuba como un bastión importante en el enfrentamiento entre capitalistas y socialistas en América Latina, pero también facilitó realizar el bloqueo por mar.

Otro de los mejores ejemplos de la condición insular, pero en el que dirigentes y población supieron sacar beneficio fue Inglaterra, país cuya cercanía al continente le generó tanto ventajas como desventajas ante las constantes guerras con los países con litoral. Asimismo, su condición de isla le permitió desarrollar rutas marítimas y una flota mercante que se constituyó como la fuerza naval más sólida desde el siglo XVIII a mediados del siglo XX.

Así, el factor geográfico hace alusión a la situación geográfica de los actores, sus fronteras, sus costas, salidas al mar, orografía, hidrografía, clima, etc.; es decir, las características físicas del territorio o de los Estados en cuestión. Es evidente que en este caso los Estados son actores centrales, debido a que el territorio forma parte esencial de la conformación del Estado.

Su consideración en el estudio de las relaciones internacionales ha sido determinante para otros campos de estudio como la geopolítica, disciplina en la que el análisis de las condiciones geográficas resultan fundamentales para el establecimiento de estrategias. En los siglos XVII, XVIII y XIX, principalmente,

\section{Imagen 1 \\ Invasión napoleónica a Rusia}

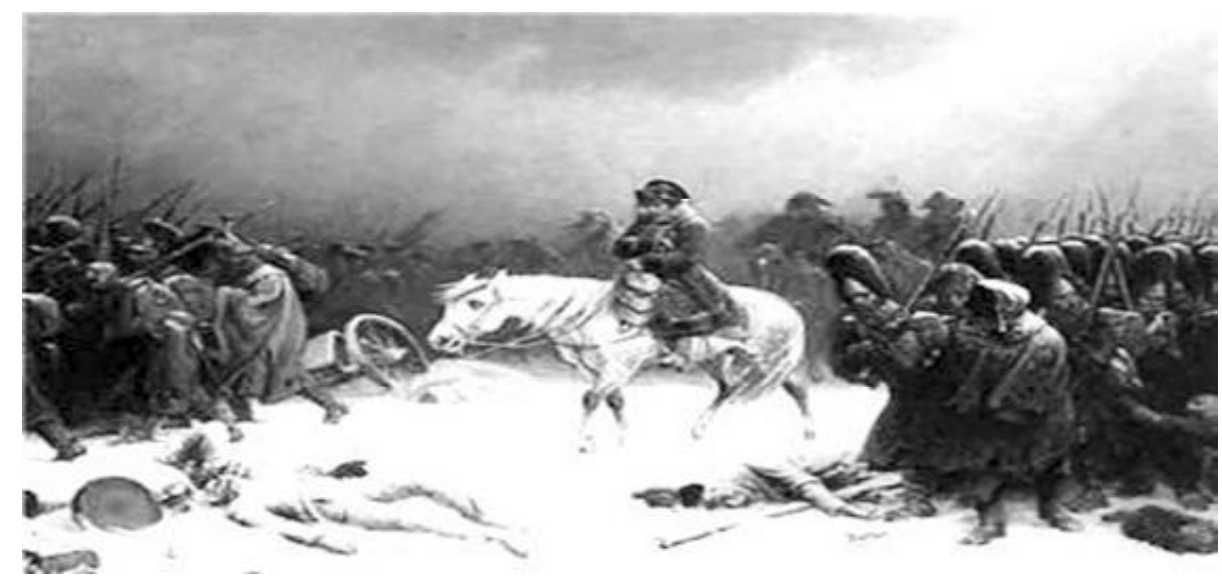

Fuente: http:/ facilparanosotros.blogspot.mx/2013/01/la-marcha-hacia-moscu.html 
Imagen 2

Invasión napoleónica a Rusia

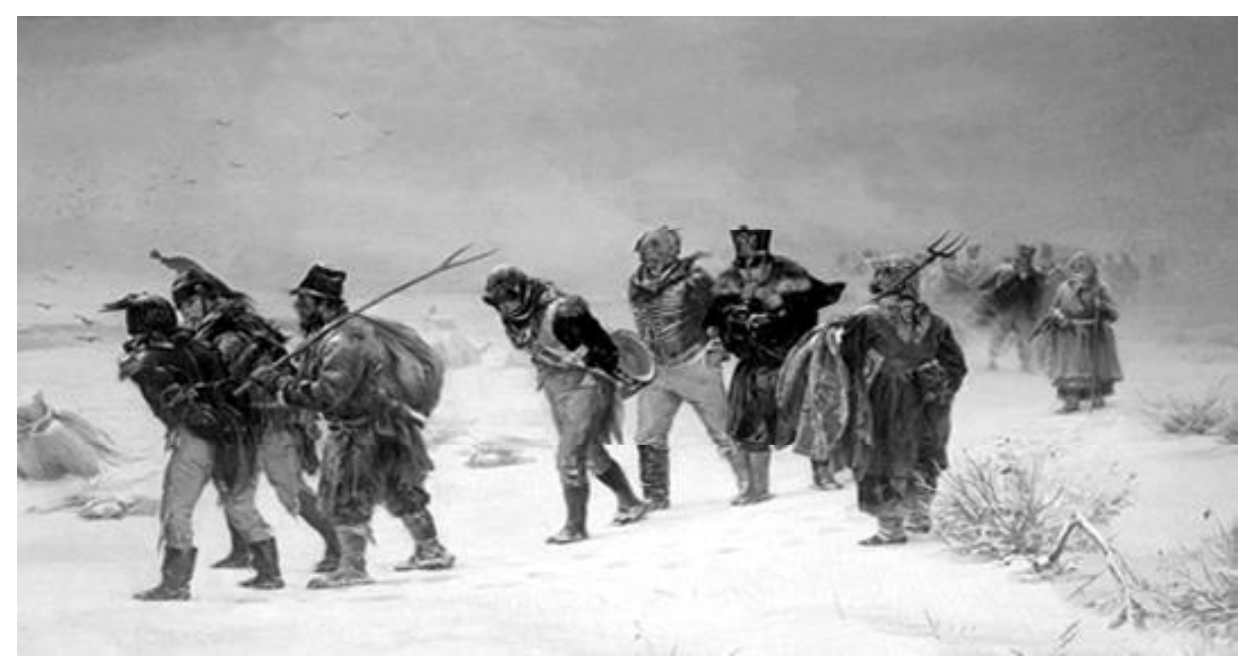

Fuente: http://spanish.ruvr.ru/2012_08_12/aniversario-marcha-Paris-1812-guerra-Napoleon/

el factor geográfico incidía en las interacciones entre los Estados, el éxito de guerras, intervenciones, alianzas, etc., era en muchos casos determinado por el factor geográfico. Como ejemplo podemos citar la invasión napoleónica a Rusia, en la que la llegada del invierno, junto con el incendio de Moscú, fue determinante para la derrota del ejército francés; tanto el clima como la distancia que existía de países en los que pudieran obtener abastecimiento, incidieron en su derrota.

Sin embargo, en el siglo XX, el desarrollo de la tecnología ha permitido que el factor geográfico, el cual en un inicio puede inclinar la balanza hacia uno de los bandos, pueda ser superado. Un ejemplo de ello es la Guerra de las Malvinas, entre Argentina y el Reino Unido, en 1982. El factor geográfico parecía beneficiar a Argentina, principalmente por la cercanía para el abastecimiento de sus tropas en armamento, alimentos y combustible, pero fue gracias a la tecnología y a la capacidad económica y militar de Reino Unido, que superaban la capacidad de las tropas argentinas, que lograron, en relativamente poco tiempo, recuperar la posesión de las islas. Por último, hemos de recordar que la condición orográfica de un país puede facilitar o dificultar una invasión, así como limitar o favorecer el desarrollo de actividades económicas de un país.

No podemos concluir este apartado sin hacer mención del cambio climático. Si bien el desarrollo de la tecnología ha hecho posible que las condiciones 


\section{Imagen 3}

Guerra de las Malvinas

\section{LA GUERRA DE LAS MALVINAS}

A 30 años de la derrota argentina en el conflicto por la soberanía de las islas del Atlántico Sur.

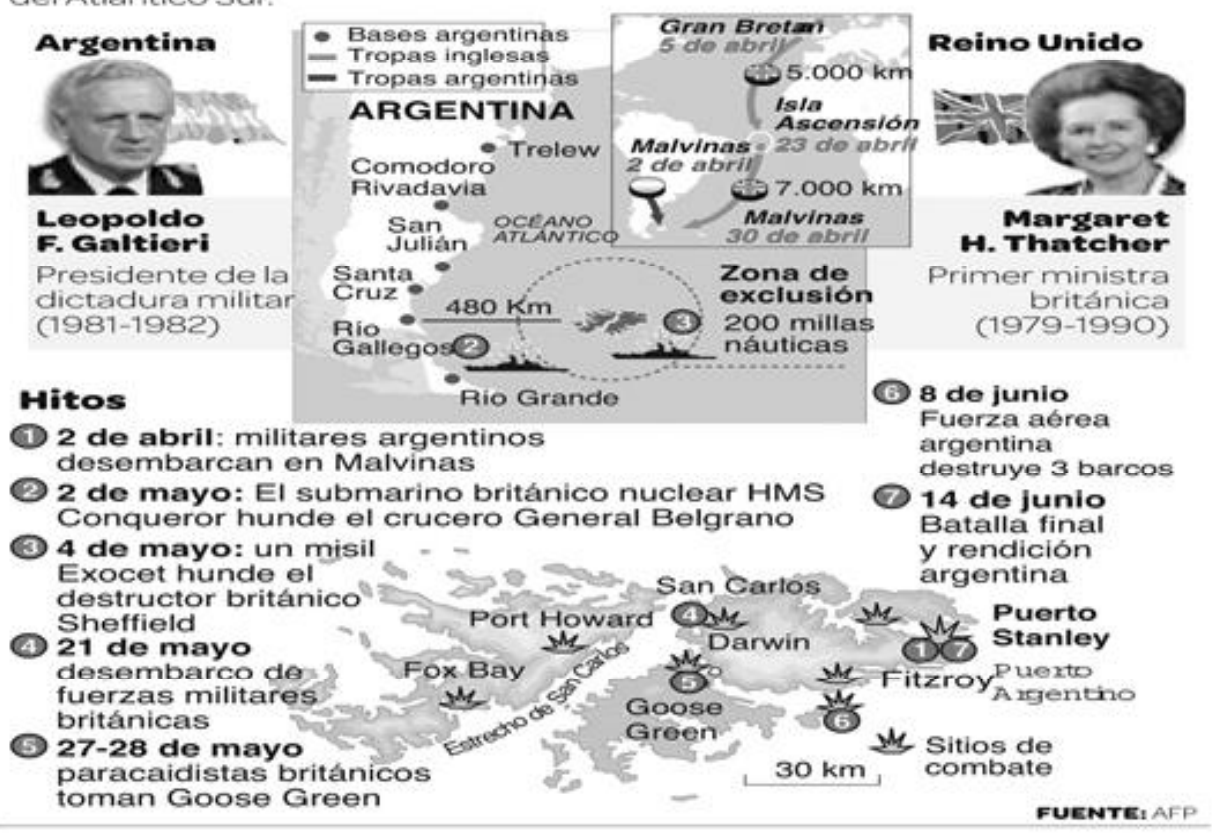

Fuente: http://infografiasdelperu.blogspot.mx/2012/03/la-guerra-de-las-malvinas.html

geográficas no sean una limitante para la acción de los Estados, y de los actores internacionales en general, ese mismo desarrollo tecnológico ha generado un desequilibrio en el medio ambiente. El alcance de esta problemática ha llevado a que se considere como un tema de Relaciones Internacionales, en tanto que la solución requiere del trabajo conjunto de los diversos actores internacionales, ${ }^{6}$ así como de acciones individuales. Asimismo, la complejidad del tema implica un esfuerzo de interdisciplinariedad, en el que tanto las Ciencias Sociales como las ciencias naturales se encuentran en la búsqueda de soluciones que los Estados

${ }^{6}$ Cfr., Emmanuelle Mühlenhöver, "De l'environnement au développement durable?" en Frédéric Charillon, Les relations internationales, La Documentation Française, Paris, 2006, pp. 135144. 
deberían implementar y las empresas acatar en beneficio de la permanencia de la vida como la conocemos hasta el día de hoy. ${ }^{7}$

\section{Factor demográfico}

La población de los Estados siempre ha sido considerada como un elemento importante, en tanto que es la que se considera para la integración de los ejércitos, pero también como mano de obra en el proceso productivo. Sin embargo, es importante distinguir la conformación de la población, es decir, la población económicamente activa, la población menor a 15 años y la población mayor a 65 años, tanto para la elaboración de políticas internas, como en la consideración de las capacidades de un Estado frente a otro.

Durante mucho tiempo se consideró que el factor demográfico era un asunto de política interna, que si bien era beneficioso contar con un gran número de jóvenes y adultos en edad para integrarse al ejército o bien contar con el mayor número de manos que labrasen el campo o se incorporaran a sectores productivos, no dejaba de ser un elemento que involucrara más en sus políticas nacionales a los Estados.

En la actualidad, el factor demográfico ha adquirido mayor relevancia, no sólo como asunto de Estado, sino en función de problemas globales cuya solución implica la colaboración internacional en temas como el deterioro ambiental y pandemias como el VIH/SIDA, entre otros, y que afectan directamente a la población.

La población mundial se ha incrementado significativamente, alcanzando una cifra cercana a los siete mil millones de habitantes, con lo que eso implica respecto a los servicios que deben ser suministrados, la atención de salud, alimentación, vivienda, educación, etc.

La creciente preocupación por las condiciones de pobreza y falta de acceso a satisfactores mínimos como agua potable, servicios de salud, entre otros, ha llevado a que los Estados a través de organizaciones internacionales establezcan desde un concepto de desarrollo más complejo que incorpore, además del incremento del Producto Interno Bruto, otros indicadores que permitan percibir una mejor distribución de la riqueza entre la población, además de los llamados Objetivos del Milenio entre los que se encuentran la disminución de la mortalidad

\footnotetext{
${ }^{7}$ Cfr., John Vogler, "Environmental issues" en John Baylis, Steve Smith y Patricia Owens, The Globalization of World Politics. An introduction to international relations, 4 a edición, Oxford University Press, Nueva York, 2008, cap. 20, pp. 352-368.
} 
FACTORES, PROCESOS Y TEMAS DE LA AGENDA INTERNACIONAL

\section{Cuadro 1. Población mundial}

\begin{tabular}{|c|c|c|c|c|c|c|}
\hline Año & $\begin{array}{c}\text { Población } \\
\text { Mundial }\end{array}$ & $\begin{array}{c}\text { Población } \\
\text { Económicamente } \\
\text { Activa (\%) }\end{array}$ & $\begin{array}{c}\text { Mujeres } \\
(\%)\end{array}$ & $\begin{array}{c}\text { Población } \\
\text { entre 0 y } \\
14 \text { años } \\
(\%)\end{array}$ & $\begin{array}{c}\text { Población } \\
\text { entre 15 y } \\
64 \text { años } \\
(\%)\end{array}$ & $\begin{array}{c}\text { Población } \\
\text { de } 65 \text { años } \\
\text { de edad y } \\
\text { más }(\%)\end{array}$ \\
\hline 2002 & $6.272 .454 .870,2$ & 65.2 & 49.6 & 29.4 & 63.5 & 7.0 \\
\hline 2005 & $6.503 .186 .030,0$ & 65.2 & 49.6 & 28.2 & 64.5 & 7.3 \\
\hline 2007 & $6.658 .468 .720,0$ & 64.8 & 49.6 & 27.6 & 65 & 7.4 \\
\hline 2009 & $6.815 .849 .599,0$ & 64.4 & 49.6 & 27.1 & 65.4 & 7.5 \\
\hline 2011 & $6.973 .738 .433,0$ & $64.2(2010)$ & 49.6 & 26.6 & 65.7 & 7.7 \\
\hline
\end{tabular}

Fuente: Elaboración propia con base en datos del Banco Mundial. Disponible en: http:// datos.bancomundial.org/

infantil, la eliminación del analfabetismo, la promoción de la igualdad de género, mejorar la salud materna y el combate de enfermedades como el VIH/SIDA y la malaria, entre otros. ${ }^{8}$

La falta de crecimiento económico en algunos países, pero sobre todo de mejores condiciones de vida, entre las que se encuentra tanto el creciente desempleo como el subempleo, lleva a un fenómeno que si bien forma parte de la historia de los pueblos, en la actualidad ha adquirido una mayor relevancia tanto por las condiciones económicas en algunos países, como por las facilidades que ofrece la globalización y el desarrollo tecnológico en el sector transportes: la migración.

La migración es uno de los aspectos del factor demográfico que a través del tiempo ha significado un cambio en la conformación de los Estados, así como en sus interacciones. Diversas son las causas de la migración, entre las que se encuentran guerras, persecuciones políticas, ideológicas o religiosas; problemas económicos como desempleo y pobreza, sin descartar incluso casos de desastres naturales.

En la actualidad existe una gran movilidad de población, pero los motivos y características difieren en función del lugar de procedencia. Un ejemplo de migración es la que se genera por movilidad laboral, y que resulta ser legal entre los países miembros de la Unión Europea, donde nacionales se trasladan a otros países por cuestión laboral. En esta región se ha incrementado la migración ilegal

\footnotetext{
${ }^{8}$ Véase Caroline Thomas, "Poverty, development and hunger" en John Baylis, op. cit., capítulo 27 , pp. 470-488.
} 
proveniente de África, Sudamérica y Turquía, entre otros. Este tipo de migrantes tienen motivaciones diferentes, pero predomina lo económico, así como quienes huyen de conflictos bélicos en África. La migración por motivos económicos se da principalmente de los países en vías de desarrollo hacia los centros industriales como las ciudades de países desarrollados.

Estos movimientos de población llevan a los gobiernos a promover acciones con el objetivo de que países desarrollados no sientan la presión del incremento repentino de la población, como que los países en desarrollo no sufran, tal como sucede, la pérdida de cerebros, es decir, población de alto nivel académico, en la que el Estado invirtió proporcionándole educación y salud, entre otros beneficios, y que una vez concluidos los estudios, deciden migrar en busca de mejores condiciones económicas y de vida.

Entre las acciones que se han instaurado en busca de limitar la migración a países desarrollados podemos citar el cierre de fronteras, a través de medidas burocráticas, como las restricciones en el visado y a manera de ejemplo podemos mencionar el caso de Canadá y México; o bien la construcción de barreras físicas tales como vallas (caso México-Estados Unidos o Chipre dividiendo la parte griega de la turca, entre otros).

Otra forma en que los Estados pueden dar solución a este fenómeno son acuerdos para la atracción de cierto número de trabajadores y para sectores en los que los países desarrollados carecen de suficiente mano de obra; tal es el caso del Acuerdo Bracero entre México y Estados Unidos en los años cuarenta y cincuenta.

Asimismo, la atracción de inversión extranjera y el establecimiento de industrias, maquilas y empresas permiten, o al menos ese sería uno de los objetivos, retener a la población en el país de origen al ofrecer oportunidades de empleo, lo que no necesariamente significa riqueza ni desarrollo para el país receptor de la inversión.

La diversidad de soluciones que los países dan a la migración va en función, principalmente, de las condiciones económicas, la situación social y lo favorables o no que sean respecto a la integración de los migrantes. Hay países cuya condición de poca población o su situación económica, así como sus valores, resultan tener políticas más benévolas respecto a los migrantes, pero en los últimos años es innegable que la situación económica ha ejercido una gran presión para contener la migración.

\section{Factor económico}

El elemento económico resulta tener incidencia por sí solo en las interacciones de los actores, y en las últimas décadas este factor no sólo ha sido considerado 
como un elemento de negociación o disputa entre Estados, sino que actores como las empresas transnacionales han adquirido una gran importancia en la definición tanto de políticas internas como hacia el exterior.

Esto último representa un cambio significativo con respecto a siglos anteriores, incluso, a inicios del siglo xx, momento en el que surge la disciplina de Relaciones Internacionales, las empresas transnacionales no tenían la presencia internacional ni la incidencia que adquirieron a partir de la segunda década del siglo xx. En la actualidad, juegan un papel relevante en la política mundial al tener la capacidad de invertir, establecer filiales e industrias en otros países, así como comprar empresas de otros países.

La inversión que realizan estas empresas transnacionales puede generar empleo en los países receptores, sin embargo, estos mismos Estados, en ocasiones, se ven obligados a establecer una serie de beneficios y condiciones que favorezcan la obtención de ganancias de estas empresas, incluso se han presentado casos en los que estas empresas hacen pagos mínimos de impuestos al gobierno receptor, lo que redunda en su perjuicio.

Aunado a lo anterior, y por lo que nos interesa en este caso abordar el tema de las Empresas Transnacionales es por su incidencia en la política de los Estados, tanto interna (como los casos que mencionamos anteriormente) como hacia el exterior. Al interior, los Estados pueden realizar modificaciones a su reglamentación para adecuarse a las demandas y necesidades de estas empresas, y al exterior, sus acciones pueden estar condicionadas por los vínculos con ellas. Sin embargo, es importante no confundir que si bien las empresas tienen cada vez mayor incidencia en la política internacional, éstas siguen funcionando, primordialmente, a través de los Estados que son los que realizan los acuerdos para establecer las medidas y modificaciones necesarias para promover las inversiones y la liberalización del comercio.

Podemos encontrar varios ejemplos de la incidencia que tienen las empresas transnacionales en la historia de la política mundial, principalmente en la segunda mitad del siglo XX, así como en el siglo XXI. Tan sólo mencionemos la crisis económica más reciente de 2008, que nos lleva a una de las grandes empresas financieras estadounidenses: Lehman Brothers, que precisamente había sido reconocida como una de las más importantes a nivel mundial.

Para ejemplificar el valor económico que representan a continuación reproducimos la lista de las 25 más importantes en el mundo.

El factor económico es relevante en la participación de los Estados en la política internacional, en tanto que le confiere una mayor capacidad de interacción y de recursos frente a otros. "La potencia de un Estado depende de los factores 
Teresa del Socorro Pérez Rodríguez

\section{Cuadro 2}

Las mejores 25 empresas en el mundo (Valores en Billones de dólares, USD)

\begin{tabular}{|c|c|c|c|c|c|c|c|}
\hline Lugar & & Compañía & País & Ventas & Ganancias & Bienes & $\begin{array}{l}\text { Valor de } \\
\text { mercado } \\
\end{array}$ \\
\hline 1 & ExxonMobil & Exxon Mobil & $\begin{array}{l}\text { Estados } \\
\text { Unidos }\end{array}$ & $\$ 433.5$ & $\$ 41.1$ & $\$ 331.1$ & $\$ 407.4$ \\
\hline 2 & $\begin{array}{l}\text { JPMORGAN } \\
\text { CHASE \&CO }\end{array}$ & $\begin{array}{c}\text { JPMorgan } \\
\text { Chase }\end{array}$ & $\begin{array}{l}\text { Estados } \\
\text { Unidos }\end{array}$ & $\$ 110.8$ & $\$ 19$ & $\$ 2,265.8$ & $\$ 170.1$ \\
\hline 3 & & $\begin{array}{l}\text { General } \\
\text { Electric }\end{array}$ & $\begin{array}{l}\text { Estados } \\
\text { Unidos }\end{array}$ & $\$ 147.3$ & $\$ 14.2$ & $\$ 717.2$ & $\$ 213.7$ \\
\hline 4 & & $\begin{array}{c}\text { Royal Dutch } \\
\text { Shell }\end{array}$ & Países Bajos & $\$ 470.2$ & $\$ 30.9$ & $\$ 340.5$ & $\$ 227.6$ \\
\hline 5 & ICBC (53) & ICBC & China & $\$ 82.6$ & $\$ 25.1$ & $\$ 2,039.1$ & $\$ 237.4$ \\
\hline 6 & HSBC $\mathbf{E}$ & $\begin{array}{c}\text { HSBC } \\
\text { Holdings }\end{array}$ & Reino Unido & $\$ 102$ & $\$ 16.2$ & $\$ 2,550$ & $\$ 164.3$ \\
\hline 7 & & PetroChina & China & $\$ 310.1$ & $\$ 20.6$ & $\$ 304.7$ & $\$ 294.7$ \\
\hline 8 & BnsatHeas:- & $\begin{array}{l}\text { Berkshire } \\
\text { Hathaway }\end{array}$ & $\begin{array}{l}\text { Estados } \\
\text { Unidos }\end{array}$ & $\$ 143.7$ & $\$ 10.3$ & $\$ 392.6$ & $\$ 202.2$ \\
\hline 9 & $\begin{array}{l}\text { WELLS } \\
\text { FARGO }\end{array}$ & Wells Fargo & $\begin{array}{l}\text { Estados } \\
\text { Unidos }\end{array}$ & $\$ 87.6$ & $\$ 15.9$ & $\$ 1,313.9$ & $\$ 178.7$ \\
\hline 10 & & $\begin{array}{c}\text { Petrobras- } \\
\text { Petróleo } \\
\text { Brasil } \\
\end{array}$ & Brasil & $\$ 145.9$ & $\$ 20.1$ & $\$ 319.4$ & $\$ 180$ \\
\hline 11 & & $\mathrm{BP}$ & Reino Unido & $\$ 375.5$ & $\$ 25.7$ & $\$ 292.5$ & $\$ 147.4$ \\
\hline 12 & & Chevron & $\begin{array}{l}\text { Estados } \\
\text { Unidos }\end{array}$ & $\$ 236.3$ & $\$ 26.9$ & $\$ 209.5$ & $\$ 218$ \\
\hline 13 & 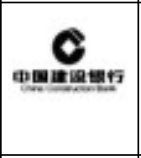 & $\begin{array}{c}\text { China } \\
\text { Construction } \\
\text { Bank } \\
\end{array}$ & China & $\$ 68.7$ & $\$ 20.5$ & $\$ 1,637.8$ & $\$ 201.9$ \\
\hline 14 & & Citigroup & $\begin{array}{l}\text { Estados } \\
\text { Unidos }\end{array}$ & $\$ 102.6$ & $\$ 11.1$ & $\$ 1,873.9$ & $\$ 107.5$ \\
\hline
\end{tabular}


FACTORES, PROCESOS Y TEMAS DE LA AGENDA INTERNACIONAL

\begin{tabular}{|c|c|c|c|c|c|c|c|}
\hline 15 & Ğeazprom & Gazprom & Rusia & $\$ 117.6$ & $\$ 31.7$ & $\$ 302.6$ & $\$ 159.8$ \\
\hline 16 & Walmart & $\begin{array}{l}\text { Wal-Mart } \\
\text { Stores }\end{array}$ & $\begin{array}{l}\text { Estados } \\
\text { Unidos }\end{array}$ & $\$ 447$ & $\$ 15.7$ & $\$ 193.4$ & $\$ 208.4$ \\
\hline 17 & & $\begin{array}{c}\text { Volkswagen } \\
\text { Group }\end{array}$ & Alemania & $\$ 221.9$ & $\$ 21.5$ & $\$ 328.7$ & $\$ 79.5$ \\
\hline 18 & & Total & Francia & $\$ 216.2$ & $\$ 15.9$ & $\$ 213$ & $\$ 132.4$ \\
\hline 19 & & $\begin{array}{c}\text { Agricultural } \\
\text { Bank of } \\
\text { China }\end{array}$ & China & $\$ 62.4$ & $\$ 14.4$ & $\$ 1,563.9$ & $\$ 154.8$ \\
\hline 20 & Darpanass & BNP Paribas & Francia & $\$ 119$ & $\$ 7.9$ & $\$ 2,539.1$ & $\$ 61.5$ \\
\hline 21 & (ㄷ) 1844 & $\begin{array}{c}\text { Bank of } \\
\text { China }\end{array}$ & China & $\$ 60.8$ & $\$ 15.8$ & $\$ 1,583.7$ & $\$ 129.1$ \\
\hline 22 & & Apple & $\begin{array}{l}\text { Estados } \\
\text { Unidos }\end{array}$ & $\$ 127.8$ & $\$ 33$ & $\$ 138.7$ & $\$ 546$ \\
\hline 23 & & $\begin{array}{c}\text { Banco } \\
\text { Santander }\end{array}$ & España & $\$ 109.6$ & $\$ 6.9$ & $\$ 1,624.7$ & $\$ 75.6$ \\
\hline 24 & & $\begin{array}{l}\text { Sinopec- } \\
\text { China } \\
\text { Petroleum }\end{array}$ & China & $\$ 391.4$ & $\$ 11.6$ & $\$ 179.8$ & $\$ 104.2$ \\
\hline 25 & $\frac{(8)}{\text { TOYOTA }}$ & Toyota Motor & Japón & $\$ 228.5$ & $\$ 4.9$ & $\$ 358.3$ & $\$ 147.9$ \\
\hline
\end{tabular}

Fuente: “The World Biggest Public Companies”, Forbes, disponible en: http:/ /www.forbes.com/ global2000/ 
geográfico, demográfico y económico, principalmente", 9 al respecto, Daniel Colard describe tres vertientes que explican la importancia del factor económico, las cuales resaltan su importancia en las relaciones internacionales. Durante el siglo XIX, los liberales entendían que existía una desvinculación entre la política y la economía en las relaciones internacionales, no así para los marxistas, quienes afirman que existe la supeditación de la política a los elementos económicos; en tanto que desde la vertiente realista, como lo señala el autor, reconocen una complementariedad y retroalimentación entre ambos elementos; por lo que se posiciona lejos del determinismo económico, tanto como sucede con el demográfico o el geográfico.

No cabe duda de que el factor económico, en sus múltiples variables: comercio, finanzas, inversión, etc., es de suma importancia en las relaciones internacionales. Desde la necesidad de apropiación de materias primas, metales, minerales, etc., ${ }^{10}$ como en la actualidad el petróleo y el gas, entre otros productos, constituyen una riqueza para el funcionamiento industrial de los países.

Asimismo, el comercio es en la actualidad un elemento que genera acuerdos, uniones aduaneras, crea organismos internacionales (Acuerdo General de Aranceles y Comercio, hoy Organización Mundial del Comercio), así como también enfrentamientos, de los cuales la historia nos proporciona un sinnúmero de ejemplos, tan sólo en la actualidad y ante una crisis mundial, la Unión Europea estableció impuestos arancelarios a los paneles solares chinos, por la sospecha de subvención a la producción y exportación de estos materiales al mercado europeo, y la respuesta de este país será restringir las importaciones de vino europeo, lo que significaría un golpe importante a las exportaciones de países como Francia, España e Italia, que representa en la actualidad un poco más de $4 \%$ de las exportaciones de los países de la Unión Europea al país asiático.

Lo anterior, tanto la participación de las empresas transnacionales como la búsqueda de materias primas, así como el interés de ampliar mercados, denotan la interacción constante que se pueden generar entre la política y las iniciativas o intereses económicos. "De tal manera que, el deseo de obtener acceso a mercados de materias primas (...) es la causa de presiones políticas, y a veces de conflictos

\footnotetext{
${ }^{9}$ Colar, Daniel, "Chapitre 2, Les facteurs de Relations Internationales", Relations Internationales, Masson, Paris, 1981, pp. 35-57; consultado en Ileana Cid Capetillo (compiladora), Lecturas básicas para introducción al estudio de Relaciones Internacionales, FCPYS-UNAM, 2001, p. 216 (traducción libre).

${ }^{10}$ Como ejemplo podemos citar la colonización de América Latina así como de otras regiones del mundo, como África.
} 
armados" $"$. Asimismo, las medidas económicas o restricciones económicas pueden ser un mecanismo de presión política, como sería el caso del embargo en los años sesenta a Cuba.

La industrialización en el siglo XX encontró en el petróleo y el gas una fuente de energía más potente y con mayores capacidades que el carbón en los siglos XVIII y XIX, lo que ha generado una dependencia hacia el petróleo como combustible, convirtiendo a éste en un producto fundamental para el desarrollo y crecimiento de los países. Lo anterior ha generado especulaciones con respecto a su producción y sobre todo a su comercialización.

Tabla 3

Producción de petróleo

(miles de barriles al día)

\begin{tabular}{|l|c|c|c|}
\hline Región & $\mathbf{2 0 0 1}$ & $\mathbf{2 0 0 6}$ & $\mathbf{2 0 1 1}$ \\
\hline Norteamérica & 13914 & 13739 & 14301 \\
\hline Centro y Sudamérica & 6722 & 6997 & 7381 \\
\hline Europa y Eurasia & 15412 & 17531 & 17314 \\
\hline Medio Oriente & 23035 & 25608 & 27690 \\
\hline África & 7897 & 9966 & 8804 \\
\hline Asia Pacífico & 7786 & 7949 & 8086 \\
\hline Mundial & 74767 & 81687 & 83576 \\
\hline
\end{tabular}

Norteamérica $=$ Estados Unidos, Canadá y México

Centro y Sudamérica $=$ Argentina, Brasil, Colombia, Ecuador, Perú, Trinidad y Tobago, Venezuela y otros.

Europa y Eurasia= Azerbaiyán, Dinamarca, Kasajstán, Noruega, Rumania, Federación Rusia, Turkmenistán Reino Unido, Uzbekistán y otros.

Medio Oriente $=$ Irán, Irak, Kuwait, Omán, Qatar, Arabia Saudita, Siria, Emiratos Árabes Unidos, Yemen y otros.

África $=$ Argelia, Angola, Chad, República del Congo, Egipto, Guinea Ecuatorial, Gabón, Libia, Nigeria, Sudán y Sudán del Sur, Túnez y otros.

Asia Pacífico= Australia, Brunei, China, India, Indonesia, Tailandia, Malasia, Vietnam y otros.

${ }^{11}$ Colard, op. cit, p. 216 (traducción libre). 


\section{Gráfica 1}

Producción de petróleo

(miles de barriles al día)

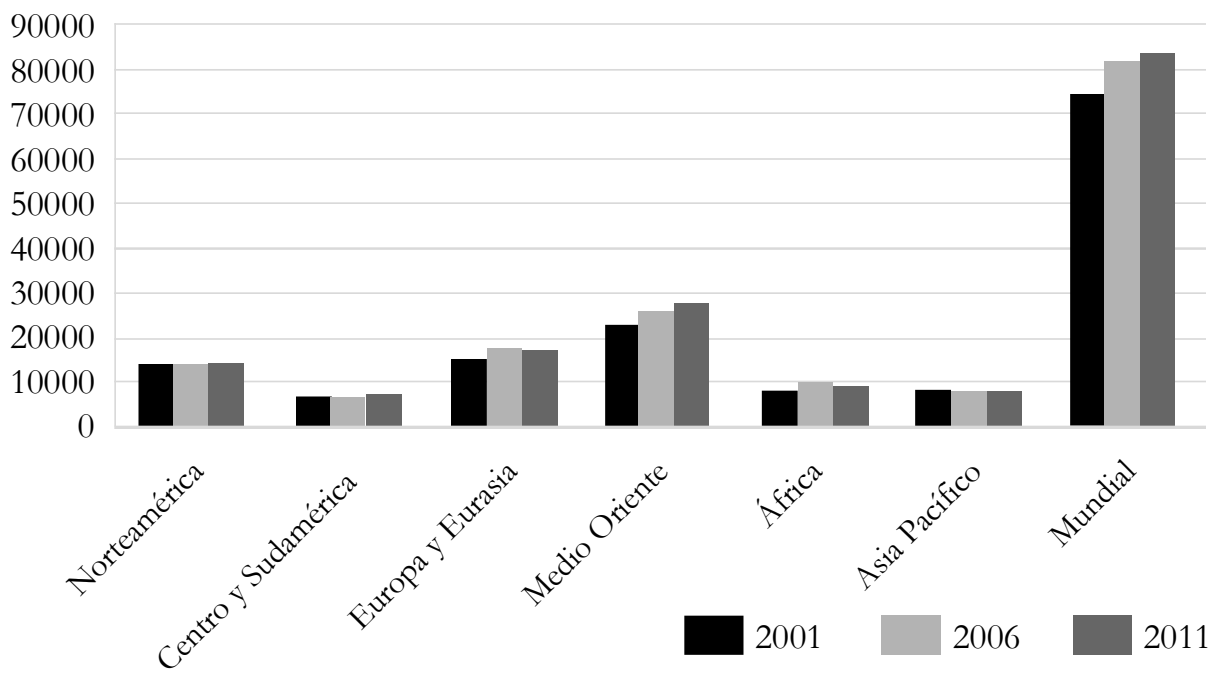

Tabla 4

Consumo de petróleo

(miles de barriles al día)

\begin{tabular}{|l|c|c|c|}
\hline Región & $\mathbf{2 0 0 1}$ & $\mathbf{2 0 0 6}$ & $\mathbf{2 0 1 1}$ \\
\hline Norteamérica & 23595 & 24953 & 23596 \\
\hline Centro y Sudamérica & 4945 & 5233 & 6241 \\
\hline Europa y Eurasia & 19593 & 20342 & 18924 \\
\hline Medio Oriente & 5260 & 6615 & 8076 \\
\hline África & 2510 & 2855 & 3336 \\
\hline Asia Pacífico & 21343 & 24875 & 28301 \\
\hline Mundial & 77245 & 84873 & 88034 \\
\hline
\end{tabular}

Norteamérica $=$ Estados Unidos, Canadá y México

Centro y Sudamérica $=$ Argentina, Brasil, Colombia, Ecuador, Perú, Trinidad y Tobago, Venezuela y otros.

Europa y Eurasia = Azerbaiyán, Dinamarca, Kasajstán, Noruega, Rumania, Federación Rusia, Turkmenistán Reino Unido, Uzbekistán y otros.

Medio Oriente $=$ Irán, Irak, Kuwait, Omán, Qatar, Arabia Saudita, Siria, Emiratos Árabes Unidos, Yemen y otros.

África $=$ Argelia, Angola, Chad, República del Congo, Egipto, Guinea Ecuatorial, Gabón, Libia, Nigeria, Sudán y Sudán del Sur, Túnez y otros.

Asia Pacífico $=$ Australia, Brunei, China, India, Indonesia, Tailandia, Malasia, Vietnam y otros. 
FACTORES, PROCESOS Y TEMAS DE LA AGENDA INTERNACIONAL

Gráfica 2

Consumo de petróleo

(miles de barriles al día)

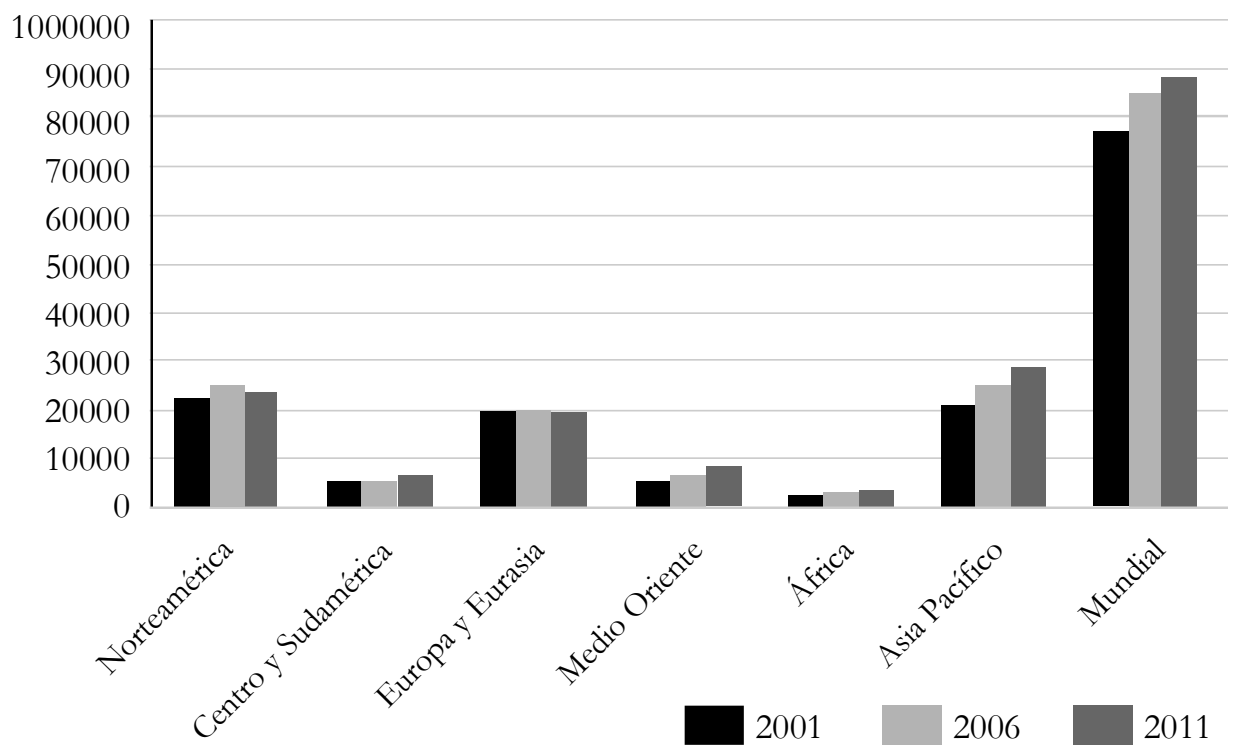

Fuente de todas las cifras: BP Statistical Review of World Energy, June 2012, http://www.bp.com/ assets/bp_internet/globalbp/globalbp_uk_english/reports_and_publications/ statistical_energy_review_2011/STAGING/local_assets/pdf/statistical_review_ of_world_energy_full_report_2012.pdf

Las cifras presentadas ponen en evidencia el déficit que existe entre la producción.

Las cifras presentadas ponen en evidencia el déficit que existe entre la producción de barriles de petróleo y el consumo y, por ende, la preocupación de los países por obtener el recurso. Esto nos lleva a la explicación de que desde finales del siglo XX, la preocupación por el abastecimiento de energéticos fósiles, como el petróleo y el gas, ha generado que se cuestione la dependencia de tales energéticos y por tanto la búsqueda de nuevas fuentes de energía, de ahí que la tecnología se esté convirtiendo en un factor importante para el desarrollo, en tanto que los países que invierten con este recurso, les es posible empezar a perfilar nuevas formas de producción. Al menos eso es lo que se esperaría desde una perspectiva muy optimista.

El hecho es que en la actualidad, el petróleo y el gas siguen siendo las principales fuentes de energía tanto para la industria como para otras actividades diarias, como son la calefacción, los automóviles, etc. Condición que ha llevado a situaciones de conflicto que han puesto en riesgo a millares de personas. Ejemplo 
de ello fue la suspensión de gas a Europa en 2009. La empresa Gazprom cesó de transferir gas a los países europeos tras comprobar que al pasar por Ucrania, se presentaban fugas, por lo que el gas no llegaba en su totalidad al destino pactado. Ello puso en evidencia la dependencia de Europa del gas ruso, por lo que se promovió la creación de un gasoducto destinado a trasladar el gas ruso por el fondo del Mar Báltico, de Rusia a Alemania, también conocido como el Nord Stream. ${ }^{12}$

Si bien el gas y el petróleo, así como otros minerales e incluso el agua, son recursos naturales, su incidencia en la industria y el desarrollo de la civilización está haciendo de ellos elementos de preocupación tanto para países desarrollados como para los que están en vías de desarrollo, lo que puede generar conflictos de diversos tipos entre las naciones. Su escasez puede generar situaciones de enfrentamiento, intervenciones u otras situaciones que podrían degenerar en conflictos armados. Sin embargo, siempre se podrá pensar en esquemas de cooperación o de comercialización, como es el caso del gas ruso y los países europeos, así como en la generación de nuevas fuentes de energía: energía solar, eólica, entre otras.

\section{Factor tecnológico}

Otro de los factores que en las últimas décadas ha generado cambios importantes en la forma en cómo se socializa la información, se realizan las transacciones económicas y en general ha transformado todos los ámbitos sociales incluso la política internacional, es la tecnología.

El desarrollo tecnológico ha tenido desde siempre una fuerte repercusión en otros factores como el económico, el militar, el social, etc., y esto se ha acentuado en años recientes. A partir de la creación de las computadoras y de la Internet a finales de los años setenta, se inició una revolución en lo que se refiere a las transacciones económicas y financieras, lo que generó una aceleración de las mismas y sus efectos no se hicieron esperar al multiplicar los riesgos y repercusiones que afectarían cualquier parte del mundo, generando olas de crisis financieras como sucedió en los años noventa, cuando se presentaron en varios puntos del planeta como en México ("Efecto Tequila"), Argentina ("Efecto Tango"), sudeste asiático (“Efecto Dragón”) cuyas repercusiones se sintieron en diversas partes del mundo.

\footnotetext{
${ }^{12}$ Véase "Rusia corta todo el gas hacia Europa" en El País, jueves 8 de enero de 2009, disponible en http://elpais.com/diario/2009/01/08/internacional/1231369201_850215.html.
} 
FACTORES, PROCESOS Y TEMAS DE LA AGENDA INTERNACIONAL

En el desarrollo de las telecomunicaciones, el uso de microcircuitos hizo posible la creación de computadoras personales, que evolucionaron a computadoras portátiles y hoy disfrutamos de teléfonos llamados inteligentes por la multiplicidad de tareas que pueden realizar, así como las tabletas que tienen relativamente pocos años en venta.

Estos aparatos han hecho mucho más fácil el uso de Internet de forma inalámbrica, lo que ha transformado la comunicación entre los individuos. De la evolución de la Internet surgieron diversos programas de comunicación que permiten la conexión casi inmediata con otras latitudes y con ello nos referimos a la posibilidad de comunicación entre individuos ubicados en diferentes países en tiempo real. En este proceso destaca la creación de dos programas que han acelerado la socialización de la información y la comunicación, e incluso en los últimos cinco años han sido utilizados para convocar movimientos sociales en diversas partes del mundo: Facebook y Twitter.

Facebook fue creado en 2004 y en 2006 se creó la primer versión de Twitter. El primero es una red social cuyo objetivo es el intercambio de contenidos entre usuarios de la Internet, ${ }^{13}$ y Twitter es definido como "una red de microblogging que permite escribir y leer mensajes en Internet que no superen los 140 caracteres. Estas entradas son conocidas como tweets". ${ }^{14}$

A través de estos dos mecanismos, los jóvenes acceden al intercambio de información de manera casi inmediata y lo relevante de estos instrumentos es que se han convertido en espacios para el intercambio de opiniones sobre diversos tópicos que afectan la vida cotidiana, desde preocupaciones por el medio ambiente, opiniones y críticas a políticos, hasta convocatorias a manifestaciones y movimientos sociales como sucedió en varios países de Medio Oriente, así como en Madrid contra los recortes y ajustes económicos en España impuestos para hacer frente a la crisis iniciada en 2008.

Cabe resaltar que el factor tecnológico ha transformado la participación de la sociedad civil en temas que antes permanecían en otros ámbitos, hoy, gracias a la tecnología, la participación de la sociedad es constante y se multiplica y amplía a otras regiones del mundo, lo que ejerce una presión sobre la toma de decisiones en los gobiernos. Las siguientes gráficas son muestra de la relevancia que han adquirido estos mecanismos como forma de comunicación en el mundo:

${ }^{13}$ http:/ / www.cnnexpansion.com/tecnologia/2012/10/04/1000-millones-de-personas-usanfacebook

${ }^{14}$ http://mashable.com/2011/05/05/history-of-twitter/ 
Gráfica 3

Los 20 países con mayor número de cuentas twitter cuentas creadas antes de 01-07-2012

\section{$\begin{array}{lllllllllllllll}0 & 10 & 20 & 30 & 40 & 50 & 60 & 70 & 80 & 90 & 100 & 110 & 120 & 130 & 140\end{array}$}

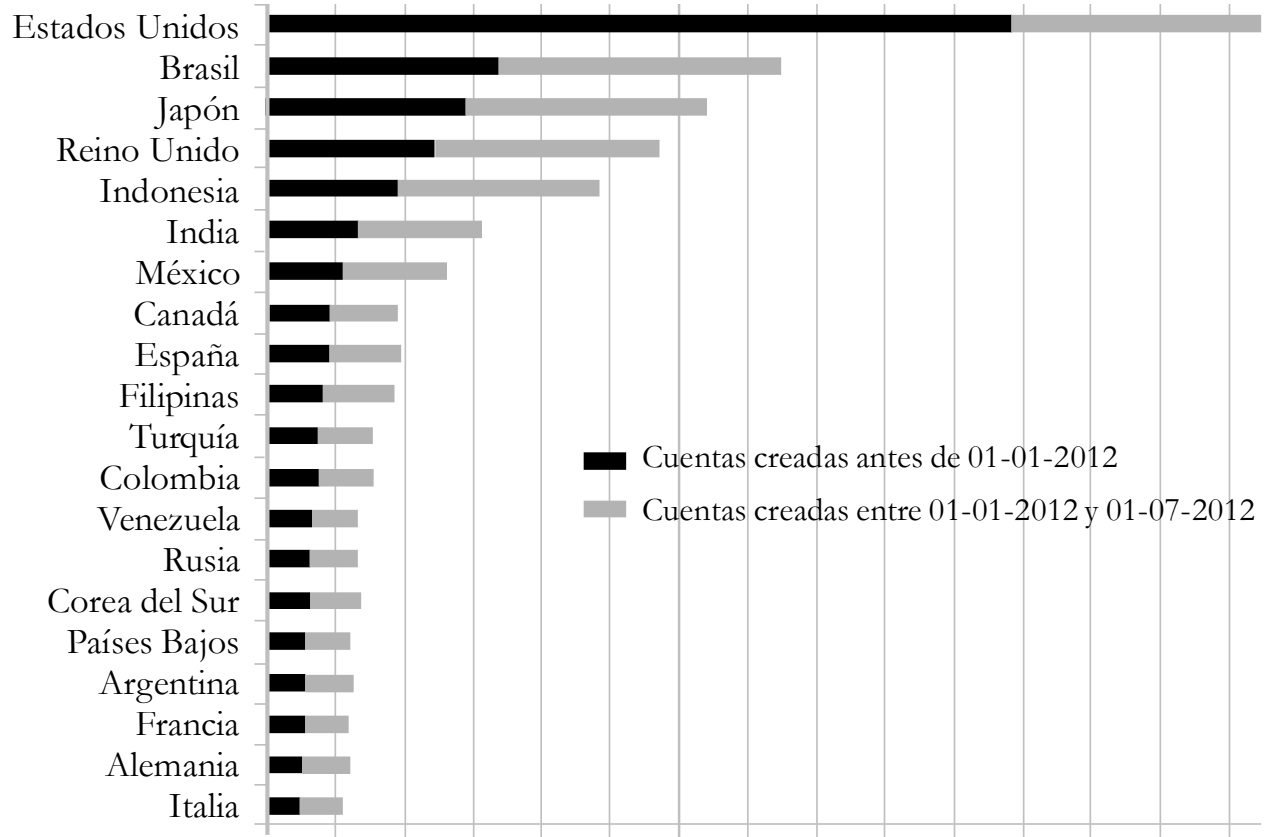

Fuente:http://semiocast.com/publications/2012_07_30_Twitter_reaches_half_a_billion _accounts_140m_in_the_US

\section{Gráfica 4}

Usuarios de Facebook por país

157.4 (millones)

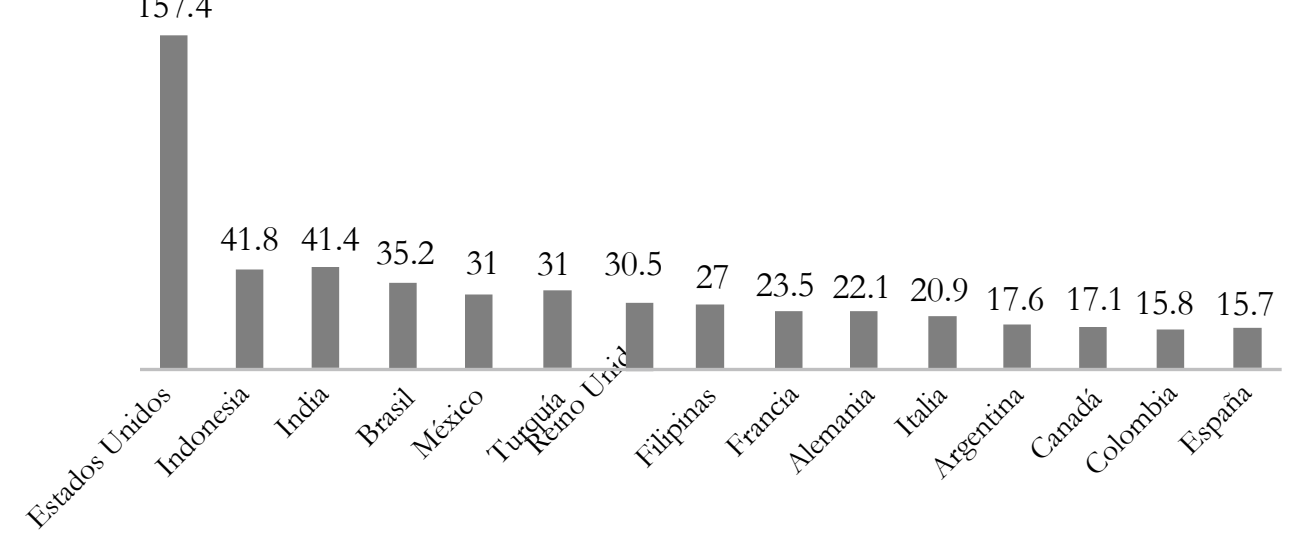

Fuente: Elaboración propia con datos de http://www.fortunecat.it/ 
FACTORES, PROCESOS Y TEMAS DE LA AGENDA INTERNACIONAL

Tabla 5

Porcentaje de usuarios por género de Facebook por país

\begin{tabular}{|l|c|c|}
\hline \multicolumn{1}{|c|}{ País } & Hombres & Mujeres \\
\hline Estados Unidos & $45.2 \%$ & $54.8 \%$ \\
\hline Indonesia & $59.3 \%$ & $40.7 \%$ \\
\hline India & $72.6 \%$ & $27.4 \%$ \\
\hline Brasil & $45.6 \%$ & $54.4 \%$ \\
\hline México & $50.3 \%$ & $49.7 \%$ \\
\hline Turquía & $63.3 \%$ & $36.7 \%$ \\
\hline Reino Unido & $48.4 \%$ & $51.6 \%$ \\
\hline Filipinas & $48.3 \%$ & $51.7 \%$ \\
\hline Francia & $48.5 \%$ & $51.5 \%$ \\
\hline Alemania & $51.9 \%$ & $48.1 \%$ \\
\hline Italia & $53.6 \%$ & $46.4 \%$ \\
\hline Argentina & $48.0 \%$ & $52.0 \%$ \\
\hline Canadá & $46.5 \%$ & $53.5 \%$ \\
\hline Colombia & $49.4 \%$ & $50.6 \%$ \\
\hline España & $49.6 \%$ & $50.4 \%$ \\
\hline
\end{tabular}

Fuente. Elaboración propia con datos de http://www.fortunecat.it/

De igual manera, la tecnología ha transformado otros aspectos de la política internacional, como la manera de hacer la guerra. El tema tecnológico siempre ha sido importante en la creación de armas; en la actualidad, éstas han evolucionado al grado en que se han incorporado robots teledirigidos para la supervisión en zonas de guerra, así como para el ataque, esto último ha puesto en cuestionamiento las prácticas y resultados militares con respecto a ataques a civiles.

Lo militar es un factor que está estrechamente vinculado al factor económico y al tecnológico; además, su eficiencia depende de otros elementos como lo serían el entorno geográfico y/o el ideológico, ya que el primero, por ejemplo, podría limitar el traslado de armas o el paso de tanques o automotores, por condiciones montañosas, pantanosas, fluviales, etc.; y el segundo, en el caso de una población que se sienta agredida ante la intervención de otro país, puede establecer acciones de defensa civil. Un caso que podemos citar para ejemplificar lo anterior sería la intervención estadounidense en Viet Nam, donde la sociedad tuvo una participación importante en la defensa de su territorio, resistiendo el embate 
tecnológico y armamentista con el que contaba Estados Unidos; aunado a la condición selvática del país que obligaba a los soldados estadounidenses a avanzar por tierra, y con un mínimo de automotores, lo que facilitaba las acciones de resistencia de los nacionales.

\section{Factor ideológico}

Otro de los factores que ha sufrido cambios importantes es el ideológico. Las ideologías, de acuerdo a la definición de Marcel Merle, "son conjuntos de representaciones que implican a la vez una visión coherente de la realidad, apta para proporcionar una explicación de la totalidad de los fenómenos, y la adhesión a un sistema de valores capaz de justificar el compromiso con la acción". ${ }^{15}$

Si bien a mitad de los años cincuenta del siglo XX, después de la Segunda Guerra Mundial, el factor ideológico jugaba un papel fundamental en la política internacional al estar dividido el mundo en dos bloques político-militares e ideológicos: capitalismo versus socialismo; el fin de la Guerra Fría y la desintegración del bloque socialista, y por ende la transición de los países exsocialistas a economías de mercado y a sistemas democráticos fue el origen del cambio respecto a este factor.

Una explicación que se da respecto al cambio ideológico es que el enfrentamiento entre capitalistas y socialistas se transformó en un enfrentamiento entre "civilizaciones", o "choque de civilizaciones" como lo llamaba Samuel Huntington, en el que la confrontación hace referencia a modelos democráticos y laicos frente a los modelos autocráticos propios de los pueblos islamistas. En este caso podemos retomar la definición de Merle en la que se hace referencia a la adhesión a un sistema de valores. Se presentará la exaltación de valores en ambos casos.

La democracia y la exaltación de las libertades, así como la defensa de los derechos humanos, tomaron lugar frente a los sistemas islámicos, en los que aún persisten, al menos así lo es en algunos países, prácticas religiosas vinculadas a la política, restricciones a las mujeres, entre otros aspectos que representan, para las sociedades democráticas del siglo XXI, violaciones a los derechos humanos, especialmente de las mujeres y los niños. Sin embargo, ésta es sólo una explicación del cambio de valores que se suscitó tras el fin de la confrontación Este-Oeste,

\footnotetext{
${ }^{15}$ Marcel Merle, Sociología de las relaciones internacionales, op. cit., p. 313.
} 
FACTORES, PROCESOS Y TEMAS DE LA AGENDA INTERNACIONAL

que dominó la última mitad del siglo XX. Indudablemente la desintegración del bloque socialista y el consecuente descrédito del socialismo real llevaron a nuevas formas de asociación y sobre todo a la identificación de valores diversos como los nacionalismos o el liberalismo, e incluso han surgido grupos neofascistas y neonazis.

El factor ideológico, en tanto que representa un conjunto de valores, incluye a la religión, la identidad y el nacionalismo, entre otros, que van más allá de lo que los gobiernos pueden administrar; cuando los valores de la población coinciden o son reforzados por los gobiernos, el Estado se consolida, de lo contrario, puede colapsar o enfrentarse a movimientos sociales, que a pesar de estar en su esfera de política interna, tendrán incidencia en su política exterior y sus relaciones con vecinos y socios internacionales.

\section{A modo de conclusión}

El análisis de los factores debe ser considerado como el reconocimiento del entorno en el que se suscitan los vínculos entre los actores. Es decir, son aquéllas condiciones que enmarcan las relaciones entre actores. Sería un error, tal como lo menciona Marcel Merle, apreciar a los factores como los elementos más importantes a considerar en un análisis de relaciones internacionales, ya que forman parte del sistema internacional, permiten identificar algunas de sus características, sin embargo, no representan al sistema en su totalidad. Las interacciones que se dan entre los actores contemplan los factores, es decir, el entorno en el que se desarrollan, así como las capacidades de los actores involucrados, y pueden incidir en la toma de decisiones de los gobiernos, por lo que no pueden obviarse. En resumen, quien desee hacer un análisis del ámbito internacional debe considerar los factores, los actores y sus capacidades, para realizar un análisis eficiente que considere los elementos del sistema internacional, pero no como la suma de las partes, sino como los elementos que constituirán un todo diferenciado.

\section{Fuentes}

Baylis, John; Smith, Steve y Owens, Patricia, The Globalization of World Politics. An Introduction to international relations, Oxford University Press, New York, 2008, $622 \mathrm{pp}$. 
Colar, Daniel, "Chapitre 2, Les facteurs de Relations Internationales", Relations Internationales, Masson, Paris, 1981, pp. 35-57, en Ileana Cid Capetillo (compiladora), Lecturas básicaspara Introducción al Estudio de Relaciones Internacionales, FCPyS-UNAM, 2001, p. 216.

Del Arenal, Celestino, Introducción a las relaciones internacionales, Tecnos, Madrid, $5^{\text {a }}$ reimpresión, 2003, 495 pp.

Duroselle, Jean-Baptiste, Todo imperio perecerá. Teoría sobre las relaciones internacionales, FCE, México, 1998, 468 pp.

Merle, Marcel, Sociología de las relaciones internacionales, Alianza Editorial, España, $7^{\text {a }}$. Edición, 1995, 587 pp.

Mingst, Karen, Fundamentos de las Relaciones Internacionales, CIDE, Colección de Estudios Internacionales, 2a . reimpresión, 2009, 600 pp.

Mühlenhöver, Emmanuelle, "De l'environnement au développement durable?" en Frédéric Charillon, Les relations internationales, La Documentation Française, Paris, 2006, pp. 135-144.

Ortiz, Eduardo, El estudio de las Relaciones Internacionales, FCE, Chile, 2000, 197 pp.

Renouvin, Pierre y Duroselle, Jean-Baptiste, Introducción a la historia de las relaciones internacionales, FCE, México, 519 pp.

Truyol y Serra, Antonio, La sociedad internacional, Alianza Editorial, Madrid, edición de 2008, 260 pp. 


\section{EN TORNO AL ENTORNO: LOS FACTORES INTERNACIONALES}

\section{María Fuencisla Marín Castán*}

Con esta comunicación se pretende incidir en la colaboración que debe guiar el trabajo de los internacionalistas, docentes e investigadores que conforman nuestra comunidad científica. Se estima así la oportunidad de detenernos sobre algunos extremos relevantes a propósito de la conceptualización de los factores internacionales, de la identificación de sus rasgos característicos y de su clasificación cuando se mantiene una desatención al respecto que dificulta la vertebración de las Relaciones Internacionales y su elevación al rango de ciencia madura que no puede seguir pasando desapercibida. Para ello se toma como pretexto las incorrecciones que se cometen al considerar al agua como un "factor internacional".

Entiendo que es en el marco abarcador de la ciencia de Relaciones Internacionales en que encuentra mejor acomodo la idea de globalización cuyo empleo se generaliza a raíz de la toma de conciencia de la interdependencia descontrolada tras de la desaparición del orden bipolar, donde cabe recibir y evaluar cualquier aportación que contribuya a teorizar acerca de los factores internacionales. Se aspira aquí a apuntar hacia la necesidad de un tratamiento sistematizado de dichos condicionantes que despierte el interés de los especialistas más reconocidos de manera que, entre otros elementos doctrinales dispersos, reciban la ubicación correspondiente en el corpus disciplinario.

No puede ser nuestro cometido un análisis que compete a las ciencias físico naturales pero tampoco se puede obviar la complejidad de las combinaciones que organizaron la vida y, por consiguiente, la trayectoria de la humanidad sobre la faz de la Tierra, pues en el caso que nos ocupa, el agua -por exceso o por defecto- es causa de muerte y produce epidemias y hambrunas por doquier relegando a segundo plano cualesquier otras pérdidas cuantificables en términos económicos y obscureciendo la armonía cotidiana de su aprovechamiento. Lo

* Doctora en Derecho Internacional Público y Relaciones Internacionales. Profesora titular de Universidad, Sección Departamental del Departamento Interfacultativo de Derecho Internacional Público y Relaciones Internacionales (Estudios Internacionales) de la Universidad Complutense de Madrid. 


\section{María Fuencisla Marín Castán}

único positivo de tales tragedias es que activan el quehacer de quienes nos dedicamos a prever acontecimientos del porvenir para alertar comportamientos adecuados a los riesgos que se consigan identificar sirviéndonos de cuantas experiencias y recursos procuren utilidad. Lo negativo, sin embargo, es un predominio de versiones catastrofistas que eluden el contacto multidisciplinar para adentrarse en la hondura de la realidad objeto de estudio y que subestiman la inteligencia ajena para movilizarse conjuntamente contra la degradación medioambiental contribuyendo, así, a que el agua se perciba más como un enemigo excepcional y fuente de conflicto que como el aliado sempiterno del hombre.

Bajo algunos de estos prejuicios recurrentes que vienen a otorgar al agua atribuciones perjudiciales o benefactoras al punto de transferirle responsabilidad sobre la salud y el patrimonio de las personas, subyace el silencio acerca de la dimensión emocional de quienes sí sabemos con certeza que contamos inevitablemente con sentimientos que no sólo proyectamos sobre nuestros semejantes y que nos procuran bienestar o nos sumen en la infelicidad. Tratándose del agua, la laguna es importante porque, junto a las terapias que requiere el soporte físico de la existencia inseparable del derecho legítimo de la población mundial a la sanidad integral, debería prestarse atención a aquellos trastornos todavía reservados a la esfera de la intimidad individual que irrumpen ahora, desde cualquier procedencia y cada vez con mayor fuerza, en la convivencia internacional en la medida en que el reparto aleatorio de los recursos naturales y la disputa por los mismos genera, en ocasiones, niveles patológicos de violencia próximos a la locura.

En el proceso de arriesgarse a abandonar la seguridad de lo aprendido a través de la bibliografía especializada en combinación con la introspección que requiere la propia consideración en relación con los demás y en simbiosis sobre el ecosistema, e ir depurando de valoraciones acientíficas las conclusiones alcanzadas en busca de aquello que se desconoce pero se intuye imprescindible para aprehender en su multidimensionalidad los procesos y los fenómenos que tienen lugar en el seno de la sociedad internacional, ha sido de gran valor la guía de Rafael Calduch, quien ha venido madurando el estudio de los factores

\footnotetext{
${ }^{1}$ Véase Rafael Calduch Cervera, "Cultura y civilización en la sociedad internacional" en Iglesia, Estado y Sociedad Internacional. Libro homenaje a D. José Jiménezy Martinez de Carvajal, Editorial San Pablo-CEU, Madrid, 2003, pp. 299-323; así como "Cultura y civilización en la conformación de la sociedad internacional" en Derechos Humanos y conflictos internacionales. Curso de Derecho Internacionaly Relaciones Internacionales de Vitoria-Gasteiz,2006, Servicio Editorial de la Universidad del País Vasco, Bilbao, 2006, pp. 25-80.
} 
internacionales, más recientemente focalizando su atención en el factor cultural. ${ }^{1}$ A partir de sus explicaciones, de su producción y de la documentación por él procesada que indiscriminadamente nos ofrece, se puede avanzar la exposición que sigue acerca de los factores internacionales.

\section{El contexto}

La ciencia de Relaciones Internacionales tiene como objeto material la sociedad internacional sea ésta particular o general, pretérita o actual y entendida como el ámbito preciso en que se lleva a cabo relaciones (cooperativas, conflictivas, asociativas o comunicativas) entre actores (cualquier colectividad e incluso individuos de cuyas actuaciones se deriven efectos que contribuyan a la formación, el desarrollo o la crisis de dicha macrosociedad). Los contactos, vínculos e interconexiones (relaciones) que llevan a cabo grupos humanos dotados de poder autónomo y efectiva capacidad de proyección exterior (actores) alcanzan -en ambos casos- la calidad de internacionales cuando una sociedad internacional acusa su actividad y protagonismo con independencia del momento histórico, de su correspondiente naturaleza estabilizadora o dinamizadora, de su composición, sus dimensiones, su localización o su grado de integración. ${ }^{2}$

Este planteamiento resulta aceptado por la comunidad científica como se observa de la simple contrastación de los índices de los manuales y contenidos de los programas de los centros docentes en que se imparte la asignatura de Relaciones Internacionales. Basta comprobar cómo junto a una justificación teórica y a un encuadre histórico de extensión variable, aparece tradicionalmente un capítulo o una lección que trata el Estado, las grandes potencias, la guerra, la solución pacífica de conflictos, la carrera armamentista, la diplomacia, la división Norte/Sur, la protección de los Derechos Humanos, la Organización de las Naciones Unidas, las alianzas defensivas, las organizaciones regionales, las empresas multinacionales, etc. En los textos y en las explicaciones se observa un énfasis en el peso de algunos actores y singularmente de aquellos cualificados en orden de potencia o poder en detrimento de los grupos de carácter cultural, financiero, tecnológico o religioso como, igualmente, resulta revelador comparar el número de páginas y de horas lectivas que se dedican a destacar la beligerancia del medio internacional sobre el escaso volumen y la insuficiente elaboración

${ }^{2}$ Véase al respecto los capítulos 1 (pp. 19-41), 3 (pp. 63-83), 4 (pp. 85-103) y 5 (pp. 105-111) de Rafael Calduch Cervera, Relaciones Internacionales, Ed. Ciencias Sociales, Madrid, 1991. 
que caracteriza el tratamiento de abundantes colectivos comprometidos en colaborar en todos los sectores a lo largo y ancho del planeta y por encima y hasta en contra de las barreras políticas.

No debe extrañarnos, por tanto, que el acuerdo se diluya en paralelo a la evidencia de una realidad que acaba arrojando un saldo favorable a la cooperación -como demuestra el progreso constante de la humanidad- y que continúa generando grupos sociales cuyo papel se minusvalora o aún se desestima, bien porque operan en la clandestinidad, bien porque desbordan la capacidad individual como, correlativamente, es el caso de las migraciones, de las mafias o de cualquiera de las grandes pasiones compartidas capaces de arrollar el más exhaustivo análisis asentado sobre criterios restringidos del fenómeno del poder. ${ }^{3}$

Para conciliar las divergencias quizá bastaría con conceder a los factores internacionales la atención que merecen de tal manera que, adheridos al núcleo de nuestro objeto de estudio, consideráramos la sociedad internacional como el conjunto de relaciones internacionales condicionadas por los distintos factores internacionales y protagonizados por actores internacionales igualmente sometidos a la influencia factorial en cadena. Esta configuración teórica de la sociedad internacional podemos plasmarla en la primera imagen que presentamos, la cual se puede perfeccionar aumentando o disminuyendo el tamaño de las figuras que representan a los actores internacionales para visualizar la jerarquía internacional. Cabe también poner de relieve la polaridad internacional en función del número de flechas que representan las relaciones internacionales siempre complejas y que, en mayor número, frecuencia e intensidad irradian de los actores-polo destacando su influencia. Como, igualmente, se puede jugar con los colores y/o las formas para distinguir los actores homogéneos de los heterogéneos y es posible concentrar o dispersar los puntos que, dentro de los actores, se corresponden con los individuos que los componen, para medir la cohesión interna que permite alcanzar acuerdos susceptibles de convertirse en normas de obligado cumplimiento o en instituciones tendentes a ordenar la vida internacional. Asimismo, las relaciones internacionales que expresamos con flechas, pueden contener rayas que semejan la influencia de interacciones y/o tonalidades diferentes para remarcar la interacción-clave que define la tipología relacional. De igual manera que utilizamos una especie de cadena que simboliza la interdependencia de los factores internacionales que se sobreponen a las relaciones internacionales alcanzando el interior de los actores internacionales (ver figura 1).

\footnotetext{
${ }^{3}$ Véase el capítulo dedicado al poder y las relaciones internacionales en Rafael Calduch Cervera, Relaciones Internacionales, op. cit., pp. 43-62.
} 

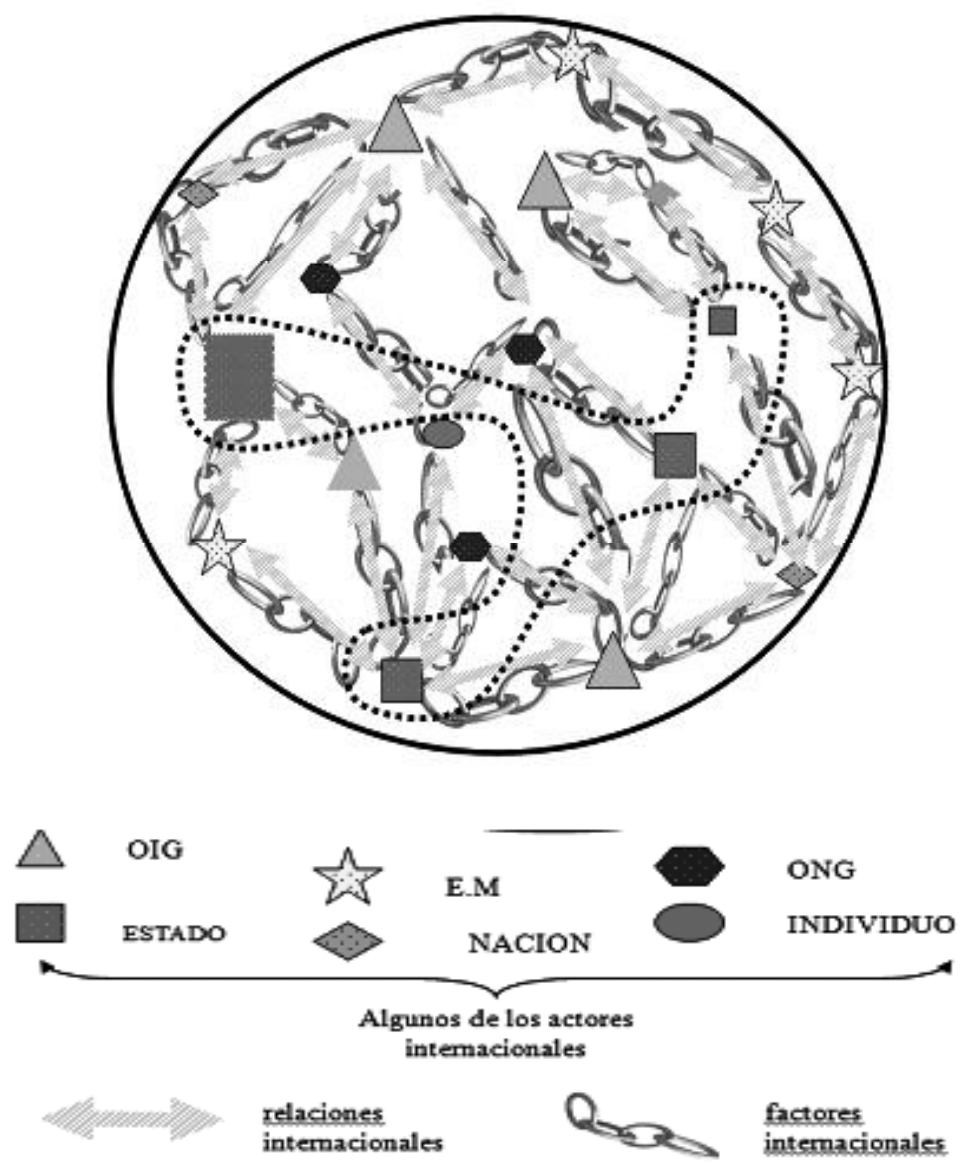

Elaboración: María Fuencisla Marían Castán y Lorena Alemán Santana

Con la segunda imagen que ofrecemos, abundamos en la desproporción arriba señalada respecto de la producción bibliográfica especializada que se puede subsanar recurriendo a la diversidad estructural característica -si se quiere, más difusa- de la sociedad internacional pero que puede entenderse fácilmente a partir de la dualidad estructural en que se desdobla la estructura de cada individuo. Así, resulta evidente que todos contamos con dos planos organizativos esenciales, distintos e interrelacionados, que no evolucionan en la misma medida ni con iguales ritmos temporales pero que en las personas sanas consiguen mantener el equilibrio dinámico. Se trata de la subestructura funcional que afecta a las necesidades materiales imprescindibles para sobrevivir, como el agua, los 
alimentos, el refugio o el vestido y de la subestructura formal que se refiere al ámbito espiritual, a los sentimientos, a las pasiones o a los valores que, en el caso de que pudiéramos reprimir cuando estamos conscientes, aparecen descontrolados nada menos que durante la tercera parte de nuestra vida cuando dormimos.

Para nivelar la tensión que se produce al tener que procurarnos recursos del medio físico mientras proyectamos impulsos que pertenecen al plano inmaterial, surge una tercera subestructura que se hace mucho más patente cuando constituimos grupos sociales donde se ha de organizar la convivencia y preservar su integridad. La subestructura político-militar completa, pues, el esquema que evidencia la indisociable conexión ya que, por ejemplo, el soldado (subestructura político-militar) necesita armas (subestructura económica) tanto como espíritu de sacrificio (subestructura cultural). ${ }^{4}$

Simbólicamente, los sentidos se corresponden con lo material, el corazón con lo pasional y el cerebro con lo racional y no es difícil descubrir un predominio $\mathrm{u}$ otro en nuestra propia trayectoria vital, en la de cualquier grupo social y en la de los actores internacionales que podemos clasificar atendiendo a este criterio y así lo podemos representar situándolos en una única subestructura, a caballo, entre dos o simultáneamente en las tres, como es el caso del Estado que se subsume en la política internacional sin perjuicio del protagonismo con que cuente en cada plano organizativo. Debe observarse el espacio relativamente reducido que ocupa la política internacional al igual que ha de repararse en los vacíos en que se insertan, por una parte, lo que podríamos denominar la marginalidad, mientras en la parte opuesta se señala el lugar de los actores opacos, aquellos que alcanzan la calidad de actor internacional, precisamente, porque nos son desconocidos. La posibilidad de enlace entre quienes transitan estos espacios en blanco ha de ser objeto de análisis detallado pues, con frecuencia, quienes pretenden destruir el orden establecido -como es el caso de las redes terroristas- o quienes se adhieren al poder en una simbiosis parasitaria -como es el caso del crimen organizado en cualquiera de sus facetas- encuentran su caldo de cultivo en la exclusión de demasiados seres humanos (ver figura 2). ${ }^{5}$

${ }^{4}$ B. Landheer, "Les Théories de la Sociologie Contemporaine et le Droit International", Recueil des Cours de l'Academie de Droit International de La Haye, Tomo 92, Vol. II, La Haya, 1957, pp. 530-566.

${ }^{5}$ Una versión interesante sobre la distribución actual del poder mundial puede verse en Robert Cox, "Historia, teoría y política mundial hoy" y "Norteamérica y el mundo: el reto para Canadá y México", XXX Coloquio Internacional de Primavera. Evaluación y prospectivas de las Relaciones Internacionales, Facultad de Ciencias Políticas y Sociales, UNAM, México, 16-21 de mayo de 2005. (Libro electrónico en soporte CD rom en que no aparece numeración general de las páginas). 


\section{La sociedad internacional presentando la diversidad estructural}

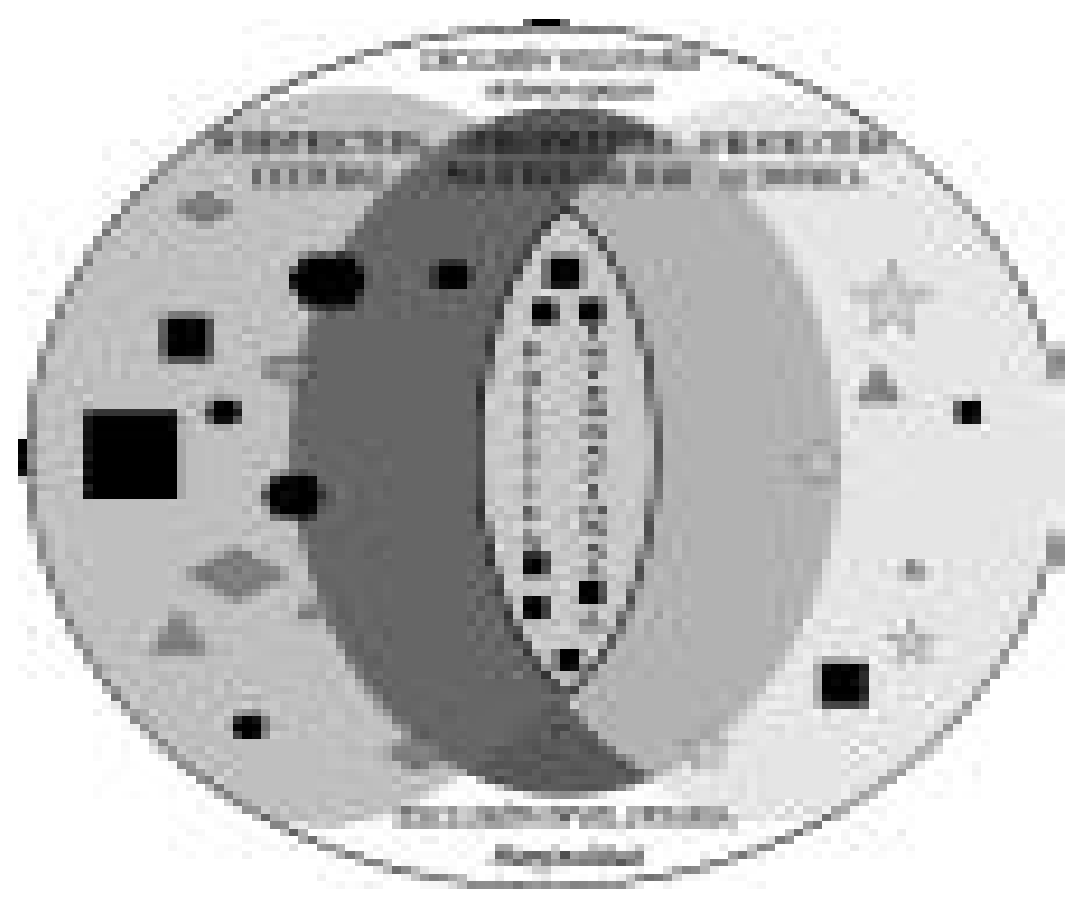

No se incluyen las relaciones y los factores para no complicar el dibujo.

Elaboración: María Fuencisla Marían Castán y Lorena Alemán Santana

Cuando, además, se trata de conocer la sociedad internacional de nuestros días sumida en la turbulencia que implica el tránsito desde la vieja sociedad internacional bipolar hacia la consolidación de la sociedad internacional global, la conceptualización de los factores internacionales resulta indispensable ya que todos ellos, en plena movilidad y afectándose mutuamente, están marcando la trayectoria del entramado de interacciones entre actores que sobreviven, nuevos protagonistas del panorama mundial y residuos resistentes a la desaparición de los grupos que anteriormente los comprendieron. En definitiva, si admitimos que, en buena medida, los cambios producidos en y por los factores internacionales han arrastrado radicales transformaciones de las formas de relación internacional y han modificado la estructura de numerosos y significativos grupos humanos hasta el punto de consumar la extinción de sociedades internacionales precedentes 
y de propiciar el nacimiento de otras nuevas, podríamos estar en condiciones de subrayar una de las líneas más borrosa en la construcción definitiva de la Teoría de las Relaciones Internacionales (ver figura 3$){ }^{6}$

\section{Ciclos de evolución de la sociedad internacional}

\section{Representación gráfica de las etapas de evolución}

histórica de las sociedades internacionales

Evolución

de la

sociedad internac.

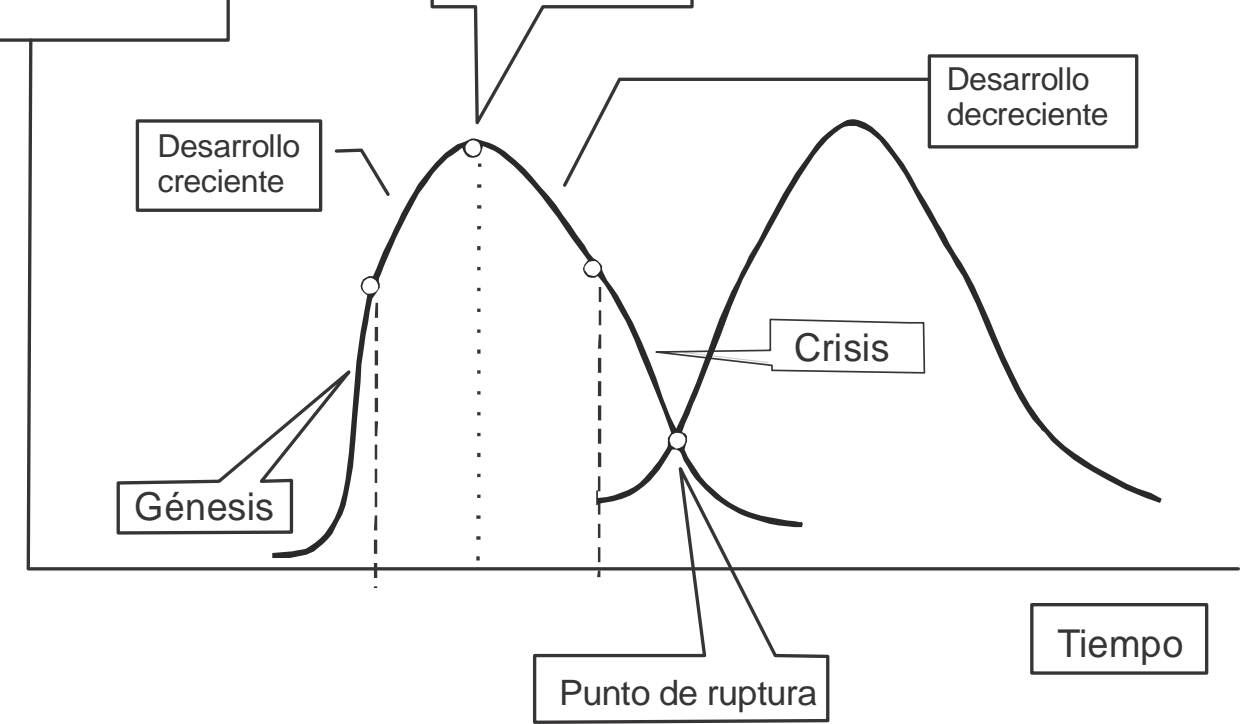

Elaboración: Rafael Calduch

${ }^{6}$ Entendiendo por Teoría “...un conjunto coherente y, en principio, sistemático de generalizaciones sobre un fenómeno o fenómenos sociales, obtenidas a partir de ciertos postulados o inducidas de la realidad, que explican lógicamente o dan sentido a esa misma realida que es objeto de consideración". Celestino del Arenal, Introducción a las Relaciones Internacionales, Ed. Tecnos, Madrid, 1990, p. 438. 


\section{E1 concepto}

Mientras en el estudio de las comunidades organizadas es frecuente encontrar cierta sistematización de los datos que proporciona el análisis de los factores condicionantes del complejo relacional interno, resulta difícil remitirse a una formulación suficientemente desarrollada de un corpus teórico que defina, identifique, rasgos comunes y presente una tipología de los factores internacionales. Esta distinción entre factores internos y factores internacionales parece superada por la porosidad de los compartimentos que convencionalmente contienen a cada categoría societaria pero que se estima necesario mantener en base a la distinción metodológica que establece los niveles correspondientes a la microinternacionalidad y a la macrointernacionalidad, pues mientras el primero de los planos apuntados se restringe al enfoque que cabe parcelar entre diferentes disciplinas de cuya conjunción se obtiene una explicación coherente, al introducimos en el segundo entraremos de lleno en el encuadre complejo de las relaciones internacionales donde la suma de las partes no da necesariamente como resultado el todo. Así, partiendo de que en cada cual de estos dos niveles de análisis difieren el tipo de relaciones, la concurrencia de actores, la incidencia de los factores y la selección de los métodos y técnicas de análisis, asumimos que también tendrán que ser distintas las soluciones a los problemas que se nos presentan de tal manera que, por ejemplo, ante el excedente de población de un país (nivel microinternacional) cabe recomendar políticas favorables a la emigración que conducirían a un caótico tráfico humano en caso de que la presión demográfica y las medidas individualmente adoptadas para aliviarla se extendieran al conjunto de la sociedad internacional (macrointernacionalidad). ${ }^{7}$

De ahí que se haya de considerar por separado los factores internos que perteneciendo a las estructuras internas de los actores internacionales considerados individualmente, condicionan directamente el proceso de toma de decisiones y el funcionamiento de los actores internacionales e indirectamente las relaciones

\footnotetext{
${ }^{7}$ La utilidad de la distinción entre microinternacionalidad y macrointernacionalidad, en Rafael Calduch. Nuevos métodos y técnicas de investigación aplicables a las Relaciones Internacionales, en http:www.ucm.es/info/sdrelint/unamredu.htm Para las teorías ambientales aplicadas al ámbito estatal, regional e internacional, véase, entre otros, J. E. Dougherty y R. L. Pfaltzgraff. Contending Theories of International Relations. Harper-Collins Publishers, New York, 1990; hay edición en español Teorías en pugna de las Relaciones Internacionales, traducción Cristina Piña, Grupo Editorial Latinoamericano, Buenos Aires, 1993, pp. 63-90. Y, por lo que respecta a autores españoles, ver P. Lozano Bartolozzi, Estructura y dinámica de las Relaciones Internacionales, Mitre, Barcelona, 1987, pp. 111-132.
} 
con otros actores internacionales, cuyo estudio debe ser contemplado desde la microinternacionalidad; y los factores internacionales que pertenecen a las estructuras internacionales y condicionan directamente la dinámica de la sociedad internacional, el proceso de toma de decisiones y el funcionamiento de los actores internacionales y deben ser contemplados desde la macrointernacionalidad.

Hecha esta aclaración y centrándonos en los factores internacionales, se ha de partir de la constatación del hecho de que ciertas causas materiales -como el espacio, la población o los recursos-influyen en la conducta de todos los grupos sociales desde el más reducido hasta el conjunto de la sociedad internacional que, a su vez, al modificar su comportamiento, acaban alterando dichos condicionamientos naturales. Como ejemplo nos serviría la disminución del número de nacimientos a consecuencia del cambio en las prácticas sexuales derivadas del conocimiento de la eficacia de la higiene y la sanidad en la supervivencia infantil que termina por reflejarse en los indicadores de la demografía a escala mundial. El mismo ejemplo ilustra la consideración de que, junto a las realidades materiales mencionadas, es preciso detenerse en las realidades inmateriales e intangibles, como las subyacentes a las directrices de determinadas religiones natalistas y antiabortistas o aquellas que se vinculan a cualquier adscripción cultural que identifique fertilidad con abundancia y prestigio.

Si de lo que se trata es de progresar en la lucha secular del hombre contra los desafíos de la naturaleza utilizando, claro está, las capacidades, los conocimientos y las técnicas que le permiten sobrevivir y avanzar y si admitimos que nada de ello hubiera podido desarrollarse sin un sustrato cultural que activara la decisión, organizara la actuación y suscitara la evaluación del esfuerzo realizado, parece indicado aplicar idéntico proceder a la hora de dotarnos de criterios de precisión científica en los términos propuestos por Rafael Calduch para definir los factores internacionales como "los diversos elementos o variables básicos que configuran las estructuras internacionales, condicionando durante amplios periodos las relaciones entre los actores internacionales y la propia dinámica de la Sociedad Internacional en su conjunto."

${ }^{8}$ Rafael Calduch Cervera. Apuntes no publicados donde se toma en consideración las principales obras de referencia que siguen siendo A. Toynbee, A Study of History, Abridgement, Royal Institute of International Affairs, Londres, 1946; edición en español Estudio de la Historia. 3 volúmenes traducción L. Grasset, Alianza, Madrid, 1970, vol. I, pp. 23-75; Marcel Merle, "Facteurs et acteurs dans les relations internationales" en Manuel Medina, Roberto Mesa y P. Mariño (coords), Pensamiento Jurídico y Sociedad Internacional. Estudios en honor del Profesor D. Antonio Truyoly Serra, 2 volúmenes, Centro de Estudios Constitucionales, Universidad Complutense de Madrid, Madrid, 1986, vol. II, pp. 799-810. Así como Sociología de las Relaciones Internacionales, 
Merece la pena, pues, explorar la posibilidad de tomar como punto de partida lo que necesitamos conocer, o sea, los factores internacionales, aunque ello conlleve el riesgo de tener que cuestionar lo que no ignoramos o creemos saber porque ya ha sido sistematizado por aquellos autores que estiman prioritario apuntalar los conceptos de sociedad internacional, de actor internacional y de relaciones internacionales. Este es un paso delicado en la medida en que hay que lanzarse desde lo aprendido hacia lo que es necesario aprender a favor de la propia coherencia profesional y personal y que, no obstante resulta imperioso para poder transmitir una explicación completa del objeto de nuestro estudio. Así, en principio, únicamente cabría sostener con rotundidad que no son menos importantes los factores internacionales que los actores internacionales o que las relaciones internacionales. De manera que, si en clave factorial los actores internacionales se nos presentan como conjuntos organizados de personas que comparten el medio físico que sustenta la vida, podemos, a continuación afirmar con certeza la existencia de contactos hombre-hombre/hombre-espacio o, lo que es lo mismo, las relaciones internacionales. Es más, de ahí se puede deducir que los factores internacionales constituyen elementos estructurales de los actores internacionales y de la sociedad internacional que los comprende, pues representan las constantes que sólo cambian a largo plazo en contraste con la movilidad espacial y temporal que es característica de quienes se mantienen en actividad, o sea, de los actores internacionales. Incidir en la conexión entre estructura y acción permitiría ir diluyendo las carencias, las imprecisiones y la confusión conceptual priorizando el análisis de lo permanente para fundamentar las explicaciones de lo coyuntural abriendo, así, toda una panorámica teórico-metodológica a partir de la ponderación de los distintos factores internacionales al servicio de la previsión de escenarios posibles y la articulación de medidas eficaces que obviarían muchos debates académicos estériles y fundamentarían criterios que permitieran presionar con autoridad sobre los gobernantes reacios a aceptar asesoramiento calificado y a someter su gestión a controles objetivos. ${ }^{9}$

traducción Roberto Mesa, Alianza, Madrid, 1990. Raymond Aron, Paix et guerre entre les nations, Calmann-Levy, París, 1962; versión en español Pazy guerra entre las naciones, Alianza, Madrid, 1985, tomo I. C. Kelman, “Journal of Social Issues”, vol. XI (1995), reproducido en Stanley H. Hoffman, Contemporary Theory in International Relations, Ed. Prentice Hall, Englewood Cliffs, 1960; edición en español, Teorías contemporáneas sobre las Relaciones Internacionales, traducción M. D. López Martínez, Tecnos, Madrid, 1963, pp. 257-271.

${ }^{9}$ El interés por esta temática de quien presenta este trabajo ya ha producido alguna publicación entre las cuales cabe señalar: María Fuencisla Marín Castán, "Los factores internacionales: 


\section{María Fuencisla Marín Castán}

\section{Las características}

Siguiendo a Calduch y pese a que deba aún pulirse este epígrafe, se avanzan los principales rasgos comunes o características generales de los factores internacionales, entre las cuales destacamos la interdependencia, la persistencia histórica y la evolución diacrónica que presentan tales condicionamientos, junto con la transmisión desfasada de los cambios que los mismos ocasionan y la relatividad de los efectos que todos ellos pueden llegar a ocasionar.

La interdependencia se ha de entender en un doble nivel por cuanto afecta a los vínculos que se producen entre los actores internacionales y los factores internacionales alcanzando, igualmente a las influencias mutuas entre los propios factores internacionales. Cuando se coincide en afirmar la repercusión de dichos condicionamientos en la configuración y el comportamiento de los actores internacionales conviene señalar, no obstante, que resulta mucho más aventurado generalizar a la vista de las diferentes respuestas que los actores internacionales presentan ante la incidencia de los factores internacionales en similar momento histórico y en el mismo marco espacial. Esta pluralidad de reacciones posibles ante iguales estímulos influye, a su vez, sobre la evolución futura de los factores internacionales y sobre los distintos condicionamientos que ocasionarán y nos muestran la posibilidad de que los seres humanos consigan trazar su propio destino dentro de los límites de tales condicionamientos. Si de lo que se trata es de afirmar la interdependencia factorial, resulta sencillo poner en evidencia la imposibilidad de explicar cualquiera de los factores internacionales de manera individualizada y desconectada de los demás, pues no tendría sentido estudiar la población (factor demográfico) sin vincularla al territorio que ocupa (factor geográfico), a los recursos necesarios para su subsistencia (factor económico), a la organización y a la defensa de dicho espacio y dichos recursos (factor político), etc.

La persistencia histórica se deriva de la constatación de la permanencia de una serie de retos, necesidades y desafíos que han acompañado invariablemente al género humano desde la noche de los tiempos a la hora de alimentarse, de comunicarse, de reproducirse, de organizarse, etc., a pesar de que la manera de abordarlos ha ido evolucionando como las propias y diversas formas de agrupación social.

concepto, características, clasificación e importancia en la sociedad internacional de nuestros días", en XXX Coloquio Internacional de Primavera, op. cit. (libro electrónico en que no aparece numeración de las páginas). 
En cuanto a la evolución diacrónica, esta característica hace referencia a los distintos ritmos de cambio que experimentan los factores internacionales a través del espacio y del tiempo y que a veces nos inducen a confundir la velocidad con la intensidad y con la relevancia. Así, por ejemplo, el factor científico/técnico en la actualidad nos puede parecer que ha evolucionado más de prisa y que condiciona en mayor medida, cuando lo cierto es que el factor cultural -es decir, el cambio en las ideas y en las formas de vida o en la manera de percibir la realidad-, ha conocido una aceleración y ha ejercido una influencia igualmente notable aunque no percibida con la misma relevancia. Por ello, no se puede sostener la existencia de un factor-clave sin ubicarlo en su lugar y en su momento.

La transmisión desfasada de los cambios factoriales responde a la manera en que los efectos de los cambios experimentados por un factor internacional alcanzan a los demás factores, a los actores internacionales que interactúan en consecuencia, así como a la sociedad internacional. A este respecto hay que señalar que cuando un factor internacional sufre alteraciones, el resto de los factores se van viendo afectados de forma desigual y generalmente comenzando por los más próximos, ensanchándose el radio de influencia hasta alcanzar a todos los factores internacionales y, finalmente, al contexto general que los engloba.

Por último, la relatividad de los condicionamientos factoriales implica rechazar toda interpretación determinista en la medida en que las capacidades y la voluntad humana aportan múltiples alternativas a los problemas que presenta el medio, el contacto interpersonal y la dependencia derivada del arraigo cultural. Los factores internacionales que han de observarse en el corto, medio y largo plazo reparando en las variadas respuestas que suscitan no son, en sí mismos, ni positivos ni negativos y tampoco aceleran o retardan los cambios de manera inexorable, aunque se puede aceptar que hay cambios factoriales prolongados cuyos efectos repercuten en relaciones significativas entre numerosos actores internacionales e incluso su crisis y desaparición.

\section{La clasificación}

La tipología que se propone al objeto de clasificar los factores internacionales surge de la combinación de dos criterios que se pueden considerar clásicos a partir de las obras citadas de Toynbee, de Aron, de Merle, de Kelman y de los pocos autores que, al respecto, han introducido aportaciones destacables donde, de nuevo, se ha de singularizar a Calduch. El primer criterio atiende a la naturaleza intrínseca de cada factor internacional ya sea material, subjetivo, organizativo, 
instrumental o valorativo, mientras que el segundo contempla la naturaleza de los cambios que ocasiona y que pueden afectar bien a la realidad primaria de la sociedad internacional, bien a las relaciones entre seres humanos o de estos con su entorno. Combinando ambas opciones podríamos distinguir, en primer lugar, los factores estructurales que constituyen la base misma de toda sociedad y, por consiguiente, también de la sociedad internacional donde identificamos el factor geográfico y el factor demográfico.

Como factor material el geográfico se encuentra en íntima relación con la población y cobra importancia cuando la sociedad internacional planetaria se enfrenta a limitaciones físicas que podrían ser subsanables mediante la explotación de los fondos oceánicos o la extracción de recursos del espacio extra-atmosférico. Por su parte, se ha de considerar subjetivo el factor demográfico pues cuantitativa y cualitativamente los habitantes de cualquier sociedad son al mismo tiempo la causa y la finalidad de su existencia, siendo esta realidad evidente aplicable igualmente a la propia sociedad internacional.

En segundo lugar y como segunda categoría, los factores relacionales se desprenden de los factores estructurales y condicionan las relaciones humanas o las del hombre con el medio subdividiéndose, a su vez, en los factores organizativos -representados por el factor económico, que ordena las relaciones entre los hombres y la naturaleza, y el factor político que ordena las relaciones de los hombres entre sí-; los factores instrumentales entre los que distinguimos el factor científico/técnico -que aporta los conocimientos y medios aplicados a la optimización o sustitución de los recursos y capacidades humanas junto con el factor jurídico que sirve a la regulación de la convivencia social; y, finalmente, el factor valorativo o, lo que es lo mismo, el factor cultural que incluye las ideologías y las religiones y depende de las diferentes formas de socialización de cada grupo humano a través de la educación y de los medios de comunicación e implica valoraciones y preferencias arraigadas en el inconsciente individual y colectivo. La importancia del factor cultural se destaca en la medida en que incide directamente en los dos factores estructurales pues, si se estima inevitable sentir afecto, aversión o indiferencia hacia otras personas como lo propio del factor demográfico, esto es, de la relación hombre/hombre, no es menos cierta una similar proyección de sentimientos sobre el medio físico en la relación hombre/ espacio que converge en el factor geográfico hasta el punto de dar la vida por la tierra propia o arrasar ciudades enemigas. Dada la interconexión de ambos factores estructurales, aquellos otros que de ellos se derivan muestran, a simple vista la interdependencia ya apuntada puesto que se acepta o se rechaza la devaluación de una divisa o la imposición de una tasa (factor económico) tanto 
como la dictadura o el régimen republicano (factor político), de igual manera que suscita filias y fobias la investigación con células-madre o las pruebas (factor científico/técnico) y la pena de muerte o la igualdad de la mujer (factor jurídico). En la figura 4 se representa gráficamente lo hasta aquí expuesto.

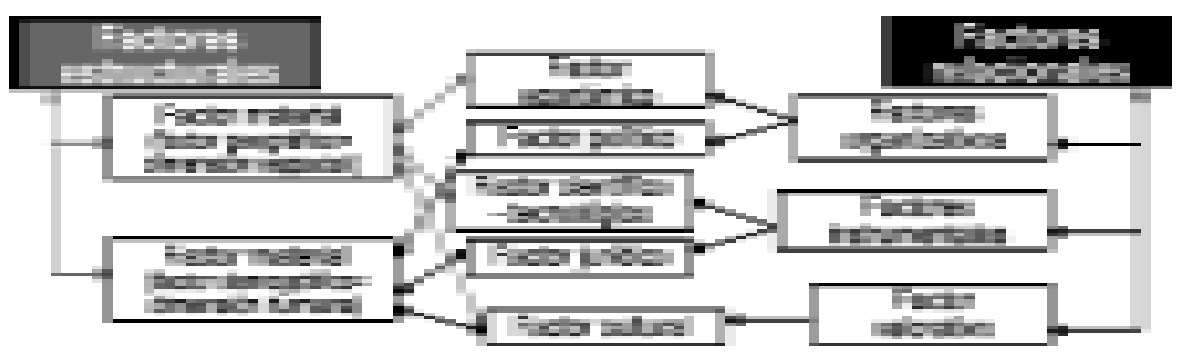

\section{Las conclusiones}

En los momentos en que nos situamos y cuando toda clase de versiones de las obras de referencia de los más ilustres pensadores circulan en la red al lado de análisis valioso de internacionalistas acreditados o no y junto a innumerables contribuciones de múltiple procedencia rechazadas por los editores, es recomendable revisar los resultados de la voz factores internacionales en los buscadores que se estimen más completos y en relación con el área de conocimiento que nos ocupa. Es conveniente insistir en caso de que no se encuentre el enunciado de algún tema dentro de los programas de asignaturas o de módulos de Relaciones Internacionales que se han de cursar para obtener titulaciones universitarias de diferente rango. Se puede probar con combinaciones de términos como condicionamientos de la sociedad internacional, variables recurrentes en la sociedad internacional, elementos dinamizadores/estabilizadores de la sociedad internacional o cualesquiera otras que encajen en una doctrina en torno al entorno, es decir, a los factores internacionales al nivel que desde aquí se reclama.

Concluya cada cual, entonces, si conviene aplicarse en los aspectos más endebles de la común Teoría internacional y si ha llegado la hora de sustituir el conflicto académico por la cooperación a favor del orden metodológico que sirva mejor al análisis de casos puntuales como lo es, dentro del factor geográfico, el agua que sacia la sed de las personas (factor demográfico), proporciona riqueza (factor económico), se puede potabilizar (factor científico/técnico), es objeto de reglamentación (factor jurídico) y se estima o se teme (factor cultural). 
María Fuencisla Marín Castán

\section{Fuentes}

Aron, Raymond, Paix et guerre entre les nations, Calmann-Levy, París, 1962. Edición en español Pazy Guerra entre las naciones, Alianza, Madrid, 1985.

Calduch Cervera, Rafael, "Cultura y civilización en la sociedad internacional" en Iglesia, Estado y Sociedad Internacional. Libro homenaje a D. JoséJiménezy Martínez de Carvajal, Editorial San Pablo-CEU, Madrid, 2003.

Calduch Cervera, Rafael, "Cultura y civilización en la conformación de la sociedad internacional" en Derechos Humanos y conflictos internacionales. Curso de Derecho Internacionaly Relaciones Internacionales de Vitoria-Gasteiz 2006, Servicio Editorial de la Universidad del País Vasco, Bilbao, 2006.

Calduch Cervera, Rafael, Relaciones Internacionales, Ed. Ciencias Sociales, Madrid, 1991.

Calduch Cervera, Rafael, Nuevos métodos y técnicas de investigación aplicables a las Relaciones Internacionales, en http://www.ucm.es/info/sdrelint/unamredu.htm

Cox, Robert, "Historia, teoría y política mundial hoy", XXX Coloquio Internacional de Primavera. Evaluación y prospectivas de las Relaciones Internacionales, Facultad de Ciencias Políticas y Sociales, UNAM, México, 16-21 de mayo de 2005.

Cox, Robert, "Norteamérica y el mundo: el reto para Canadá y México", XXX Coloquio Internacional de Primavera. Evaluación y prospectivas de las Relaciones Internacionales, Facultad de Ciencias Políticas y Sociales, UNAM, México, 16-21 de mayo de 2005.

Del Arenal, Celestino, Introducción a las Relaciones Internacionales, Ed. Tecnos, Madrid, 1990.

Dougherty, J. E. y Pfaltzgraff, R. L. Contending Theories of International Relations, Harper-Collins Publishers, New York, 1990. Edición en español, Teorías en pugna de las Relaciones Internacionales, traducción Cristina Piña, Grupo Editorial Latinoamericano, Buenos Aires, 1993.

Kelman, I.C., "Journal of Social Issues", vol. XI (1995), reproducido por Stanley H. Hoffman, Contemporary Theory of International Relations, Ed. Prentice Hall, Englewood Cliffs, 1960. Edición en español, Teorías contemporáneas sobre las relaciones internacionales, traducción M. D. López Martínez, Tecnos, 1963.

Landheer, B., "Les Théories de la Sociologie Contemporaine et le Droit International!, Recueil des Curses de l'Academie de Droit International de La Haye, Tomo 92, vol. II, La Haya, 1957.

Lozano Bartolozzi, P., Estructura y dinámica de las Relaciones Internacionales, Mitre, Barcelona, 1987. 
Marín Castán, María Fuencisla, "Los factores internacionales: concepto, características, clasificación e importancia en la sociedad internacional de nuestros días", XXX Coloquio Internacional de Primavera. Evaluación y prospectivas de las Relaciones Internacionales, Facultad de Ciencias Políticas y Sociales, UNAM, México, 16-21 de mayo de 2005.

Merle, Marcel, "Facteurs et acteurs dans les relations internationales" en Medina, Manuel, Roberto Mesa y P. Mariño (coords.), Pensamiento Jurídico y Sociedad Internacional. Estudios en honor del Profesor D. Antonio Truyol y Serra, 2 volúmenes, Centro de Estudios Constitucionales, Universidad Complutense de Madrid, Madrid, 1986.

Merle, Marcel, Sociología de las Relaciones Internacionales, traducción de Roberto Mesa, Alianza, Madrid, 1990. 
194 BLANCA 
Temas introductorios al estudio de Relaciones Internacionales editado por la Facultad de Ciencias Políticas de la UNAM se terminó de imprimir el 2 de diciembre de 2013. La producción se realizó mediante el sistema offset y estuvo a cargo de Comercial de Impresos MB, Petróleos Mexicanos 11, Coyoacán. La composición se hizo en Garamond 11.5/13.5, la impresión se realizó en papel cultural de 75 grs. La edición consta de 500 ejemplares. El cuidado de la edición estuvo a cargo de Domingo Cabrera Velázquez. 